\title{
Geothermal resources \\ and local development in Poland
}

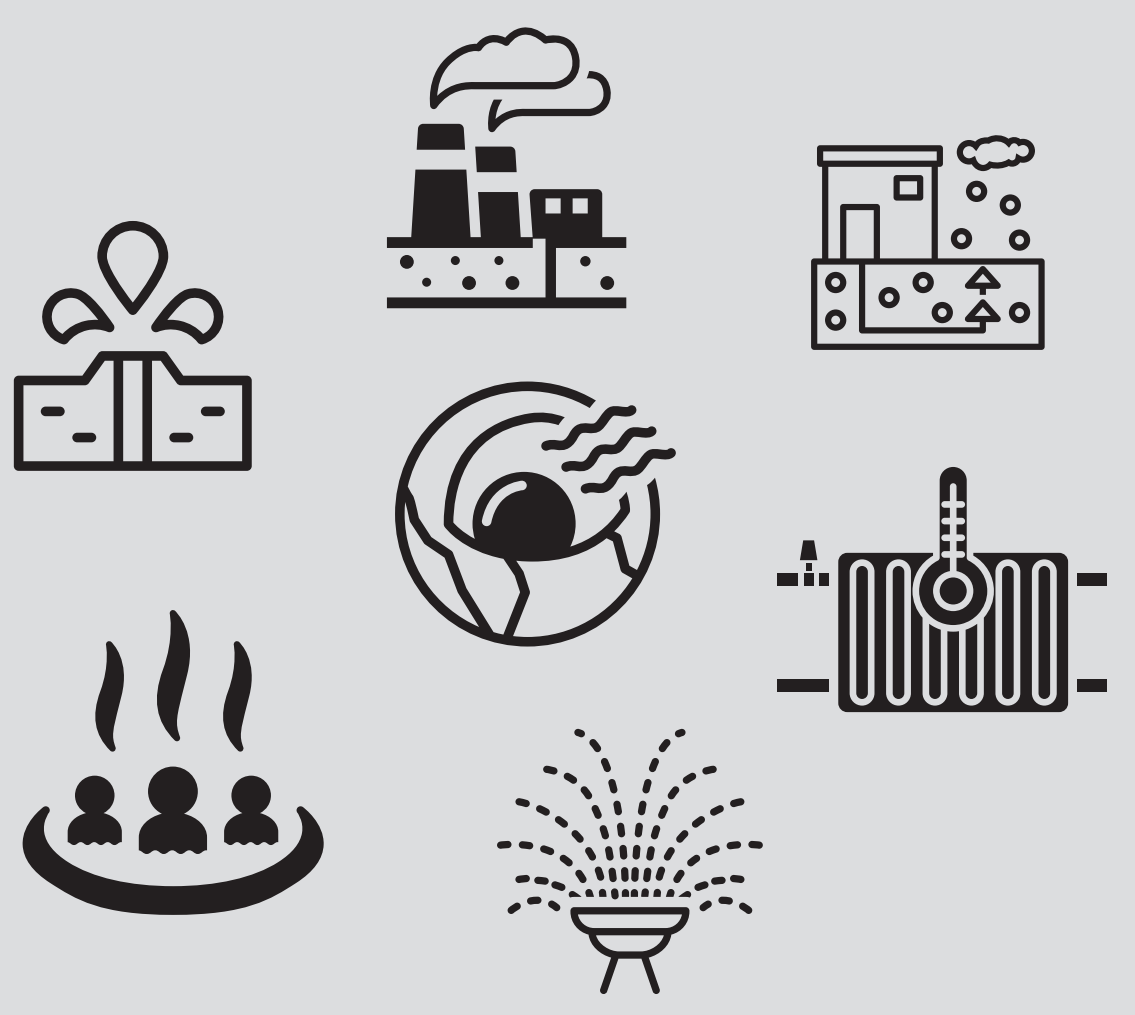

Katarzyna A. Kurek 



\section{Propositions}

1. Locally produced geothermal energy is positively related to local competitiveness. (this thesis)

2. The use of the geothermal resources for the development of recreational centers and spas is an engine of growth for service sectors.

(this thesis)

3. The phase-out of fossil fuels as foreseen in the European Green Deal will have a profound positive impact on the European landscape.

4. Endogenous regional development is the result of resources availability and innovations.

5. In a market economy, forecasting of a cluster's precise location is impossible.

6. In the current times of methods' multiplicity the over 700 years old Ockham's razor remains an effective research problem solving tool.

Propositions belong to the thesis: Geothermal resources and local development in Poland.

Katarzyna A. Kurek

Wageningen, 15 April 2021 



\section{Geothermal resources and local development in Poland}

Katarzyna A. Kurek 

Thesis Committee

\section{Promotor}

Prof. Dr W.J.M. Heijman

Special professor Regional Economics

Wageningen University and Research

\section{Co-promotors}

Dr J. van Ophem

Associate professor, Urban Economics Group

Wageningen University and Research

Dr J. Strojny

Associate professor, Faculty of Management

Rzeszów University of Technology

Poland

\section{Other members}

Prof. Dr N.B.M. Heerink, Wageningen University and Research

Dr H.P. Weikard, Wageningen University and Research

Prof. Dr D.H. Bruhn, Delft University of Technology

The Netherlands

Dr Sc. B. Kępińska, Mineral and Energy Economy Research Institute (MEERI PAS) Polish Academy of Sciences

Poland 



\section{Geothermal resources and local development in Poland}

Katarzyna A. Kurek

Thesis

submitted in fulfilment of the requirements for the degree of doctor

at Wageningen University

by the authority of the Rector Magnificus,

Prof. Dr A.P.J. Mol,

in the presence of the

Thesis Committee appointed by the Academic Board

to be defended in public

on Thursday $15^{\text {th }}$ April 2021

at 11.00 a.m. in the Aula. 
Katarzyna A. Kurek

Geothermal resources and local development in Poland, 214 pages.

PhD thesis, Wageningen University, Wageningen, the Netherlands (2021) With references, with summary in English and Polish

ISBN: 978-94-6395-724-3

DOI: https://doi.org/10.18174/542196 


\section{Table of contents}

GLOSSARY

\section{CHAPTER 1}

1. Introduction: Geothermal resources and local aspect ..................................................... 1

1.1 The energy of the earth and mankind ....................................................... 3

1.2 The state of play and geothermal developments............................................ 10

1.3. Geothermal energy in Poland........................................................................ 15

1.4. Research problem definition ..................................................................... 18

1.5 Research objective and research question ..................................................... 21

1.6 Theoretical framework …………………………...................................... 23

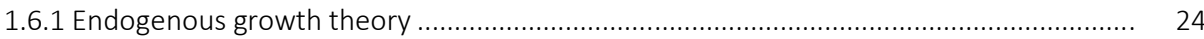

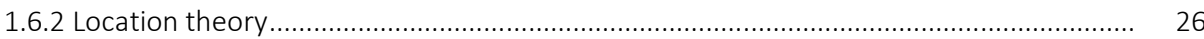

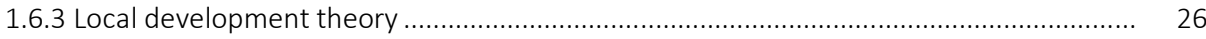

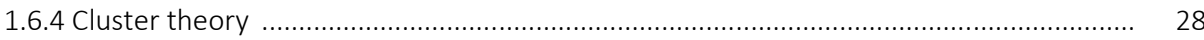

1.7 Research methodology ......................................................................... 28

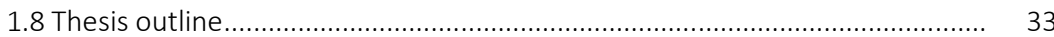

\section{CHAPTER 2}

2. Geothermal spas as a local development factor, the case of Poland ................................... 37

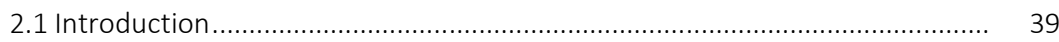

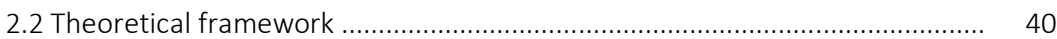

2.3 Data and methods .................................................................................. 44

2.4 Model results interpretation ..................................................................... 48

2.5 Discussion and conclusions............................................................................... 50 


\section{CHAPTER 3}

3. The impact of geothermal resources on the competitiveness of municipalities: evidences from Poland

3.1 Local competitiveness drivers ………………………............................ 55

3.2 Competitiveness of the geothermal energy ……........................................... 57

3.3 Local competitiveness model ...................................................................... 58

3.4 Competitiveness model data ................................................................ 62

3.5 Municipality competitiveness concept ……………................................... 63

3.6 Panel model robustness check ................................................................... 67

3.7 Discussion and conclusions ..................................................................... 71

\section{CHAPTER 4}

4. Measuring local competitiveness: comparing and integrating two methods PCA and AHP

4.1 Introduction

4.2 The PCA and AHP competitiveness models .................................................. 77

4.3 Comparison of the PCA and AHP local competitiveness models..................... 80

4.4 The local competitiveness index by the PCA and AHP methods ..................... 82

4.4.1 Principal Component Analysis local development indicator .............................................. 82

4.4.2 Analytical Hierarchy Process local competitiveness index .............................................. 83

4.5 PCA and AHP structure modelling characteristics........................................ 84

4.6 Integration of the PCA and AHP methods..................................................... 84

4.7 Discussion and conclusions ........................................................................ 88

\section{CHAPTER 5}

5. The contribution of the geothermal resources to local employment: case study from Poland

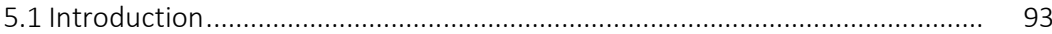

5.2 Research framework and data collection .................................................. 94

5.3 Research method ............................................................................. 98

5.4 Results and analysis.......................................................................... 100

5.5 Discussion and conclusions ........................................................................ 109 


\section{CHAPTER 6}

6. Dataset for the model of municipality competitiveness in relation to the geothermal resources exploitation in Poland 113

6.1 Specifications Table 115

6.2 Value of the data 117

6.3 Data description 118

6.4 Experimental design, materials and methods 120

\section{CHAPTER 7}

7. Synthesis 121

7.1 General discussion 123

7.2 Discussion on chapters findings 127

7.3 Discussion on geothermal resources impact on local development 131

7.4 Some considerations on and research limitations 135

7.5 Discussion on function of the geothermal energy in local economy 136

7.5.1 Geothermal resources - local alternative for the decarbonized societies 136

7.5.2 Geothermal development scenario for Poland 141

7.6 Final word

REFERENCES

APPENDIX 185

Expert Questionnaire: Model of municipality competitiveness 


\section{GIossary}

AHP - Analytical Hierarchy Process

BDL - Local Data Bank (pol. Bank Danych Lokalnych), largest section of data and statistical indicators on the statistical localities, municipalities, poviats, voivodships and Poland according to the nomenclature NUTS. It is a data repository of the Central Statistical Office in Poland.

Geothermal resource - an underground reservoir of heat in either solid rock or in fluids that fill the fracture and pore spaces within a rock; economically extractable and industrialized.

Impact - powerful effect on the structure of one object (or phenomenon) on another.

Local competitiveness - theoretical advancement promoting actions aimed at adding value to local economy, by creating an innovative environment. and to upgrade the level of competitiveness of the overall local economy. It is an ability of a location to ensure a sustained economic growth and development and attract capital and innovations.

Local development - theory of regional economics that bases on the identification and use of the resources and endogenous potentialities of a community, neighborhood, city, municipality or equivalent. The local development approach considers the resources and endogenous factors of a territory as key to its social and economic development.

Multicriteria decision analysis - a family of methods (MCA) commonly implemented by decision support systems (DSS) to compare alternative courses of action on the basis of multiple factors, and to identify the best performing solution. Multicriteria analysis moves towards a solution that is satisfactory from the point of view of various and independent criteria.

Municipality - (pol. gmina) basic unit of territorial division in Poland, NUTS-5 level.

NACE - statistical classification of economic activities in the European Community (fr. Nomenclature statistique des activités économiques dans la Communauté européenne) is the classification of economic activities in the European Union. It is a four-digit classification providing the framework for presenting a large range of statistical data according to economic activity.

NUTS - nomenclature of territorial units for statistics (fr. Nomenclature des Unités Territoriales Statistiques) is a geographical system, according to which the territory of the European Union is divided into hierarchical levels. In Poland, the five hierarchical levels descending are known as NUTS-1, NUTS-2, NUTS-3, NUTS-4 and NUTS-5.

PCA - Principal Component Analysis

Poviat - (pol. powiat) is the second-level unit of local government and administration in Poland, equivalent to a county or district, NUTS-4 level.

Socioeconomic indicators - key indicators of the socioeconomic composition of a community that can be considered individually and in combination; can be measured at multiple units of geography and include information of households, employment, infrastructure, poverty, demography and health among others.

UM - Townhall (pol. Urzq̨d Miasta)

UG - Municipal Office (pol. Urzq̨d Gminy)

Voivodeship - (pol. województwo) is the highest-level administrative division of Poland, corresponding to a concept of province, NUTS- 3 level. 


\section{Energy measures}

GJ - gigajoule equals to one thousand million joules, common unit of measurement of energy production.

GWh - gigawatt hours is a unit of energy representing one billion watt hours, it is equivalent to one million kilowatt hours.

EJ - exajoule equals to one quintillion $\left(10^{18}\right)$ joules unit of energy.

Mtoe - millions of tons of oil equivalent is a unit of energy used to describe the amount of energy released when burning one mega tone (1000 kilograms) of crude oil.

MW - megawatt equals to one million watts, where watt is the unit of power.

MWe - megawatt electric is the electricity output capability of a power plant.

MWt - megawatt thermal refers to the input energy required at a power plant.

MWth - megawatt thermal means power input (thermal) in megawatts (MW).

$\mathrm{TJ}$ - terajoule equals to one trillion $\left(10^{12}\right)$ joules, where a joule is a basic measure of energy. It is related to the watt: one watt equals one joule per second.

TW - terawatt equals to one trillion $\left(10^{12}\right)$ watts, where watt is a unit of power. Terawatts are commonly used to measure the total power used by humans worldwide.

TWh - terawatt-hour equals to 1 trillion watt hours, it is often used to expresses major energy production or consumption.

Energy units glossary based on Wolfson (2012) and Eurostat. 
Chapter 1

Introduction: Geothermal resources and local aspect 


\subsection{The energy of the earth and mankind}

Geothermal energy is one of the oldest types of power known to the human kind. Since the Paleolithic era about 14.000 years BC, the hot springs served man for various purposes including healing and heating. Archaeologists claim that the geothermal energy was used among people across the whole globe, from the American continents through Japan and China, Middle East and Oceania to Europe. Examples of the prehistoric cave drawings in Turkey, dated to be 12,000 years old, testify to the acknowledgment of the geothermal resources in everyday life (Özgüler \& Kasap, 1999). Cataldi \& Chiellini (1995) argue that the availability of geothermal resources determined the building of human settlements since early times. Geothermal localities offering various geothermal by-products including fertile volcanic soil and water sources attracted primitive forms of urbanization. The authors refer to a formation of a mangeothermal energy relationship since historic evidence shows that nomadic tribes of the Middle East began to settle down in the geothermal areas. For centuries these areas inspired myths and religious practices. Temples were built devoted to the hot springs and their believed gods. Pilgrims movements to worship the geothermal springs and to receive healings are found in ancient India (Chandrasekharam, 1995) and pre-Colombian Americas (Hernández-Galán et al., 1999). The hot water outlets were used for instance for public baths, as feasting centers and social gatherings places during the Greek and Roman empires. The Greek god Asclepios, known as the god of medicine, was believed to reside at the geothermal waters estuary.

The word spa- salus per aquam (lat.) means "health through water". It represents a belief in the curative powers of the geothermal waters. Spas provide various balneotherapeutic practices. The commercial use of the geothermal resources is evidenced in the Roman built public baths at the conquered English territory (today known as Bath in England). Fed with mineral geothermal waters and equipped with floor heating, this bathing center charged an admission fee for guests. The significant role of the geothermal resources for the ancient societies was noticed by Greek and Roman philosophers as e.g. Homer, Hippocrates, Plato, Aristoteles and Pliny the Elder (Fytikas, Leonidopoulou, \& Cataldi, 1999). The Nordic tribes practiced common baths in the hot springs as peace building practices after the battles. Etruscans went a step further and learnt the mineral extraction from the geothermal water (Cataldi, 1993), initiating the industrial application of the resources. Salt extraction from the geothermal brine was discovered in China and supplied this mineral the landlocked areas with no sea access. Ancient Chinese technology was able to drill geothermal wells up to 1000 meters deep. These technical solutions were reported by e.g. Marco Polo and imported to Medieval Europe (Kurlansky, 2011). A geothermal powered district heating is built for the first time in the XIV century in France in Chaudes-Aigues (fr. hot waters), and it functions until today (Lund, 2006). Further expansion of the geothermal energy led to the industrial harnessing at the end of $19^{\text {th }}$ century in the USA and at the beginning of the $20^{\text {th }}$ century in Italy as attempts of district heating and minerals extraction. The first geothermal plant in Larderello, in Italy built in 1904 set an example of a large scale geothermal energy generation. In the 1920s, the first 
geothermal heat powered greenhouse farm was developed in the state of Idaho in the USA, while also serving for heating purposes (Rafferty, 1992). Electricity generation began in the 1960s in California. Iceland introduced municipal space heating based on geothermal heat already in the 1930s (Cleveland \& Morris, 2005).

From these large- scale geothermal experiments the exploitation of the resources has developed worldwide. First bottled geothermal water sold as a medicine is introduced in India in the $19^{\text {th }}$ century (Chandrasekharam, 1995) and used as a cure drink in Japan (Sekioka, 1995) and China (Ji-Yang, 1995) since the early AD times. Nevertheless, the expansion of oil and gas business in the 1960s and 1970s marginalized the geothermal development. With the oil crisis in the late 70 s and 80 s the tables turned. More sustainable energy resources were sought and geothermal explorations became incentivized (Small, 1974). Thanks to the progress in geosciences and improved technologies the geothermal energy became broadly used. The wide application for industry and energy production purposes makes the geothermal resources highly competitive with the fossil fuels and as well as with other renewables.

Bubbling mud, geysers, and hot springs are the primary indictors of the geothermal energy sources. However, the geothermal activity happens underground since the energy comes from the heat within the earth. The adjective geothermal stems from the Greek language and translates as gê meaning the earth and thermós, the heat. Due to the decay of naturally existing radioactive isotopes like e.g. thorium and uranium on the level of earth's core the heat is being generated. Surrounding the earth's core is the mantle, thought to be partly rock and partly magma. Temperatures at the core-mantle boundary reach over $4.000^{\circ} \mathrm{C}$ (Dickson \& Fanelli, 2013). The high temperature and forces of pressure induce some rock to melt resulting in portions of the mantle convecting upwards. Throughout the cracks in the earth crust the magma (molten rock) is pressed up close to the surface. When near the surface, the heat is transferred to rocks or water (sometimes up to $370^{\circ} \mathrm{C}$ ), and an usable form of geothermal energy is created. Therefore, the energy manifests itself in hot water, steam or dry hot rocks. It is called a renewable energy source because the water is replenished by rainfall, and the heat is continuously produced by the earth.

An advantage of the geothermal over other renewables is its non-intermittent character (Richard Wolfson, 2011). Unlike the wind, hydro or solar power the geothermal energy is continuously produced uninterrupted by any weather conditions, which means it can be used at any time of the day, any day of the year. This feature allows for a reliable baseload power provider, especially for the electric grid. The total global geothermal energy amounts to about 42 million megawatts, however only a fraction of it can be utilized (Meyers, 2012). Exploitation of this renewable is limited to areas where geological conditions permit a carrier i.e. water or steam to conduct the heat from the earth core nearer the earth surface. The Earth becomes hotter by about $25^{\circ} \mathrm{C}$ per kilometer of depth by average. In the geothermal hot spots, the temperature increases $60^{\circ} \mathrm{C}$ per kilometer of depth, creating optimal conditions for harvesting 
geothermal energy (Richard Wolfson, 2011). Thus, areas situated on the hot spots have a natural access to the high temperate geothermal resource. Exploitation of this renewable is therefore feasible in terms of costs and technologies. A typical drilled well is 2-3 km deep with the scale of temperatures between $40^{\circ} \mathrm{C}$ and over $300^{\circ} \mathrm{C}$ (Bloomquist et al., 1989) and an average cost of a $2 \mathrm{~km}$ geothermal borehole costs \$1-2 million (Gul \& Aslanoglu, 2018; Hammons, 2007), however the cost can vary depending on the drilling conditions (Beckers et al., 2013). The technology is currently limited to $5 \mathrm{~km}$ depth of drilling owing to the underground heat and fluids melting or corroding the drilling equipment. Figure 1.1 presents a geothermal energy overview. The geothermal resources are used according to the scale of temperatures. There are three basic geothermal system types (Lee, 2001):

1. Hydro-geothermal resources: consist of either a hot steam and water or a mixture of both, where water is the medium of the geothermal energy. They are most frequently used. Since it requires advanced drilling operations, it is classified as deep geothermal.

2. Petro- geothermal resources: the energy is stored in the dry rocks and hot salt domes, the heat is collected by an artificial agent i.e. the injected liquid that by contact with the rocks receives the temperature and carries it back to the surface. This type of geothermal is called the Engineered Geothermal Systems (EGS) and it is classified as deep geothermal reservoir.

3. Geothermal heat pumps (GHP): a heat pump operating on the principle of an aggregator transfers heat from the underground which at the 6-7 meter deep level retains the constant temperature of an average annual air temperature. A ground source heat pump extracts ground heat in the winter (for heating) and transfers heat back into the ground in the summer (for cooling). The GHP is classified as shallow geothermal. 


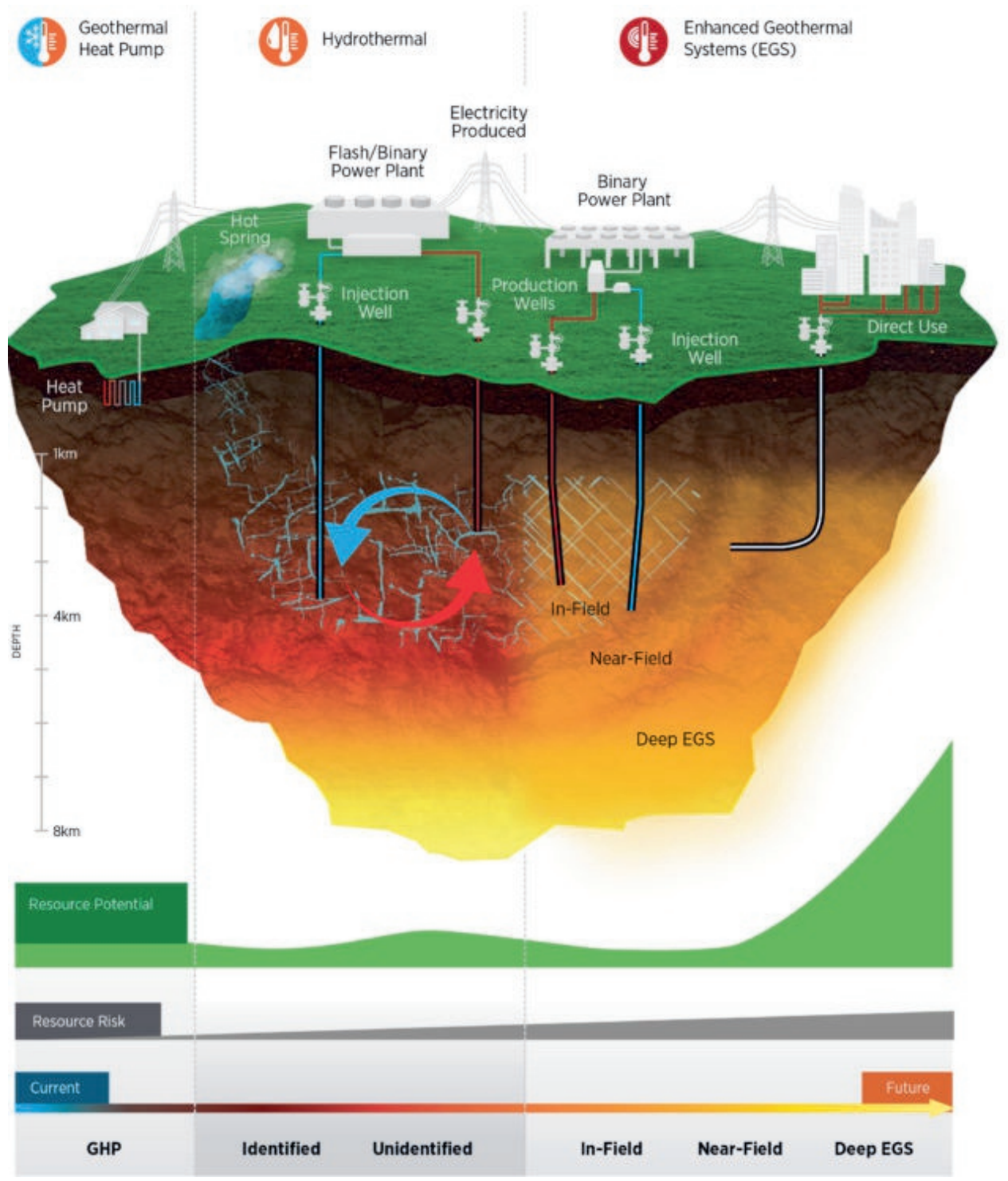

Figure 1.1: Geothermal energy overview, GeoVision (2019).

The identification of the mantle hot geothermal spots is done by geologists and engineers who follow the heat and fluid content and the permeability of the rocks thereby supported with satellite mappings. Geothermal resources have the advantage of a direct and indirect use. The direct application bases in heat of low temperatures $\left(<150^{\circ} \mathrm{C}\right)$. It usually takes the form of hot water and delivers heat. The heat pump systems classify as the direct form of geothermal use as well. The indirect use takes place when the hot temperature of the geothermal resources reaches over $150^{\circ} \mathrm{C}$. The hot steam is extracted from the deep geothermal reservoirs and drives the turbines producing electricity. In both cases, a geothermal plant is constructed in 
the vicinity of the resource with dedicated production and injection wells. There are two systems of geothermal power: steam power and binary circuits. Steam power plants generate electricity using geothermal vapor. This system requires an access to a dry and saturated steam e.g. volcanic or geyser areas. A more popular system is the binary circuit, in which two fluids (geothermal water and a chemical medium) exchange the temperatures creating vapor to be directed through a turbine. This technology is operating in either an organic Rankine cycle or Kalina cycle ${ }^{2}$ and allows for cooler geothermal resources to produce electricity.

While the direct use of geothermal resources takes place at varying temperatures (from low to very high), high temperature levels and underground pressure are key parameters for the production of geothermal electricity. World Energy Council (2013) reports that the low temperature resources have the heat potential of circa 140 EJ/year compared with the calculated world heat consumption to be $420 \mathrm{EJ} / \mathrm{year}$. The high temperature geothermal resources are able to sustain about 10 percent of world's electricity demand. Geothermal resources concentrate at the geologic plate boundaries (i.e. convergence zones, subduction zones, transform faulting) or the mantle hot spots. Depending on the location the geothermal is technically easier available. Figure 1.2 depicts the distribution of the geothermal energy in the world, and Figure 1.3 zooms into the resources location in Europe.

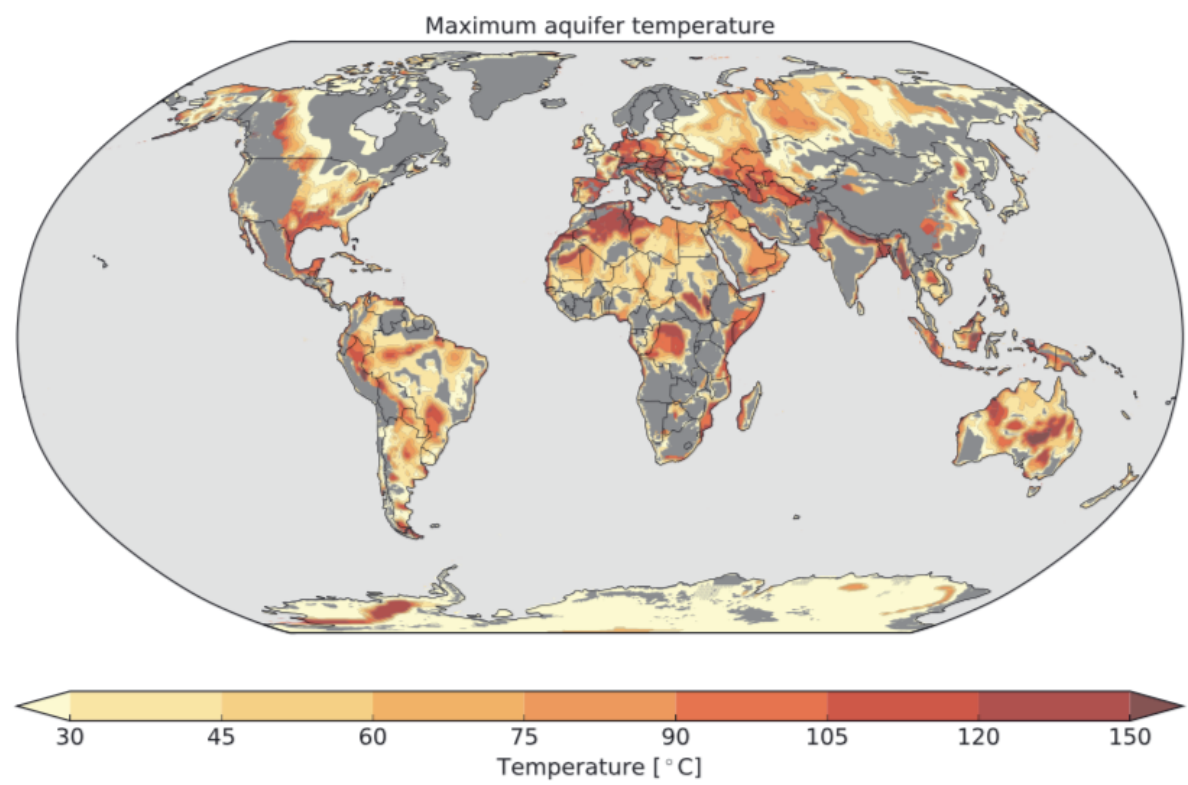

Figure 1.2: Distribution of the geothermal energy worldwide according to the temperature scale, Limberger et al. (2018).

\footnotetext{
${ }^{2}$ More on the thermodynamic processes for converting low gradient thermal energy in mechanical power using fluids (water and ammonia in Kalina cycle and pure water in Rankine cycle) in Dincer (2018).
} 


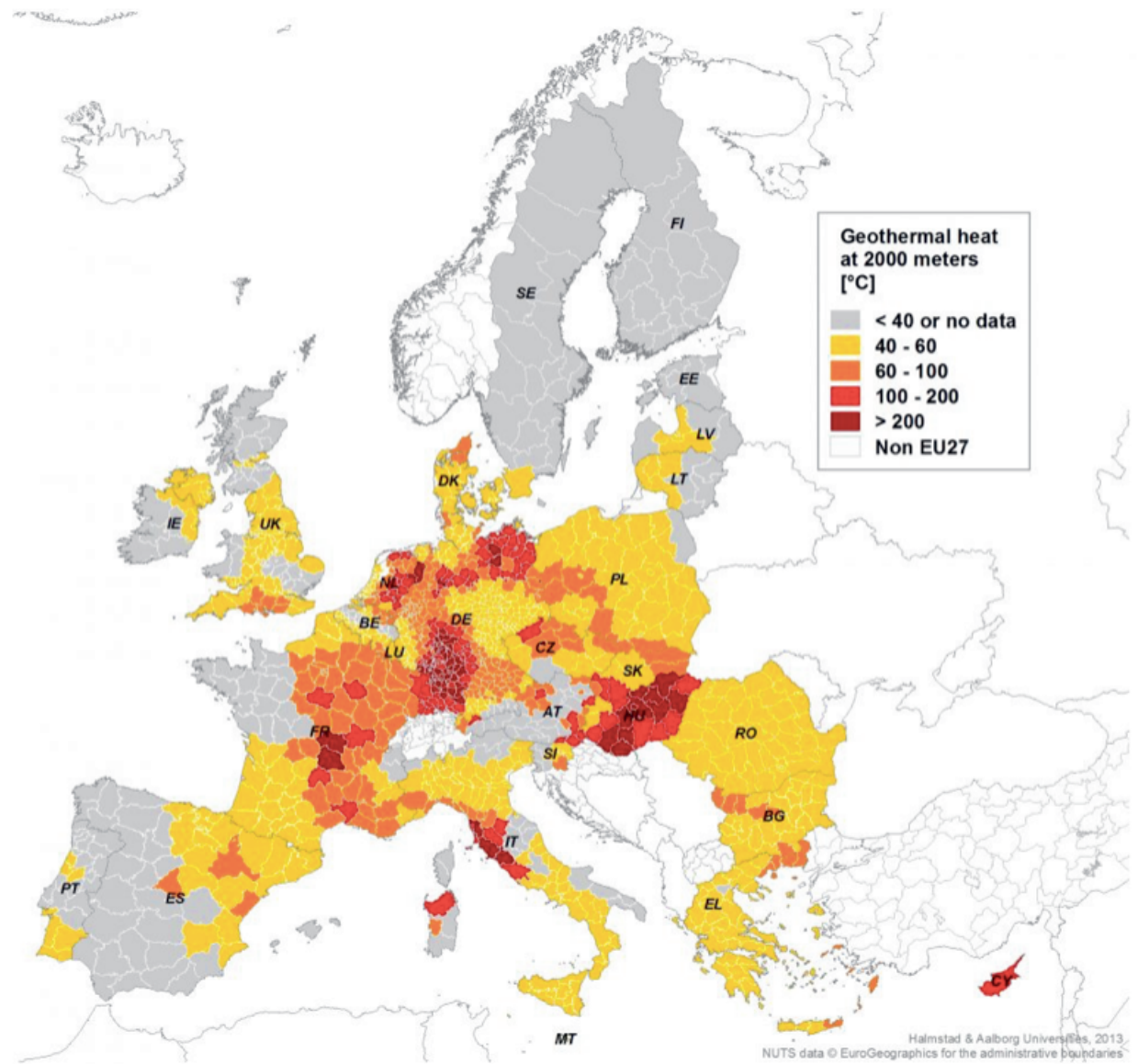

Figure 1.3: Geothermal resources by temperature at 2000 meters depth by EU NUTS3 regions, Persson (2013).

Despite the large availability, geothermal energy lacks sufficient public knowledge. Other renewable technologies as solar, wind or hydropower are visually understandable, therefore better known to the public. Moreover, some of the renewable energy installations are adjusted to individual consumption, and so are more familiar and affordable to people.

Fridleifsson (2003) argues that the value of the geothermal energy lies in the consistency of the temperature when moving downward. The access to the resource at the reservoir it is undisturbed by other geological forces. Whereas other renewables are space intense, the geothermal energy requires a plant space and usually uses the system of already existing heating pipelines and the grid. Moreover, geothermal installations are rather harmless for the environment and the wildlife, opposite to e.g. wind turbines. Nevertheless, Rybach (2014) observes that despite the highest potential and technologies, geothermal energy development is rather moderate in comparison to wind or solar resources. The geothermal power development is as well below its capacity. Figure 1.4 illustrates these findings for the case of the European Union. Despite the general growth trend of the use of all renewable resources 
throughout the time, geothermal energy is moderately used in comparison with other renewables.

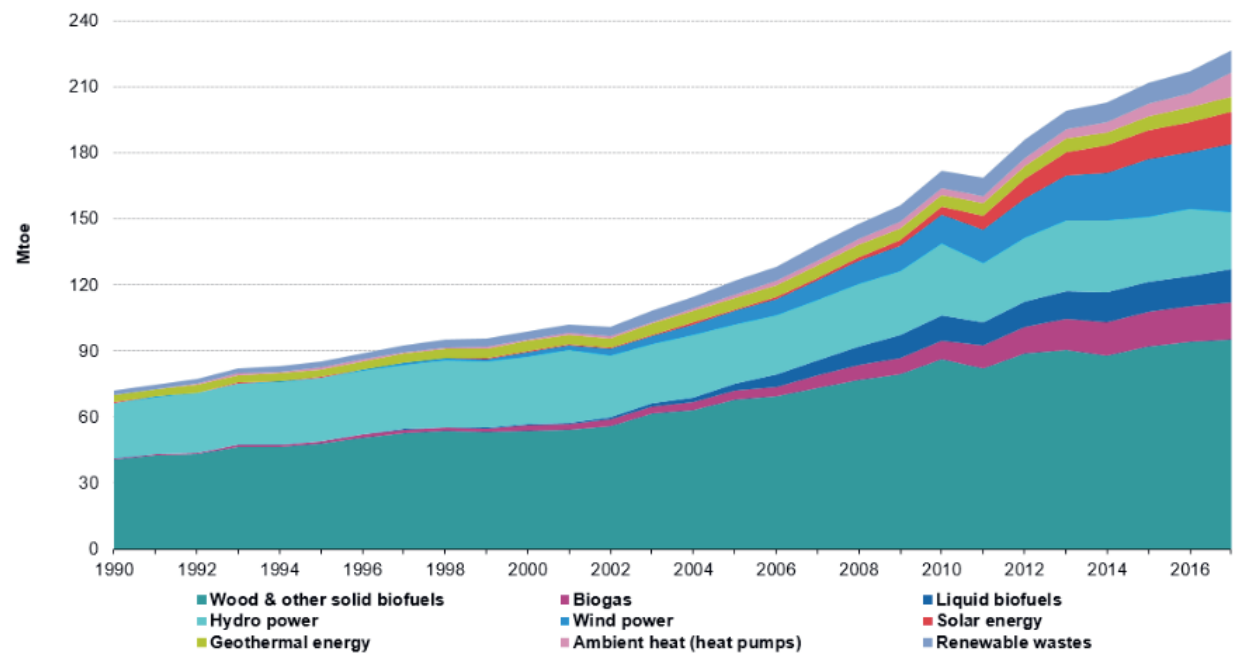

Figure 1.4: Primary production of energy from renewable sources in EU-28 in period 1990-2017, Eurostat (2019).

Björnsson (2009) lists the benefits of the geothermal energy that distinguishes it from other renewables. It is found to be the major alternative to the traditional fossil fuels. The main advantage is the environmental friendly technology to generate heat and electricity. A geothermal heating plant emits almost no $\mathrm{CO}_{2}$ in comparison to heavily polluting coal or oil plants. Moreover, geothermal energy production is not related to any other energy resources and therefore is unaffected by the fluctuations in fuel costs. Björnsson quotes further the studies showing a competitive advantage of the costs of geothermal heat and power in comparison to conventinal resources and other renewables. In addition, geothermal energy as being independent from the weather conditions has one of the highest capacity factors and its infrastructure does not require intense maintenance. The capacity factor is the unitless ratio of actual energy output over a given period of time to the hypothetical maximum possible energy output over the same amount of time (NRC 2017). Depending on the reservoir enthalpy, geothermal has a high resource efficiency (up to 90 per cent in case of a heating plant, and up to 30 percent for an electric one) in comparison with other renewables. Still, the transformation processes at the geothermal power stations cause the fluid's loss of initial energy. Regardless the high upfront investment costs in infrastrucure, geothermal projects have relatively low operating costs as well. Gudmudsson et al. (2001) claims that geothermal energy next to being a renenwable resource (i.e. a resource that is naturally replaced at the same scale of exctraction) has a sustainable advantage over other energy resources. Geothermal sustainability refers to the technical process of its exploration and sustaining the energy production level over long period of time. The resources are not mined, and are continuously replenished by the forces of nature (Hähnlein et al., 2013; Rybach, 2003). The 
sustainability is as well linked with the local character of geothermal energy. Exploitation and use of the geothermal potential takes place locally (Shortall et al., 2015b). Moreover, geothermal energy is often based in existing local energy networks and infrastructure. An ideal utilization is the combined heat and power geothermal plant, when geological conditions allow.

\subsection{The state of play and geothermal developments}

Among the 17 sustainable development goals (SDGs) for human development and sustainable livelihood adopted by the United Nations in 2015, goal number seven calls for providing affordable, reliable, sustainable and modern energy to all (UN, 2019). This relates to a significant increase in the global energy mix with the renewable resources. It can be facilitated by clean energies development and technological and political support. The demand for energy grows with the increasing number of world population. Despite the political advancements yet circa 1.3 billion people have very limited access or none to modern energy resources (IEA, 2019). Among the sustainable options, geothermal energy meets the conditions of the sustainable development, environmentally benevolence and a large scale energy provision (Avtar \& Kumar, 2016; Fridleifsson et al., 2008). Geothermal power is highly scalable from a rural village to an entire city, (Lund \& Boyd, 1999), making it a vital part of the renewable energy transition. Still, the geothermal potential remains untapped, in both direct and indirect use. Figure 1.5 shows the global geothermal power generation and the International Energy Agency predictions. The geothermal power is technically harnessable in 100 countries for heating and cooling purposes, of which 27 have a total installed power generation capacity of 14.600 MW (IRENA, 2019).

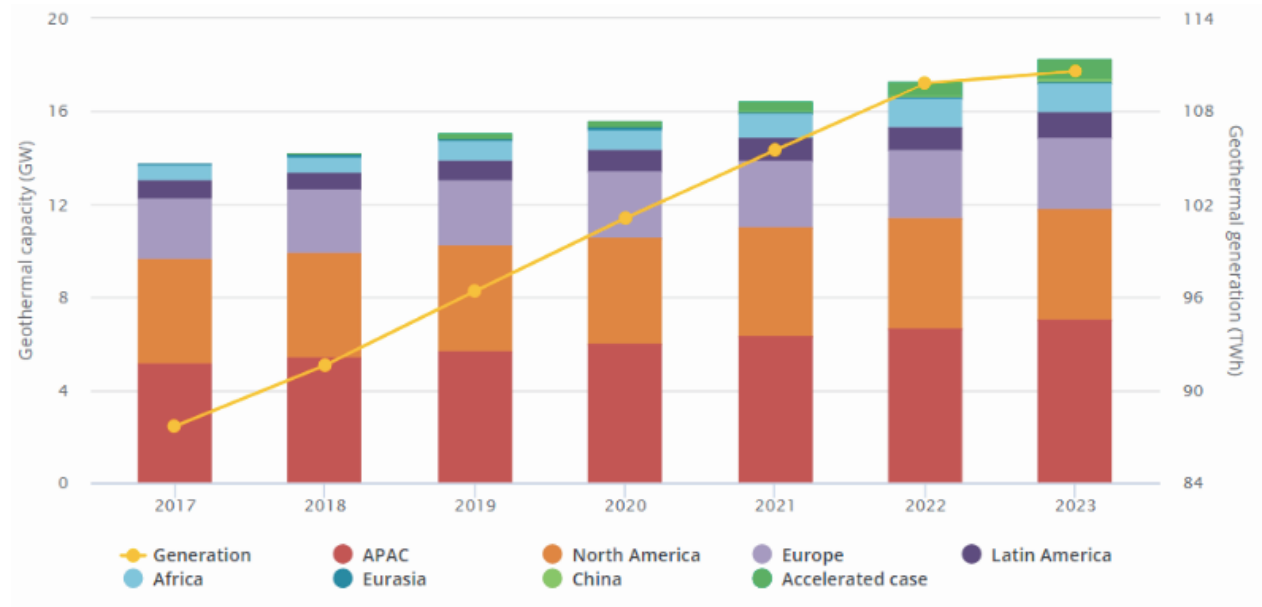

IEA All rights reserved.

Figure 1.5. Geothermal power generation and cumulative capacity by region, 2017-2023, IEA (2020). 
Geothermal energy displays a steady growth, though not a rapid one in comparison with other renewables (see Figure 1.4). The largest untapped potential for geothermal energy is utilizing the heat directly for all kinds of applications needing heat including industrial applications. The heating and cooling sectors represent half of the energy demand together with transportation and electricity generation (IEA, 2020). In the context of the energy transition that requires carbon emissions cuts, heating and cooling have a crucial role since they still heavily rely on fossil fuels. The majority of the countries where geothermal utilization is recorded are developing or transitional countries (Fridleifsson \& Ómarsdóttir, 2013). The potential for geothermal energy use to improve living standards in those countries is thus very high. The following compilation in Table 1.1 presents the top ten countries using the geothermal energy according to the direct use (heating and cooling) and indirect use (electricity generation). Geothermal power plants can be built only on the geological hot spots, that with current technologies naturally limits the geothermal electricity production to a certain number of locations. The direct use is widely spread and is geographically concentrated in regions above the $35^{\circ}$ latitude due to weather conditions that need heating. The direct use is dominated by China, followed by Europe with almost 30 percent of global geothermal consumption.

Table 1.1 Top ten geothermal energy producing countries, installed capacity in 2017, World Energy Council (2018), Pandeyet al. (2018).

\begin{tabular}{lllll}
\hline & direct use & Mtoe & indirect use & MW \\
\hline 1 & China & 4.1 & USA & 3.591 \\
2 & USA & 3.26 & Indonesia & 1.925 \\
3 & Turkey & 1.28 & Philippines & 1.868 \\
4 & Sweden & 1.24 & Turkey & 1.155 \\
5 & Iceland & 1.09 & New Zealand & 980 \\
6 & Philippines & 887 & Mexico & 951 \\
7 & Indonesia & 864 & Italy & 944 \\
9 & Japan & 848 & Iceland & 755 \\
10 & New Zealand & 830 & Kenya & 676 \\
& Italy & 716 & Japan & 542 \\
\hline
\end{tabular}

The International Energy Agency (IEA 2020) assumes the geothermal grows from 0.66 per cent of global electricity generation to 4.9 per cent by 2050 . Such increase is calculated to reduce emissions by 16.6 gigatons of carbon dioxide and save $\$ 1$ trillion in energy costs over 30 years and $\$ 2.1$ trillion over the lifetime of the infrastructure. Before 2050 a tenfold increase in the global production of heat and electricity from the geothermal resources is expected (IEA, 2020). The untapped potential is mostly observed in the direct use of the resources in the application of ground heat pumps and heating/cooling systems. In the industrialized countries, 35-40 percent of total energy consumption is used in buildings, whereas in the developing 
countries space and water heating or cooling remains a significant economic challenge (IEA, 2019).

The broad application of the geothermal resources were intuitively discovered and used by people throughout history. The temperature of the resource determines the possibilities of use. This is specified by an Icelandic engineer Baldur Lindal, who structured the possible forms of geothermal application. His diagram indicating the temperature range of geothermal water and steam suitable for various use is referred in the literature as the Lindal diagram (Gudmundsson, et al, 1985; Patsa et al., 2015). Geothermal energy is a unique resource that can be practically completely used in any form and temperature; unlike other renewables that have a determined character. The spectrum of use is depicted in Figure 1.6. The direct use of geothermal water spans the entire temperature scale, which can be even extended below $22^{\circ} \mathrm{C}$ to include heat pump applications up to the steam that serves for electricity generation. The binary power production starts already at the mid-range point of $84^{\circ} \mathrm{C}$ and industrial geothermal use occupies the mid-to-high section of the diagram, where the mid-low end of the scale are the for less high energy demanding applications such as space heating and agriculture.

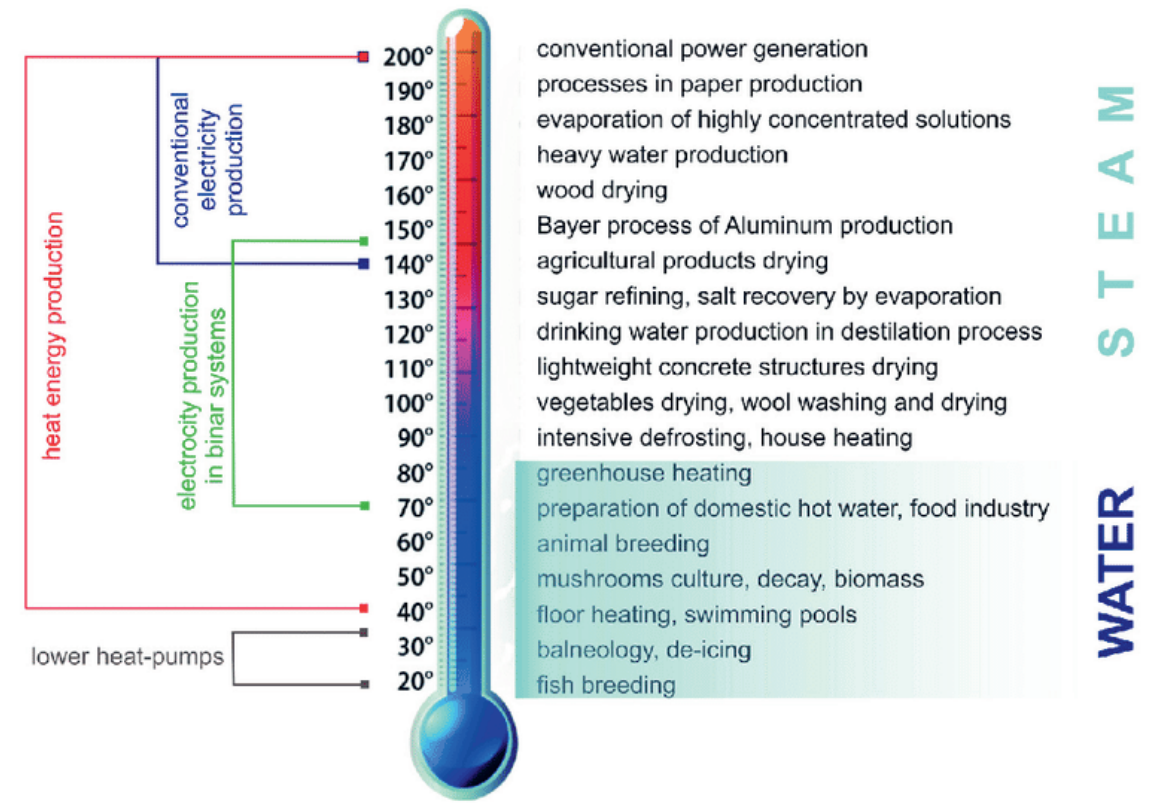

Figure 1.6: Modified Lindal diagram, Operacz \& Chowaniec (2018).

The technology, reliability, economics, and environmental acceptability of direct use of geothermal energy is demonstrated throughout the world. Whereas the Lindal diagram presents the possibilities for geothermal energy, Figure 1.6 depicts the actual distribution of direct global geothermal applications. Despite the vast opportunities of geothermal usage, half 
of the world geothermal energy is used for heat pumps purposes (Figure 1.7 a). Secondly, geothermal waters are used for recreational, bathing and balneotherapy purposes followed by the space heating function. Further substantial use refers to various agriculture and industrial applications (Figure 1.7 b). Category 'other' classifies not frequently provided categories of use including animal husbandry, cultivation of spirulina, and carbonation of soft drinks (Lund \& Boyd, 2016).

a. Total energy used (TJ/year)

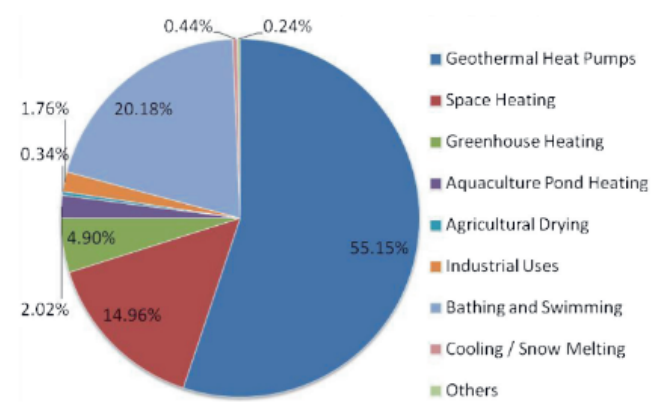

b. Total installed capacity without heat pumps (MWt)

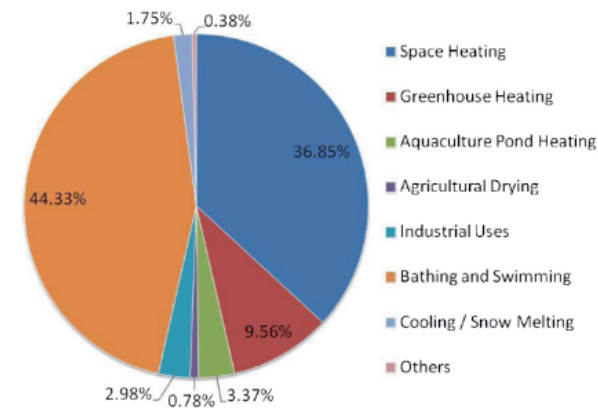

Figure 1.7. Geothermal energy direct utilization worldwide, distributed by the percentage of energy used, 2015, Lund \& Boyd (2016).

The direct geothermal application involves wide variety of end users, from an individual household to large scale industries. Since it uses both high and low temperatures it is more widespread than electricity production. Lund (1996), Balat et al. (2009), Chiasson (2015), Fridleifsson (2001) and Lund \& Boyd (2016) discuss in detail the spectrum of the geothermal direct use in the world. Nevertheless, the direct applications are specific for a local market, as steam and hot water are not to be transported over long distances from the geothermal site. Whereas the electricity from the geothermal power stations enters to the grid, the geothermal heat according to the thermodynamic law is limited in transmission distance from the extraction station. The longest geothermal heat pipeline in the world is $63 \mathrm{~km}$ and present in Iceland, where a standard economically feasible geothermal network has $10-30 \mathrm{~km}$ of pipeline (Lund, 1996) Since geothermal energy is a locally available and an endogenous heat source (Leardini \& Falcon, 1974; Sestini, 1970), the production and consumption of the energy has a local character as well. The utilization of the resources are concentrated around the locations of extraction. The diversity of geothermal energy utilization is observed in direct and indirect use. The renewable serves to i.e. provide various forms of energy to people, from the sustainable food production and animals farming, to industrial use and health and recreations purposes. Studies of Fridleifsson (2001) and Jesus (1997) introduce the positive impact of the geothermal resources for the general human wellbeing. Moreover, both direct and indirect application induce a local job creation related with the forms of geothermal utilization. Following Barbier (1997), Dursun \& Gokcol (2012) and Shortall et al. (2015b) the benefits of geothermal harnessing can be summarized as: 
- reliability and sustainability: the geothermal heat is produced by earth for millions of years and the reinjection process of the extracted fluids assures the renewability of the resource,

- non-intermittent nature: the geothermal is stable, always available to harness, not affected by weather conditions,

- massive energy potential: upper estimates show a worldwide potential of 2 terawatts (TW),

- clean energy source: the very low gas emissions energy production from the geothermal can offset the fossil fuels power plants, it is a feasible alternative for the conventional resources,

- low land use: geothermal plants require less land and infrastructure than other renewable energies, as well as the land is highly recoverable in case of plant's termination,

- competitive price: geothermal power is found to be cheaper than hard coal, lignite, fuel-oil, wind, and natural gas, respectively,

- local character: use of an endogenous resource for energy and heat generation is important from the standpoint of national and economic security. Furthermore, geothermal facilities are unaffected by fluctuations in fuel costs and potential irregularities in fuel deliveries across boundaries, that add risk to conventional power generation such as coal, oil and natural gas,

- jobs creation: the wide scope geothermal utilization induces employment.

As the disadvantages of the geothermal resource Dickson \& Fanelli (2013) list: geographical limitation of the resource exploitation; high upfront costs associated with the construction of geothermal plants; drilling and geological explorations lead to cases of earth subsidence or motions; geothermal reservoirs run the risk of depletion if the fluid is extracted faster than replaced.

Still, the qualities of the geothermal resources outperform the disadvantages. It can be argued that geothermal energy meets more than one of the sustainable development goals SDGs, (I Fridleifsson, 2007; Shortall et al., 2015a; UN, 2019). Next to the mentioned, clean energy provision sustainable development goal (SDG no. 7), the geothermal resource can contribute to the large scale food production (SGD no. 2), balneology helps to maintain the human health and wellbeing (SGD no. 3), geothermal water if meeting the mineralization parameters is available for direct consumption (SGD no. 6), opportunities of use presented by the Lindal diagram induce employment and therefore economic development (SDG no. 8), geothermal heating and cooling systems in cities are reducing the carbon footprint (SGD no. 12 and 13).

The increase of the geothermal energy use in the world depends on technological advancements and political support. Organizations like the World Bank and United Nations recognize the role of the geothermal resources in sustainable development. Dedicated 
programs and financial schemes are developed to create an impulse for a larger geothermal energy use worldwide, especially in the countries that are energy resources imports dependent e.g. Global Geothermal Development Plan (Bank, 2013), Geothermal Training Program (UN, 1996) and FAO study (Van Nguyen et al., 2015).

\subsection{Geothermal energy in Poland}

Poland's geothermal resources are classified as low and medium temperature connected with the Mesozoic sedimentary formations, with the range of temperatures of $20^{\circ} \mathrm{C}-100^{\circ} \mathrm{C}$ (Górecki et al., 2015). The country's low-enthalpy potential is one of the biggest in Europe since Poland is located on bounders of three main geological zones of Europe (Stupnicka \& Stempień-Sałek, 1997). The structure of the lithological rocks and hydrogeological qualities of the reservoirs allow the underground waters including geothermal to significantly occur under almost 80 percent of Poland's surface. Yet, considering the technical factors and economics of the exploitation, geothermal resources can be used on circa 40 percent of the territory (Ney, 1999). Geothermal resources are exploited mainly in the form of heat and water. The electricity production is in the pilot stage with a forecasted capacity of $1 \mathrm{MWe}$ (Richter, 2020). Geothermal waters in Poland characterize with low mineralization that next to the geological parameters create a favorable exploitation conditions (Chowaniec et al., 2001). It generates one of the highest potentials among the available renewables in Poland.

The active resources exploration started in the 1980s, which led to the establishment of three geothermal provinces. The best geological formation for geothermal use is in the Polish Lowland Province and in the Carpathians region (Gladysz et al.,1994). The total installed geothermal capacity accounts for circa $500 \mathrm{MWth}$ and $714 \mathrm{GWh}$ of heat production as per 2015. There are six main geothermal plants in Poland and separate geothermal installations are built for commercial purposes. Figure 1.8 depicts the direct uses of the geothermal resources in Poland. Geothermal energy is applied for the purposes of district heating; provision of drinking water; provision of water-based recreational and health centers; and single activities in cooling, food processing, farming and industry. By the end of 2018, 15 geothermal and balneotherapy centers operated in Poland. The unused geothermal hot water instead of reinjecting to the borehole is used in the geothermal recreational or spa centers. That is why the centers often emerge next to the geothermal district heating plants. Others developed individual geothermal installations for either extracting or warming the water. The heat pump market represents about $650 \mathrm{MW}$ installed capacity generating circa 2600 TJ heat output and the sector intensively develops each year (Kępińska, 2018, 2019).

The demand for geothermal energy exploitation is mainly motivated by environmental concerns. As well, by the relatively high pollution in Poland caused by the deployment of fossil fuel mostly for heating purposes. The air quality in Poland continuously exceeds the EU standards (EEA, 2020). Following the European Environment Agency (EEA) report, the concentration of the air pollutants as $\mathrm{NO}_{2}$ and $\mathrm{PM}_{10}$ in Poland is still very high comparing with 
the EU 27. Therefore, in its sustainable nature, geothermal energy can address two issues: clean energy resource provision and low emissions obligation. This geothermal opportunity is discussed in the work of: Axelsson et al. (2003), Kaczmarczyk (2018); Pająk et al. (2020), Sowiżdżał et al. (2017) and Szulc-Wrońska \& Tomaszewska (2020).

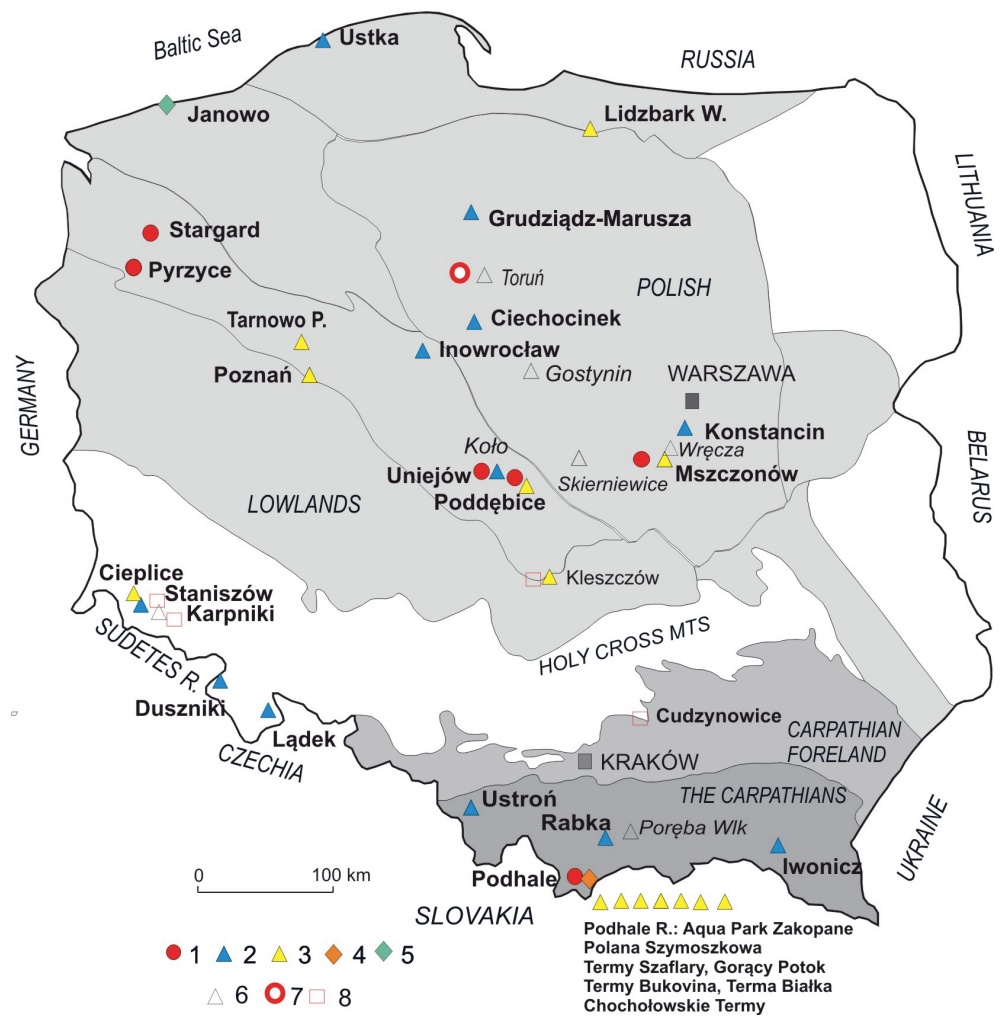

Figure 1.8. Geothermal direct use in Poland, 2018, Kępińska (2019).

Legend: 1-district heating plants, 2-balenology centers, 3- recreational/bathing centers, 4 -wood drying, 5- fish farming, 6 -recreational centers in progress, 7 -district heating plants in progress, 8- CHP (combined heat and power) installations projects.

Since geothermal resources are natural resources located on public land, public utilities and authorities are in a position to develop it. Moreover, the supply of energy for individual and collective consumers is a municipality's own task in Poland as a result of the Act on Local Government of 1990 and the Act on Energy of 2010. Local governments become responsible for planning and organizing the supply of heat, electricity and gas fuels to fulfill the requirements of sustainable energy development and the replacement of conventional fuels with the renewable energy resources. The parameters of the geothermal resources in Poland are found optimal for the space heating application (Barbacki, 2012; Bujakowski \& Barbacki, 2004). The heat demand is rather high in Poland and moreover the country has developed a dense heating network system that can be utilized for the geothermal heat transfers (Huculak 
et al., 2015). The extent communal network in Poland provides an access to consumer markets for the use of the geothermal heat (Kępińska et al., 2017). The share of renewable resources including the geothermal in heating sources is gradually increasing. Besides, the scale of geothermal energy supply is wide in Poland with over 400 district heating systems reaching more than 16.500,000 inhabitants (Euroheat, 2019). Górecki et al. (2015) discuss that over 100 Polish municipalities have the hydro-geothermal conditions that together with the existing heating infrastructure ensure an efficient local utilization of the geothermal resource. Space heating significantly dominates the geothermal usage and Poland is capable of producing $625.000 \mathrm{PJ}$ of geothermal energy whereas the annual energy consumption is only circa 5500 PJ (Ney, 1999). The potential of geothermal energy in Poland is seen unused, considering its favorable geological parameters for heating purposes. As presented in Figure 1.9, the district heating network is one of the denser in Europe. Yet, tapping into the geothermal energy capacity in Poland is low comparing with other European geothermal using countries, seen in Figure 1.9.

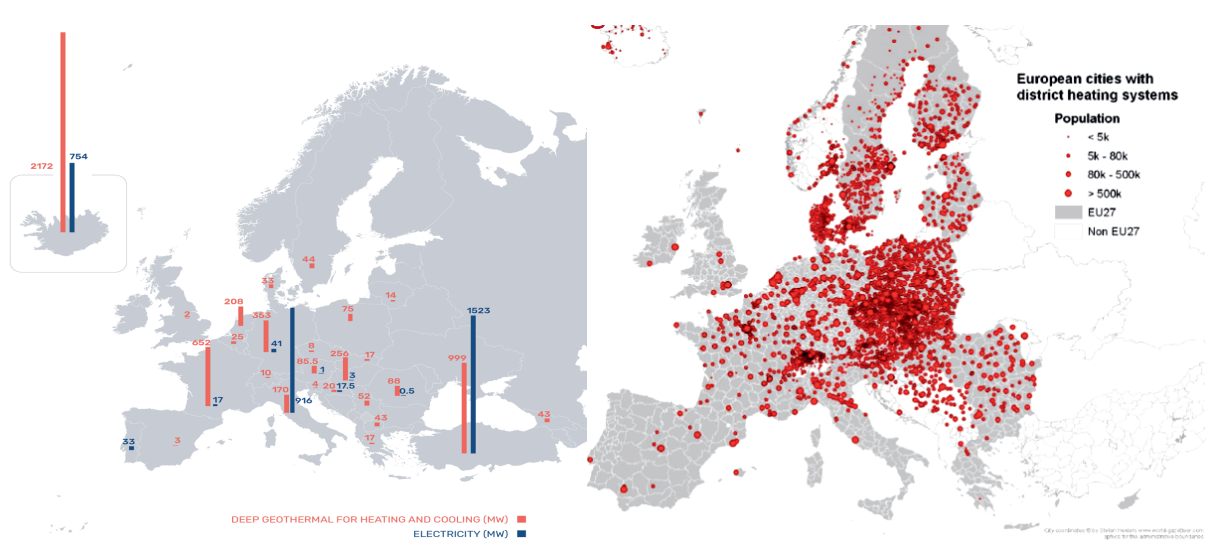

Figure 1.9. Comparison of the installed geothermal energy capacity in Europe and the density of district heating networks, 2019, EGEC (2020).

Poland only has a few examples of geothermal water applications compared to Europe at large. The heat plants in Poland operate on a small scale, considering the discussed geothermal potential in the country. It is reflected in the renewable energy statistics in Poland, where geothermal energy production accounts for 3 percent of the total renewables production share. The dominating renewable resources are biomass and wind. Nevertheless, the consumption of geothermal energy gradually increases each year. The annual geothermal energy produced is consumed in 75 percent in space and households heating and in 25 percent in trade and services (Statistics Poland, 2019). With respect to the geothermal potential in the country and the available infrastructure, this renewable can support the de-carbonization processes imposed by the European Union energy policies. The share of the geothermal energy production is expected to grow as a consequence of the national regulations, enhancing the 
use of geothermal energy in the national energy mix, e.g.: Poland's Energy Policy till 2030 and the National Energy and Climate Plan for the years 2021-2030.

\subsection{Research problem definition}

The optimal utilization of the geothermal resources is a combination of the principles of geology, engineering and economics. Each of these sciences provide valid arguments to investigate the development of the geothermal resources. As discussed, the geothermal energy is location specific; the geothermal reservoir must be present in order to exploit the resource. Armstead (1983) argues that the large potential of the geothermal energy is only locally available. Although the energy sometimes manifest itself directly (e.g.: geysers, hot springs), the utilization requires technology and human intervention. The wide scope of application introduced by the Lindal diagram (Figure 1.6) indicates local implementation as the direct use (Dickson \& Fanelli, 2013). The local use of the geothermal energy led to the inclusion in the international energy policies. The formalized policies requirements of the low-emission economy and the limitations of coal-fired heating plants constitute another argument for the development of locally available renewable energy, including the geothermal one (European Commission, 2019; Directive EU, 2009). The Renewable Energy Directive (RED II) adopted in 2018 exceeds the obligation of the participation of the renewable energy in the energy production, heating and cooling and transportation in the European Union up to 30 percent by the year 2030 (EU, 2018). It prioritizes the use of locally available renewable resources. Special attention in the document is given to the enhancement of the concept of renewable energy communities, based on available local renewables. The articles number 46,63 and 65 of the RED II in particular discuss the geothermal energy as a potential for the benefits of a local economy and population, if geological conditions allow. Hence, the geothermal potential is recognized in the European Union energy regulations.

The geothermal energy harnessed in local communities is assumed to positively influence the economic landscape of a region. The research problem is hence determined by finding the measures of the geothermal impact on local economics. Since the geothermal energy production and consumption deposits around the reservoir (Glassley, 2014; Murai, 2002), it leads to new economic opportunities (Akorede et al., 2010; Rose, 1977) and provides options for improving local infrastructure and facilities (Arent et al., 2011; Barton et al., 2020; Mariita, 2002). The aim of this research is to determine the socioeconomic impact of this renewable resource, other than direct energy provision. Throughout the variety of geothermal resource applications represented by the Lindal diagram, geothermal enables direct, indirect and induced effects in a local economy. The direct and indirect benefits mostly refer to the geothermal energy production and consumption (Gupta \& Roy, 2006; Lund, 1996). The induced benefits remain under investigated in the literature and are limited to studies regarding the direct employment creation (Da Silva et al., 2013; De Jesus, 2016; Kagel, 2006b; Peterson et al., 2005; Rose, 1977; Zulkarnain et al., 2016). A number of direct jobs emerge as 
one of the major geothermal impact measure according to organizations like Greenpeace (2015), IRENA (2011) and NREL (2004). Sutter \& Githui (2013) and Yasukawa \& Anbumozhi (2018) initiate the discussion about the local geothermal specialization, as an induced effect.

Rybach (2003) classifies the effect of using geothermal sources as: direct (heat and water extraction), indirect (electricity generation) and derived (economic and social changes at the site of geothermal operation). From the forms of using the geothermal resources it can be assumed that the use of geothermal resources causes socioeconomic changes in the locality of exploitation. These changes are caused by new market phenomena that starts to develop through the production and use of geothermal energy locally. Shortall et al. (2015b) study the sustainable use of the geothermal resources. The induced impact of the geothermal development is underlined. It is observed in the related sectors like tourism, agriculture and land management in general. The economic multiplier effect of the geothermal energy contributes to the creation of direct and indirect employment argue Schütz et al. (2013).

Blodgett \& Slack (2009) indicate that the induced impact of the geothermal energy use can trigger changes in the structure of the local economy. Kumar's (2020) observations confirm it. It is considered as the additional local income generated from geothermal activities or individual spending on goods and services. Moreover, Lesser (1994) analyses the direct, indirect and induced economic impact of geothermal resources development. By using the input-output framework the direct, indirect and induced incomes generated by the geothermal infrastructure are assessed. Yet, the literature presents broad observations or assertions about the role of geothermal resources in regional economics. Whereas the direct and indirect forms of geothermal exploitation are tackled in the literature, the induced effect is solely covered in a general discussion. The literature review lists limited induced activities related to the geothermal exploitation and moreover the methods to assess the induced impact including employment of the geothermal resources are not developed. It creates a research gap. A major part of this thesis addresses this research problem by seeking statistical confirmation to the general observations. An empirical approach to this problem constitutes the core interest of this thesis.

Moreover, the research problem derives from the system of the geothermal energy exploitation. Geothermal investments have the highest initial costs among all of the renewable resources installations (Alberici et al., 2014; Compernolle et al., 2019; Kristjánsdóttir \& Margeirsson, 2014; Li et al., 2015). State is usually involved in the geothermal development, as a result of the prohibitive projects costs, but as well the liability issues and ownership land concerns (Sacarto, 1976; Canan, 1986; Young et al., 2017). Since the disadvantages of the resources deployment include induced seismicity, cost and risk of drilling operations, the illustration of the geothermal benefits other than energy provision is important for the social acceptance of the resources exploration. The communities near the geothermal sites can be concerned about the geothermal projects development. Caramizaru \& Uihlein (2020) discuss that the EU energy regulations e.g. RED II or Electricity Directive create the renewable energy 
communities concept. The directives recognize the role of geothermal energy for local communities that is beyond energy provision. Therefore, the identification of socioeconomic benefits of geothermal energy for local economies is an important element for the future resources development. Moreover, the state subsidies spent on geothermal investment are expected to return in the local economy. It is an argument for studying whether geothermal resources deliver any socioeconomic benefits other than the clean energy provision. This issue remains yet uncovered in the literature.

The relation between local development and renewable resources is evidenced in the literature e.g.: Boyle (1996), Del Río \& Burguillo (2008), Dincer (2000), Nijkamp et al. (1990) and Peake (2018). Geothermal resources are considered as a sustainable development factor for Bertani (2009), Chandrasekharam \& Bundschuh (2002) or Lesser (1994). Nevertheless, geothermal resources are the least discussed in comparison to biomass, wind or solar energy concerning the use of renewable resources on a local level. Therefore this study addresses this the research gap about the geothermal impact on local development. The ultimate goal of this study is to develop a methodology based on Poland's data that can be applied to other geothermal locations. This is the element of innovation expected from this study and furthermore a contribution to broaden the knowledge about the geothermal resource use. The research problem is summarized in Figure 1.10.

RESEARCH PROBLEM DEFINED

Geothermal resources utilization is local

Lindal diagram systemizes local utilization

Variety of utilization results in local socioeconomic benefits

expected by:

- dedicated EU regulations

- state that provides public funds and subsidies

- local communities with the exploitation risks

Research gap

Figure 1.10: The concept of the thesis research problem and research potential, own elaboration. 
Figure 1.10 conceptualizes the research problem in this study and the research gap that is addressed. The geothermal impact on the local development constitutes the research problem. Inference about the resource impact comes from the fact that the utilization of the geothermal resources takes place locally. This research is dedicated to the direct application of the geothermal resources and takes the case of Poland. The scope of economic use of the geothermal systemized by the discussed Lindal diagram. From the variety of geothermal resources local utilization in production, industrial and commercial activities their benefits reveal locally. The scope of use is local since the geothermal resources harnessing is limited the proximity of the geological reservoir. The literature identifies the benefits as both economic and environmental. Therefore, the expected recipients of the geothermal economic impact are the local communities and local authorities whereas the environmental advantages are a primary interest for the regulators. This reasoning represents the research potential in the geothermal impact studies explored in this thesis.

\subsection{Research objective and research question}

The idea behind this thesis is to investigate local cases of geothermal energy utilization. Since we argue that geothermal is location specific, we study changes caused by geothermal energy at the level of municipalities. A principal assumption is that geothermal resources create an impact on the location where used. In this study, the supply side of the geothermal energy utilization is analyzed. The focus is on the resources capacity that are already exploited. The geothermal supply refers here to the consumption of the total amount of the energy produced locally. For this purpose, we first determine the potential measures of the geothermal impact. These measures aim to test if a socioeconomic change takes place related to the geothermal resources exploitation. Therefore, the induced impact of the geothermal resources on the locations is the main analysis subject.

The scientific problem is to be employed on the cases of local geothermal utilization in Poland. The analysis focuses on the lowest administrative level, the municipalities. Since the effect of the geothermal resources use is expected to reveal in the local economy, we look into socioeconomic measures of the municipalities and their relationship with the geothermal energy. The demand side is to be analyzed, therefore the already exploited geothermal sites in Poland undergo the analysis. In general, the demand of the geothermal energy in Poland identifies the potential of using the geothermal energy in the Polish municipalities. According to the Polish Geological Institute as per 2015, 54 municipalities in Poland had a cost-effective geothermal potential and efficient geothermal wells to extract resources (Skrzypczyk \& Sokołowski, 2015). Hence, these municipalities have geothermal applications possibilities. In addition, the municipalities in Poland are responsible for energy provision for individual and collective customers, an obligation imposed by the national directives as Act on Local Government of 1990 and the Act on Energy of 2010. This study seeks to determine the relation 
between the geothermal energy production and its local socioeconomic effect. The resources supply is not the research objective, but the effect that it delivers to the municipalities. The studies of Bundschuh et al. (2017), Jenei (2012) and Ruggero (2017) indicate that the sustainable use of geothermal resources is optimized locally. Moreover, the demand for clean heat sources in Poland enhances expansion of the geothermal. Further investments in the geothermal energy creates more local opportunities of use it.

The thesis research objective is to discuss the local socioeconomic development as a result of exploiting the available local geothermal potential in Poland. The following main research question is set: What is the impact of the geothermal resources utilization on the development of the municipalities in which they occur? This study aims to answer this main question in five thesis chapters using research sub-questions. Figure 1.11 depicts the diagram of the research questions in their mutual relationship:

RQ 0: What is the impact of the geothermal resources utilization on the development of the municipalities in which they occur

RQ 1: Whether the geothermal resources utilization impacts the performance of a municipality?
RQ 2: How comparable are the results yielded by the Principal Component Analysis and Analytical Hierarchy Process methods in the situation of secondary data?
RQ 3: whether the local employment structure changes while using the geothermal resources?
RQ 4: Which data conceptualize local competitiveness?
RQ 1.1: Whether the introduction of a geothermal spa in a municipality increases the local socioeconomic development?
RQ 1.2: Is there a relationship between the development of geothermal energy and the competitiveness of the municipalities?

Figure 1.11. The diagram of the thesis research questions, own elaboration.

All the research questions are to be answered on the cases of selected municipalities in Poland that exploit geothermal resources. The research questions RQ 1 whether the geothermal resources utilization impacts the performance of a municipality is answered by two supplementary studies and two research questions $R Q 1.1$ and RQ 1.2. It analyzes the impact of the geothermal resources use in a municipality on socioeconomic development and as on competitiveness. The methodological foundation of the thesis is tackled by two research 
questions ( $R Q 2$ and $R Q 4)$. The RQ 5 is set to approach the impact of the geothermal resources on employment in local economies in Poland.

By answering the research questions, the role of the geothermal resources for the development of municipalities in Poland is to be determined using econometric methods. A review of the literature in this field does not comprehensively address the research questions. Moreover, a substantial lack of the socioeconomic angle in the geothermal publications is noticed. The technical and geological studies significantly prevail in the geothermal literature. Whereas approximately 5390 results come up in the Google search concerning general geothermal resource, this number is reduced to 221 results when the filter 'local economy', 'local development' and 'socioeconomic impact' or 'geothermal competitive advantage' is applied $^{3}$. Hence, this thesis fits in the research gap in the socioeconomic studies of the resource exploitation at a local level.

\subsection{Theoretical framework}

This section is dedicated to the theories that support the thesis research question. An overview of concepts delivers a frame, in which the geothermal resources impact on local development is analyzed. The scope of the selected development theories is presented, that relate to the natural resources use. With the theoretical references each of the research question in the thesis is answered. Since there is no single theory that provides a base for the geothermal resources and local development, the relationship of the two phenomenon is established in an set of theoretical references. The theories selected to motivate the research problem address the origin of what impacts the local development. Throughout the presented approaches the factors of development are explained.

The theoretical background of this work intersects in several theories in the field of economics, regional studies and natural resource management. Theories of development constitute the theoretical reference of the thesis. Economic development is a widely discussed concept from the classics of eighteenth and nineteenth century political economy, through the European historical school of the early twentieth century, to the various streams of modern economic growth with the development principle. ${ }^{4}$ Joseph Schumpeter, one of the most influential economists of the twentieth century dedicated his research to the origin of development (Schumpeter, 1934). His division into exogenous and endogenous factors of growth became a foundation for the twenty century economic development theories. The Schumpeterian approach relates exogenous growth to accumulated factors of production and capital transfers

\footnotetext{
${ }^{3}$ Google Search engine own search on 14.03 .2020

${ }^{4}$ Trends of development economics have common roots in the classical political economy work of A. Smith, T.R. Malthus and D. Ricardo and classical political economy inspired by J.S. Mill or K. Marx has patterns of development definitions. The end of the nineteenth century exposed the fundamental to the development theory work of J. Schumpeter next to the research of A. Marshall and J.M. Keynes who introduced the competitive markets concept into the development studies.
} 
(both human and financial); and endogenous growth that comes from within the economic system through entrepreneurship and innovation. Schumpeter stresses that structural change and the development of an economy is triggered by introducing innovations. Technological progress creates new industries that replace the traditional ones, attributed wrongly to capital accumulation (Schumpeter, 1942). In addition, Schumpeter builds on the idea called the "gale of creative destruction". He describes the process of free market where appearance of new entrepreneurs or new industries is a force that sustains a long run economic development (Reinert \& Reinert, 2006). Such change causes the companies holding monopolistic positions to lose it. Therefore, Schumpeter introduces the market mechanism by which new product replaces outdates ones, referring to the core of capitalism. This idea can serve to interpret the change in fossil fuels consumption and the role of renewable resources in economic development according to for instance: Clarke (2019), Gliedt \& Parker (2007), Green \& Newman (2017) and Nanda et al. (2014).

The development paths relate to various disciplines. From a political role of development that stands behind decision-making processes (McAdam et al.,1996) to the welfare economics and capital accumulation processes (Pletsch, 1981). The development definition originated in organized interventions and affairs to improve living conditions and economic growth related to fostering entrepreneurship (Martinussen, 2004). The following selection of development theories outlines the market concepts, in which a renewable resource is considered a stimulating development factor.

\subsubsection{Endogenous growth theory}

According to the endogenous growth theory the internal forces determine economic growth. Emerged in the 1980s as a theory of development economics, it shifts attention to endogenous factors of growth i.e. innovations, knowledge or human capital (Romer, 1994). These endogenous features are the major contributors to a technological change according to Romer (1990). Whereas for Lucas (1988) endogenous growth is determined by the market specialization and labor productivity. This view contrasts the neoclassical economics, where the economic growth bases in dynamics between market supply and demand. The neoclassical approach includes the models (i.e. the Solow-Swan model), where a technological progress in the society is exogenous factors dependent (Solow, 1956; Swan, 1956). The endogenous growth theory argues that improvements in productivity can be tied directly to faster innovation and more investments in human capital from both governments and private sector. It arose by questioning the gaps between developed and undeveloped regions that persist even if investment in physical capital is a subject to diminishing returns. One angle of the endogenous growth model addresses issues of resources and environment, considering resources as endogenous public goods. Following Brander \& Taylor (1998), Dalton et al.(2005), Johansson et al. (2011), Plummer et al. (2014) endogenous resources are a core element to regional specialization and are found to initiate growth in small size economies. The essence of the endogenous growth theory is reflected in the equation $Y=A K$, where $A$ are the forces of 
technology and $K$ is the human or physical capital (Lucas Jr, 1988; Rebelo, 1991; Romer, 1986). This model introduces the investment (in human or physical capital) as a component of a durable and sustained growth. Another approach to endogenous growth equation is the interpretation where $K$ is the quality of inputs, in other words the specialization or specialized labor (Grossman \& Helpman, 1991; Romer, 1990). It is an alternative to the Solow-Swan neoclassical model, where a ratio of capital to input is constant therefore, diminishing returns to capital and labor are incorporated in the growth model (Pack, 1994). Capital and labor grow at the same time according to the neoclassical economists, whereas the endogenous scholars argue for increasing returns to human capital by the spillovers of knowledge accumulation. The endogenous growth theory continues on the neoclassical economic research of factors of growth, presenting models where the critical variables are the knowledge spillovers and investment in physical and human capital. The endogenous, physical capital is recognized as the natural energy resources by e.g.: Aghion et al. (1998), André \& Smulders (2004), Foster (2014), Mankiw et al. (1992). The relation between the resources and endogenous forces of growth are discussed in the work of: Arrow (1962), Barbier \& Homer-Dixon (1996), Barbier (1999), Elbasha \& Roe (1996), Krutilla \& Reuveny (2006), Madlener \& Alcott (2009), Rebelo (1991), where the resources are considered as efficient and effective means of production. The flagship ideas of the endogenous growth theorists imply that innovations fuel the persistent economic growth as well as the investment in infrastructure.

Renewable energy resources as the endogenous growth factors are discussed in the works of i.e.: Ayres (2001), Krutilla \& Reuveny (2006), Pittel \& Rübbelke (2011), Popp et al. (2010), Tahvonen \& Salo (2001) Van der Zwaan et al. (2002), Van Zon \& Yetkiner (2003), where the renewables are found to initiate an endogenous technological change. Role of the private sector is underlined in the endogenous growth approach linking private sector investments in $R \& D$, education or resources with increasing returns to scale (Button, 1998; Glomm \& Ravikumar, 1992). Moreover, the investment in human capital is seen as supporting entrepreneurship and the creation of new job markets is a vital component of the endogenous growth and innovations (Braunerhjelm et al., 2010; Sacco \& Segre, 2009; Shaw, 1992).

The endogenous resources are considered as an element to regional specialization and initiating growth in small size economies according to: Acs \& Armington (2003), Brander \& Taylor, 1998; Dalton et al., 2005; Picchi, 1994; Plummer et al., 2014). Since resources including energy ones are considered as endogenous public goods, it applies as well to the geothermal resources. (Rybach, 2010; Szymańska \& Chodkowska-Miszczuk, 2011) prove that developing renewable resources revitalizes and enhances the economic potential of a location. Moreover, complementary findings of Kagel (2006a), Sánchez-Velasco et al. (2003) discuss the socioeconomic impact on local development. Geothermal energy considered as an endogenous resource is produced and used locally thus, it delivers added value for local communities according to: Chakravorty et al. (1997), Hübler et al. (2012), Parpairis \& Lagos (2013), Pedamallu et at. (2017). 


\subsubsection{Location theory}

Location theory emerged as a path of the regional sciences providing guidance on the issues of regional specialization, determinants of industrial location or social and economic land-use change. The core discipline of the theory analyses primary causes of industrial locations and urban development. Weber (1929) delivers the foundation of this theory describing the algorithm for optimal establishing of an industrial location. His base model includes access to strategic resources (also energy) among the agglomerative forces. An agglomerative factor, according to him is a factor which provides an advantage in production or marketing a commodity simply because industry is located at one place. The theory precursors like Isard (1965) derive localization factors from the costs of obtaining resources for business, transport costs, and market access opportunities; or like Lösch (1954) who searches for maximal benefits in business location through access to the competitive natural resources. Local development arises then in a new urban landscape, made by powerful regional economies, where resources play an essential role in sustaining economic growth. A modern interpretation of Korff (2003) argues that economic development is created through interactions between local knowledge and market power derived from available resources. Moreover, locally controlled resources efficiently organize a locality structure. Boyce (2003) drives attention to the role of locationspecific competitive advantages that attract business location. According to this theory geothermal resources exploitation is assumed to be a local competitive advantage and enables related businesses location. According to the eclectic paradigm introduced by Dunning (1993) the location specific advantage is a determinant for the choice of business investment. Location advantage in Dunning's concept include advantages considered as a country's factor endowments as natural resources, geographic location, labor but as well advantages of infrastructure, laws and regulations, market capacity etc. The eclectic paradigm explains the function of local advantages that in the long run attract foreign investments and international capital. Hence, according to Dunning's theory, the location advantages fosters internationalization of the market. In the light of this concept, the geothermal resources considered as local advantage create investment opportunities. In addition to large firms, entrepreneurship and small firms become a creative destruction feature, and therefore receives significance in most economies. Following Malecki (2001), it is most evident in the case of regions where new firms and new industries are common.

\subsubsection{Local development theory}

Location theories initiate the discussion about local factors of growth. From the regional economics that discuss the causalities of laws and models within a "space" a focus is moved to "territory", where local growth models include economic resources for the firms situated within (Capello, 2011). In other words, a local approach zooms into determinants of local production system competitiveness. Local development theories incorporate the concept of factor endowment as the source of territorial competitiveness. Factor endowment theory 
states that various resources (e.g. land, labor, entrepreneurship, natural resources) at disposal determine a comparative advantage of a location. Moreover, factor endowments also affect the opportunity cost of specializing in producing certain goods relative to others (Wilson, 1977). The literature recognizes the role of geothermal resources as a local factor endowment (see: Kristjánsdóttir \& Margeirsson, 2012; Wang et al., 2012; Xia \& Zhang, 2019).

The phenomenon of local development bases on identification and use of the resources and endogenous potentialities of a community, a neighborhood, a city, a municipality or equivalent (OECD, 2001). Community development as a base for local development was initiated by the Big Push model of Rosenstein-Rodan in the 1943 (Alacevich, 2020; Murphy et al., 1989). One of the development conditions discussed by Rosenstein-Rodan is the emergence of domestic markets and domestic production of competitive goods. In his view, the traditional sectors become overtaken by new industries and private capital is accumulated, all allowing for growth without sustained aid dependence.

The literature presents a wide scope of local development definitions. Traditional factors of local development include: natural resources, capital resources, and labor resources. Nevertheless, recent methodologies of local development refer to two concepts: sustainability and economic well-being (European Commision, 2010). The OECD (2003) agrees on the multidimensional approach to local development and defines it throughout the capacity of a territory to improve its economic future and the quality of life for its inhabitants. Gradually, development becomes a multilevel, multiscale series of efforts, simultaneously taking place at levels lower than the nation, leading to a community and location level with a view to endogenous development. Most of the socio-economic activities that evolve into global trends start locally argues Korff (2003). Local development is viewed as the sustainable use of the local endogenous resources and measured in socio-economic output by: Coffey \& Polese (1985) Pike et al. (2016), Walker et al. (2007). Pieterse Nederveen (2010) and Woolcock \& Narayan (2000) underline the role of endogenous growth oriented policies for communities and local development. Models of local development centered on entrepreneurship and local knowledge accumulation are examined by: Blakely (1989), Luke et al. (1988) and Malecki (1993). Therefore, the multidimensional approach of local development refers to the sustainability, eco development, competitive advantage creation and public management, according to a definer.

In the Polish literature dedicated to the local development, a driving force of local development is attributed to local governments (Myna, 1998; Szewczuk et al., 2011; Sztando, 1998), as mobilizing local endogenous potential. Parysek (2001) finds the local development as a process that enables the economic use of resources and the population's co-participation. Among the factors of local development, the hard (tangible) ones concern the geographical location, infrastructure, or sort of service operators, whereas the soft factors (intangible) refer to the entrepreneurship climate, structure of social capital and ecological projects (Brdulak, 2013). A 
part of this study tests the hard and soft development factors linked with the exploitation of geothermal resources by applying a set of local socioeconomic indicators.

\subsubsection{Cluster theory}

The foundations of Porter's cluster theory (Porter, 1990) refers to the concept of local and regional development affected throughout dynamic clusters of economic activities. Cluster encompass an array of linked industries and other entities important to competition including specialized input suppliers and complementary services. Porter finds clusters to deliver a competitive advantage for the region or community which results in elevating wellbeing of the inhabitants. Another benefit of clusters is knowledge intensification and local specialization, which is often enabled by a potential of available resources. The local specialization is an element of the endogenous growth theory and a part of the local competitiveness strategy. Further works of Porter (1994), Krugman (1995), Amin (1999), Scott (1995) and Cooke (1997) link local development to the emerge of geographically concentrated activities- the clusters. A linking argument are the available local resources that determine competitiveness and specialization. Moreover, Porter (2001) discusses a phenomenon of good practice that is achieving a competitive advantage in sustaining the level of operational effectiveness, which is then followed by others in the same way. Porter dedicates a single, comprehensive analysis of the geothermal resources competitiveness. His study (Porter, 2010) on the case of Iceland's geothermal potential delivers arguments for the geothermal energy production that leads to the creation of geothermal clusters. Porter's developed diamond model is applied to the selected geothermal cases. One of the main findings is that the establishment of geothermal clusters optimizes the local use of the resource. Interactions between various actors of the geothermal energy utilization generate local knowledge and market opportunities. Porter argues that geothermal resources become a competitive advantage at a scale of deployment, i.e. increase of geothermal capacity utilization is the key to competitiveness. Moreover, Porter underlines the opportunities, the spillovers of the geothermal clusters for all industries considering the clusters as the future of economic development. The developed good practice of the Icelandic clusters can be adopted to other locations where the geothermal resources are exploited. In this sense, local specialization and geothermal clusters of accompanying services are potential long-term development factors.

\subsection{Research methodology}

The theoretical background that supports the research problem adopts the concepts of local development and competitiveness. The theories of local development and competitiveness refer to a system and territory. While local competitiveness is determined by local competitiveness factors that impact concentration of economic activities, the local development is referred to the capacity of local communities to acknowledge and accommodate these factors (Conti \& Giaccaria, 2013). Both approaches are used in the thesis 
to characterize the local socioeconomic growth and a function of geothermal resources within it.

The foundation of mesoeconomics delivers methods to analyze local forces of socioeconomic growth. Schumpeter's legacy is a basis for the mesoeconomics concept. Mesoeconomics is a field of economic sciences dedicated to description and analysis of phenomena related to the processes of structural changes, i.e. changes in the relationships between branches and sectors of employment production and regions $(\mathrm{Ng}, 1986)$. It portrays a change in structure and it measures its effects in the economy (Mann, 2011). This discipline constructed in analogy with micro and macroeconomics serves to analyze generic systems; for instance, the local environment that both micro and macro approaches fail to describe (Dopfer et al. 2004). Dopfer (2006) draws on the role of local commodities in creating opportunities for individuals within the frames of mesoeconomics. It became a widely adopted concept, especially by urban economists, as it analyses economic structure and change, regional economics, environmental economics and policymaking (Peters, 1981; Zavadskas et al., 2004). Mesoeconomics addresses multicriteria issues of development models other than micro and macroeconomics measures of economic units according to Mamalakis, (1996) and Popov (2005). Economic models built in accordance to the mesoeconomics assumptions base in the microeconomic analysis application of macroeconomic variables ( $\mathrm{Ng}, 1986)$. This applies to the structure of the thesis research problem and composition of economics models to solve it. Mesoeconomics study focuses on links between regions or locations and sectors of the economy seeking mutual dependencies. It can therefore accommodate the assumption of the relationship between local socioeconomic development and the geothermal renewable resource. Hence, a microeconomic evaluation of local activities related to geothermal use can be conducted using macroeconomic development indicators. Moreover, the mesoeconomic approach refers to a novelty element that is responsible for changing the structure of a system. According to the meso-framework, the geothermal resources as a new economic element change the structure of municipalities.

The operationalization of a research problem specifies an intended concept in relation to a particular study, and provides criteria that empirically prove the existence of that concept (Berg et al., 2004). Measuring instrument such as: categories, index, scale, observation, questionnaire has to be adequately selected to follow the research operationalization (Mouton \& Marais, 1996). Therefore, observations of the municipalities' socioeconomic indicators serve to conclude on the geothermal impact on local development and tackle the research question. The philosophy behind constructing the models to the research questions takes into account that the development process is approached as a change in the municipality's endogenous potential. In the case of determining the resources impact on development, observation and relevant measurement are commonly practiced.

The development of a relevant set of indicators, i.e. the measures constituting the core of the research methodology in this case. Manuals for indicators creation and evaluation dedicated 
to local development (e.g.: Atkinson \& Willis, 2006; Kościelecki et al., 2010; UNESCO, 2009; Zall Kusek \& Rist, 2004) indicate that indicators are the practical approach to the determining variables of existing occurrence, expected target or quality control. Indicator should be defined, valued and presented on a measuring scale (Kościelecki et al., 2010). In another words indicator $A$ means that the goal $B$ is achieved or situation/ occurrence $C$ takes place. Due to the methodological coherence this thesis has to identify right indicators to illustrate if selected locations measures demonstrate socioeconomic growth related to the exploitation of the geothermal resource. Indicator (indicatum) is a studied phenomenon- the aim of this doctoral research, whereas an element illustrating the phenomenon (definiens) is a supportive phenomenon defining index/indices. Therefore, when employing the socioeconomic effect as the indicatum (to the development of the geothermal municipalities), the index (definiens) can be numerically associated with: local productivity, employment rate, industrialization, wages level, and population mobility explain Cingano \& Schivardi (2004).

Applying adequate scales and measures allows to compare the socioeconomic performance. Scales of: ordinal, nominal, interval or ratio are used to collate the outcomes of the selected municipalities' socioeconomic performance indicators. The essence of comparative analysis is application of complementary methods like benchmarking. Smith \& Albaum (2004) argue that a paired comparison well accommodates the ordinal scale of the indicators and supports the rating process. Rating methods are used to evaluate the socioeconomic impact of the geothermal industry for a selection of municipalities and their benchmarks. A benchmarking procedure followed the benchmark criteria proposed by Davis \& Davis (1994) and RondoBrovetto \& Saliterer (2007). The concept of benchmark is applied in this study for verification of the developed models. Since the presented studies refer to a retrospective data research Weisbrod \& Weisbrod (1997) debate that using historic socioeconomic data is a methodological fit to evaluate the development progress. In case of presented research question the retrospective data analysis demonstrates if a change in the socioeconomic indicators and structure is related to the geothermal resources exploitation in time.

Using the data of the years 1995-2018 the socioeconomic indicators are created. The indicators represent the information of municipalities performance adjusted to the availability of the data source. The purpose of the ex-post data selection is to evaluate the results and after they have occurred. The models that serve to answer the thesis research questions refer to ante acta dictaque reasoning i.e. building arguments of past phenomena. Following Quintilian, one of the leading ancient Roman rhetoricians and philosophers, the argument is drawn from the circumstances related to the thesis which is proved (Lew, 2005). Therefore, it is inferred about the present from the past. As a source of the socioeconomic data the Central Statistical Office (known as Statistics Poland) data repository is used. It is an official source of the socioeconomic data in Poland. A dedicated section of the Local Data Bank provides a homogeneous data for all of the administrative units (following the Eurostat NUTS statistical classification). 
The subject of the study are the geothermal municipalities in Poland. Since municipalities correspond with a local administrative level, the research objective is oriented towards the explorative methods of local development. The research question set tackles the municipalities in Poland that explore the geothermal resources for a minimum of 5 years. This condition is set to reduce the risk of bias assessment and obtain statistically valid observations. Therefore, the main research question in the thesis: what is the impact of the geothermal resources utilization on the development of the municipalities in which they occur is to be tested on the following selection of eleven municipalities in Poland, see Table 1.2.

Table 1.2: Municipalities chosen for the analysis with the starting year of geothermal operations, own elaboration.

\begin{tabular}{llc}
\hline no & municipality & geothermal operations initiating year \\
\hline 1 & Biały Dunajec & 1996 \\
2 & Bukowina Tatrzańska & 2006 \\
3 & Grudziądz & 2006 \\
4 & Mszczonów & 1999 \\
5 & Poddębice & 2011 \\
6 & Poronin & 2001 \\
7 & Pyrzyce & 1997 \\
8 & Stargard & 2005 \\
9 & Szaflary & 1993 \\
10 & Uniejów & 2001 \\
11 & Zakopane & 2001 \\
\hline
\end{tabular}

A multicriteria analysis approach is taken as the main methodological axis of this study. It aims to compare, select or hierarchize solutions according to the multicriteria. This approach introduces as well the weighting procedures to the adopted criteria. In case of this study, the multicriteria are the socioeconomic indicators of municipalities. San Cristóbal (2012) discusses the functionality of a multicriteria method for the analysis of socioeconomic systems, complex problems that include various forms of data and information. Many statistical methods, including factor analysis, are encompassed within the multicriteria frame. Multifactor (or multicriteria) analysis is a popular method in regional studies to approach a matrix of different indicators while searching for a linking pattern, or to ascribe a trend. Research methods that refer to multicriteria analysis are applied throughout this study. The selected research methods in relation to each of the research questions are motivated in the studies presented in the Chapters: 2, 3, 4 and 5 of this work. A separate study in Chapter 6 is dedicated to building the socioeconomic indicators model, used for testing the geothermal resources impact. In each chapter, a different method is developed to examine the research question. Results from the chapters are to address the main research question what is the impact of the geothermal resources utilization on the development of the municipalities in which they occur. Table 1.3 summarizes the chapters research focus, the data type and the used method. 
Table 1.3: Research methodology overview corresponding with chapters and research questions, own elaboration.

\begin{tabular}{|c|c|c|c|c|c|}
\hline Thesis Chapter & Focus & Data collection & $\begin{array}{l}\text { Level of } \\
\text { analysis }\end{array}$ & $\begin{array}{l}\text { Economic } \\
\text { theory frame }\end{array}$ & Method \\
\hline $\begin{array}{l}\text { Chapter 2: } \\
\text { RQ 1.1. Whether } \\
\text { the introduction of } \\
\text { a geothermal spa in } \\
\text { a municipality } \\
\text { increases the local } \\
\text { socioeconomic } \\
\text { development? }\end{array}$ & $\begin{array}{l}\text { Quantitative } \\
\text { analysis of a local } \\
\text { development } \\
\text { model in } \\
\text { reference to the } \\
\text { geothermal } \\
\text { establishments }\end{array}$ & $\begin{array}{l}\text { Socioeconomic } \\
\text { secondary data } \\
\text { (Central } \\
\text { Statistical Office) }\end{array}$ & $\begin{array}{l}\text { Multicriteria } \\
\text { analysis, data } \\
\text { dimension } \\
\text { reduction } \\
\text { method, } \\
\text { Quantitative }\end{array}$ & $\begin{array}{l}\text { Local } \\
\text { development } \\
\text { theory }\end{array}$ & $\begin{array}{l}\text { Principal } \\
\text { Component } \\
\text { Analysis, } \\
\text { Switch } \\
\text { regression model }\end{array}$ \\
\hline $\begin{array}{l}\text { Chapter 3: } \\
\text { RQ 1.2. Is there a } \\
\text { relationship } \\
\text { between the } \\
\text { development of } \\
\text { geothermal energy } \\
\text { and the } \\
\text { competitiveness of } \\
\text { the municipalities? }\end{array}$ & $\begin{array}{l}\text { Quantitative and } \\
\text { qualitative } \\
\text { analysis of } \\
\text { selected } \\
\text { geothermal } \\
\text { parameters as a } \\
\text { local } \\
\text { competitiveness } \\
\text { function }\end{array}$ & $\begin{array}{l}\text { Socioeconomic } \\
\text { secondary data } \\
\text { (Central } \\
\text { Statistical } \\
\text { Office), } \\
\text { geothermal } \\
\text { primary data }\end{array}$ & $\begin{array}{l}\text { Multicriteria } \\
\text { analysis, } \\
\text { decision-making } \\
\text { technique, } \\
\text { Qualitative and } \\
\text { quantitative }\end{array}$ & $\begin{array}{l}\text { Endogenous } \\
\text { economic } \\
\text { growth, } \\
\text { Local } \\
\text { Competitiveness, } \\
\text { Competitive } \\
\text { advantage, } \\
\text { Cluster theory, }\end{array}$ & $\begin{array}{l}\text { Benchmarking, } \\
\text { Analytical } \\
\text { Hierarchy } \\
\text { Process, } \\
\text { Panel data } \\
\text { analysis }\end{array}$ \\
\hline $\begin{array}{l}\text { Chapter 4: } \\
\text { RQ } 2 \\
\text { How comparable } \\
\text { are the results } \\
\text { yielded by the } \\
\text { Principal } \\
\text { Component } \\
\text { Analysis and } \\
\text { Analytical Hierarchy } \\
\text { Process methods in } \\
\text { the situation of } \\
\text { secondary data? }\end{array}$ & $\begin{array}{l}\text { Quantitative } \\
\text { evolution of two } \\
\text { multicriterial } \\
\text { methods, } \\
\text { integration of } \\
\text { methods }\end{array}$ & $\begin{array}{l}\text { Socioeconomic } \\
\text { secondary data } \\
\text { (Central } \\
\text { Statistical Office) }\end{array}$ & $\begin{array}{l}\text { Multicriteria } \\
\text { decision-making } \\
\text { method, Meta- } \\
\text { analysis, } \\
\text { Qualitative and } \\
\text { quantitative }\end{array}$ & $\begin{array}{l}\text { Local } \\
\text { development } \\
\text { theory, } \\
\text { Research } \\
\text { paradigms, } \\
\text { Pragmatic } \\
\text { epistemology }\end{array}$ & $\begin{array}{l}\text { Non-parametric } \\
\text { correlation }\end{array}$ \\
\hline $\begin{array}{l}\text { Chapter 5: } \\
\text { RQ } 3 \\
\text { Whether the local } \\
\text { employment } \\
\text { structure changes } \\
\text { while using the } \\
\text { geothermal } \\
\text { resources? }\end{array}$ & $\begin{array}{l}\text { Analysis of } \\
\text { employment } \\
\text { structure of the } \\
\text { geothermal } \\
\text { municipalities }\end{array}$ & $\begin{array}{l}\text { Socioeconomic } \\
\text { secondary data, } \\
\text { (Central } \\
\text { Statistical } \\
\text { Office), } \\
\text { Personal } \\
\text { communication, } \\
\text { Interviews }\end{array}$ & $\begin{array}{l}\text { Comparative } \\
\text { analysis, } \\
\text { Qualitative and } \\
\text { quantitative }\end{array}$ & $\begin{array}{l}\text { Location theory, } \\
\text { Cluster theory }\end{array}$ & $\begin{array}{l}\text { Benchmarking, } \\
\text { Shift share } \\
\text { analysis, } \\
\text { CATI, CAWI } \\
\text { technique }\end{array}$ \\
\hline $\begin{array}{l}\text { Chapter 6: } \\
\text { RQ } 4 \\
\text { Which data } \\
\text { conceptualize local } \\
\text { competitiveness? }\end{array}$ & $\begin{array}{l}\text { Creation of } \\
\text { socioeconomic } \\
\text { indicators based } \\
\text { local } \\
\text { development } \\
\text { model }\end{array}$ & $\begin{array}{l}\text { Socioeconomic } \\
\text { secondary data } \\
\text { (Central } \\
\text { Statistical Office) }\end{array}$ & $\begin{array}{l}\text { Multicriteria } \\
\text { analysis, } \\
\text { Qualitative and } \\
\text { quantitative, } \\
\text { Expert method }\end{array}$ & $\begin{array}{l}\text { Local } \\
\text { development } \\
\text { theory }\end{array}$ & $\begin{array}{l}\text { Analytical } \\
\text { Hierarchy } \\
\text { Process, } \\
\text { Questionnaire }\end{array}$ \\
\hline
\end{tabular}




\subsection{Thesis outline}

The thesis is organized in the sequence of chapters that compose a comprehensive approach to the main research question. The following Figure 1.12 captures the structure of the thesis. It starts with introducing the research argument in the Chapter 1 and conceptualization of the study. The core analysis is run in the Chapters 2-6, split between examining the research questions and assessing the methods used. Chapter 7 synthesizes the major findings of the chapters, answers the main research question and initiate the general discussion.

\section{Chapter 1}

Introduction: Geothermal resources and local use argument, setting the research problem. Local socioeconomic indicators and geothermal resources analysis

\section{Chapter 2}

Link between local development model and geothermal establishments

\section{Chapter 3}

Relation between geothermal resources utilization and measures of local competitiveness

Evaluation of the methods, reference to Chapters 2, 3 and 6

\section{Chapter 4}

Methodological discussion over the two applied multicriteria methods, comparing the models and their results. Justification of the model.

\section{Spatial analysis of geothermal utilization}

\section{Chapter 5}

Analysis of the employment structure between the geothermal municipalities and reference administrative areas.

\section{Methodology of the local socioeconomic model}

\section{Chapter 6}

It introduces the data and method behind building the local socioeconomic indicator model. Argumentation of the synthetic index. It refers to Chapter 2 and 3.

\section{Chapter 7}

Synthesis: Discussion of findings and conclusions

Figure 1.12: Thesis chapters structure, own elaboration. 
The impact of geothermal energy on local development is tested applying two approaches in Chapters 2 and 3. Chapter 2 examines if there is a statistical relationship between the multicriteria model of local development and the geothermal recreational and health centers in the municipalities. The geothermal establishments are assumed to impact the levels of local development index. The analysis serves as a tentative examination of the local socioeconomic data structure relation with a geothermal variable. The local development and its tempo is assumed associated with the geothermal centers activities. The results obtained from this study encourage for further examination of the geothermal municipalities.

The benchmark approach is used in the research in Chapter 3. A competitiveness index is built using another multifactor method for the geothermal municipalities and attributed benchmark groups. The local index is generated for the municipalities with geothermal resources and a set of benchmarked municipalities that do not utilize the resources in their economies. This index constitutes one of the variables in the geothermal competitiveness model. The model undergoes the sensitivity analysis in the panel analysis format to test the relationship between the competitiveness index and the geothermal exploitation parameters.

In Chapter 4 delivers a methodological discussion. The local development and competitiveness indexes presented in the Chapter 2 and 3 are built using the same socioeconomic dataset. Their comparison sets a research problem regarding the used methods. The two multicriteria procedures led to establishing two independent models that test the impact of the geothermal resources use in the municipalities (and benchmarks). Since the methods base on different principles, this study analyses the results obtained from the two methods in order to check if any method is more accurate. For this purpose, the weights assessment is conducted using rank correlations. Weights are the determinants of each of the applied method and their analysis is a deciding factor for the best fitting multicriteria approach. Chapter 4 therefore focuses on the justification of the research method and the validation of the models.

The direction of the research deviates towards the analysis of the employment structure in Chapter 5. As an indication of the geothermal resources impact on the municipalities the employment effect is assumed and then examined. A choice of the method refers to a dedicated comparative technique of the employment categories on a regional level. Therefore, the geothermal municipalities employment data is compared to a regional employment data seeking structural differences. As a method support, a structured personal communication with the local geothermal experts is used.

Whereas, Chapter 6 is the data study and explains the conceptualization of the generic local development model used in the thesis. The data choice and process of building the socioeconomic indicators is also explained. As a result of the generic model, a measure of local development i.e. the synthetic index is created. This index serves as a dependent variable in all of the statistical procedures applied in the thesis. 
Chapter 7 synthesizes the conclusions from the chapters 2-6. Throughout the chapters analysis the main research question of the thesis is addressed. Furthermore, it adds a critical debate on the limitation of the thesis. Reflections linked with the chapters' major findings are presented. It as well provides a further research recommendation and directs towards the geothermal resources in the discussions about energy transition and the renewable energies function in the societies. A final word recapitulates this study. 
Chapter 2

Geothermal spas as a local development factor, the case of Poland 


\section{Abstract 5}

This paper investigates whether the endogenous geothermal energy resources used for local tourism facilities are a factor of local development. This research question is answered by examining the local socioeconomic development dynamics in years 1995-2015 in the six selected Polish municipalities that established geothermal spas at different years. A model introduces the concept of switch variables, where a geothermal spa is the assumed switching factor in a municipality's socioeconomic development. The statistical procedures are adopted from factor analysis and trend estimation methodologies. Conclusions lead to a positive assessment of a geothermal water park's contribution to a municipality's socioeconomic development.

${ }^{5}$ Chapter published as: Kurek, K. A., Heijman, W., van Ophem, J., Gędek, S., \& Strojny, J. (2020). Geothermal spas as a local development factor, the case of Poland. Geothermics, 85, 101777. 


\subsection{Introduction}

Geothermal waters correspond with the sanum per aquam (spa) concept and are optimal for tourism and recreational purposes. According to Csirmaz \& Pető (2015) recreational bathing and water parks gain popularity in many countries and regions. In fact, this is the second most common use of geothermal water resources after heating and energy generation. The work of Lund \& Boyd (2016) estimates that $25 \%$ of the geothermal water worldwide is used in bathing and health facilities due to its balneotherapeutic potential. The report of the World Energy Council (2016) suggests that the use of geothermal resources in bathing centers and balneology (therapeutic geothermal water treatments) being a $\$ 50$ billion worth business in 75 countries (Yeung \& Johnson, 2014). These numbers show the global character of the geothermal spa industry and that geothermal spa tourism is growing out of its niche.

This paper focuses on the phenomenon of geothermal resources used in recreational water centers and tourism infrastructure in Poland. Tourism among other local economy sectors profits is the primary recipient of benefits of geothermal water establishments argue Demirbas (2008), Sæpórsdóttir et al. (2010) and Shortall \& Kharrazi (2017) since they create multiuse commercial possibilities. Moreover, the geothermal water recreational and wellness business derive from the primary function of the geothermal resources i.e. energy generation (e.g. Kępińska, 2002 and Hjartarson et al., 2005). Geothermal waters' based tourism is an intense worldwide practice, but it is just an upcoming application in Poland despite their prospective resource potential there. In our opinion opportunities related to geothermal water bathing centers (spas) emerge for municipalities that decide to introduce them. Moreover, geothermal spas considered as mass tourism imply a new standard to the local market. Therefore, we set a research question of whether the introduction of a geothermal spa in a municipality enhances the local socioeconomic development. We assume the geothermal centers as a development factor in municipalities. However, we do not map all the possible development factors in the municipalities next to the geothermal exploitation. This analysis zooms into a sole relation between the phenomenon of geothermal centers and local development.

Although health resorts and balneology centers that use warm springs resources have a long tradition in few localities in Poland (Dryglas, 2013) they are not included in this research. The focus here is on the geothermal bathing centers or spas that emerged in several municipalities as a result of developing the geothermal heating networks from the mid-90s. Geothermal recreational centers are the most popularized applications of the resource in Poland after the energy provision. Since the tourism activities related to geothermal recreation take place locally, therefore as a result we expect that municipalities develop in socioeconomic terms in time. The years of 1995-2015 as the graduate geothermal energy development period in Poland is taken under research. This approach remains underrepresented in the literature, and it is a knowledge gap in the case of Poland. 
This introduction explaining the purpose of the study is followed by a theoretical approach to the topic that includes the model we aim to use. Next, the data sourcing and methods to tackle the model followed by the outcomes of the analysis is discussed. A chapter with conclusions closes the chapter.

\subsection{Theoretical framework}

This study draws attention to the application of geothermal resources in tourism and its assumed impact on increasing development potential. The recreational tourism sector becomes climate and sustainability sensitive argue Martin (2005) and Scott et al. (2009). Favorable climate as well as attractive environmental resources present locally are conducive to the development of touristic opportunities. The resource that corresponds to the climate and environmental challenges is geothermal energy.

The sustainable character of the resource encourages into further than energy provision including application in tourism (Kristmannsdóttir \& Ármannsson, 2003; Rybach, 2003, Fabbri et al., 2017; Yasukawa et al., 2018). Moreover, Jones et al. (2003), Mariita (2002), Hoenig (2005) and Erfurt-Cooper and Cooper (2009) observe that the local tourism sector emerges next to geothermal resources exploitation with a contribution to the local communities. Jóhannesson et al. (2003) argue that geothermal water pools entail new services in the local economy, such as hospitality or transport, and empower other local resources and networks. Fridleifsson (2001), Barbier, (2002), Del Rio and Burguillo, (2008) and Stigka et al. (2014) have studied the relation between the exploitation of geothermal resources and local socioeconomic benefits. Observations of Toth et al. (2015) show that geothermal bathing centers on the urban outskirts develop rural and peripheral parts of the municipalities that face restructuring difficulties. Therefore, the benefits of geothermal recreation in local development go beyond the economic factor.

Cárdenas-García et al. (2015) broadly discuss the link between tourism and socioeconomic development. The authors deliver an analysis of tourism benefits for communities by observing the socioeconomic development in time. Endogenous resources, tourism and bottom-up entrepreneurism are among the factors that determine the local development status (Coffey \& Polèse 1984). References to tourism and entrepreneurship in the context of geothermal resource exploitation are found in the work of Tabbachi (2008), Jiricka et al. (2010), Nagy (2011), Tomić et al. (2013) and Milićević \& Petrović (2016). Studies of Juma et al., (2001), Pejanović et al. (2011), Davidson-Hunt \& Turner (2012) and Cuka \& Rachwal (2013) indicate the central role of the geothermal spa plays in local economies and societal change. Geothermal based tourism is considered as an integral factor of local development as the endogenous resources i.e geothermal waters are utilized and used locally. Its benefits relate to both visitors profiting from entertainment, baths and treatments in geothermal waters as well as local economies providing spa establishments. In addition, studies of e.g. Bohdanowicz et al. (2001), Prinsloo (2013) \& Beer et al. (2018) discuss the phenomenon of renewable energy 
establishments including geothermal development that become tourist attractions. Scholars interpret the increased interest in visiting particular venues as a result of applying locally available renewable resources and tourists interest in geothermal waters experience.

Article 5 of the Geological and Mining Law Act in Poland (2011) defines thermal water as underground water, which notes a temperature of not less than $20^{\circ} \mathrm{C}$ at the water intake. While the literature describes both thermal and geothermal waters as one phenomenon, this definition captures the endogenous characteristics of the resource. Geological conditions in Poland reveal a high geothermal potential with adequate aquifer characteristics that can sustain stable operating parameters over a long period of time (Górecki et al., 2006) in addition to the favorable mineral and salinity specifics of the Polish geothermal resources in Europe (Tomaszewska \& Szczepański, 2014). The majority of geothermal spas opened between 2006 and 2016 in which year the installed capacity was 26 MWt, reports Kępińska (2016). It indicates the development of the usage of geothermal resources for local tourism and recreation in Poland. Figure 2.1 presents a map of the geothermal resources exploitation in Poland in 2018 that includes the geothermal recreational centers. This map illustrates the phenomenon that in most cases they were established next to the geothermal plants supplying the municipal district heating networks. Moreover, the construction of geothermal spas allows for the optimization of the costs borne by both public authorities and private investors in geothermal infrastructure investment.

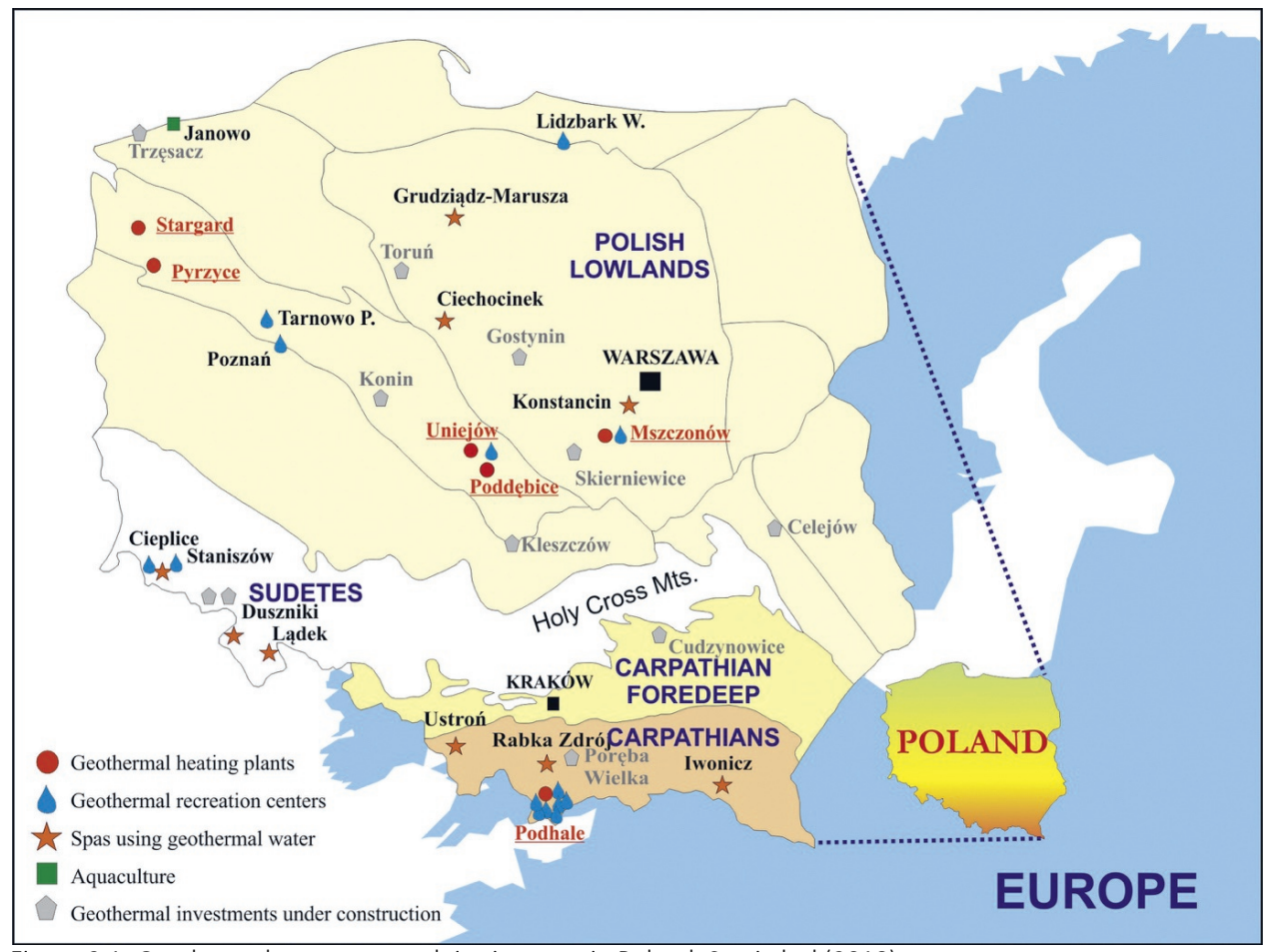

Figure 2.1: Geothermal resources exploitation map in Poland, Sowizdzal (2018). 
Halaj (2015) \& Górecki et al. (2015) state that there is a growing demand for geothermal water recreational facilities in Poland. Furthermore, Sala (2017) argues that Polish geothermal waters have optimal properties for wellness businesses and geothermal bathing centers. As a whole, the increasing inflow of geothermal spa visitors each year (Góra, 2013 and Dryglas \& Hadzik, 2016) has a stimulating effect on the development of tourism infrastructure and the municipalities where a spa is located.

According to Pulido Fernandez and Sanchez Rivero (2010) tourism industry is water and energy intensive, so geothermal energy and water are an obvious tourism resource. Studies of Dej et al. (2013) deliver a comprehensive study about the recreational use of geothermal waters in Central Europe with a close look at Polish facilities. The authors conclude that municipalities with geothermal spas note the job creation and the alleviation of the local budget that derives from the accompanying services and the new specialization in tourism. From this information, we deduce the role geothermal spas play in the transition of municipalities into new tourist destinations.

As presented above, the literature outlines the benefits of the geothermal spas or water centers. Nevertheless, to deliver a measurable argument an examination of cases is missing. Based on the economic approach and the literature findings we argue that geothermal spas trigger local socioeconomic development. For this purpose, we present the hypothesis that the introduction of a geothermal spa accelerates the socioeconomic development of the municipality in which it is established. This assumption is to be verified by socioeconomic development empirical observations of selected locations in Poland in the years 1995-2015. Since the geothermal recreational centers were built in different years, this long period of time allows for socioeconomic observation of municipalities development in time before and after the centers emerged. A theoretical model is used to assess if a structural change in a municipality's socioeconomic development takes place when additional parameters of a geothermal spa are incorporated. We introduce these parameters as switch variables, based on the assumption that they cause a positive change in the local socioeconomic development dynamics.

We present Model 1, which describes changes in the socioeconomic development of a municipality over time:

$D_{t}=\alpha+\beta t+\varepsilon_{t}$,

where:

$D$ - the value of the socioeconomic development indicator of the municipality in the $t$-th moment, $\alpha$ - a constant, 
$t$ - the time variable, where $t_{0}=1994^{6}$,

$\beta$ - the regression coefficient,

$\varepsilon_{t}-t$-th residual.

If the estimator of $\beta$ is significantly different from zero, it means $D$ changes at the rate of the estimated value of $\beta$ per one unit of time.

However, Model 1 assumes that $\alpha$ and $\beta$ do not change over time. Relaxation of this assumption leads to Model 2:

$D_{t}=\alpha^{\prime}+\beta^{\prime} t+\gamma S_{t}+\delta W_{t}+\varepsilon^{\prime} t$

where:

$D$ - the value of the socioeconomic development indicator of the municipality in the $t$-th moment,

$\alpha^{\prime}$ - a constant,

$t$ - the time variable,

$\beta^{\prime}$ - the regression coefficient,

$S_{t}$ - a switch variable $(0,1)$ that indicates the presence $(1)$ or lack $(0)$ of a geothermal spa, $S_{t}=0$ for $t<t_{s}$ and $S_{t}=1$ for $t \geq t_{s,}$,

$\gamma$ - the regression coefficient that identifies the change in the constant of the model (value of $\left.D_{0}\right)$,

$W_{t}$ - a switch variable, $W_{t}=0$ for $t<t_{s}$ and $W_{t}=t$ for $t \geq t_{s}$ ( $t_{s}$, as above, is the moment of the assumed structural change i.e. the year of introducing a geothermal spa),

$\delta$ - the regression coefficient that identifies the change in the $D$ model acceleration changing over time, the coefficient of $W_{t}(\delta)$ indicates the measure of socioeconomic development if a switch took place,

$\varepsilon_{t}^{\prime}$ - the $t$-th residual.

Model 2 is used to test the hypothesis that the introduction of a geothermal spa accelerates the socioeconomic development of the municipality in which it is established. If at least one of the two switch coefficients ( $S$ and $W$ ) is significant, a structural change in the $D$ model occurs and the geothermal spa changes the $D$ indicator conversion over time. This assumption is made following the interpretation of switch regression by Maddala \& Lahiri (1992) and Goldfeld \& Quandt, (1973). The Prais-Winsten procedure (Prais \& Winsten 1954) is proposed to solve the problem of serial autocorrelation by employing generalized least squares methods. This procedure is particularly effective in the case of short time series (Canjels \& Watson 1997 and Fried \& Gather 2005), as in the case of this research. The a posteriori method serves to remove insignificant variables (Draper \& Smith 2014).

\footnotetext{
${ }^{6}$ While defining the time variable in Gretl the $t_{0}=1994$ and $t_{1}=1995$, except for Mszczonów and Grudziądz, where $t_{0}=1$. This coding difference left no effect on the quality of the model results.
} 


\subsection{Data and methods}

The description of data collection process and reasoning behind building the socioeconomic development model for the selected municipalities is provided in the data article of Kurek (2019). The central position of this paper is the observation of the socioeconomic development of six Polish municipalities where locally available geothermal resources are applied to the spa businesses. Since municipalities seek to optimize the operation of the geothermal heating plants, geothermal waters recreational centers are often built to improve the economic efficiency of public geothermal utilization investments. There are 15 geothermal water parks in Poland in 2018 that either were established next to the municipal geothermal heating plants or as individual ventures with own infrastructure. However, to be able to draw statistically relevant observations, six municipalities conditioned to a required minimum of five years of functioning in the 2015 year (Table 2.1) are selected for the purpose of testing the hypothesis. Within the administrative district of the Bukowina Tatrzańska municipality two geothermal recreational centers were built in the given time. The municipality of Szaflary has two geothermal establishments as well.

Table 2.1: Selection of municipalities in Poland with the geothermal establishments, Termalni.

\begin{tabular}{ccccc}
\hline no & Municipality & Name & Initiation year & Installation type \\
\hline 1 & Mszczonów & Termy Mszczonów & 2008 & Municipal geothermal network \\
2 & Uniejów & Termy Uniejów & 2008 & Municipal geothermal network \\
3 & Szaflary & Termy Szaflary & 2007 & Municipal geothermal network \\
& & Termy Gorący Potok & 2014 & Municipal geothermal network \\
4 & Bukowina Tatrzańska & Termy Bukovina & 2008 & Private geothermal venture \\
& & Terma Bania & 2011 & Private geothermal venture \\
5 & Zakopane & Aqua Park & 2006 & Mix \\
\hline 6 & Grudziądz & Geotermia Grudziądz & 2006 & Private geothermal venture \\
\hline
\end{tabular}

The phenomenon of socioeconomic development of the six selected municipalities is examined over time with the assumption that introducing a geothermal spa positively changes the structure in the socioeconomic development trend. The pattern of studies that look for statistical significance between local resources and development dynamics exists in the literature (Hamilton, 1989; Moschos, 1989; Thompson \& Rushing, 1996; Asafu-Adjaye, 2000; Beugelsdijk et al., 2004; Kim \& Chen, 2006).

The Principal Component Analysis (PCA) method is used to define the socioeconomic municipality development model. As a factor analysis the PCA is particularly suited to examine a set of correlated variables in socioeconomic studies (Jolliffe, 1986; Kolenikov \& Angeles, 2005; Vyas \& Kumaranayake, 2006 and Abdi \& Williams, 2010). We adopt the approach that a municipality development is determined by a set of socioeconomic indicators (see: Mitchell et al., 1995; Gareev, 2012; Jakovlev et at., 2016). They are constructed from the municipalities' 
performance variables available in the homogenous source, i.e. Local Data Bank, a section of the Central Statistical Office in Poland ${ }^{7}$. Selection of the municipalities' indicators is based on the studies of Klijs et al. (2012) and Kurek (2016) who elaborated on the categories of development indicators related to the research problem. The socioeconomic model of municipality is a construction of development categories and related indicators. Model data refers to the period of 1995 to 2015 due to the socioeconomic indicator database availability. A full data set for the six municipality indicators within the tested period consists of 1.040 observations. Table 2.2 presents the underlying variables serving as the input indicators for the PCA procedure.

Table 2.2: Categories and indicators of local socioeconomic development, own elaboration.

\begin{tabular}{|c|c|c|c|c|c|}
\hline $\begin{array}{l}\text { Population } \\
\text { Resources }\end{array}$ & $\begin{array}{l}\text { Local } \\
\text { Economy }\end{array}$ & Public Finance & Tourism & Infrastructure & Level of Life \\
\hline $\begin{array}{c}\text { Internal } \\
\text { migration/ } \\
10.000 \\
\text { inhabitants }\end{array}$ & $\begin{array}{c}\% \text { of } \\
\text { employed } \\
\text { inhabitants }\end{array}$ & $\begin{array}{c}\text { Municipal } \\
\text { income/inhabitant }\end{array}$ & $\begin{array}{c}\text { Polish tourists } \\
\text { accommodated/ } \\
1000 \\
\text { inhabitants }\end{array}$ & $\begin{array}{l}\text { Industrial and } \\
\text { domestic water } \\
\text { consumption } \\
\text { /inhabitant }\end{array}$ & $\begin{array}{c}\text { Outpatient } \\
\text { healthcare } \\
\text { facilities/10.000 } \\
\text { inhabitants }\end{array}$ \\
\hline $\begin{array}{c}\text { Natural } \\
\text { increase/ } \\
10.000 \\
\text { inhabitants }\end{array}$ & $\begin{array}{c}\text { No of private } \\
\text { economic } \\
\text { activities }\end{array}$ & $\begin{array}{l}\text { Municipal } \\
\text { investment } \\
\text { expenditure/ } \\
\text { inhabitant }\end{array}$ & $\begin{array}{c}\text { Foreign tourists } \\
\text { accommodated/ } \\
1000 \\
\text { inhabitants }\end{array}$ & $\begin{array}{l}\text { Cubic volume of } \\
\text { delivered buildings } \\
\text { / inhabitant }\end{array}$ & $\begin{array}{l}\text { Environmental } \\
\text { protection } \\
\text { investment/ } \\
\text { inhabitant }\end{array}$ \\
\hline $\begin{array}{c}\% \text { of } \\
\text { population } \\
\text { in } \\
\text { productive } \\
\text { age }\end{array}$ & $\begin{array}{c}\text { No of } \\
\text { national } \\
\text { commercial } \\
\text { companies }\end{array}$ & $\begin{array}{l}\text { PIT income/ } \\
\text { employed } \\
\text { inhabitant }\end{array}$ & $\begin{array}{c}\text { Tourism } \\
\text { accommodation } \\
\text { units/1000 } \\
\text { inhabitants }\end{array}$ & $\begin{array}{c}\text { Km of water-supply } \\
\text { and sanitation } \\
\text { network/inhabitant }\end{array}$ & $\begin{array}{c}\text { Primary and Lower } \\
\text { secondary } \\
\text { education } \\
\text { expenditure/pupil }\end{array}$ \\
\hline Birth rate & $\begin{array}{c}\text { No of } \\
\text { commercial } \\
\text { companies } \\
\text { with foreign } \\
\text { capital }\end{array}$ & $\begin{array}{l}\text { Budget deficit/ } \\
\text { inhabitant }\end{array}$ & $\begin{array}{c}\text { No of overnight } \\
\text { stays }\end{array}$ & $\begin{array}{c}\text { Residential water } \\
\text { system connections } \\
\text { /inhabitant }\end{array}$ & $\begin{array}{l}\text { \% of population } \\
\text { connected to } \\
\text { wastewater } \\
\text { treatment plants }\end{array}$ \\
\hline
\end{tabular}

The principle of the PCA implies computing and reducing the number of variables in order to detect the principal components and in this case reducing the data to reach a single, synthetic socioeconomic development indicator for each of the geothermal municipalities. The method of the SPSS (Statistical Package for Social Sciences) version 22 is used. PCA computation, which includes the loadings of components exceeding the acceptable value of 0.5 , varimax with Kaiser rotation and explained variance larger than 60\%, results in establishing the main components of a socioeconomic development model for each of the tested municipalities. PCA assesses as well a weight for each component (Table 2.2 data). Next, for the components and

\footnotetext{
${ }^{7}$ Selection of available and consistently collected socioeconomic indicators bases in the Local Data Bank in Central Statistical Office of Poland.
} 
weights of each municipality a standardized sums formula is applied. It results in a singular synthetic indicator for the tested time period $(D)$. Its observation determines the development model for the examined geothermal municipalities. Table 2.3 presents the synthetic socioeconomic development indicator scores for the time period 1995 to 2015.

Table 2.3: Synthetic socioeconomic development indicators $(D)$ resulting from the components summing formula, own elaboration.

\begin{tabular}{lcccccc}
\hline year & Mszczonów & Uniejów & Szaflary & Bukowina Tatrzańska & Zakopane & Grudziądz \\
\hline 1995 & 0.35 & 0.11 & 0.15 & 0.14 & 0.28 & 0.11 \\
1996 & 0.41 & 0.12 & 0.14 & 0.15 & 0.30 & 0.12 \\
1997 & 0.41 & 0.14 & 0.14 & 0.16 & 0.31 & 0.13 \\
1998 & 0.51 & 0.16 & 0.14 & 0.16 & 0.31 & 0.13 \\
1999 & 0.53 & 0,18 & 0.16 & 0.19 & 0.29 & 0.14 \\
2000 & 0.57 & 0.20 & 0.13 & 0.15 & 0.27 & 0.14 \\
2001 & 0.66 & 0.22 & 0.13 & 0.17 & 0.29 & 0.16 \\
2002 & 0.66 & 0.23 & 0.15 & 0.15 & 0.29 & 0.15 \\
2003 & 0.65 & 0.25 & 0.13 & 0.17 & 0.32 & 0.16 \\
2004 & 0.69 & 0.25 & 0.14 & 0.19 & 0.33 & 0.16 \\
2005 & 0.77 & 0.28 & 0.14 & 0.19 & 0.33 & 0.18 \\
2006 & 0.76 & 0.32 & 0.17 & 0.21 & 0.34 & 0.20 \\
2007 & 0.74 & 0.33 & 0.16 & 0.23 & 0.37 & 0.21 \\
2008 & 0.89 & 0.37 & 0.18 & 0.23 & 0.36 & 0.22 \\
2009 & 0.90 & 0.36 & 0.17 & 0.22 & 0.37 & 0.21 \\
2010 & 0.85 & 0.37 & 0.15 & 0.23 & 0.32 & 0.22 \\
2011 & 0.91 & 0.40 & 0.19 & 0.25 & 0.38 & 0.23 \\
2012 & 0.93 & 0.43 & 0.18 & 0.28 & 0.36 & 0.26 \\
2013 & 0.92 & 0.35 & 0.17 & 0.29 & 0.40 & 0.22 \\
2014 & 0.95 & 0.39 & 0.19 & 0.29 & 0.41 & 0.26 \\
2015 & 1.00 & 0.44 & 0.19 & 0.33 & & 0.21 \\
\hline
\end{tabular}

Goldfeld \& Quant find (1973) the switch regression models suitable for the time series applications with a small number of parameters and propose standard regression packages for computation. Switch variable modeling is particularly effective in the environment of dummy variables reflecting a discreet change or a continuous variable that leads to gradual change. Discreet growth explains better a man-made system change according to Gandolfo (1997) and Parker (2012) including economic processes and development dynamics. With discrete growth, a change happens after a specific event. A switch variable represents this momentum related to a change in structure often expressed by events related to economic development (Moschos, 1989 and Glauben et al., 2009).

We assume that adding the geothermal spa parameters to the model results in a discrete change of each municipality's indicator $D$ dynamics. The switching regression model incorporates the vectors of parameter regimes that could change due to the structural change (Goldfeld \& Quant, 1973; Gandolfo, 1997 and Davis et al., 2006). Where a geothermal spa is 
expected to accelerate the $D$ pace, this method addresses the assumption of a structural change in the socio-economic development. Application of Model 2 regression analysis results in the scores shown in Table 2.4.

Table 2.4: Model 2 application for the selected geothermal spa municipalities, own elaboration.

\begin{tabular}{|c|c|c|c|c|c|c|}
\hline Municipality & Variable & $\begin{array}{l}\text { Regression } \\
\text { coefficient } \\
\text { estimator }\end{array}$ & t-statistics & $p$-value & R-squared & D-W statistics \\
\hline \multirow{4}{*}{ Mszczonów } & constant & -19.368 & -8.487 & 0.0000 & \multirow{4}{*}{0.9257} & \multirow{4}{*}{2.1538} \\
\hline & $t$ & 0.0098 & 8.571 & 0.0000 & & \\
\hline & $S$ & 0.1202 & 2.761 & 0.0133 & & \\
\hline & W & -0.0072 & -2.707 & 0.0150 & & \\
\hline \multirow{4}{*}{ Uniejów } & constant & 0.2146 & 7.207 & 0.0000 & \multirow{4}{*}{0.9475} & \multirow{4}{*}{2.0276} \\
\hline & $t$ & 0.0159 & 2.488 & 0.0251 & & \\
\hline & $S$ & 0.1914 & 2.757 & 0.0135 & & \\
\hline & W & 0.0103 & 7.417 & 0.0000 & & \\
\hline \multirow{4}{*}{ Szaflary } & constant & 0.1627 & 70.960 & 0.0000 & \multirow{4}{*}{0.8461} & \multirow{4}{*}{2.0784} \\
\hline & $t$ & 0.0031 & 5.679 & 0.0000 & & \\
\hline & $S$ & 0.0357 & 1.921 & 0.0007 & & \\
\hline & W & 0.0044 & 4.112 & 0.0070 & & \\
\hline \multirow{5}{*}{$\begin{array}{l}\text { Bukowina } \\
\text { Tatrzańska }\end{array}$} & constant & 0.0750 & 2.664 & 0.0170 & \multirow{5}{*}{0.9641} & \multirow{5}{*}{2.0000} \\
\hline & $t$ & 0.0043 & 2.761 & 0.0139 & & \\
\hline & $S$ & 0.1395 & 2.958 & 0.0093 & & \\
\hline & $W_{1}$ & 0.0104 & 3.142 & 0.0063 & & \\
\hline & $W_{2}$ & 0.0091 & 4.119 & 0.0008 & & \\
\hline \multirow{4}{*}{ Zakopane } & constant & 0.3025 & 42.56 & 0.0000 & \multirow{4}{*}{0.7953} & \multirow{4}{*}{1.9561} \\
\hline & $t$ & 0.0035 & 1.815 & 0.0172 & & \\
\hline & $S$ & 0.3037 & 35.48 & 0.0000 & & \\
\hline & W & 0.0065 & 2.655 & 0.0161 & & \\
\hline \multirow{4}{*}{ Grudziądz } & constant & -22.394 & -11.23 & 0.0000 & \multirow{4}{*}{0.9803} & \multirow{4}{*}{1.7125} \\
\hline & $t$ & 0.0112 & 11.29 & 0.0000 & & \\
\hline & $S$ & 0.0060 & 2.904 & 0.0099 & & \\
\hline & W & -0.0058 & -3.632 & 0.0021 & & \\
\hline
\end{tabular}

The GRETL statistical package (known as Gnu Regression, Econometrics and Time-series Library) is used to test the hypothesis. The obtained results are satisfactory because of the high $R^{2}$ value of each equation, a low autocorrelation coefficient and, as a result, the Durbin-Watson statistics close to 2 . The time trend $(t)$ is also significant and related with the $D$ indicator, meaning that the $D$ indicator increases with time $(t)$. The switch variables $S$ and $W$ are found to be significant in the equation in each of the six cases. Thus, the $D$ synthetic socioeconomic indicator is related to the introduction of geothermal spas into the development model. It is 
expressed in the value of the $S$ coefficient. A score of variable $S$ indicates how much the development indicator starts to increase from the moment of establishing a geothermal spa. In each of the examined municipalities the coefficient $S$ observes a positive result. It interprets the change of the local development indicator and switch of its position. The $W$ variable depicts the growing tempo of the municipality socioeconomic development afterwards. It represents the pace of local development. A negative coefficient of the $W$ variable (cases of Mszczonów and Grudziądz) indicates a slower growth after the geothermal spa construction since the angle of the regression trend line is reduced. However, a negative coefficient of a switch variable does not imply a negative relation in the switch regression model (Quandt, 1972; Hamilton, 1989; Lee \& Solon, 2009).

\section{4 Model results interpretation}

Model testing observes a positive development trend after the introduction of a geothermal spa in a municipality. At this moment a qualitative change in the model initiates and the average level of the $D$ variable switches. Depending on the score of the switch variables $S$ and $W$, the $D$ indicator increases faster or slower. The following interpretations zoom into the results of the switches (Table 2.4) for each municipality. The case of Szaflary is used to visualize the switch regression examination, including the two geothermal centers variables. Actual chart (the scores of the $D$ ) and fitted chart illustrate the change in development indicator related to the two geothermal centers.

\section{Szaflary}

The model observes all variables to be significant, including $W_{1}$ and $W_{2}$, which represent two geothermal spas. Their introduction in 2007 and 2015 induces a structural change in the municipality development model. A change in constant value indicates that a switch in the development indicator level (coefficient value $S$ ) and an increase in the development tempo (coefficient value $W$ ) is noticed twice between the years 2006 and 2007 as well as between 2014 and 2015. Both actual and fitted $D$ variable models display the significant increase related to the two geothermal spas. Figure 2.1 displays this observation. 


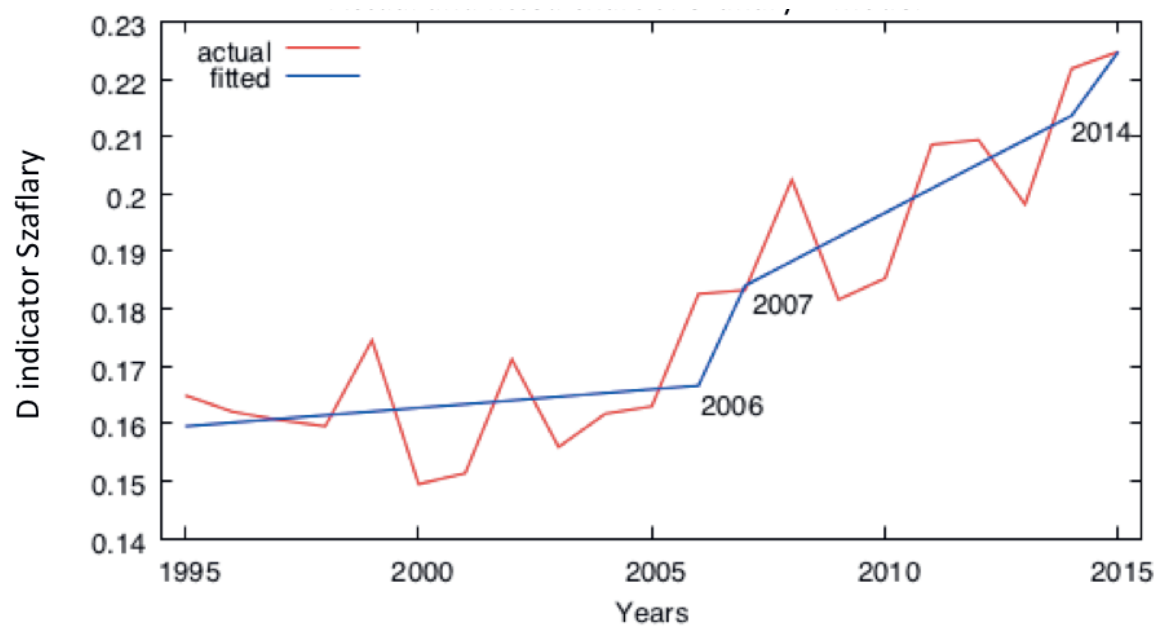

2007 and 2014 - years of opening the two geothermal spas in Szaflary

Figure 2.1: Actual and fitted chart of the switch regression model $D$ for Szaflary, source: GRETL modelling, own elaboration.

\section{Bukowina Tatrzańska}

All the variables in the Bukowina Tatrzańska model result significant. Variable $D$ is significantly related to the variables of time $(t)$ and presence of two geothermal spas $\left(S, W_{1}\right.$ and $\left.W_{2}\right)$. $A$ significant switch in the municipality $D$ model and growth of the socioeconomic development is noted after the introduction of the first geothermal spa, after 2008. The opening of the second geothermal spa in 2011 additionally increases the development trend. Therefore, the two geothermal spas accelerate Bukowina Tatrzańska's socioeconomic development.

\section{Zakopane}

All variables of the Zakopane $D$ model are found to be significant. We observe a correlation between the $D$ variable and the geothermal spa in the municipality. The $D$ variable observes a faster growth, from the geothermal spa momentum. Nevertheless, the size and the touristic profile of this municipality may all together question that the geothermal spa is a sole development factor. Due to other, stronger elements that led to the development of Zakopane a weak relationship is assumed. A switch in the development model is partially linked to the introduction of a geothermal spa in 2006.

\section{Mszczonów}

All model variable results are significant. The model responds to the introduction of the switch variables $S$ and $W$ in 2008 with a jump regardless of a reduced socioeconomic development tempo illustrated by a negative $W$ coefficient. Socioeconomic development is significantly and systematically changing over time $(t)$, and a geothermal spa contributes to accelerate the level of the $D$ variable. This switch takes place in the year of a geothermal spa introduction. 
However, the tempo of the development that $W$ explains is then moderate. The municipality appears to develop slower afterwards however, the geothermal center contributes to keeping the development exceeding.

Uniejów

All variables are significant for the Uniejów socioeconomic development model. A moderate growth is interrupted with the introduction of a geothermal spa in 2008 ( $S$ and $W$ input variables). This introduction causes a significant switch in the level of the indicator $D$ between the years 2007 and 2008. The tempo of the development indicator of Uniejów is also faster afterwards, as indicated by the value of the $W$ coefficient.

\section{Grudziądz}

The variables of the Grudziądz model observation are found to be significant. The model observes a switch in the $D$ indicator structure, which relates to the opening of a geothermal spa in 2006 since the geothermal spa changes the average $D$ indicator value. The score of the Durbin-Watson statistics is slightly lower than in the cases of the other municipalities examined. However, it does not fall into the critical area of the statistical test. The variable $S$ is associated with the development indicator therefore the geothermal spa has a role in the local development. A change in constant value, where the equation results in a slower development tempo after the introduction of the geothermal spa interprets the negative $W$ coefficient result. Yet, the municipality continues to develop with the geothermal spa effect on its socioeconomic indicators.

\section{5 Discussion and conclusions}

Between years 1995 and 2015, in each of the municipality models tested the variables related to the geothermal spa ( $S$ and $W$ ) change the structure of the socioeconomic development model. A switch in the regression line to a higher level is observed. The socioeconomic development model parameters significantly increase when the geothermal spa variables are inserted. The results of the model based on both estimations and visual inspection allow a positive verification of the hypothesis that the introduction of a geothermal spa accelerates the socioeconomic development of the municipality in which it is established.

We observe a general growing trend in the tested municipalities, related to the positive and prevalent development of the Polish economy. The socioeconomic development indicator $(D)$ of a municipality grows in each of the six cases examined at the time when a geothermal water park is respectively introduced. We connect this growth with the use of local resources, such as local labor force, tax revenues or infrastructure (components of the socioeconomic development indicator) that a geothermal spa entails. The faster or slower tempo of development is related to the opportunities that emerge due to the introduction of a geothermal spa. 
The model we present is particularly relevant for municipalities that introduce a geothermal spa as a new element of the local economy. A positive effect of the geothermal water park is observed in already touristic locations, i.e. Zakopane and Bukowina Tatrzańska and where it is a single and new element of the local economy, i.e. Uniejów and Szaflary. In these cases, the socioeconomic development indicator observes a double growth. Geothermal spas trigger the touristic potential locally, specifically Uniejów and Szaflary are now considered in public opinion as new tourist destinations in Poland (Hałaj, 2012; Dej et al., 2014; Dryglas \& Hadzik, 2016). Zakopane and Bukowina Tatrzańska note as well an increased number of tourists (Nowobilska, 2011; Kruczek, 2016; Hełdak, 2017). Nevertheless, Zakopane and Bukowina Tatrzańska are well known tourist destination in Poland. Especially in the case of Zakopane establishment of the geothermal recreational center cannot be interpret as a sole development factor due to the general socioeconomic growth there, induced by the intense tourism sector. Yet, the results of our model indicate a positive impact of the geothermal spa on the trend of local socioeconomic development. We can assume that a geothermal water park in these two locations increases the touristic attractiveness and provides another tourist amenity.

A geothermal water park in a municipality generates an impulse for local tourism and its related economic activities. The relation between the acceleration of socioeconomic development and geothermal parks is also positively verified in the cases of Mszczonów and Grudziądz. However, the fact that the average development tempo slows down suggests an impact of other economic circumstances that might burden these municipalities development tempo. The illustrated development tempo of Mszczonów and Grudziądz indicates its growth before the geothermal parks were built. In these cases, a geothermal spa contributes to the municipality's development, but it isn't its main driver.

To conclude, observations of the model results lead to the following findings: geothermal water parks as new touristic elements significantly impact local development in municipalities without a strong economic profile. However, it is an asset to the development factor in each of the municipalities tested. This corroborates the research hypothesis and the main assumption of this paper. Further studies investigating the contribution of the geothermal spa to the local development adding another perspective are advised. This article attempts to establish a link between geothermal based tourism and municipality development, without considering other development factors in the municipality. In case of our research cases a geothermal water park is found to accelerate the municipality socioeconomic development in various degrees. 
Chapter 3

The impact of geothermal resources on the competitiveness of municipalities: evidence from Poland 


\begin{abstract}
8
In addition to large-scale environmental benefits, geothermal resources are nowadays expected to deliver an endogenous competitive advantage. The aim of this study is to investigate this phenomenon for Poland. Since geothermal resources are of an endogenous nature, their competitive advantage character for eleven selected municipalities in Poland is assumed. A municipality competitiveness model is built using an expert method. Panel data analysis is used to estimate four models of geothermal competitiveness. A sensitive analysis examines if the results are dependent on the model we developed. All four model scenarios are robust. The results show that the geothermal estimators significantly impact the created municipality competitiveness indicator. The geothermal energy production and geothermal bathing centers are both significant elements of municipality competitiveness in Poland. Therefore, this work provides an argument for further expansion of the extraction of the available geothermal resources in Poland.
\end{abstract}

${ }^{8}$ Chapter published as: Kurek, K. A., Heijman, W., van Ophem, J., Gędek, S., \& Strojny, J. (2020). The impact of geothermal resources on the competitiveness of municipalities: evidence from Poland. Renewable Energy, 151, 1230-1239. 


\subsection{Local competitiveness drivers}

The endogenous growth theory that emerged in the 1980's shifts attentions to the endogenous factors and forces of economic growth (Stöhr \& Taylor, 1981; Boltho \& Holtham, 1992). Opposite to neoclassical theories, the endogenous growth model omits the role of technology emphasizing determinants approached as endogenous, such as human or natural capital. Endogenous growth theory scholars seek a sustainable long-run growth through the deployment of human and natural resources into innovation and R\&D (Romer, 1994; Grossman \& Helpman, 1994; Aghion \& Howitt, 1998). Moreover, this theory emphasizes the role of natural resources in generating innovations and increasing macroeconomic returns to scale according to Helpman (1992), Barbier (1999) and England (2000). References for concepts of local and regional competitiveness in the endogenous growth model are found in the works of Cheshire \& Magrini (2000), Acs \& Armington (2004), Harrison (2007), Button (2011), Stimson et al. (2011) and Taylor \& Plummer (2011), where endogenous local attributes and processes are recognized as drivers of growth. Kitson et al. (2004), for example, underlines the endogenous local drivers' crucial role in stimulating economic development, whereas Pike et al. (2006) determine the economic potential of naturally occurring resources in localities, among other endogenous factors, as a source of local development. Based on the perspective of Audretsch et al. (2015), natural energy resources are local assets and therefore are considered as critical drivers of local competitiveness.

From the perspective of regional studies, definitions of local competitiveness vary among scholars. However, general findings refer to two concepts: economic welfare and sustainability. Regarding economic welfare, Stroper (1997) and Meyer-Stamer (2008) define local competitiveness as an ability to attract capital for similar localities, which results in an increasing local standard of living. The study of Hunt (1999) finds it profitable that a locality is able to compete against others on forms of using local resources. Plummer et al. (2014) underline the role of local commodities supply in building the competitive advantage. For Camagni (2002) local competitiveness is a phenomenon of local policymaking that emphasizes local resources and needs. According to lopollo et al. (2016), a locality is competitive by integrating resources into its local sustainable system and as a result by improving the local quality of life. Competition analysis of Porter (1998, 2000a, 2000b) finds a competitive advantage in the application of local resources and knowledge. The concepts of local clusters emergence and regional economic spillovers are seen as optimizations of endogenous resources. In Porter's studies, the measure of competitive advantage is how an endogenous innovation transforms into local know-how, i.e. a specialization. Environmental sustainability also creates opportunities for inter-regional and inter-local competitiveness. The transition of a locality according to sustainability principles becomes a competitive advantage and an attractive argument for potential investors (O'Riordan \& Voisey, 1997; Sykora, 2002; Krueger $\&$ Gibbs, 2008). Jonas et al. (2010) argue that low carbon initiatives become new competitive strategies and result in the reconstruction of the local economy. 
The endogenous character of geothermal energy (Chakravorty et al., 1997) opens a discussion about the scale of the resource competitiveness in the local dimension. The competitive characteristics of geothermal energy compared with other renewables are seen in its resource energy efficiency (Seyboth, 2008; Aydin, 2014) and non-intermitted potential and storage capability (Fridleifsson, 2003; Matek \& Gawell, 2015). Social characteristics add to the competitive advantage of this resource, such as environmental attributes and sustainable exploitation (Mock et al., 1997). Geothermal energy is considered a local capital in Porter's (2010) studies, which are dedicated to the concept of geothermal competitive advantage. Porter's main findings discuss the establishment of geothermal clusters where the potential of the resource is optimally and locally used. Interactions between various actors of geothermal energy utilization generate local knowledge and market opportunities. However, Porter underlines the fact that geothermal resources become a competitive advantage at the scale of deployment. In other words, an increase of geothermal capacity utilization is the key to the competitiveness.

One of the ways to study the geothermal resource is to link it with the concept of endogenous growth theory. This approach is not yet sufficiently illustrated in the literature. The substantiation of the proposed study is the relative difficulty of mining and profitability of investment in the geothermal energy. A heavy capital drilling is necessary to exploit the geothermal heat or water, that as well carries certain risks. Therefore, this resource is expected to deliver more than energy production benefit to the local economy. Despite the high capital investment in geothermal exploration and the related risks for local authorities, we assume the resource is a local competitive advantage. However, regardless the arguments of geothermal advantage, it is not obvious that geothermal resource drives the local economy. It is not conditioned to exploration only, other activities have to take place. We base our concept on the endogenous nature of the resource and the variety of its direct exploitation according to the Lindal diagram (Fig. 1.6 in Chapter 1; Gudmundsson et al., 1985). In order to verify this assumption, we propose a research question about the relationship between the development of geothermal energy and the competitiveness of the municipalities in Poland. Due to the complexity of the topic and the definitions of local competitiveness, we operationalize the research problem with the help of experts.

This chapter is divided into the following sections: Competitiveness of the geothermal energy, Local competitiveness model, Competitiveness model data, Municipality competitiveness concept, Panel model robustness check and lastly Discussion and conclusions. 


\subsection{Competitiveness of the geothermal energy}

Geothermal energy is considered as a source of clean energy and becomes substantially cheaper than fossil fuels fired energy if supported by the state following Armstead (1978), Duffield \& Sass (2003), Energy Roadmap 2050 (2011). According to sustainability criteria for heating and cooling, the geothermal renewable reveals the highest $\mathrm{CO}_{2}$ capture potential (Randolph \& Saar, 2011), and it leads in sustainable performance over biomass and solar energy (Dincer \& Acar, 2015). Moreover, International Energy Agency (2011) and IRENA (2018) predictions point to an upcoming tenfold increase in the geothermal heat and power capacity in Europe.

References to geothermal resources as a competitive feature of local economy and a sustainably factor are found in the works of Murphy \& Niitsuma (1999), Cataldi (2001), Chandrasekharam \& Bundschuh (2002), Niitsuma \& Nakata (2003), Rybach (2003), Green \& Nix (2006), Carley et al. (2011), Goldstein et al. (2011), Dumas \& Angelino (2015), Michaelides (2016) and Kurek (2016) among others. The main observations point to the role of the geothermal resource in the economic development, especially the low-grade resources, e.g. the geothermal waters application in geothermal bathing centers.

In the case of Poland, the geothermal resource is competitive on the supply side. It is found under $80 \%$ of the country beneath the earth's crust, one of the highest percentages in Europe. $40 \%$ of this potential is technically ready to deliver economically attractive geothermal heat and energy, argue Kępińska (2003) and Górecki et al. (2012). Moreover, Poland can produce $625.000 \mathrm{PJ}$ of geothermal energy annually, whereas the annual energy consumption is circa 5500 PJ (Ney, 1997; Huclak et al., 2015). According to Skjærseth (2014) and Szulecki et al. (2016), increased geothermal production creates a degree of energy independence from conventional resources and imports. Jarczewski et al. (2015) discusses that optimal conditions for geothermal exploitation are found in relatively small to mid-size municipalities in Poland with dense housing and an infrastructure network that are at the source of or in close vicinity to the renewable geothermal energy. It provides them with geothermal related opportunities, such as local energy source, job creation, local budget alleviation and increased entrepreneurship. Despite the resource potential in Poland, the geothermal renewable is used for the local district heating and the recreational or bathing centers (Halaj, 2015; Sowizdżał, 2018). Since geothermal investment and operations in Poland are mostly carried out locally in the area of a municipality, the potential competitiveness is therefore assumed to reveal itself there. Hence, we set the following hypothesis: The exploitation of the geothermal resource has a positive impact on the competitiveness of a municipality. In practice it is presumed that an increase of local competitiveness is explained by the scale of the geothermal resource utilization. 
To test the hypothesis, we employ a statistical model of municipality competitiveness and introduce geothermal parameters in order to observe the assumed relation. We aim to measure how the two forms of geothermal exploitation, i.e. heat energy and recreational/spa centers, determine the level of municipality competitiveness. Municipality competitiveness is represented by a synthetic indicator, a measure that is comprised of elaborated socioeconomic indicators. A similar approach to creating a synthetic index for measuring regional competitiveness in Poland is found in studies by Bronisz et al. (2008), Heijman et al. (2010), Michalek \& Zarnekow (2012), Grzebyk \& Stec (2015), Kusz et al. (2015) and Strojny et al. (2015). In order to examine the competitiveness of a municipality in relation to geothermal exploitation, a comparison is required. The local competitiveness model is to be carried out for municipalities with geothermal exploitation and for municipalities that do not deploy geothermal resources. The benchmark groups are introduced. A benchmark methodology allows us to analyze the local competitiveness model, where geothermal parameters are the competitiveness determinants.

\subsection{Local competitiveness model}

The model that tests the relation of geothermal exploitation to local competitiveness requires adequate variables. The data is primary built since this research is a quite pioneering one. Therefore, the variables result from authors' approach to the research problem and availability of sources. The model is relation testing oriented hence we had to build variables that can illustrate an assumed relation. Since the research problem is limited by data availability we attempt to conceptualize the model with data that best describe the phenomenon studied. Competitiveness on the municipality level is represented by relevant indicators that illustrate economic welfare and sustainability as per the local competitiveness interpretation. For this purpose, a local competitiveness index is built by coupling the indicators, and it constitutes the model's dependent variables. Its construction is explained in Section 5 of this chapter. Model testing implies a valid statistical relation between the model components. As model determinants, we appoint variables that reflect the size of the geothermal resource exploitation in Poland. The technical data on the exploitation of the resource is not meeting the model assumptions, thus other data illustrating the use of the resource but not its extraction has to be found. Since the other purposes of geothermal resources in Poland are still in the initial stage of development, there are two descriptive variables that refer to the local geothermal operations, i.e. the establishment of a geothermal spa/ recreational center and a volume of geothermal energy produced at the local geothermal plants. If the geothermal energy production has a competitiveness potential for a municipality, we use the geothermal energy production variable measured in GJ, not the processed geothermal heat power in megawatts (MW). Due to its structure, the geothermal spa parameter is converted into a dummy variable, whereas the geothermal GJ output is a numeric value. 
In order to be able to determine the geothermal variables' contribution to the municipalities' competitiveness indicators, control variables are required. The selection of control variables aims to reduce the geothermal variables bias in the local competitiveness model. This selection is to control for other factors that are relevant in the research assumption. We introduce these variables to validate the model results. Without the control variables the growth of the municipality competitiveness cannot be identified as related to the geothermal resources exploitation, but attributed to other factors. Therefore, one control variable is a competitiveness indicator for municipalities that do not exploit geothermal resources. It bases in the benchmarking concept. The benchmark competitiveness indicator used as a control check if the competitiveness is a general trend in the municipalities. It filters out the overall trend of rising competitiveness indicators. Two other control variables refer to the administrative area of a county where a geothermal municipality is located. County (poviat) is the second degree of local government and administrative area of Poland, equal to the NUTS4 geographical nomenclature. The county level measured income per capita and the heat energy provision helps to identify clearly the relationship geothermal variables have with the model. A lagged variable is introduced to measure the dynamics of geothermal developments in the municipalities. A time lagged variable tackles the issue of values from the previous period affecting the one being tested. The application of a lagged variable is used since the effects of geothermal operations and investment have a delayed impact on the economy (Lovekin, 2000; Ngugi, 2014; Daniilidis et al., 2017). Table 3.1 introduces the model variables and their reasoning. These variables seem to possibly describe the phenomenon of geothermal energy in a commune and its potential impact on local competitiveness.

Table 3.1: Description of the model variables, own elaboration.

\begin{tabular}{|c|c|c|c|}
\hline variable & value & description & reference \\
\hline $\begin{array}{l}\text { dependent } \\
\text { variable } y_{t} \text { : } \\
\text { geothermal } \\
\text { municipality } \\
\text { competitiveness } \\
\text { index }(\mathrm{Cl})\end{array}$ & $\begin{array}{l}\text { Synthetic } \\
\text { indicator of } \\
\text { geothermal } \\
\text { municipality } \\
\text { competitiveness } \\
0 \leq y_{t} \leq 1\end{array}$ & $\begin{array}{l}\text { Geothermal } \\
\text { municipality } \\
\text { competitiveness } \\
\text { level. }\end{array}$ & $\begin{array}{l}\text { Explains the appointed } \\
\text { measures of local } \\
\text { competitiveness in the form of } \\
\text { a synthetic indicator. }\end{array}$ \\
\hline $\begin{array}{l}\text { independent } \\
\text { variable } \times 1 \text { : } \\
\text { geothermal } \\
\text { spa/ } \\
\text { recreational } \\
\text { center }\end{array}$ & $\begin{array}{l}\text { Binary value } \\
{[0,1]}\end{array}$ & $\begin{array}{l}\text { Exploitation of the } \\
\text { resource for a } \\
\text { geothermal spa/ } \\
\text { recreational bathing } \\
\text { center. }\end{array}$ & $\begin{array}{l}\text { Indicates if a geothermal waters } \\
\text { spa is present in a given year; } 0 \\
\text { denotes that within a given } \\
\text { year a geothermal spa is not } \\
\text { present; } 1 \text { denotes that within a } \\
\text { given year a geothermal spa is } \\
\text { present. }\end{array}$ \\
\hline
\end{tabular}




\begin{tabular}{|c|c|c|c|}
\hline $\begin{array}{l}\text { independent } \\
\text { variable x2: } \\
\text { geothermal GJ }\end{array}$ & $\begin{array}{l}\text { Numerical } \\
\text { variable } \\
{[0 \ldots \mathrm{N}]}\end{array}$ & $\begin{array}{l}\text { Geothermal energy } \\
\text { (in GJ) produced for } \\
\text { heating purposes. }\end{array}$ & $\begin{array}{l}\text { Output of geothermal } \\
\text { production in GJ. Depicts the } \\
\text { intensity of geothermal use and } \\
\text { implies the occurrences of } \\
\text { geothermal activities in a } \\
\text { municipality. }\end{array}$ \\
\hline $\begin{array}{l}\text { control variable } \\
x 3 \text { : benchmark } \\
\text { municipality } \\
\text { competitiveness } \\
\text { index }\end{array}$ & $\begin{array}{l}\text { Synthetic } \\
\text { indicator of } \\
\text { benchmarked } \\
\text { municipalities } \\
\text { competitiveness } \\
0 \leq x 3 \leq 1\end{array}$ & $\begin{array}{l}\text { Benchmarks } \\
\text { competitiveness } \\
\text { level. }\end{array}$ & $\begin{array}{l}\text { Built of the same measures as } \\
\text { the geothermal } \mathrm{Cl} \text {. Applied to } \\
\text { observe the local } \\
\text { competitiveness measures in } \\
\text { benchmark municipalities with } \\
\text { similar socioeconomic } \\
\text { structures and no geothermal } \\
\text { operations. }\end{array}$ \\
\hline $\begin{array}{l}\text { control variable } \\
x 4 \text { : county heat } \\
\text { per capita }\end{array}$ & $\begin{array}{l}{[\mathrm{O} \ldots \mathrm{N}]} \\
\text { numerical } \\
\text { variable }\end{array}$ & $\begin{array}{l}\text { Heat dam }{ }^{3} \text { produced } \\
\text { per county } \\
\text { inhabitant, (where } \\
\left.1 \text { dam }^{3}=10 \mathrm{~m}^{3}\right) \text {. }\end{array}$ & $\begin{array}{l}\text { Units of heat from all sources } \\
\text { delivered to a country's } \\
\text { infrastructure. Helps to identify } \\
\text { if a municipality's } \\
\text { competitiveness is related to } \\
\text { the increased heat energy } \\
\text { provision from all sources (or } \\
\text { only the local geothermal heat } \\
\text { energy). }\end{array}$ \\
\hline $\begin{array}{l}\text { control variable } \\
x 5 \text { : county } \\
\text { income per } \\
\text { capita }\end{array}$ & $\begin{array}{l}{[\mathrm{O} \ldots \mathrm{N}]} \\
\text { numerical } \\
\text { variable }\end{array}$ & $\begin{array}{l}\text { Own income in } \\
\text { Polish zlotys per } \\
\text { capita of a county } \\
\text { where a geothermal } \\
\text { municipality is } \\
\text { located. }\end{array}$ & $\begin{array}{l}\text { Indicates the general level of } \\
\text { wealth of an administrative } \\
\text { area where the geothermal } \\
\text { municipality belongs. It } \\
\text { functions in the model as a } \\
\text { verification if a municipality's } \\
\text { competitiveness is related to its } \\
\text { county wealth. }\end{array}$ \\
\hline $\begin{array}{l}\text { control variable } \\
x 6 \text { : time lag }\end{array}$ & $y_{t-1}$ & $\begin{array}{l}\text { Delayed variable } \\
\text { (lagged). }\end{array}$ & $\begin{array}{l}\text { Assumes the lagged effect of } \\
\text { the geothermal energy } \\
\text { exploitation on the local } \\
\text { economy. }\end{array}$ \\
\hline
\end{tabular}

The data on the geothermal municipalities and their benchmark municipalities offers time series observations. A methodological approach is to test the assumption that forms of geothermal resource exploitation increase the indicators of municipality competitiveness. As a time series analysis, panel analysis serves to verify the hypothesis. Panel research is used in economics to conduct the longitudinal analysis of development, change and related socio- 
economic phenomena. It endows regression with both spatial (cross units) and temporal (time series) observations and applies in situations of data heterogeneity, assuming unchanging phenomenon in time data. In the panel econometric models that are estimated on the basis of the panel data it is generally assumed that the evolution of an explanatory variable is influenced by unmeasurable, constant in time factors that are specific to a given object (Baltagi, 2008). Panel analysis is used in studies that seek links and long-term determinants of data relationships. Studies that use panel modelling in local competitiveness analysis (Naudé \& Saayman, 2005; Zhang \& Jensen, 2007; Nevima \& Melecký, 2011) underline the accuracy of this methodology in tackling the unobservable individual effects of a country, an area or subject such as natural environments, unique attractions or the climate constant over time. A panel data regression model (or a panel data model) is an econometric model specifically designed for panel data. This methodology addresses the traditional statistical problems in regression, incorporating the unobserved effects and model uncertainty (Greene, 2000). A major advantage of the panel data analysis is its ability to control for omitted (unobserved or mismeasured) variables, argues Hsiao (2003). However, in general a threat to time series data models is the variables' non-stationarity characteristics, which often lead to the identification of apparent intercorrelations (Phillips, 1986).

In general, we adopt the regression panel model structure that is based on the Least Square Dummy Variable model. Due to the variable structure, it is a multivariate panel model. We estimate this model to be static or dynamic, depending on the lagged variable employment. When static, it is a fixed effects regression panel model. It assumes the correlation between an entity's error term and its predictor variable isn't related to any other model characteristic. In this case, the competitiveness index is assumed related to the geothermal variables. When dynamic, it takes the form of a dynamic panel model. A dynamic panel model is based on the general fixed panel model, but with a difference of containing error components with a lagged dependent variable. The Hausman test is executed to test the appropriateness of the fixed effect model choice.

We introduce the panel model in the following formula:

$y_{i t}=\delta \gamma y_{i, t-1}+\beta_{i} x_{i t}+\left(\alpha_{i}+\varepsilon_{i t}\right), \quad i=1, \ldots N, t=1, \ldots T$,

where:

$i=1, \ldots, N$ (objects)

$t=1, \ldots$, (time units)

$y_{i t}$ - dependent variable

$x_{i t}$ - independent variable vector

$\beta$-vector with the $\mathrm{N}$ dimension of the structural parameters of the model

$\delta$ - panel parameter $[0,1]$, where $\delta=0$ in the static panel model and $\delta=1$ in the dynamic panel model 
$\gamma$-structural parameter

$\alpha_{i}$ - group effect for observation $i$

$\varepsilon_{i t}$ - pure random error (Baltagi, 2003)

Panel data methodology allows for observations of the interdependency between the geothermal exploitation variables and the competitiveness index of a municipality where the geothermal resource is exploited. The specifics of the dynamic panel model include a lagged variable. The verification of the hypothesis boils down to the application of the geothermal municipality competitiveness index and the independent model variables forming a panel data set based on the developed formula 1 . The results of the model testing are expected to reveal a significant relationship between the dependent variable and the geothermal parameters. The relationship with the control variables is to be determined. Outcomes of the panel analysis are displayed in the Table 3.6.

\subsection{Competitiveness model data}

The panel data observes selected indicators of local competitiveness in years 1999-2017. This time period is determined by the administrative reform in Poland that took place in 1999, which introduced the administrative county units. Counties data constitutes the two models' control variables. The model's variables data (shown in Table 1) comes from two sources: the geothermal enterprises and the Central Statistical Office in Poland.

Table 3.2 presents a selection of eleven municipalities in Poland that have geothermal operations limited to a minimum of 5 years of resource exploitation. Otherwise no competitiveness observations are statistically valid. They are actually the majority of municipalities in Poland where geothermal installations are present except few installations for the recreational purposes in other locations. Geothermal enterprises of various ownership, including local authorities, produce the geothermal heat and water that are further distributed to the communal network or power the geothermal recreational center. Geotermia Podhalańska S.A. powers four municipalities located in the proximity. Geothermal recreational centers are established in seven out of the eleven municipalities. In the case of Poddębice, the geothermal recreational center was built before the geothermal municipal heating plant. Information about the geothermal energy production in GJ is collected directly from the geothermal enterprises, and it constitutes the primary data. We inquired about the access to the data either in person or via correspondence. The data of years 1999-2017 form panel data, which have a different size for each of the municipalities depending on the start time of their geothermal operations (see Table 3.2).

${ }^{9}$ B.H. Baltagi, 2003, Econometric Analysis of Panel Data, John Wiley \& Sons, LTD, England 2003, Ch.8. 
The impact of geothermal resources...

Table 3.2: Selection of the geothermal municipalities in Poland, sources: Polish Geological Institute, Termalni.pl.

\begin{tabular}{cllcc}
\hline & Geothermal enterprise & Municipality & Installation year & Recreational center \\
\hline 1 & Geotermia Mazowiecka S.A. & Mszczonów & 1999 & 2008 \\
2 & Geotermia Uniejów LLC & Uniejów & 2001 & 2008 \\
3 & Geotermia Poddębice LLC & Poddębice & 2013 & 2011 \\
4 & Geotermia Podhalańska S.A. & Zakopane & 2001 & 2006 \\
5 & Geotermia Podhalańska S.A. & Szaflary & 1993 & $2007\left(1^{\text {st }}\right)$ and 2015 $\left(2^{\text {nd }}\right)$ \\
6 & Geotermia Podhalańska S.A. & Biały Dunajec & 1996 & n.a. \\
7 & Geotermia Podhalańska S.A. & Poronin & 2001 & n.a. \\
8 & Bukowina Geothermal Society LLC & Bukowina Tatrzańska & 2008 & $2008\left(1^{\text {st }}\right)$ and 2011(2 $\left.2^{\text {nd }}\right)$ \\
9 & NZOz Geotermia & Grudziądz & 2006 & 2006 \\
10 & Geotermia Pyrzyce LLC & Pyrzyce & 1999 & n.a. \\
11 & Geotermia Stargard LLC & Stargard & 2005 & n.a. \\
\hline
\end{tabular}

The competitiveness model variables and the control variables are collected from the Local Data Bank of the Central Statistical Office at the level of NUTS 4 and $5^{10}$ for the years 1999 2017. A benchmarking approach is used to determine the control variable of the municipalities with no geothermal operations. Following the benchmarking concept taken from regional studies in Poland (Kobylińska \& Glińska, 2008; Gędek et al. 2013; Strojny 2015), the eleven geothermal municipalities receive a matching benchmark group composed of five municipalities with corresponding size (population and territory in $\mathrm{km}^{2}$ ), administrative profile and geographical location. The control variable aims to represent a similar socioeconomic structure as the geothermal municipality but without any exploitation of the geothermal resources. The composition of the municipality competitiveness indicator for the geothermal municipalities and for the benchmarked municipalities is explained in the next section.

\subsection{Municipality competitiveness concept}

As discussed in Section 3.1, the concept of local competitiveness has a wide definition. For such a methodological issue, an expert method may serve as a solution. In our case, an expert opinion supports the specification of the local competitiveness model. The Analytical Hierarchy Process (AHP) expert method is used to determine the local competitiveness index construction. Since our research discusses the aspects of regional economics and a renewable energy resource exploitation the expert group is built in relation to these two research problems.

According to the AHP expert selection criteria (Saaty, 1994) eleven professors and doctors from the Economic Department of Rzeszów Technical University and nine mayors of the examined

\footnotetext{
${ }^{10}$ NUTS is the Eurostat's Nomenclature of Territorial Units for Statistics. In Poland, NUTS levels 4 and 5 correspond with counties and municipalities administrative units respectively.
} 
geothermal municipalities involved in the local geothermal development are considered as experts in this study. In total, the experts batch accounts for 20 mixed experiences professionals. Since the evaluation of method results is made by the type of experts, what counts is the appropriate selection of experts, not their number. First, experts are asked to assess the best measuring indicators of municipality competitiveness from the data available at the Local Data Bank for years 1999-2017. Data for each municipality is collected on the NUTS-5 level. Table 3.3 presents the selection of indicators that best refer, according to the experts, to economic welfare and sustainability dimensions. Consequently, the competitiveness model of a municipality is organized into 6 main categories and 4 subcategories, which yields in total a matrix of 24 indicators determining municipality competitiveness in Poland. Due to the various data structures, the 24 indicators are normalized by the Zero Unitarization Method (Kukula, 2014) with the normalization range [0-1].

Table 3.3: The expert model of indicators determining municipality competitiveness in Poland, own elaboration.

Model of the synthetic competitiveness indicator $(C l)$

\begin{tabular}{|c|c|c|c|c|c|}
\hline \multicolumn{6}{|c|}{ categories } \\
\hline $\begin{array}{l}\text { Population } \\
\left(C_{p}\right)\end{array}$ & $\begin{array}{c}\text { Local } \\
\text { Economy }\left(\mathrm{C}_{\mathrm{e}}\right)\end{array}$ & $\begin{array}{l}\text { Local government } \\
\qquad\left(C_{g}\right)\end{array}$ & Tourism $\left(C_{t}\right)$ & Infrastructure $\left(C_{i}\right)$ & Level of life $\left(C_{1}\right)$ \\
\hline \multicolumn{6}{|c|}{ subcategories } \\
\hline $\begin{array}{l}\text { Internal } \\
\text { migration } \\
\left(C_{p} 1\right)\end{array}$ & $\begin{array}{c}\% \text { of } \\
\text { employed } \\
\text { inhabitants } \\
\left(C_{e} 1\right)\end{array}$ & $\begin{array}{l}\text { Own municipality } \\
\text { income per } \\
\text { inhabitant }\left(C_{g} 1\right)\end{array}$ & $\begin{array}{c}\text { Polish tourists } \\
\text { accommodated per } \\
1000 \text { inhabitants } \\
\left(C_{t} 1\right)\end{array}$ & $\begin{array}{l}\text { Water consumption } \\
\text { for industrial and } \\
\text { domestic purpose } \\
\text { per inhabitant }\left(C_{i} 1\right)\end{array}$ & $\begin{array}{c}\text { Outpatient } \\
\text { health care } \\
\text { facilities per } \\
10.000 \\
\text { inhabitants }\left(C_{\mid} 1\right)\end{array}$ \\
\hline $\begin{array}{c}\text { Natural } \\
\text { increase }\left(C_{p} 2\right)\end{array}$ & $\begin{array}{l}\text { No. of private } \\
\text { economic } \\
\text { activities }\left(C_{e} 2\right)\end{array}$ & $\begin{array}{c}\text { Municipality } \\
\text { investment } \\
\text { expenses per } \\
\text { inhabitant }\left(C_{\mathrm{g}} 2\right)\end{array}$ & $\begin{array}{c}\text { Foreign tourists } \\
\text { accommodated per } \\
1000 \text { inhabitants } \\
\left(C_{t} 2\right)\end{array}$ & $\begin{array}{l}\text { Dwellings delivered } \\
\text { per } 100 \text { inhabitants } \\
\qquad\left(\mathrm{C}_{\mathrm{i}} 2\right)\end{array}$ & $\begin{array}{l}\text { Environmental } \\
\text { protection } \\
\text { investment per } \\
\text { inhabitant }\left(C_{1} 2\right)\end{array}$ \\
\hline $\begin{array}{l}\% \text { of the } \\
\text { population } \\
\text { with a } \\
\text { productive } \\
\text { age }\left(C_{p} 3\right)\end{array}$ & $\begin{array}{c}\text { No. of } \\
\text { national } \\
\text { commercial } \\
\text { companies } \\
\left(\mathrm{C}_{\mathrm{e}} 3\right)\end{array}$ & $\begin{array}{l}\text { PIT income per } \\
\text { employed } \\
\text { inhabitant }\left(C_{g} 3\right)\end{array}$ & $\begin{array}{c}\text { Tourism } \\
\text { accommodation } \\
\text { establishments per } \\
1000 \text { inhabitants } \\
\left(C_{\mathrm{t}} 3\right)\end{array}$ & $\begin{array}{c}\mathrm{km} \text { of water } \\
\text { network and } \\
\text { canalization per } \\
\text { inhabitant }\left(C_{i} 3\right)\end{array}$ & $\begin{array}{l}\text { Primary and } \\
\text { lower secondary } \\
\text { education } \\
\text { expenses per } \\
\text { pupil }\left(C_{1} 3\right)\end{array}$ \\
\hline $\begin{array}{l}\text { Live births } \\
\qquad\left(C_{p} 4\right)\end{array}$ & $\begin{array}{l}\text { No. of } \\
\text { commercial } \\
\text { companies } \\
\text { with foreign } \\
\text { capital }\left(C_{e} 4\right)\end{array}$ & $\begin{array}{l}\text { Budget deficit } \\
\qquad\left(C_{g} 4\right)\end{array}$ & $\begin{array}{l}\text { Overnights spent } \\
\qquad\left(C_{t} 4\right)\end{array}$ & $\begin{array}{l}\text { Water system } \\
\text { connections leading } \\
\text { to residential } \\
\text { buildings and } \\
\text { residences for } \\
\text { communities per } \\
\text { inhabitants }\left(C_{i} 4\right)\end{array}$ & $\begin{array}{l}\text { Population } \\
\text { connected to } \\
\text { wastewater } \\
\text { treatment plants } \\
\text { (C,4) }\end{array}$ \\
\hline
\end{tabular}


Legend

1 - Both criteria have the same impact on the choice

3 - One criterion is slightly more important than the other

5 - One criterion is more important than the other, but the advantage is at an average level

7 - One criterion is clearly more important than the other

9 - One criterion is much more important than the other

The Analytical Hierarchy Process (AHP) method created in the 70s by Saaty is popular among the multicriteria analysis methods with particular applications in assessing socioeconomic and management problems (Saaty, 1990, 2000; Herath \& Prato, 2006; Lee \& Chan, 2008; Sipahi \& Timor, 2010; Linkov \& Moberg, 2011; Subramanian \& Ramanathan, 2012). The benefits of engaging experts from the examined scientific subject is addressed in the works of Cox et al. (2000), Boulanger \& Bréchet (2005), Rezaei-Moghaddam \& Karami (2008), Singh \& Nachtnebel (2016) and Strojny \& Heijman (2016), among others. The AHP procedure is based on a hierarchical modelling of the criteria and their subcriteria. Experts evaluate their relationship in pairs using the Saaty's 1-9 scale (see Table 3 legend). On the basis of the significance analysis in a given pair made by experts, the weight of a particular indicator is assigned. The AHP is a mixed quantitative and qualitative method. The essence of the method is also the consistency of the comparison in the matrix determined by the Consistency Ratio coefficient (CR). Expert preferences are examined, while the remainder is a mathematical procedure during which the consistency of each expert's response ratio is calculated. The function of the $C R$ is to ensure the internal validity of responses. Therefore, there is no need for additional verification of results, the method itself takes over this task and itself examines the internal consistency of expert responses (Ho, 2008). We use the dedicated AHP software Super Decisions (version 3.2) to accept or reject the weighting of given indicators while considering the CR score. The AHP tool that was distributed to the experts, i.e. the questionnaire of municipality competitiveness with the elaborated Saaty's scale is explained in the data article (Kurek, 2020d) and presented the Appendix.

Resulting from the pairwise comparisons, each model element receives a weight, specifically the weight of the model category, $w_{i}$, and the subcategory indicator weight, $w_{i} i$. The experts' judgements decompose the problem to a reciprocal matrix (KXK) of $P$ criterions where numbers in each criterion pair $p_{i}$ and $p_{j}$ to represent a ratio $\left(p_{i} / p_{j}\right) / 1$ (Saaty \& Kearns, 1985; Oddershede et al., 2007). According to the AHP methodology, weights in each category sum up to 1 (or $100 \%)$ since the elements from the same level are compared and weighted relative to each other. Therefore, a weight is interpreted from the significance of an indicator in the experts' opinion. Table 3.4 illustrates the obtained weights for each of the municipality competitiveness indicators (see Table 3.3). 
Table 3.4: The AHP computed municipality competitiveness indicators weights, own elaboration.

\begin{tabular}{|c|c|c|c|c|c|}
\hline \multicolumn{6}{|c|}{ Model of the synthetic competitiveness indicator $(C I)$} \\
\hline \multicolumn{6}{|c|}{ weights of categories } \\
\hline$w C_{p}=0.14$ & $w C_{e}=0.24$ & $w C_{g}=0.12$ & $w C_{t}=0.17$ & $w C_{i}=0.19$ & $w C_{1}=0.14$ \\
\hline \multicolumn{6}{|c|}{ weights of subcategories } \\
\hline$w C_{p} 1=0.26$ & $w C_{e} 1=0.25$ & $w C_{g} 1=0.19$ & $w C_{t} 1=0.23$ & $w C_{i} 1=0.16$ & $w C_{1} 1=0.18$ \\
\hline$w C_{p} 2=0.29$ & $w C_{e} 2=0.23$ & $w C_{g} 2=0.39$ & $w C_{t} 2=0.29$ & $w C_{i} 2=0.38$ & $w C_{12}=0.28$ \\
\hline$w C_{p} 3=0.28$ & $w C_{e} 3=0.28$ & $\mathrm{wC}_{\mathrm{g}} 3=0.26$ & $w C_{t} 3=0.21$ & $w C_{i} 3=0.25$ & $w C_{13}=0.38$ \\
\hline$w C_{p} 4=0.17$ & $w C_{e} 4=0.24$ & $w C_{g} 4=0.17$ & $w C_{t} 4=0.27$ & $w C_{i} 4=0.22$ & $w C_{1} 4=0.16$ \\
\hline
\end{tabular}

The stages of the AHP experts procedure can be summarized as: step one: creating a model of variables describing competitiveness at the municipality level (Table 3), step two is the assessment of individual elements in pairs according to Saaty's scale. Then, the expert responses are processed through the AHP software, which includes only the consistent expert assessments. The last step is the calculation of the average value of all the individual experts assessments obtained, the final effect of which are the weights of each competitiveness indicator (Table 3.4). These steps follow the principles of the AHP method experts proceedings (Saaty, 1994; Al-Harbi, 2001).

Next, following the aggregation procedure of normalized competitiveness indicators (Table 3.3) and corresponding weights (Table 3.4) a single score i.e. the competitiveness index (Cl) is generated according to the following formula.

$C l=\sum^{n} w_{i} C_{i}=w_{i} C_{i}\left(\sum_{i=1}^{n} w_{i} C_{i}\right)(2)$, where

$\sum_{i=1}^{n_{i}} W_{i}=1 \quad$ (3) and $\sum_{i=1}^{n_{i}} W_{i}=1$

$W_{i} C_{i}$ - weight of the category of local competitiveness

$w_{i} i C_{i} i$ - weight of the subcategory of local competitiveness

$i=1, \ldots, N$ (observation)

As a result of aggregation computations, each of the geothermal municipalities and the benchmark municipalities receive the competitiveness index $(C l)$, a singular indicator of competitiveness for each of the observed years. The $\mathrm{Cl}$ places in the $0-1$ range, where 1 represents the highest score of geothermal municipality competitiveness throughout the observed time period. As the model dependent variable, the $\mathrm{Cl}$ determines the level of the municipality competitiveness. Table 3.5 presents the compilation of the $\mathrm{Cl}$ scores for the geothermal and benchmark municipalities. 
Table 3.5: The synthetic competitiveness index $(C l)$ for the geothermal municipalities and the established benchmark municipalities, own elaboration.

\begin{tabular}{|c|c|c|c|c|c|c|c|c|c|c|c|c|c|c|c|c|c|c|c|}
\hline & $\begin{array}{l}\vec{b} \\
\ddot{\bullet}\end{array}$ & 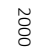 & 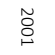 & $\begin{array}{l}\text { ్ } \\
\text { 옹 }\end{array}$ & 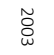 & $\begin{array}{l}\text { ㅇ } \\
\circ\end{array}$ & 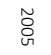 & 용 & 음 & $\tilde{\circ}$ & $\tilde{\circ}$ & $\begin{array}{l}\tilde{O} \\
\stackrel{\sigma}{\circ}\end{array}$ & $\underset{\stackrel{\sim}{\ominus}}{\stackrel{\sim}{\ominus}}$ & $\underset{\stackrel{N}{\sim}}{\stackrel{\sim}{\circ}}$ & $\underset{\stackrel{\sim}{\circ}}{\stackrel{\sim}{\omega}}$ & $\underset{\stackrel{\sim}{\circ}}{\stackrel{\sim}{\circ}}$ & $\begin{array}{l}\tilde{O} \\
\text { 㟧 }\end{array}$ & $\begin{array}{l}\tilde{O} \\
\text { ڤ̆ }\end{array}$ & $\stackrel{\widetilde{O}}{\stackrel{\Xi}{v}}$ \\
\hline Mszczonów & 0.36 & 0.49 & 0.51 & 0.52 & 0.44 & 0.53 & 0.51 & 0.54 & 0.51 & 0.51 & 0.44 & 0.42 & 0.43 & 0.39 & 0.41 & 0.42 & 0.45 & 0.45 & 0.49 \\
\hline Benchmarks & 0.42 & 0.37 & 0.36 & 0.34 & 0.39 & 0.35 & 0.39 & 0.41 & 0.37 & 0.37 & 0.42 & 0.42 & 0.42 & 0.38 & 0.41 & 0.40 & 0.39 & 0.40 & 0.36 \\
\hline Uniejów & 0.52 & 0.53 & 0.52 & 0.58 & 0.60 & 0.55 & 0.56 & 0.60 & 0.59 & 0.58 & 0.59 & 0.62 & 0.65 & 0.66 & 0.65 & 0.67 & 0.69 & 0.68 & 0.71 \\
\hline Benchmarks & 0.40 & 0.37 & 0.35 & 0.38 & 0.41 & 0.40 & 0.39 & 0.39 & 0.34 & 0.35 & 0.35 & 0.35 & 0.38 & 0.39 & 0.36 & 0.41 & 0.37 & 0.36 & 0.32 \\
\hline Poddębice & 0.61 & 0.58 & 0.57 & 0.53 & 0.51 & 0.54 & 0.55 & 0.45 & 0.57 & 0.51 & 0.50 & 0.63 & 0.63 & 0.63 & 0.61 & 0.65 & 0.66 & 0.69 & 0.66 \\
\hline Benchmarks & 0.48 & 0.46 & 0.54 & 0.52 & 0.50 & 0.53 & 0.52 & 0.48 & 0.48 & 0.48 & 0.49 & 0.52 & 0.50 & 0.53 & 0.50 & 0.49 & 0.50 & 0.53 & 0.57 \\
\hline Szaflary & 0.52 & 0.45 & 0.49 & 0.48 & 0.41 & 0.47 & 0.41 & 0.49 & 0.47 & 0.55 & 0.66 & 0.57 & 0.58 & 0.63 & 0.57 & 0.59 & 0.46 & 0.54 & 0.61 \\
\hline Benchmarks & 0.49 & 0.54 & 0.56 & 0.52 & 0.52 & 0.57 & 0.57 & 0.54 & 0.57 & 0.54 & 0.56 & 0.58 & 0.55 & 0.58 & 0.56 & 0.54 & 0.55 & 0.52 & 0.60 \\
\hline Bukowina Tat. & 0.71 & 0.65 & 0.77 & 0.61 & 0.60 & 0.65 & 0.68 & 0.73 & 0.67 & 0.70 & 0.68 & 0.77 & 0.80 & 0.75 & 0.84 & 0.88 & 0.98 & 0.85 & 0.86 \\
\hline Benchmarks & 0.49 & 0.49 & 0.49 & 0.46 & 0.50 & 0.46 & 0.52 & 0.48 & 0.43 & 0.47 & 0.48 & 0.50 & 0.48 & 0.51 & 0.51 & 0.52 & 0.53 & 0.57 & 0.52 \\
\hline Poronin & 0.70 & 0.62 & 0.61 & 0.66 & 0.65 & 0.68 & 0.60 & 0.64 & 0.72 & 0.67 & 0.65 & 0.72 & 0.67 & 0.64 & 0.64 & 0.65 & 0.68 & 0.66 & 0.67 \\
\hline Benchmarks & 0.49 & 0.47 & 0.47 & 0.49 & 0.51 & 0.49 & 0.45 & 0.45 & 0.45 & 0.48 & 0.45 & 0.47 & 0.51 & 0.46 & 0.52 & 0.45 & 0.48 & 0.49 & 0.51 \\
\hline Zakopane & 0.94 & 0.97 & 0.98 & 1.00 & 1.00 & 0.98 & 0.98 & 0.96 & 1.00 & 0.96 & 1.00 & 1.00 & 1.00 & 0.98 & 0.99 & 0.96 & 0.85 & 0.76 & 0.86 \\
\hline Benchmarks & 0.46 & 0.49 & 0.52 & 0,49 & 0.48 & 0.49 & 0.51 & 0.53 & 0.52 & 0.49 & 0.48 & 0.47 & 0.48 & 0.52 & 0.48 & 0.50 & 0.47 & 0.48 & 0.46 \\
\hline Biały Dunajec & 0.80 & 0.84 & 0.62 & 0.71 & 0.67 & 0.66 & 0.67 & 0.67 & 0.61 & 0.64 & 0.62 & 0.57 & 0.60 & 0.60 & 0.62 & 0.61 & 0.71 & 0.75 & 0.75 \\
\hline Benchmarks & 0.42 & 0.46 & 0.50 & 0.51 & 0.44 & 0.45 & 0.46 & 0.50 & 0.50 & 0.50 & 0.47 & 0.47 & 0.50 & 0.50 & 0.47 & 0.50 & 0.55 & 0.54 & 0.56 \\
\hline Grudziądz & 0.55 & 0.53 & 0.57 & 0.60 & 0.53 & 0.64 & 0.44 & 0.59 & 0.62 & 0.61 & 0.52 & 0.55 & 0.53 & 0.50 & 0.52 & 0.57 & 0.50 & 0.58 & 0.56 \\
\hline Benchmarks & 0.65 & 0.65 & 0.66 & 0.64 & 0.67 & 0.65 & 0.66 & 0.59 & 0.60 & 0.63 & 0.60 & 0.71 & 0.65 & 0.58 & 0.62 & 0.56 & 0.67 & 0.54 & 0.57 \\
\hline Pyrzyce & 0.61 & 0.62 & 0.57 & 0.62 & 0.57 & 0.51 & 0.55 & 0.61 & 0.62 & 0.54 & 0.43 & 0.48 & 0.46 & 0.39 & 0.54 & 0.45 & 0.46 & 0.45 & 0.61 \\
\hline Benchmarks & 0.57 & 0.56 & 0.54 & 0.56 & 0.50 & 0.53 & 0.56 & 0.60 & 0.61 & 0.64 & 0.64 & 0.62 & 0.62 & 0.63 & 0.65 & 0.65 & 0.62 & 0.59 & 0.59 \\
\hline Stargard & 0.47 & 0.53 & 0.46 & 0.51 & 0.46 & 0.50 & 0.46 & 0.45 & 0.46 & 0.51 & 0.52 & 0.47 & 0.45 & 0.47 & 0.45 & 0.39 & 0.42 & 0.48 & 0.45 \\
\hline Benchmarks & 0.56 & 0.57 & 0.56 & 0.55 & 0.60 & 0.59 & 0.60 & 0.56 & 0.59 & 0.53 & 0.58 & 0.56 & 0.55 & 0.57 & 0.55 & 0.58 & 0.58 & 0.50 & 0.56 \\
\hline
\end{tabular}

These $\mathrm{Cl}$ indexes are normalized to be used in the panel analysis. The next section discusses the results of panel modelling after the application of the model variables (see Table 3.1 and Table 3.5) to the model formula. The outcomes are expected to verify our hypothesis.

\subsection{Panel model robustness check}

Panel data econometrics attempts to address the research question if the geothermal exploitation parameters are significant in the municipality competitiveness model. Due to the composition of the data set and the observation of entities across the time, a balanced (full data set) and univariate panel model is used (Greene, 2000). The software GRETL is used to run the verification of model 1 and the model variables (Table 3.1), whereas the dependent variable $\mathrm{Cl}$ scores are collected in Table 5 . We examine the model using four scenarios of the composition of the independent variables. Cross validation of the selection of model variables in the four scenarios tests the sensitivity of the model and allows us to check the regression fit's robustness. Sensitive analysis is used with multivariate modelling in order to determine how independent variable values impact a particular dependent variable under a given set of assumptions (Chatterjee \& Hadi, 2009). 
Since we assume that municipality competitiveness is dependent on the exploitation of geothermal resources in terms of a geothermal recreational center or geothermal energy production, we introduce four panel models. The two static and the two dynamic scenarios identify the influential independent model parameters and help to validate the hypothesis. These simulations test if the relation between the competitive index and geothermal variables changes while employing additional independent variables to the model. The two dynamic panel models test if the assumption of the time lag better explains the effect of the geothermal variables on local competitiveness, since the geothermal GJ production increases over time and geothermal bathing centers or spas are long-term investments in a municipality. With reference to the panel model formula 1 , the summary of the simulations is enclosed in Table 3.6.

Table 3.6: Results of the estimation of the univariate parameters describing the impact of geothermal variables on the municipality competitiveness level, GRETL own elaboration.

\begin{tabular}{|c|c|c|c|c|c|c|}
\hline \multicolumn{7}{|c|}{ Model 1: geothermal and control variables, fixed in time $(\gamma=0), 209$ observations } \\
\hline \multicolumn{7}{|c|}{ Time series length=19 } \\
\hline \multicolumn{7}{|c|}{ Dependent variable: geot $\mathrm{Cl}$} \\
\hline & Stand $\beta$ & Coefficient & Std. Error & t-ratio & $p$-value & Sig. \\
\hline const & & 0.384258 & 0.101533 & 3.7846 & 0.0002 & $* * *$ \\
\hline geot spa & 0.184453455 & 0.068732 & 0.0274329 & 2.5055 & 0.0131 & $* *$ \\
\hline geot GJ & 0.360533707 & 7.81262e-07 & $1.29084 \mathrm{e}-07$ & 6.0524 & $<0.0001$ & $* * *$ \\
\hline benchmark Cl & 0.0363085 & 0.0788234 & 0.141606 & 0.5566 & 0.5784 & \\
\hline county income & 0.543747745 & 0.00090932 & 0.000290393 & 3.1313 & 0.0020 & $* * *$ \\
\hline county heat & -0.158056124 & -0.861717 & 0.814754 & -1.0069 & 0.2815 & \\
\hline
\end{tabular}

Model 2: geothermal and control variables, dynamic in time $(\gamma=1), 198$ observations Time series length $=18$ Dependent variable: geot $\mathrm{Cl}$

\begin{tabular}{lcccccc}
\hline & Stand $\beta$ & Coefficient & Std. Error & t-ratio & $p$-value & Sig. \\
const & & 0.237192 & 0.0982136 & 2.4151 & 0.0167 & $* *$ \\
geot spa & 0.195100347 & 0.0726993 & 0.0253881 & 2.8635 & 0.0047 & $* * *$ \\
geot GJ & 0.435171921 & $9.43651 \mathrm{e}-07$ & $1.23888 \mathrm{e}-07$ & 7.6170 & $<0.0001$ & $* * *$ \\
benchmark Cl & 0.00722578 & 0.0156867 & 0.13304 & 0.1179 & 0.9063 & \\
county income & 0.362484544 & 0.00060619 & 0.000270435 & 2.2415 & 0.0262 & $* *$ \\
county heat & -0.131774552 & -1.37994 & 0.767378 & -1.7983 & 0.1038 & \\
time lag & 0.309629192 & 0.35017 & 0.0600092 & 5.8353 & $<0.0001$ & $* * *$ \\
\hline
\end{tabular}




\begin{tabular}{|c|c|c|c|c|c|c|}
\hline \multicolumn{7}{|c|}{$\begin{array}{l}\text { Model 3: geothermal and control variables (no county incl.), fixed in time }(\gamma=0), 209 \text { observations } \\
\qquad \begin{array}{c}\text { Time series length }=19 \\
\text { Dependent variable: geot } \mathrm{Cl}\end{array}\end{array}$} \\
\hline & Stand $\beta$ & Coefficient & Std. Error & $t$-ratio & $p$-value & Sig. \\
\hline const & & 0.586737 & 0.0800365 & 7.3309 & $<0.0001$ & $* * *$ \\
\hline geot spa & 0.197449088 & 0.0735745 & 0.0280039 & 2.6273 & 0.0093 & $* * *$ \\
\hline geot GJ & 0.38200 & $8.28795 e-07$ & $1.31065 \mathrm{e}-07$ & 6.3235 & $<0.0001$ & *** \\
\hline benchmark $\mathrm{Cl}$ & -0.038635194 & -0.0838745 & 0.134686 & -0.6227 & 0.5342 & \\
\hline county heat & -0.035336501 & -0.370043 & 0.731449 & -0.5059 & 0.6135 & \\
\hline
\end{tabular}

\begin{tabular}{|c|c|c|c|c|c|c|}
\hline \multicolumn{7}{|c|}{$\begin{array}{c}\text { Model 4: geothermal and control variables ( } \text { no county incl.), fixed in } \\
\text { Time series length }=18\end{array}$} \\
\hline & Stand $\beta$ & Coefficient & Std. Error & t-ratio & $p$-value & Sig. \\
\hline const & & 0.358289 & 0.0829219 & 4.3208 & $<0.0001$ & $* * *$ \\
\hline geot spa & 0.204643717 & 0.0762554 & 0.0256171 & 2.9767 & 0.0033 & $* * *$ \\
\hline geot GJ & 0.45400 & $9.84034 \mathrm{e}-07$ & $1.23919 \mathrm{e}-07$ & 7.9410 & $<0.0001$ & $* * *$ \\
\hline benchmark $\mathrm{Cl}$ & -0.04247073 & -0.0922012 & 0.125393 & -0.7353 & 0.4631 & \\
\hline county heat & -0.049223659 & -0.515469 & 0.67072 & -0.7685 & 0.4432 & \\
\hline time lag & 0.32847115 & 0.371479 & 0.059903 & 6.2013 & $<0.0001$ & $* * *$ \\
\hline
\end{tabular}

Notes: 1$) * * *$ and $* * *$ denote $p<0.05, p<0.01$ and $p<0.001 .2)$ Stand $\beta$ stands for the standardized beta coefficient, according to the Goldberg equation, Kim \& Ferree (1981, p.189).

The four models examined reveal the significant relationship between the geothermal parameters of a geothermal spa and of geothermal GJ production, and the competitiveness index $\mathrm{Cl}$. Among the control variables, only the county income per capita results are significant in the proposed model. Yet, model 3 and 4 without this variable confirm the significant relation between the geothermal variables and the dependent variable $\mathrm{Cl}$. This variable is a considerably contributing factor to local competitiveness. However, our study shows that it is not a main determinant. The two other control variables are insignificant in the model. We can argue that local competitiveness in the case of the geothermal municipalities is not related to the amount of energy other sources deliver to a municipality. Moreover, the benchmark municipality competitive index in the model was insignificant. Among the four scenarios of municipality competitiveness, the models 2 and 4 with the lagged variable presents with a better quality. Interpretation confirm the assumption of a postponed impact of the geothermal investment on local economy. Table 3.7 captures the statistical quality of the four models. 
Table 3.7: Comparison of the statistical tests for the four panel models, GRETL own elaboration.

\begin{tabular}{lcccc}
\hline Stat. test & Model 1 & Model 2 & Model 3 & Model 4 \\
\hline LSDV R $^{2}$ & 0.267963 & 0.388263 & 0.230772 & 0.371282 \\
Within R & 0.253172 & 0.369326 & 0.215230 & 0.351819 \\
P-value (F) & $1.07 \mathrm{e}-07$ & $9.72 \mathrm{e}-13$ & $2.38 \mathrm{e}-06$ & $3.10 \mathrm{e}-12$ \\
Akaike criterion & -213.6834 & -237.8399 & -205.3262 & -234.4184 \\
rho & 0.294794 & -0.040573 & 0.325588 & -0.041071 \\
Durbin-Watson & 1.319759 & 1.981371 & 1.261327 & 1.985350 \\
Hausman test & $\chi^{2}(5)>20.2401$ & $\chi^{2}(6)>17.3994$ & $\chi^{2}(4)>9.59967$ & $\chi^{2}(5)>13.8017$ \\
& $\mathrm{p}=0.00112648$ & $\mathrm{p}=0.00792225$ & $\mathrm{p}=0.0477391$ & $\mathrm{p}=0.0169194$ \\
\hline
\end{tabular}

Results show that the best quality models according to the statistical tests are the dynamic models 2 and 4 . The instruments of the two tests are statistically valid, i.e. uncorrelated with the random component of the model. The $\mathrm{R}^{2}$ interpretation confirms the better fit of the two dynamic models. Static models 1 and 3 are of a lower quality, yet statistically justified. The results of the Hausman test indicate the correct model assumption of the variables' exogeneity and the fixed effects panel model fit. Low p-values count against the GRETL determined null hypothesis that the random effects model is consistent and support the fixed effects model choice.

The geothermal GJ are produced locally in the thousands, whereas a geothermal spa is either present or not in a municipality. Therefore, the analysis of these two variables coefficients is ambiguous. In addition, the units of all the model variables are distinct and have widely varying statistical means and variances, which hinders coefficient interpretation (each of the model variables is expressed in different units). In such a case, Kim \& Ferree (1981), Menard (2004) and Vittinghoff et al. (2011) advise regression coefficient standardization. Baguley (2009) argues that coefficient standardization raises statistical discussion. However, he accepts this procedure in the situation of metrics variety.

Standardization enables the comparison of the size of the impact of the model variables on the municipality competitive index. As a respective procedure, standardization does not change the statistical significance of the model variables. The standardized coefficient values estimate the strength of each predictor evaluated in identical metrics, i.e. in standard deviation units. Therefore, standardization observes how much of the $\mathrm{Cl}$ standard deviation changes when one of the model explanatory variables changes by one of its standard deviation. In the case of geothermal GJ production, we can observe a general impact of the variable on the competitiveness index (not an impact of 1 geothermal GJ on the competitiveness index). The standardized coefficient analysis indicates in the presented four models that the scale of the geothermal GJ production has a bigger impact on the examined municipality competitiveness than a geothermal recreational center. Although in all four scenarios, both geothermal variables are significantly related to the municipalities' competitive index. 
From the comparison of the four models, we conclude that the dynamic models 2 and 4 are the best fit for the methodological concept of our study. The interpretation of the best model with the strongest coefficients value points (model 4) indicates that while the parameter of geothermal GJ production changes by one standard deviation, it results in a 0.45 change in the standard deviation of the municipality competitiveness index. In the case of the geothermal spa parameter, its increase by one standard deviation causes a 0.20 increase of the $\mathrm{Cl}$ variable standard deviation. In addition, the standardization of coefficients confirms no statistical significance of the control variables in the models. Although a statistical relation is observed between the competitiveness index and the county income control variable, we may reject it as a core component of the geothermal municipality competitiveness. No significant change is observed among the four models if this variable appears in the model or not. Observation of the model outcomes corroborates the hypothesis that geothermal energy exploitation in our model approach has a positive effect on the municipality competitiveness indicators.

\subsection{Discussion and conclusions}

This research attempts to discover if geothermal resources exploitation contributes to municipality competitiveness. We test the statistical relation between the parameters of geothermal exploitation in Poland and municipality competitiveness that we conceptualized. Our hypothesis states that the exploitation of the geothermal resources as the geothermal heat production and the establishment of geothermal recreational centers positively impacts municipality competitiveness. The hypothesis is tested using panel data econometrics. In order to verify the hypothesis, 11 municipalities in Poland are selected according to the criteria of statistical relevance for the panel analysis. Municipality competitiveness is represented by the competitiveness index $(C l)$, which is determined by the expert Analytical Hierarchy Process method.

We develop a panel model, where the local competitiveness index is tested in relation to the geothermal parameters and appointed control variables to exclude the biased interpretation of the geothermal predictors. The selection of the model variables is rooted in the argument of this study and aims to tackle the phenomenon of local geothermal exploitation. Using static and dynamic panel regressions, we examine whether the selection of variables is dependent on the model specification. As the sensitive analysis, we run four model scenarios to support the hypothesis verification. For the better quality of analysis the control variables are employed. Application of the developed model formula delivers robust results. Regardless of the higher statistical quality of the dynamic models, the analysis leads to one conclusion. In all four simulations, the geothermal variables, e.g. recreational bathing centers and GJ production, have a significant and positive impact on the developed municipality competitiveness index. Statistical significance of the appointed lagged variable stipulates that the effects of local geothermal exploitation are delayed. As such, the level of the competitiveness index for a municipality from a previous period generates the current level of 
the $\mathrm{Cl}$. Therefore, we argue that the benefits of geothermal resource usage in a municipality intensify with time.

Coefficient standardization is applied in order to observe an impact of each of the geothermal predictors on the competitiveness index. The results obtained for the standardized coefficients support the significant role of geothermal energy production and geothermal recreational centers in enhancing the municipality competitiveness. Whereas, the results of the control variables suggest that except for county income per capita, they do not significantly affect municipality competitiveness. The comparison of the county level control variables shows that the competitiveness of the examined municipalities does not follow the financial condition of the region (county). However, the county income per capita is important in two model scenarios. We can argue that a reverse effect of the local geothermal exploitation on the county where the municipality is situated occurred. The geothermal centers with accompanying services generate various revenues to the local and regional budgets. Further research is needed about the level of financial impact of geothermal centers on public budget and relation with the competitiveness indicator. Yet, it does not affect the conclusions of this study, all of the models display a relationship between the geothermal parameters and the competitiveness level. As well, the county heat energy provision through sources that are not geothermal is insignificant in the model. Therefore, we observe a significant role of geothermal energy activities in the municipalities and their competitiveness is not related with any energy resources, but geothermal explicitly. The benchmark municipality competitiveness index displays no relation with our model structure. It is introduced in the model to exclude the general trend of the competitiveness (regional or national trends) in the tested municipalities. Hence, the model results suggest that it is the geothermal resource that significantly impacts the local competitiveness. It also corroborates the hypothesis.

Following the model outcomes, we conclude that in terms of the proposed selection of Polish geothermal municipalities, the exploitation of the endogenous geothermal resources is an element in their competitiveness structure. Model observations justify the conclusion that a municipality's competitiveness improves with an increased use of the available geothermal energy produced in local geothermal plants and with the establishment of geothermal recreational centers. As endorsed by Porter in his study on geothermal competitiveness (Porter, 2010), local geothermal exploitation in Poland fits in the context of the endogenous growth principle. However, until now a relatively small number of Polish municipalities make use of the available geothermal resources irrespectively of the geothermal use potential. Our results deliver an argument for further consideration of developing the geothermal resources in Poland. 
Chapter 4

Measuring local competitiveness: comparing and integrating two methods PCA and AHP 


\section{Abstract ${ }^{11}$}

This chapter discusses two methods to measure the concept of local competitiveness: Principal Component Analysis (PCA) and Analytical Hierarchy Process (AHP). The goal of this analysis is to determine whether these two methods used in scientific research lead to comparable model results. By non-parametric tests it is shown that there is a significant correlation between the PCA and AHP local competitiveness indexes. Thereafter, a developed mixed method examination of whether the methods can be used interchangeably is presented and illustrated with detailed examples of two mixed approaches. The mixed method confirms the correlation between the PCA and AHP models. However, the mixed modelling results indicate the utility of the PCA in the situation of a multicriteria local competitiveness data examination.

11 Chapter is under consideration at a peer reviewed international scientific journal as: Kurek, K. A., Heijman, W., van Ophem, J., Gędek, S., \& Strojny, J. (2021). Measuring local competitiveness: comparing and integrating two methods PCA and AHP. 


\subsection{Introduction}

The choice of a research method is determined by the type of data or its collection systems. The mixed method approach depends on the type of the study's research question and moreover reflects on the subjective and objective knowledge of the research problem according to Tashakkori \& Teddlie (2010). Sharp et al. (2012) point to the advantage of mixed methods in mostly in decision making process studies. A multicriteria decision-making method in its principle analyses sets of variables simultaneously on different observations. This paper tackles the concept a local competitiveness model, presented in the thesis chapters (Kurek et al. 2020b and Kurek et al. 2020a), referred further as Chapter 2 and Chapter 3. Two multifactor methods i.e. Principal Component Analysis (PCA) and Analytical Hierarchy Process (AHP) were applied to build a local competitiveness models in both studies. These procedures led to the establishment of local competitiveness indexes for the analyzed municipalities in Poland, which were used for further econometric analysis. In this article we focus on the structure of the local competitiveness models developed by the PCA and AHP methods. Both the PCA and AHP methods enabled the computation of a singular competitiveness index, which measures the level of local competitiveness. This index allows for the observation of trends in development over time, and the comparison of competitiveness levels among the sampled municipalities. Approaches to a single competitiveness index used in regional and local studies can be found in works by: Huovari et al. (2002), Plummer et al. (2014), Huggins (2003), Ozaslan et al. (2006), Bronisz et al. (2008), Bulu (2011), Dijkstra et al. (2011), Lengyel \& Rechnitzer (2013), Makštutis at el. (2012), Sáez \& Periáñez (2015), Trisnawati et al. (2008), with attention given to the weighting system decisive to the model outcome.

An essential element of regional competitiveness is the presence of natural resources (Gross \& Ringbeck, 2008; Porter, 2004, 2008; Rutkauskas, 2008) that allow for infrastructural development (Camagni \& Capello, 2013; Eskelinen, Hannibalsson, Malmberg, Maskell, \& Vatne, 2002; Palei, 2015). It supports our research assumption about the positive relation between local competitiveness and geothermal resources in Chapter 2 (Kurek et al. 2020a) and Chapter 3 (Kurek et al. 2020b). Nevertheless, the literature does not point to one exclusive approach in defining local competitiveness. In the two studies about the impact of geothermal resources on local competitiveness, we developed two approaches to construct a local competitiveness index, a PCA and a AHP model. Both indexes were based on the same indicator's dataset input, i.e. secondary data collected from the same statistical data source. Still, the value of the indexes delivered by the PCA and AHP differ due to the weight structures that each method employs.

Although there are various techniques for normalizing multicriteria criteria and determining their weights, the construction of a local indicators-based model in the referenced geothermal papers has been tackled by two methods that are different in nature. The PCA, as a multivariate analysis, built the local model by transforming indicators without losing information and by 
identifying new variables with greater meaning. As a multicriteria decision-making method predominantly qualitative, the AHP evaluated the local indicators by asking experts and applied priority scales into the construction of the model. Yet, both techniques result in a weights model applicable to the criteria that are examined.

The research question of this study is how comparable are the results yielded by the PCA and AHP methods in the situation of secondary data? We draw this research question from applying the two approaches to the similar problems in the both referred studies. The two models based on the same socioeconomic secondary data delivered two indexes i.e. the measures of local competitiveness or development. A statistical comparison of these rankings constitutes the core analysis of this paper. By using statistical procedures, we aim to methodically determine whether PCA and AHP results are comparable, or whether the methods can be used interchangeably for a phenomenon of socioeconomic data. This comparison of both methods is legitimate if we find a significant relationship between the results obtained by the PCA and AHP. To explore the comparison, we propose mixed weights modelling, which is an experimental method in the context of our research problem and the methods' specificities. Such a practical approach is not yet found in the existing methodological literature and related socioeconomic studies.

The theoretical framework of this work sits in the nature of the epistemology. This discipline is driven by the process of knowledge and seeking validation for already known ideas. In its variation, it also discusses the criteria to corroborate a concept (Bunge, 2001). Modern interpretation of epistemology in social sciences includes areas of research methods and methodology. Throughout the analysis the research question is addressed by the justification of the methods selection and the results. The design of a mixed method refers to the motivation for their integration and to the so-called pragmatic epistemology. In this article, the purpose for integration derives from the data structure and assumed convergent findings delivered by the two methods. Moreover, the motivation behind developing the mixed methods approach is also influenced by the paradigm of choices emphasized by Patton (1990). His concept refers to the choice of a research method determined by the type of research problem rather than by methodological appropriateness. In this way, the mixed methods approach serves for better analysis of the core of our study, i.e. the comparison of two multicriteria methods with different assumptions. According to the paradigm of choices, the research question and context dictate the choice of appropriate techniques and the degree of mixing methods in order to be able to answer the research question, argues Mason (2006).

This introduction explaining the purpose of the study is followed by the presentation of the developed local competitiveness models. Then, the analysis of the models takes place. Next, the used methods are explained. The new, mixed approach of presenting two mixed models is proposed further with the section on outcomes testing. A section with conclusions and discussion closes this chapter. 


\subsection{The PCA and AHP local competitiveness models}

The form of a competitiveness model is dependent on the composition of the variables that build it. Thus, the selection of the competitiveness variables is a decision-making process. It mainly concerns the dataset that is available and comparable at the given level and at the same time reflects its competitive performance. In the case of our research problem, the dataset had to reflect the local competitiveness indicators at the municipality level. The models of local competitiveness in Chapter 3 concerned a selection of municipalities in Poland. This full group of municipalities was conditioned by the research assumptions in the two studies and limited to 63 municipal units in Poland. The concept of local competitiveness model followed the local competitiveness definition of Storper (1997) that points at the local potential of sustaining an attractive and stable environment for market growth and providing standards of living for those who participate in it. Therefore, the design of the indicators model encompasses socioeconomic data representing local economic condition and development potential. Local socioeconomic data used in Chapter 2 and Chapter 3 is collected from a homogenous source - the Local Data Bank, which is a section of the Central Statistical Office in Poland ${ }^{12}$ at the level of NUTS $5^{13}$ for the years 1995-2017. This source allowed for the assurance of data coherency and comparability for the observed municipalities. From the available and coherent socioeconomic data, the local competitiveness indicators were constructed in theoretical reference to work of: Malecki (2004), Olewiler (2006), Pires et al. (2014), Scipioni et al. (2009) and Strojny (2015). Hence, Table 4.1 depicts the indicators that compose the local competitiveness model used in both studies.

Table 4.1: Categories and indicators of local competitiveness model, Kurek et al. (2020a) and Kurek et al. (2020b).

\begin{tabular}{|c|c|c|c|c|c|}
\hline \multicolumn{6}{|c|}{ categories } \\
\hline $\begin{array}{l}\text { Population } \\
\qquad\left(C_{p}\right)\end{array}$ & $\begin{array}{c}\text { Local } \\
\text { Economy } \\
\left(C_{e}\right)\end{array}$ & $\begin{array}{c}\text { Local } \\
\text { government }\left(C_{g}\right)\end{array}$ & Tourism $\left(C_{t}\right)$ & Infrastructure $\left(C_{i}\right)$ & Level of life $\left(C_{1}\right)$ \\
\hline \multicolumn{6}{|c|}{ subcategories } \\
\hline $\begin{array}{c}\text { Internal } \\
\text { migration } \\
\left(C_{p} 1\right)\end{array}$ & $\begin{array}{c}\% \text { of } \\
\text { employed } \\
\text { inhabitants } \\
\left(C_{e} 1\right)\end{array}$ & $\begin{array}{c}\text { Own } \\
\text { municipality } \\
\text { income per } \\
\text { inhabitant }\left(\mathrm{C}_{\mathrm{g}} 1\right)\end{array}$ & $\begin{array}{c}\text { Polish tourists } \\
\text { accommodated } \\
\text { per } \\
1000 \text { inhabitants } \\
\left(C_{t} 1\right)\end{array}$ & $\begin{array}{c}\text { Water } \\
\text { consumption for } \\
\text { industrial and } \\
\text { domestic purpose } \\
\text { per inhabitant } \\
\left(C_{i} 1\right)\end{array}$ & $\begin{array}{c}\text { Outpatient } \\
\text { health care } \\
\text { facilities per } \\
10.000 \\
\text { inhabitants } \\
\left(C_{\mid} 1\right)\end{array}$ \\
\hline
\end{tabular}

\footnotetext{
12 Selection of available and consistently collected socioeconomic indicators sourced in the Local Data Bank of Central Statistical Office of Poland.

${ }^{13}$ NUTS is the Eurostat's Nomenclature of Territorial Units for Statistics. In Poland, NUTS 5 corresponds with the municipal administrative unit.
} 


\begin{tabular}{|c|c|c|c|c|c|}
\hline $\begin{array}{c}\text { Natural } \\
\text { increase } \\
\left(C_{p} 2\right)\end{array}$ & $\begin{array}{c}\text { No. of } \\
\text { private } \\
\text { economic } \\
\text { activities } \\
\left(\mathrm{C}_{\mathrm{e}} 2\right)\end{array}$ & $\begin{array}{c}\text { Municipality } \\
\text { investment } \\
\text { expenses per } \\
\text { inhabitant }\left(C_{g} 2\right)\end{array}$ & $\begin{array}{c}\text { Foreign tourists } \\
\text { accommodated } \\
\text { per } \\
1000 \text { inhabitants } \\
\left(C_{t} 2\right)\end{array}$ & $\begin{array}{l}\text { Dwellings } \\
\text { delivered per } 100 \\
\text { inhabitants }\left(C_{i} 2\right)\end{array}$ & $\begin{array}{c}\text { Environmental } \\
\text { protection } \\
\text { investment per } \\
\text { inhabitant }\left(\mathrm{C}_{1} 2\right)\end{array}$ \\
\hline $\begin{array}{l}\% \text { of the } \\
\text { population } \\
\text { with a } \\
\text { productive } \\
\text { age }\left(C_{p} 3\right)\end{array}$ & $\begin{array}{c}\text { No. of } \\
\text { national } \\
\text { commercial } \\
\text { companies } \\
\left(C_{e} 3\right)\end{array}$ & $\begin{array}{l}\text { PIT income per } \\
\text { employed } \\
\text { inhabitant }\left(C_{g} 3\right)\end{array}$ & $\begin{array}{c}\text { Tourism } \\
\text { accommodation } \\
\text { establishments } \\
\text { per } 1000 \\
\text { inhabitants }\left(C_{t} 3\right)\end{array}$ & $\begin{array}{c}\text { km of water } \\
\text { network and } \\
\text { canalization per } \\
\text { inhabitant }\left(\mathrm{C}_{\mathrm{i}} 3\right)\end{array}$ & $\begin{array}{c}\text { Primary and } \\
\text { lower } \\
\text { secondary } \\
\text { education } \\
\text { expenses per } \\
\text { pupil }\left(\mathrm{C}_{1} 3\right)\end{array}$ \\
\hline $\begin{array}{l}\text { Live births } \\
\qquad\left(C_{p} 4\right)\end{array}$ & $\begin{array}{l}\text { No. of } \\
\text { commercial } \\
\text { companies } \\
\text { with foreign } \\
\text { capital }\left(C_{e} 4\right)\end{array}$ & $\begin{array}{l}\text { Budget deficit } \\
\qquad\left(C_{g} 4\right)\end{array}$ & $\begin{array}{l}\text { Overnights spent } \\
\qquad\left(C_{t} 4\right)\end{array}$ & $\begin{array}{l}\text { Water system } \\
\text { connections } \\
\text { leading to } \\
\text { residential } \\
\text { buildings and } \\
\text { residences for } \\
\text { communities per } \\
\text { inhabitants }\left(\mathrm{C}_{i} 4\right)\end{array}$ & $\begin{array}{l}\text { Population } \\
\text { connected to } \\
\text { wastewater } \\
\text { treatment } \\
\text { plants }\left(C_{1} 4\right)\end{array}$ \\
\hline
\end{tabular}

This model pursued by the PCA and AHP methods resulted in the local competitiveness indexes that we aim to compare. As discussed, although the input model data was the same in both studies, we obtained different values of the local competitiveness indexes. The PCA and AHP indexes values and the data they are built of is stored in the Mendeley data repository with a detailed explanation (Kurek, 2020).

Hence, the element that differentiated these results is the weights that both methods yield in reference to the model indicators. These weights constitute the system decisions about the importance of each of the competitiveness indicators, that were further synthetized in the form of an index. Where the PCA as a factor analysis regrouped the original structure of the local competitiveness model (Table 4.1), the AHP expert method did not change its presumed structure (Table 4.1). Experts followed the given model, assessing the weights according to their own judgements. Tables 4.2 and 4.3 present the obtained weights of the local competitiveness indicators from each method. The labels of the indicator's weights refer to the classification indicators from Table 4.1. 
Table 4.2: The AHP computed municipality competitiveness indicators weights model, Kurek et al. (2020a).

\begin{tabular}{|c|c|c|c|c|c|}
\hline \multicolumn{6}{|c|}{ weights of categories } \\
\hline$* w C_{p}=0.14$ & $w C_{e}=0.24$ & $w C_{g}=0.12$ & $w C_{t}=0.17$ & $w C_{i}=0.19$ & $w C_{1}=0.14$ \\
\hline \multicolumn{6}{|c|}{ weights of subcategories } \\
\hline$w C_{p} 1=0.26$ & $w C_{e} 1=0.23$ & $w C_{g} 1=0.16$ & $w C_{t} 1=0.26$ & $w C_{i} 1=0.16$ & $w C_{1} 1=0.18$ \\
\hline$w C_{p} 2=0.28$ & $w C_{e} 2=0.22$ & $w C_{g} 2=0.40$ & $w C_{t} 2=0.28$ & $w C_{i} 2=0.36$ & $w C_{12}=0.27$ \\
\hline$w C_{p} 3=0.25$ & $w C_{e} 3=0.30$ & $w C_{g} 3=0.24$ & $w C_{t} 3=0.19$ & $w C_{i} 3=0.26$ & $w C_{13}=0.34$ \\
\hline$w C_{p} 4=0.21$ & $w C_{e} 4=0.25$ & $w C_{g} 4=0.20$ & $w C_{t} 4=0.27$ & $w C_{i} 4=0.22$ & $w C_{14}=0.21$ \\
\hline
\end{tabular}

*w-weight, C-category

Table 4.3: The PCA computed municipality competitiveness indicators weights model, Kurek et al. (2020b)

\begin{tabular}{|c|c|c|c|c|c|c|c|}
\hline \multicolumn{8}{|c|}{ principal components } \\
\hline${ }^{*} w C 1=0.27$ & $w C 2=0.17$ & $w C 3=0.15$ & $w C 4=0.08$ & $w C 5=0.09$ & $w C 6=0.09$ & $w C 7=0.08$ & $w C 8=0.07$ \\
\hline \multicolumn{8}{|c|}{ factor loadings } \\
\hline$w C_{p} 4=0.11$ & $w C_{g} 3=0.49$ & $w C_{t} 1=0.35$ & $w C_{p} 1=0.30$ & $w C_{p} 2=0.64$ & $w C_{g} 2=0.44$ & $w C_{p} 3=0.77$ & $w C_{t} 4=0.34$ \\
\hline$w C_{e} 1=0.11$ & $w C_{1} 3=0.51$ & $w C_{t} 2=0.30$ & $w C_{i} 2=0.28$ & $w C_{i} 3=0.36$ & $w C_{g} 4=0.56$ & & $w C_{i} 1=0.31$ \\
\hline$w C_{e} 2=0.13$ & & $w C_{t} 3=0.35$ & $w C_{i} 4=0.42$ & & & & $w C_{1} 2=0.35$ \\
\hline \multicolumn{8}{|l|}{$w C_{e} 3=0.15$} \\
\hline \multicolumn{8}{|l|}{$w C_{e} 4=0.14$} \\
\hline \multicolumn{8}{|l|}{$w C_{g} 1=0.12$} \\
\hline \multicolumn{8}{|l|}{$w C_{1} 1=0.09$} \\
\hline$w C_{1} 4=0.15$ & & & & & & & \\
\hline
\end{tabular}

${ }^{*}$ w-weight, C-component

We observe that the PCA restructured the Table 4.1 local competitiveness model by regrouping the indicators into eight principal components. The original structure of the proposed model is kept in the AHP method's weights assessment. Therefore, the composition of weights is here the main determinant of the proposed local competitiveness model in both studies. Since the two local competitiveness indexes do not represent a normal distribution, their comparison refers to non- parametric testing. As our study aims to find out how the results delivered by both methods are comparable, we seek correlations between them. We propose to address the study objective by testing ranking correlations of the 63 municipalities built according to the PCA and AHP competitiveness index scores. The municipalities are the geothermal municipalities and associated benchmark municipalities introduced in Chapter 3. Creating rankings due to the index score is the preferred approach since local competitiveness is not 
measured at an absolute level. This arrangement allows for the comparison of the relative position of a municipality observation in the ranking due to the index score. The index value itself does not indicate the competitiveness of a municipality.

Considering the difference in the local competitiveness model design and in order to compare the methods, we test the correlations between the two competitiveness indexes. The correlations are to indicate the assumed convergence of indexes. Using correlations, we are able to measure the degree to which the two indexes move in relation to each other i.e. their association. We do not seek causal relationship between the local competitiveness indexes, but an observation as to whether and how strongly the two index variables are related. In the case of an acceptable correlation, it can be assumed that the methods can be used interchangeably when examining local competitiveness. The next section discusses the results of correlation testing that use average competitiveness indexes as the model variables.

\subsection{Comparison of the PCA and AHP local competitiveness models}

The examination of the correlation between the two local competitiveness indexes answers the research question about the comparability of the two methods, in the case of a determined set of local socioeconomic indicators used for the local competitiveness models. Therefore, the testing is intended to determine the strength of the assumed relation between the PCA and AHP generated models. The two competitiveness indexes of the examined 63 municipalities, calculated for the years 1995-2017 do not represent the normal distribution (see Kurek, 2020). Hence, the interpretation about the municipalities' competitiveness includes a relative competitive position within the range of municipalities. The local competitiveness indexes of the municipalities cannot be interpreted numerically. The interpretation lies in comparing the value of the indexes within the selected batch of municipalities on an ordinal scale. That is why the non-parametric tests ranking the municipalities' competitiveness indexes can answer our research problem. However, for the purpose of our testing we apply the final rankings of the selected 63 municipalities according to PCA and AHP, built as an average ranking position for the observed period 1995-2017. The compilation of the rankings of average municipal competitiveness are presented in the dedicated dataset (Kurek, 2020).

Siegel (1957) discusses the usefulness of the non-parametric tests for cases of ordering, classification, or rankings. Non-parametric methods, unlike classical statistical methods, do not need to estimate the parameters of a predetermined random variable distribution in the population. The non-parametric model's robustness requires a larger sample size to draw conclusions with the same degree of confidence. Moreover, non-parametric models differ from parametric ones in that the model structure is not specified a priori but is instead determined from the data type (Anderson, 1961). This is illustrated by our two cases of local competitiveness models, which depend on the determined data selection. To express the correlation between two variables, a correlation coefficient is calculated. The three most 
common non-parametric correlation coefficients are: Spearman's R, Kendall's tau and Gamma (Bagdonavicius et al. 2013). When calculating Spearman's R, it is assumed that the considered variables were measured at least on the ordinal (ranked) scale, i.e. that individual observations can be arranged in two ordered series. The statistical power of Kendall's tau is similar to Spearman's R coefficient. However, the values of both coefficients usually do not coincide, because their logical foundations and calculation formulas differ significantly. Siegel \& Castellan (1988) express the relationship between these two measures in the form of inequalities: $-1 \leq 3$ *Kendall's tau - 2 *Spearman's $R \leq 1$. More importantly, these coefficients have different interpretations. Spearman's R coefficient can be treated similarly to Pearson's linear correlation coefficient, i.e. in terms of the percentage of variability explained. The difference is that Spearman's $R$ is calculated based on rank, whereas the Kendall's tau coefficient is based on the probability, i.e. the difference between the probability, that two variables are in the same order within the observed data and the probability that their order is different. In our examination we chose Kendall's tau-c for the correlations interpretation since it is used for rectangular tables and adjusts for tied ranks. Using the SPSS software version 25 we run the non-parametric correlation test for the local competitiveness indexes (stored in Kurek, 2020) yielded by the PCA and AHP methods. The SPSS analysis includes the nonparametricity coefficients. Table 4.4 presents the test results.

Table 4.4: Cross tabs correlation calculation for the PCA and AHP local competitiveness indexes rankings, SPSS stats 25 own elaboration.

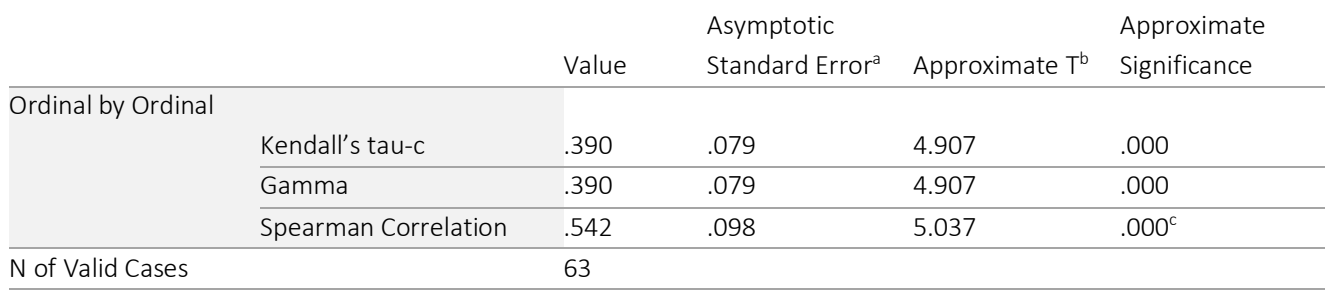

a. Not assuming the null hypothesis.

b. Using the asymptotic standard error assuming the null hypothesis.

c. Based on normal approximation.

We observe that the two distributions are acceptably correlated. Therefore, the rankings obtained by the PCA and AHP methods are correlated according to the correlation coefficients scores. The quantitative relationship between the variables is statistically significant. These two methods that are different from each other in the assumptions and procedures show a clear correlation between the results obtained. We studied the same multivariate phenomenon of local competitiveness through the PCA and AHP procedures, which proved to be related to each other. Due to the obtained research results and their convergence, we argue that both methods can be used to analyze the multicriteria concept of local competitiveness. Thus, both decision-making methods are accepted in this comparative analysis. Although the PCA and AHP models used the same dataset, the weight system of each method is nevertheless responsible 
for the yielded correlation level. The next section analyses the weights generation in the principles of the PCA and AHP method. A mixed weights experiment is then carried out.

\subsection{The local competitiveness index by the PCA and AHP methods}

A multiple criteria research problem requires the identification and weighting of the criteria to allow research topics to be ranked on the basis of a composite score (Horton et al., 1993). These weights are further used to calculate a single measure of the overall contribution of each indicator to a combined set of objectives. Huggins (2003) points to the importance of weights in creating a competitiveness index. Weights represent their relative effectiveness as a performance measure, in particular illustrating the interrelationships between the input data and output indicator value. In both our model scenarios, the weights are determined by the PCA and AHP procedures (see Table 4.2 and Table 4.3). These weights models processed with the data of the Table 4.1 indicators deliver the synthetic local competitiveness index (see Kurek, 2020). Despite the same input data, the difference in the two index values is explained by the different weights models generated by the two methods. Therefore, the acceptable level of correlation of the PCA and AHP local competitiveness indexes (Table 4.4) results from the methods' assumptions regarding the weighting system.

\subsubsection{Principal Component Analysis local development indicator}

As a multifactor analysis, the Principal Component Analysis is particularly suited to examine a set of correlated variables in socioeconomic studies (Fabrigar \& Wegener, 2011; Jolliffe, 1986; Taherdoost, Sahibuddin, \& Jalaliyoon, 2014; Vyas \& Kumaranayake, 2006). The PCA represents a method that normalizes the data through compromise, further decomposing the data concentration into a set of new orthogonal variables i.e. the principal components ordered by the amount of variance that each component explains (Abdi \& Williams, 2010; Govaert, 2013). The observation on each component is called the factor score and refers to the weight of a component in the new composition of the dataset. They are ordered by the amount of variance that each component explains. Further on, the method generates a coefficient by which each standardized original variable should be multiplied to get the component score - so-called factor loading. Therefore, the PCA weights model refers to the correspondence between the heterogenous sets of variables i.e. the importance of a dimension. Abdi et al. (2013) explain in detail the PCA procedure of multicriteria data integration, with attention given to the weighting mechanism proposed by this method. In Chapter 2 (Kurek et al., 2020b), the PCA computation (using the SPSS version 22), which includes the loadings of components exceeding the acceptable value of 0.5 , varimax with Kaiser rotation, and explained variance larger than $60 \%$ results in establishing the main components of the model for each of the tested municipalities. All of the Table 4.1 model variables met these assumptions, therefore the PCA analysis accepted all the 24 indicators. For each component and its variables, the PCA assesses the weights, i.e. the loadings, as well. Next, a standardized sums formula is applied. The formula is based in the aggregation procedure of the normalized competitiveness 
indicators from Table 1 applied to the PCA generated weights model of Table 4.3. As a normalization approach, the zero unitarization method (Kukula \& Bogocz, 2014) was applied. Therefore, the Formula 1 takes a form of:
$C l=\sum^{n} w C_{i}=w C_{i}\left(\sum_{i=1}^{n} w_{i} C i\right)$
$(1)$ where:
$\sum_{i=1}^{n} W_{i}=1$
(2) and $\sum^{n}{ }_{i=1} W_{i} i=1$
$w C_{i}$ - weight of the component
$w_{i} C i$ - weight of the loading
$i=1, \ldots, N$ (observation)

The application of the Formula 1 yields the synthetic local development indicator values presented in Kurek (2020), with an average score shown for each of the examined 63 municipalities. The index takes a value [0-1], where 1 is the highest value. Such a values arrangement generated by the method allows for further comparison techniques.

\subsubsection{Analytical Hierarchy Process local competitiveness index}

In Chapter 3 (Kurek, 2020a), we operationalize local competitiveness with the help of experts. The Analytical Hierarchy Process created in the '70s by Saaty is popular among the multicriteria decision-making methods (MCDM) with particular applications in assessing socioeconomic and management problems (Linkov \& Moberg, 2011; Saaty, 1988, 2000; Subramanian \& Ramanathan, 2012). The benefits of engaging experts from the examined scientific subject are addressed in the works of Boulanger \& Bréchet (2005), Cox et al. (2000), Kil et al. (2016), and Strojny (2016) among others. The AHP procedure is based on a hierarchical modelling of the criteria and their sub criteria. Experts evaluate their relationship in pairs using the Saaty's 1-9 scale. On the basis of the significance analysis in a given pair made by experts, the weight of a particular indicator is assigned. An important element of the method is also the consistency of the comparison in the matrix determined by the Consistency Ratio coefficient (CR), where the internal consistency of experts' judgements is checked. We used the dedicated AHP software Super Decisions (version 3.2) to accept or reject the weighting of given indicators while considering the CR score. Work of Kurek et al. (2020c) presents the AHP tool that was distributed to the experts, presented in the Appendix. Resulting from the pair-wise comparisons, each model element receives a weight, specifically the weight of the model category (global), $w_{i}$, and the subcategory indicator weight (local), $w_{i} i$. The experts' judgements decompose the problem to a reciprocal matrix (KxK) of $P$ criterions where numbers in each criterion pair $\mathrm{p}_{\mathrm{i}}$ and $\mathrm{p}_{\mathrm{j}}$ to represent a ratio $\left(\mathrm{p}_{\mathrm{i}} / \mathrm{p}_{\mathrm{j}}\right) / 1$ (Oddershede, Arias, \& Cancino, 2007; Saaty, 1988). According to the AHP methodology, weights in each category sum up to 1 (or $100 \%$ ) since the elements from the same level are compared and weighted relative to each other. Therefore, a weight is interpreted from the significance of an indicator in the experts' opinion. Table 4.2 illustrates the obtained weights for the Table 4.1 municipality indicators. The same aggregation procedure of Formula 1 as in the PCA weight model was used, resulting in the normalized local competitiveness indexes for the 63 examined municipalities. They place in the 
0-1 range, where 1 represents the highest score of a municipality competitiveness throughout the observed time period. The dataset (Kurek, 2020) contains the set of these indexes as well as the average score of the local competitiveness indexes from the observed period that is used in our testing.

\subsection{PCA and AHP structure modelling characteristics}

Where the PCA method seeks covariance between a practically unrestricted number of components, the AHP technique uses pair-wise relative comparison between each model indicators. Due to this fact, the AHP weights assignment is more complicated if the quantity of indicator pairs increases. Additionally, assessing experts as per the method requirement is the subjective decision of a scholar that decides to use the AHP (Ishizaka \& Labib, 2009; Maletič et al., 2016). The AHP method is particularly useful in the case of data inconsistency (Hartwich, 1999) and in ranking alternatives regarding the criteria of social and sustainable development aspects (Alphonce, 1997); but it does not have inbuilt techniques to indicate an optimal model structure. Therefore, the AHP permits assumptions, whereas the PCA in its rigorous, statistical procedure eliminates the inconsistent model elements (Palese, 2018). It indicates that the AHP method follows a presumed data or problem structure (Macharis et al., 2004). It is opposite to the PCA, which decomposes a data model (Abdi et al., 2013) and its ability to rotate simplifies and restructures a model (Kim et al., 1978). The different approaches to the hierarchization of the two model's components and their weights accordingly, can explain the moderate results of the local competitiveness indexes correlations (Table 4.4). This observation provides room for a mixed method experiment that is based in the strengths of both methods and their weaknesses of weighting model indicators, and at the same time explores the obtained correlation results. In this paper, we seek an answer to the question of whether the results of both methods deliver comparable knowledge about a given phenomenon. The proposition of mixed modelling can support analyzing the role of the weights structures that the PCA and AHP deliver.

\subsection{Integration of the PCA and AHP methods}

As discussed, the decision about the local competitiveness model composition in the case of the two presented methods lies in the weights assessment procedure. The relationship found in Table 4 warrants further examination. We further explore the specifics of the two methods and introduce a mixed approach. This solution is applied as a cross check of the magnitude of the PCA and AHP weights models. The proposed mixed method local competitiveness model is to be validated using the same non-parametric testing. The new approach aims at finding out how the structure of both models impacts the obtained correlation results (Table 4.4). Moreover, the integration experiment intends to compare the weights structures delivered by either the statistical operations of the PCA or the ex-ante modelling of the AHP method.

The integration is motivated in the cross validation of the model since both methods addressed a similar research question in Chapter 2 and Chapter 3. Therefore, it's a check up on the two 
methods with different strengths that yield similar results. According to the pragmatic epistemology the consideration is how to integrate them to serve the research purpose. The pragmatism refers here to the question which of the two methods is more useful in the situation of a secondary data. In the epistemological approach, mixing methods reflects on the decision making process behind each model. The pragmatic epistemology leads to the paradigm of choices introduced by Patton. The said choice ponders on adopting the research method to circumstances, in this case, the data type and multicriteria analysis. Patton's paradigm of choices is particularly useful in the methodological discourse regarding the qualitative and quantitative methods appropriateness (Patton, 2002; Johnson, 2004).

In the literature we find examples of studies on performance or comprehensive evaluations of projects where the PCA and AHP methods are integrated (see Komac, 2006; Pawluszek \& Borkowski, 2017; Shi, 2012; Subbaiah et al., 2011; Tee et al., 2017). The complementary application of the methods boils down mostly to the use of the PCA for establishing a data model of a given study or phenomenon, which is further evaluated by the AHP. The presented studies blend the PCA and AHP procedures in order to obtain a model of results.

We propose an integration of both methods to run an experimental comparison of the outcomes of local competitiveness modelling. Examples of PCA-AHP hybrids are found in operations research literature or project appraisal studies (see Feng \& Wen, 2011; Hoang et al., 2018; Lee et al., 2010; Mishra \& Mishra, 2018). In addition, Zhou et al. (2018) and Li et al. (2018) argue that the combination of the PCA and AHP methods can be optimal to eliminate the risk of dispertions in the AHP weighting system regarding the expert's judgements (Saaty \& Vargas, 2007). The literature examples present applications of both the PCA and AHP methods to deliver modelling results. The complementarity of both methods is discussed in the aforementioned studies.

Our mixed methods proposal is based on the existing and independent results obtained from the PCA and AHP analysis of the local competitiveness concept. With the mixed method, we check the impact of the choice of weights structure for a model on a singular indicator. Thus, we run an experiment with weights modelling based on the use of a weights structure generated by one method and apply the weights values generated by the other. Since we employ a determined dataset of socioeconomic indicators, we present a new approach, not found yet in the PCA and AHP hybrid studies. The mixed model 1 (Mix 1) integrates the PCAgenerated principal components structure and appoints the $\mathrm{APH}$-generated weights to the local competitiveness indicators. We reverse this concept in the mixed model 2 (Mix 2) using the AHP model structure and applying the PCA obtained weights values.

The weights of both procedures (Tables 4.2 and 4.3) are not directly comparable since they were generated in relation to the weighting assumptions of each method. Therefore, we normalize the generated weights in both methods. In this way, we obtain the weight of the indicator in relation to the entire model. The normalization formula takes the form: 


\section{Chapter 4}

$w n_{i}=w C_{i}^{*} w_{i} C_{i} i \quad(4)$ where,

$\sum_{i=1}^{n} W_{i}=1 \quad$ (5) and $\quad \sum_{i=1}^{n_{i}} W_{i} i=1 \quad(6)$

wn- normalized weight

$w C_{i}$ - weight of the PCA component or the AHP group

$w_{i} C i$ - weight of the PCA loading or the AHP subcategory

$i=1, \ldots, N$ (observation)

As a result of weights normalization, Table 4.5 and Table 4.6 illustrate the new mixed weights models according to the PCA and AHP model structures.

Table 4.5: The mixed method no. 1 of local competitiveness model PCA weights structure based, own elaboration.

\begin{tabular}{|c|c|c|c|c|c|c|c|}
\hline \multicolumn{8}{|c|}{ principal components (PCA) } \\
\hline$w C 1=0.29$ & $w C 2=0.18$ & $w C 3=0.17$ & $w C 4=0.09$ & $w C 5=0.09$ & $w C 6=0.09$ & $w C 7=0.09$ & $w C 8=0.08$ \\
\hline \multicolumn{8}{|c|}{ indicators weights (AHP) } \\
\hline$w C_{p} 4=0.07$ & $w C_{g} 3=0.37$ & $w C_{t} 1=0.32$ & $w C_{p} 1=0.24$ & $w C_{p} 2=0.46$ & $w C_{g} 2=0.70$ & $w C_{p} 3=1$ & $w C_{t} 4=0.36$ \\
\hline$w C_{e} 1=0.18$ & $w C_{1} 3=0.63$ & $w C_{t} 2=0.40$ & $w C_{i} 2=0.48$ & $w C_{i} 3=0.56$ & $w C_{g} 4=0.30$ & & $w C_{i} 1=0.33$ \\
\hline$w C_{e} 2=0.16$ & & $w C_{t} 3=0.29$ & $w C_{i} 4=0.28$ & & & & $w C_{1} 2=0.31$ \\
\hline \multicolumn{8}{|l|}{$w C_{e} 3=0.20$} \\
\hline \multicolumn{8}{|l|}{$w C_{e} 4=0.17$} \\
\hline \multicolumn{8}{|l|}{$w C_{g} 1=0.07$} \\
\hline$w C_{1} 1=0.07$ & & & & & & & \\
\hline$w C_{1} 4=0.07$ & & & & & & & \\
\hline
\end{tabular}

*w-weight

Table 4.6: The mixed method no. 2 of local competitiveness model AHP weights structure based, own elaboration.

\begin{tabular}{cccccc}
\hline \multicolumn{5}{c}{ weights of categories (AHP) } \\
\hline${ }^{*} w C_{p}=0.14$ & $w C_{e}=0.24$ & $w C_{g}=0.12$ & $w C_{t}=0.17$ & $w C_{i}=0.19$ & $w C_{1}=0.14$ \\
\hline & & weights of subcategories (PCA) & & \\
\hline$w C_{p} 1=0.13$ & $w C_{e} 1=0.21$ & $w C_{g} 1=0.17$ & $w C_{t} 1=0.30$ & $w C_{i} 1=0.20$ & $w C_{1} 1=0.18$ \\
\hline$w C_{p} 2=0.34$ & $w C_{e} 2=0.25$ & $w C_{g} 2=0.21$ & $w C_{t} 2=0.26$ & $w C_{i} 2=0.20$ & \\
\hline$w C_{p} 3=0.36$ & $w C_{e} 3=0.28$ & $w C_{g} 3=0.36$ & $w C_{t} 3=0.30$ & $w C_{i} 3=0.29$ & $w C_{1} 3=0.47$ \\
\hline$w C_{p} 4=0.17$ & $w C_{e} 4=0.26$ & $w C_{g} 4=0.26$ & $w C_{t} 4=0.14$ & $w C_{i} 4=0.31$ & $w C_{1} 4=0.22$
\end{tabular}

*w-weight 
In the next steps we carry out the same procedure to obtain the local competitiveness indicator using the mixed model weights. The aggregation procedure (Formula 1) incorporates the Table 4.1 indicators according to the Table 4.5 and Table 4.6 weights structures. The mixed method number 1 and 2 competitiveness indexes for the observed batch of 63 municipalities are enclosed in the Mendeley stored dataset (Kurek, 2020), together with the average index scores for each municipality. For the purpose of this article's nomenclature, the new indicators are labelled accordingly Mix 1 and Mix 2. Next, we repeat the ranking non-parametric correlations testing between the PCA, AHP and the two mixed methods local competitiveness indexes. As previously, we use the average municipalities' rank position of the observed period 1995-2017. Results of four correlations testing are presented in Table 4.7.

Table 4.7: Cross tabs correlations calculation for the PCA, AHP and mixed methods no.1 and no.2 local competitiveness indexes rankings, source: SPSS stats 25 own elaboration.

\begin{tabular}{|c|c|c|c|c|c|}
\hline & \multicolumn{3}{|c|}{ Asymptotic } & \multirow{2}{*}{$\begin{array}{l}\text { Approximate } \\
\text { Significance }\end{array}$} \\
\hline & & Value & Standard Error ${ }^{a}$ & Approximate $\mathrm{T}^{\mathrm{b}}$ & \\
\hline \multicolumn{6}{|l|}{ PCA - Mix 1} \\
\hline \multirow[t]{3}{*}{ Ordinal by Ordinal } & Kendall's tau-c & .862 & .030 & 28.386 & .000 \\
\hline & Gamma & .872 & .030 & 28.386 & .000 \\
\hline & Spearman Correlation & .960 & .016 & 26.788 & $.000^{c}$ \\
\hline \multicolumn{6}{|l|}{ AHP - Mix 1} \\
\hline \multirow[t]{3}{*}{ Ordinal by Ordinal } & Kendall's tau-c & .310 & .074 & 4.209 & .000 \\
\hline & Gamma & .316 & .075 & 4.209 & .000 \\
\hline & Spearman Correlation & .465 & .097 & 4.101 & $.000^{c}$ \\
\hline $\mathrm{N}$ of Valid Cases & & 63 & & & \\
\hline \multicolumn{6}{|l|}{ PCA - Mix 2} \\
\hline \multirow[t]{3}{*}{ Ordinal by Ordinal } & Kendall's tau-c & .744 & .046 & 16.168 & .000 \\
\hline & Gamma & .751 & .046 & 16.168 & .000 \\
\hline & Spearman Correlation & .893 & .037 & 15.494 & $.000^{c}$ \\
\hline \multicolumn{6}{|l|}{ AHP - Mix 2} \\
\hline \multirow[t]{3}{*}{ Ordinal by Ordinal } & Kendall's tau-c & .362 & .088 & 4.129 & .000 \\
\hline & Gamma & .367 & .089 & 4.129 & .000 \\
\hline & Spearman Correlation & .495 & .113 & 4.450 & $.000^{c}$ \\
\hline $\mathrm{N}$ of Valid Cases & & 63 & & & \\
\hline
\end{tabular}

\footnotetext{
a. Not assuming the null hypothesis.

b. Using the asymptotic standard error assuming the null hypothesis.

c. Based on normal approximation.
}

Both tests reveal that the two rankings are significantly correlated. We observe that the appointed mixed weighting structure of either PCA or AHP contributes to the correlation results. The strong correlation is discovered between the PCA or AHP indexes and the mixed method index developed on the structure of one method. Therefore, a very high correlation coefficient results from the tests of the PCA local competitiveness indexes rankings, and the mixed method number 1 (Mix 1) indexes developed on the weights structure of the PCA (see 
Kurek, 2020). A similar high correlation coefficient is observed when the AHP indexes rankings are examined against the mixed method number 2 (Mix 2), which is designed on the AHP weighting structure. Moreover, the comparable level of significant correlations is observed for the relationship between the PCA indexes rankings and the Mix 2, and the AHP indexes rankings and Mix 1 respectively. These results oscillate around a convergent value. Therefore, all of the local competitiveness index rankings yield positive and significant correlations. By analyzing the correlations experiments, the strongest relationship is noticed between the PCA indexes rankings and the mixed method number 1 indexes that followed the PCA weights structure with the Spearman coefficient of 0.96 . This observation interprets the importance of the principal components in a multivariate indicators model.

The development of the mixed methods aimed to check the association between the PCA- and AHP-generated weights structures of local competitiveness models. The conducted correlations tests with the mixed models confirm that the local competitiveness rankings obtained by the PCA and AHP methods converge. Hence, the integration of the two multicriteria methods helps address the research question of this paper. The significant relationship resulted from the correlation tests points out that the PCA and AHP methods deliver comparable results for the case of local competitiveness model design. The mixed methods experiment confirms this association through an observation of significant correlations scores between the PCA, AHP, and the mixed indexes rankings. The strongest relation is however observed between the PCA weights model and mixed weights model of the PCA structure.

\subsection{Discussion and conclusions}

In this chapter, we ask whether in the case of a local competitiveness model based on data of the same socioeconomic indicators, the Principal Component Analysis (PCA) or Analytical Hierarchy Process (AHP) deliver comparable results. The research objective is motivated by understanding how the two methods, different in assumptions and procedures, operationalize a multivariate phenomenon such as local competitiveness. To analyze this problem, we take the case of two studies from Chapter 2 (Kurek et al., 2020b), and Chapter 3 (Kurek et al., 2020a) which used the same socioeconomic data to construct competitiveness models for a selection of municipalities in Poland. The data modelling based on the PCA and AHP weighting systems delivered the local competitiveness indexes for each of the observed municipalities for the years 1995-2017. We use index rankings to compare the scores of competitiveness. The municipalities' indexes rankings enable the non-parametric correlation test in order to answer the research question about the comparability of the local competitiveness models. The test rankings of the PCA and AHP local competitiveness indexes shows statistically significant results with the moderate magnitude of index correlation (Spearman's coefficient value 0.55). In this study, we ask if the results obtained using both methods deliver comparable knowledge about the phenomenon of local competitiveness. The results of the analysis observe a convergence 
of the phenomenon described by the AHP method and the same phenomenon developed using the PCA method. Therefore, both methods can be used to analyze the concept of local competitiveness for the dataset of the socioeconomic indicators.

We take a next step towards the comparison of the two methods and propose an integration of the weights system as a form of experimental testing. Although PCA- AHP hybrid methods exist in the literature, our novel approach lies in its practical application to the determined local socioeconomic indicators model. Integration of the two methods is based on applying the weights structure delivered by one method to the indicator weights given by the other method. As a result, we conducted two mixed weights modellings. This mixed approach addresses the issue of weights generation that are the determinants of the local competitiveness indexes scores.

The repeated non-parametric correlation tests for the PCA, AHP, and two mixed models demonstrate the significant associations between the local competitiveness indexes generated by all of the methods. Moreover, very strong correlations between the PCA, AHP, and the mixed methods local competitiveness indexes rankings indicate the robustness of the local development model itself. The highest magnitude of correlation is observed in the situation where the PCA indexes model is examined against the mixed model built on the PCA weights structure (Mix 1), and accordingly the AHP indexes model is tested against the AHP-structured mixed model (Mix 2). Therefore, the analysis of the correlation results illustrates the importance of the weights structure that is found to determine the results. The strongest correlation score resulted from the examination of the PCA indexes model and the mixed method indexes model built out of the PCA model structure. It supports the strength of PCA method in operationalization of a multivariate research problem that is based on coherent secondary data such the presented local competitiveness. The outcomes of our analysis underline the decisiveness of the weighting model structure. Although the correlations test of the AHP and mixed methods show significant results, the AHP applies a presumed structure in approaching a research problem. Theoretically, this can be the method's limitation since the experts follow a given model with judgements and assess the importance of the indicators in pairs, not influencing the relationship of the indicators outside the given pairs. In practice, the PCA method can have a technical advantage over the AHP in designing a multivariate model composed of coherent, numeric, and secondary data. It decides not only about the functional relationship between the indicators but also about the structure of these indicator's dependence.

As a result of the weights models experiment, all of the correlation results are positive and significant. The proposed experiment of mixed weights structures confirms the results of the PCA and AHP indexes rankings tests. The two methods are found to deliver comparable results in the situation of a determined research phenomenon like local competitiveness. The integration experiment showed the epistemic strength of the two methods. To conclude we 
argue that the decision about a choice of a multicriteria method is to be taken according to the specifics of the problems of the decision and the sort of data that describes it. Outcomes of our analysis refer to the Patton's $(1990,2002)$ paradigm of choices, where our proposed mixed approach supports the analysis of the best approach to a multicriteria concept of local competitiveness. From the observation of the PCA and AHP rankings correlations complemented by the mixed modelling of weights, we argue that the two multicriteria methods deliver convergent results. Nevertheless, following Patton's argument, the choice of a method should be guided by the type of data and the goal of the research problem. Since the proposed mixed method results are the closest to the PCA-obtained competitiveness indexes rankings and applying the Ockham's razor principle, the simplest methodical solution should be applied in the situations of a comparable research problem. Ockham's razor resolves the heuristic problems that regard the choice between the simple and complex explanation, where both work equally well. Although both methods PCA and AHP deliver comparable results, the outcomes of mixed modelling point to the highest correlation scores with the PCA. Therefore, this method is advised for the analysis of a coherent and continuous dataset such as, in this case, the presented local competitiveness variables. 
Chapter 5

The contribution of the geothermal resources to local employment: case study from Poland 


\section{Abstract ${ }^{14}$}

Next to heat and energy production, geothermal energy presents with opportunities for rural and suburban areas linking sustainable development goals with expansion of new local economy sectors. We conduct the shift share analysis for the ten municipality cases of the geothermal exploitation in Poland, comparing their employment structure with their reference poviat as a control group, in the years 2005 and 2018. The results reveal a strong shift in the trade and service sectors employment in all of examined geothermal localities, outperforming the reference poviats. In the tested period, more jobs were generated in the geothermal municipalities than in poviats too. Moreover, the structure of the differential shift component indicates that the trade and services employment growth is related with the development of the geothermal spas and recreational centers in the examined municipalities. The hypothesis that the geothermal resources utilization increases the employment in the local services sectors is corroborated.

14 Chapter published as: Kurek, K. A., Heijman, W., van Ophem, J., Gędek, S., \& Strojny, J. (2021). The contribution of the geothermal resources to local employment: Case study from Poland. Energy Reports, 7, 1190-1202. 


\subsection{Introduction}

Among the renewable energy resources geothermal is specific to local production and consumption. The development of the renewable energies underlines the environmental benefits in the first place. Secondly, it points to the use of autochthonous resources leading to job gains and net positive impacts on the regional economies (Allan et al., 2017; Dvorák et al., 2017; Henriques et al., 2016; Martinot, 2005; Moreno \& Lopez, 2008; Ulrich et al., 2012). The employment in the geothermal related sectors is comparably low in comparison to the traditional energy sectors. However, the share is expected to rapidly grow year by year aligned with the implemented renewable energy policies (e.g. Renewable Energy Directive (EU) 2018/2001). Still, the geothermal business generated circa 100 thousand jobs worldwide until 2018 (IRENA, 2018). Moreover, the geothermal energy is said to deliver direct, indirect and induced employment to the location of exploitation (Lesser, 1994). Whereas the direct and indirect jobs indicate the dynamics of the resource utilization, the induced employment explains the effect of the renewable resource on the economy (Wei et al., 2010). The Geothermal Energy Association establishes the economic multiplier effect to be 2.5 for a geothermal investment, meaning that each 1 USD invested in this resource results in the 2.5 USD output growth for a local economy (Hance, 2005). Shortall et al. (2015) argue that the creation of employment and of induced economic activities represent strong features of the geothermal sustainable resource compared to other renewables. Moreover, the nature of the resource and economic application possibilities encourages into further than local energy provision. Fridleifsson (1998), Konak \& Pamukcu (2006), Lund et al. (2011) and Dickson \& Fanelli (2013) deliver analysis of the direct geothermal use in local economies. Furthermore, the sustainable character of the renewable and its attributes for local communities development are discussed in e.g.: Kunkel et al. (2012), Tomaszewska \& Szczepański (2014), Barbier (2002), Canan (1986), Fridleifsson (2001) and Lund \& Boyd (2016).

The innovation in the geothermal energy development are expected to as well create a societal value. Manzella et al. (2018) present the cases of Italian geothermal plants expansion that induces social benefits like direct and indirect employment. Furthermore, these arguments stand behind the public opinion about the geothermal projects development (Pellizzone et al., 2017 and Yasukawa, 2019). The ongoing decarbonization of energy resources is proven to generate more jobs than fossil fuels according to the work of Garrett-Peltier (2017) or Muniyoor (2020). Studies of Markandya et al. (2016) observe a spillover effect related to the deployment of renewable energy technologies, including geothermal. This effect considers the direct and indirect employment impacts. Poland for instance, is listed among the gainers of the energy transition and employment related to the transition into renewables resources use.

With reference to the location theory principles market activities accumulate when the cost of exploiting the resources is minimum (Puu, 2003). Developed in the early twentieth century by Alfred Weber, the location theory as a part of regional sciences addresses the questions about 
the factors and processes that induce economic activities. It aims to describe the patterns of tapping into accessible raw materials and commodities to develop private sector (Murray, 2017). Modern interpretation of the location theory study across the topics of business sector siting, service competition, and, more generally, consumer behavior. Energy resources considered as a commodity are discussed as an location factor for commercial activities (Altman, 1986; Brown, 2000; Chou, 2008; Aguilar, 2012; Register, 2012; Mehmet, 2020). According to the assumptions of location theory the features of the geothermal resources can impact the economic spatial structure. This chapter focuses on the side of economic advantage attracting employment, not the development of the geothermal industrial site.

In the renewable energy sector, the direct employment is estimated in relation to the units of produced energy (IRENA, 2013; ESMAP, 2019). The reports discuss recent trends in renewable energy costs and investment that imply varying impacts on job creation in the different segments of the value chain. Moreover, the gaps in geothermal employment data is underlined. This chapter proposes a new method of measuring the indirect and induced employment, in this case in a particular economic sector. The accessibility of the geothermal resources locally introduces opportunities to use it. Geothermal water application in the recreational and health facilities are particularly found to contribute to the increase of local budgets, augmented employment and new local market specialization e.g. in tourism (NREL, 2004; Dej et al., 2013). Therefore, we aim to find out whether the local employment structure changes while using the geothermal resources. We follow the local economic structure approach of Almeida (2007) to determine changes in employment. Our study samples a selection of the geothermal municipalities in Poland and attempts to identify a shift towards the services sector by the use of the geothermal resources. The application of the shift-share analysis is a rather novel approach in the geothermal economics studies and its versatility allows to conduct employment analysis for any geothermal resources exploiting localities in the world. After introducing the research problem, the section describing the method and data follows. Thereafter, the results of the analysis are presented and research assumptions are interpreted. The conclusion and discussion section closes this chapter.

\section{2 Research framework and data collection}

In case of Poland, the geothermal resource is available under $80 \%$ of the country's earth crust, one of the highest capacities in Europe and $40 \%$ of this potential is technically ready to deliver economically attractive geothermal heat and energy, argue Kepinska (2003) and Górecki et al. (2012). According to Skjærseth (2014) and Szulecki et al. (2016) increased geothermal production creates a degree of energy independence from the conventional resources and imports. Huclak et al. (2015) discuss that in case of Poland, the optimal conditions for the geothermal exploitation are found in locations that are at the source of the renewable geothermal energy or in close vicinity, in relatively small-mid size municipalities with a dense housing and infrastructure network. It potentially provides them the geothermal related 
opportunities assumed to be a local energy source, jobs creation, local budgets growth and increased entrepreneurship. Yet, despite the resource potential in Poland, the geothermal renewable is mostly used for the local district heating and recreational or bathing centers purposes (Halaj, 2015; Sowizdzal, 2018). Studies of Stanik et al. (2011), Hałaj (2012), Kowalski (2015), Kruczek (2016), Sala (2018) indicate that the geothermal establishments change the economic landscape of the municipalities in Poland, introducing new market sectors like tourism, health services and events activities, not present there before. We base our research concept on the large potential of its direct and local exploitation according to the Lindal diagram (Fig. 1.6 in Chapter 1; Gudmundsson, 1988). The work of Kurek (2016) shows the relation between the resource utilization and the indicators of local economy and tourism. Chapter 2 (Kurek et al., 2020b) discusses the positive role of the geothermal recreational centers and spas in the local development. We extend the research and we formulate the hypothesis that the geothermal resources utilization leads to an increase of employment in the service sector at the municipality level. The hypothesis is derived from the assumption of service related jobs that are induced next to the development of the geothermal recreational and spa centers. It is to be tested by using the comparative employment analysis between the municipalities that utilize geothermal resources and the larger administrative areas of poviats as a control group. The concept of territorial reference is motivated in justifying the hypothesis. Therefore, we assume a different pattern in the employment structure of the geothermal municipalities economies in comparison to poviats, in the years 2005 and 2018. The control group is introduced to avoid a biased interpretation of changes in employment in the geothermal municipalities. In testing the hypothesis, we compare the geothermal municipalities with the poviat they are located in, and, secondly, these poviats with the voivodeships they belong to ${ }^{15}$. In this way, we attempt to determine if an employment structure in the geothermal municipalities differs from the region. In addition, a group of experts is approached to decide on the categories of service employment that are related to the geothermal activities on a municipal level. Using the experts knowledge next to the desk research, we can identify specified services induced by the geothermal activities.

Figure 2.1 in Chapter 2 displays the geothermal resources activities in Poland. Although there are 54 economically viable geothermal boreholes, the actual geothermal exploitation is much lower that the country's potential (Felter et al., 2015). The resource is exploited in the municipalities that have decided to invest in the geothermal installations, therefore in fact, in less than a quarter of the geothermal capacity.

\footnotetext{
15 The latest administrative reform of Poland in 1999 established the basic hierarchy of administrative division in Poland. Municipality (pol. gmina) is a principle territorial unit in Poland of three types: urban, urban-rural and rural. It corresponds with a concept of commune. Poviats (pol. powiat) are the second level unit of territorial administration, composed out of a non-fixed number of municipalities. Poviat refers to a county or district. Voivodeship, similar to a province or region, (pol. województwo) is the highest level of administrative division in Poland, further divided into powiats (Central Statistical Office, 2018).
} 
Table 5.1 presents ten geothermal municipalities to be examined. They use the available geothermal resources in various forms and in a different time frame. They are the main municipalities in Poland, where geothermal installations are present, except few, sole installations for the recreational purposes in other locations as e.g. Grudziądz, Poznań or Lądek Zdrój (Sowizdzal, 2018). Geothermal enterprises of various ownership, including local authorities, produce the geothermal heat and water, that are further distributed to the communal network or power the geothermal recreational centers. Geotermia Podhalańska S.A. powers four municipalities because of to their geographic proximity. Geothermal recreational centers are established in seven out of ten examined municipalities. In case of Poddębice, the geothermal recreational center was built before the geothermal municipal heating plant. Szaflary and Bukowina Tatrzańska established two geothermal recreational centers. In Bukowina Tatrzańska geothermal resources supply the recreational and health centers without further network distribution. Opposite to Stargard and Pyrzyce, where the resource is used mainly for heating and communal purposes without applications in commercial or recreational activities.

Table 5.1: Geothermal activities in the selected municipalities in Poland, Polish Geological Institute.

\begin{tabular}{|c|c|c|c|c|}
\hline & municipality & geothermal enterprise & installation year & recreational center \\
\hline 1 & Mszczonów & Geotermia Mazowiecka S.A. & 2000 & Termy Mszczonów (2008) \\
\hline 2 & Uniejów & Geotermia Uniejów LLC & 2001 & Termy Uniejów (2008) \\
\hline 3 & Poddębice & Geotermia Poddębice LLC & 2013 & Termy Poddębice (2011) \\
\hline 4 & Szaflary & Geotermia Podhalańska S.A. & 1993 & $\begin{array}{l}\text { Termy Szaflary (2007) and } \\
\text { Gorący Potok (2015) }\end{array}$ \\
\hline 5 & Zakopane & Geotermia Podhalańska S.A. & 2001 & Aqua Park (2006) \\
\hline 6 & Poronin & Geotermia Podhalańska S.A. & 2001 & n.a. \\
\hline 7 & Biały Dunajec & Geotermia Podhalańska S.A. & 1996 & n.a. \\
\hline 8 & $\begin{array}{l}\text { Bukowina } \\
\text { Tatrzańska }\end{array}$ & $\begin{array}{l}\text { Bukowina Geothermal Society } \\
\text { LLC }\end{array}$ & 2008 & $\begin{array}{l}\text { Termy Bania (2008) and } \\
\text { Termy Bukovina (2011) }\end{array}$ \\
\hline 9 & Stargard & G-TERM Energy LLC & 2005 & n.a. \\
\hline 10 & Pyrzyce & Geotermia Pyrzyce LLC & 1999 & n.a. \\
\hline
\end{tabular}

The hypothesis is to be tested using the comparative analysis of employment structure of the geothermal municipalities and poviats for the years 2005 and 2018. Because of the methodological changes introduced in the employment statistics collection in Poland, the official data, the NACE classification, is coherent from 2005 onwards. The NACE classification corresponds with the Statistical Classification of Economic Activities in the European Community (Eurostat, 2016) and it is the set of types of socio-economic activities, systemized in sections A-U that are carried out by economic entities. In Poland, the NACE refers to the Polish Classification of Activities (pol. Polska Klasyfikacja Działalności). The NACE classification 
illustrates the specialization and the dynamics of economy, and as detailed into major sections is as follows ${ }^{16}$ :
A. Agriculture, hunting, forestry and fishing
B. Mining and quarrying
C. Manufacturing
D. Electricity, gas and hot water supply
E. Water supply and waste management
F. Construction
G. Wholesale and retail trade, repair of motor vehicles, motorcycles, personal and households goods
H. Transportation and storage
I. Accommodation and food services
J. Information and communication
K. Financial and insurance activities
L. Real estate activities
M. Professional, scientific and technical activities
N. Administrative and support service activities
O. Public administration and defense
P. Education
Q. Health and social work
R. Arts, entertainment and recreational activities
S. Other community, social and personal service activities
T. Goods and services producing households
U. Extraterritorial organizations

As a comparative employment analysis the shift-share method is to be used. We adopt the approach to the geothermal municipalities, poviats and voivodeships, comparing their employment figures. If the structure of employment differs between the examined municipalities and poviats, the assumed local change can be attributed to the geothermal resources exploitation. The data for the comparative analysis stems from the Local Data Bank of the Central Statistical Office at the level of NUTS 2, 4 and $5^{17}$ in the years 2005 and 2018. The employment data according to the NACE sections available in the database is merged in five groups, as presented in Table 5.2. Because of the statistical confidentiality of the data on the NUTS-5 level some of the single employment values were estimated. The full dataset that concerns employment numbers for the municipalities, poviats and voivodeships is stored in the Mendeley data repository (Kurek et al., 2020e).

\footnotetext{
${ }^{16}$ Polish Classification of Activities PKD, Dz. U. 251/1885, appendix to the Regulation of the Council of Ministers of 24.12.2007.

17 NUTS is the Eurostat's Nomenclature of Territorial Units for Statistics. In Poland, NUTS levels 2, 4 and 5 correspond with voivodeship, poviats and municipalities administrative units respectively (www.stat.gov.pl/en/regional-statistics/classification-of-territorial-units/classification-of-territorial-units-forstatistics-nuts/the-history-of-the-nuts-classification).
} 
Table 5.2: Groups of the NACE sections of economy, Local Data Bank.

\begin{tabular}{lll}
\hline group & NACE section & field of economy \\
\hline 1 & $\mathrm{~A}$ & agriculture \\
2 & $\mathrm{~B}, \mathrm{C}, \mathrm{D}, \mathrm{E}, \mathrm{F}$ & industry, construction, energy provision \\
3 & $\mathrm{G}, \mathrm{H}, \mathrm{I}, \mathrm{J}$ & trade, transport, accommodation and gastronomy, information and \\
& $\mathrm{K}, \mathrm{L}$ & fommunication \\
4 & $\mathrm{M}, \mathrm{N}, \mathrm{O}, \mathrm{P}, \mathrm{Q}, \mathrm{R}, \mathrm{S}, \mathrm{T}, \mathrm{U}$ & other activities including single economic activities \\
\hline
\end{tabular}

\subsection{Research method}

In most of the shift-share analysis, the regional economy is compared to the national economy. It decomposes employment changes within an economy over a specified period of time. In case of our study, we compare the municipality to the poviat in which it is located and consequently the poviat to the voivodeships in which it is located. Depending on the area in Poland, poviats usually compose from few to several municipalities, whereas a multiple number of poviats belong to voivodeships. This spatial approach allows to assess the change in the NACE sections employment between the examined units. Table 5.3 depicts the pairs of areas that undergo the shift-share analysis i.e. the geothermal municipalities with poviats, and as control groups- the poviats with voivodeships. Some of the geothermal municipalities are located within the same poviat, and by reference in one voivodeship. This is explained by the geological conditions of the geothermal resources reservoirs and accessing them (see Fig. 2.1 in Chapter 2). The classification of the municipalities according to the type of a territorial division follows from the Polish National Official Register of the Territorial Division of the Country (TERYT).

Table 5.3: Geothermal municipalities, poviats and voivodeships used in the shift-share comparative analysis, Local Data Bank.

\begin{tabular}{|c|c|c|c|c|}
\hline & municipality (NUTS-5) & type & poviat (NUTS 4) & voivodeship (NUTS 2) \\
\hline 1 & Mszczonów & urban-rural & Żyrardowski & Mazowieckie \\
\hline 2 & Uniejów & urban-rural & Poddębicki & Łódzkie \\
\hline 3 & Poddębice & urban-rural & & \\
\hline 4 & Stargard & urban & Stargardzki & Zachodniopomorskie \\
\hline 5 & Pyrzyce & urban-rural & Pyrzycki & \\
\hline 6 & Szaflary & rural & Nowotarski & Małopolskie \\
\hline 7 & Zakopane & urban & Tatrzański & \\
\hline 8 & Bukowina Tatrzańska & rural & & \\
\hline 9 & Poronin & rural & & \\
\hline 10 & Biały Dunajec & rural & & \\
\hline
\end{tabular}


The shift- share analysis is a quantitative method used to analyze an employment structure. It allows for descriptive examination of structural changes that are assumed to occur within a country, region or locality (Dunn, 1960). It helps to answer the question about the growth or decline of employment in economic sectors. The main objective of the share-shift technique is the quantification of geographical changes by decomposing growth rates in structural and competitive components. The shift-share analysis developed in the 1960 s has matured into numerous extensions (Keil, 1992 and Knudsen, 2000). In case of a local approach, this method helps as well to determine if a component contributes to the local economy or impacts local competitiveness. It is done by a retrospective decomposition of variations in the selected local economic indicators. Furthermore, throughout the descriptive analysis the structural change is compared within a referenced another geographic (or administrative) area. In this way, we can observe regional differences or assign a structural change to a particular economic sector. The shift- share analysis is therefore popularized for explaining regional factors of growth as change in employment structure (Adao et al., 2019 and Herzog Jr \& Olsen, 1977); determining factors of location (Bartholomew \& Peck, 1989); economic forecasting (Kurre \& Weller, 1989); or regional specialization (Esteban, 2000 and Márquez et al. 2009).

Stevens \& Moore (1980) underline the importance of solid and comparable data as a core of the shift-share analysis interpretation. Various studies that used the shift-share method discuss the impact of the renewable resources on the regional economy (López \& Moreno, 2010; Otsuka, 2016; Wu, 2008). We apply the shift-share analysis to the employment analysis related with the utilization of the geothermal resources at municipalities level, a novel approach in the geothermal research. A municipality as the subject of the shift-share analysis is rather uncommon in the literature dedicated to this methodology, except the work of e.g. Amorim (2009) and Nogueira \& Lopes (2008), that discuss the general trends of employment at a municipal level.

We adopt the conventional Esteban's (2000) three factor decomposition into a structural, differential and allocative component. Since our study regards the geothermal resources exploitation in municipalities the national effect is omitted. Therefore, following Márquez et al. (2009) we label the components as actual shift (allocative component), differential shift (differential component) and proportional shift (structural component). Traistaru \& Wolff (2002) provide detailed explanation of the shift-share components framework. The actual shift measures a covariance of the differential and proportional shifts, and it indicates whereas a structural change of the examined components takes place. It explains how much economic growth in a location can be attributed to overall growth rates in the regional economy. The differential shift corresponds with any local specific factors or circumstances that enabled a change in the local employment structure. Artige \& Van Neuss (2014) link the differential shift to the concept of regional or local competitiveness. In our approach the geothermal resources exploitation in the municipalities is responsible for the differential shift in the examined economic indicator. The proportional shift explains the size of a structural economic change 
between the compared units. It derives from the local specialization and usually points to growth share of the competitive sectors of a local economy. The following formulas of the shift-share analysis provide the actual (1), differential (2) and proportional (3) shift scores.

Actual shift: $S_{a}=\sum_{i=1}^{n} W_{i j t}-\frac{W_{t}}{W_{0}} \sum_{i=0}^{n} W_{i j 0}$

Differential shift: $S_{d}=\sum_{i=1}^{n}\left(W_{i j t}-\frac{W_{i t}}{W_{i 0}} W_{i j o}\right)$

Proportional shift: $S_{p}=S_{a}-S_{d}$
(3), where

$W_{i j 0}$ : the variable $i$ in municipality $j$ or poviat $j$ or voivodeship $j$ in year $O$ (starting year)

$W_{i j t}$ : the variable $i$ in municipality $j$ or poviat $j$ or voivodeship $j$ in year $t$ (final year)

$W_{t}: \Sigma W_{\text {it }}$

$W_{0}: \Sigma W_{i 0}$

Heijman \& Schipper (2010) and Shi \& Yang (2008) find the relevance of introducing the relative shifts for a better comparison of the examined regions or areas. They are obtained by dividing each shift (actual, differential and proportional) score by the $t$ value in year 0 ; in our case, a sum of each economic indicators. The relative shifts are defined as follows:

Relative actual shift: $R S_{a}=\frac{S_{a}}{\sum W_{i j 0}}$

Relative differential shift: $R S_{d}=\frac{S_{d}}{\sum W_{i j 0}}$

Relative proportional shift: $R S_{p}=\frac{S_{p}}{\sum W_{i j 0}}$

The computations of the relative shifts formulas 4, 5 and 6 with the NACE sections employment data of 2005 and 2018 (Table 2 at Kurek et al. 2020e) result in a single shift score for each of the examined geothermal municipality in reference to the poviat. The same procedure is conducted for the poviat and voivodeship pairs. If the value of the relative actual shift $\left(S_{a}\right)$ is positive, the employment in the geothermal municipality NACE sectors is assumed to grow faster than in the poviat. A positive score of the relative differential shift $\left(S_{d}\right)$ indicates a specific local condition that causes the increase in the employment, in our case the use of geothermal resources in the municipality. Whereas, a positive relative proportional shift $\left(S_{p}\right)$ shows the relative growth of employment in each of the NACE section. The poviats as the control group undergo the same shift-share procedure. If the results of the analysis do not repeat in the poviats, the research hypothesis is considered corroborated.

\subsection{Results and analysis}

The shift-share analysis aims to find out the differences in the employment structure between the geothermal municipalities and the reference poviats. We assume that the change takes place in the services sectors and that it is related to the local geothermal resources 
exploitation. The scores in Table 5.4 depict the results of the relative shift-share analysis conducted for the pairs of municipalities, poviats and voivodeships. The relative actual $\left(S_{a}\right)$, differential $\left(S_{d}\right)$ and proportional $\left(S_{p}\right)$ shifts represent the dynamic of the NACE sectors employed population indicator. The results are presented in a comparable arrangement, therefore the shifts between the municipality and poviats are represented by the municipality shifts scores and the poviats and voivodeships are represented by the poviat shifts scores. We add as well the main geothermal activities in the municipalities e.g. a geothermal heating plant $(p)$, geothermal energy network supplying locally the geothermal heat and water $(n)$, and a geothermal recreational or health center/ spa (s), (Kępińska, 2019).

Table 5.4: Results of the shift-share analysis for the examined pairs of the geothermal municipality in relation to poviat and poviat in relation to voivodeship, in the years 2005 and 2018, own elaboration.

\begin{tabular}{|c|c|c|c|c|c|}
\hline \multicolumn{2}{|c|}{ administrative unit } & \multirow{2}{*}{$\begin{array}{r}\text { relative } S_{a} \\
0.959\end{array}$} & \multirow{2}{*}{$\begin{array}{r}\text { relative } S_{d} \\
0.810\end{array}$} & \multirow{2}{*}{$\begin{array}{r}\text { relative } S_{p} \\
0.149\end{array}$} & \multirow{2}{*}{$\begin{array}{c}\text { geothermal activity* } \\
\qquad p, n, s\end{array}$} \\
\hline municipality & Uniejów & & & & \\
\hline & Poddębice & 0.302 & 0.116 & 0.186 & $p, n, s$ \\
\hline poviat & Poddębicki & -0.148 & -0.039 & -0.109 & \\
\hline municipality & Mszczonów & 0.126 & 0.066 & 0.060 & $p, n, s$ \\
\hline poviat & Żyrardowski & -0.157 & -0.140 & -0.016 & \\
\hline municipality & Szaflary & 0.158 & 0.181 & -0.023 & $p, n, s$ \\
\hline poviat & Nowotarski & -0.094 & -0.126 & 0.032 & \\
\hline \multirow[t]{4}{*}{ municipality } & Bukowina Tatrzańska & 0.978 & 1.167 & -0.189 & $p, s$ \\
\hline & Zakopane & -0.157 & 0.012 & -0.170 & $p, n, s$ \\
\hline & Biały Dunajec & -0.104 & 0.004 & -0.108 & $n$ \\
\hline & Poronin & -0.096 & 0.014 & -0.109 & $n$ \\
\hline poviat & Tatrzański & -0.076 & -0.155 & 0.080 & \\
\hline municipality & Stargard & 0.096 & 0.033 & 0.064 & $p, n$ \\
\hline poviat & Stargardzki & 0.085 & 0.076 & 0.009 & \\
\hline municipality & Pyrzyce & 0.161 & 0.041 & 0.121 & $p, n$ \\
\hline poviat & Pyrzycki & -0.087 & -0.037 & -0.050 & \\
\hline
\end{tabular}

* $p$-geothermal plant, $n$-geothermal municipal network, s-geothermal spa/ recreational center

The relative actual shifts $\left(S_{a}\right)$ is the sum of the relative differential $\left(S_{d}\right)$ and proportional shift $\left(S_{p}\right)$. The positive relative actual shift indicates the change in the employment structure of the municipality in comparison to the poviat (and the poviat to the voivodeship), whereas a positive relative differential shift explains the favorable circumstances of the employment growth. The positive relative proportional shift interprets that growing employment sectors are represented in the municipality in comparison to the poviat (and in the poviat compared with the voivodeship). The results show that the geothermal municipalities strongly outperform the poviats. The municipalities that observe the greatest shifts are: Bukowina Tatrzańska, Uniejów, Poddębice, Mszczonów, Pyrzyce and Szaflary. Their reference poviats yield opposite (negative) shifts results. Therefore, we assume stronger economic conditions for the employment growth in the geothermal municipalities than in the poviats. 
The positive results of the relative differential shifts $\left(S_{d}\right)$ are seen in each of the examined municipalities, and negative results in their reference poviats. These considerable scores indicate a local cause that stimulated the employment in the NACE sectors in the observed years. Following the hypothesis, we presume that the utilization of the geothermal resources in the municipalities triggers additional service jobs in the geothermal municipalities, that are not present in the poviats. We relate this performance with the scope of new services related mainly to the establishment of the geothermal recreational centers and spas. The forms of the resource utilization in each of the geothermal municipalities are presented along the shiftshare analysis outcomes in Table 5.4.

Table 5.5 illustrates the differential shifts of the number of employed inhabitants in each of the group of the NACE sections of employment in Table 5.2. We show the differential shifts for the compared pairs of municipalities and poviats, and poviats with voivodships (Table 3 ) resulting from the formula 2 computation of the employment data (Kurek et al., 2020e). The hypothesis testing concentrates on the analysis of the NACE sections 3 and 5 contribution to the total number of differential shift for each municipality and poviat. A growth in employment absolute numbers is therefore expected in the differential shift of these sections. They represent the trade and services categories of employment according to the data provider i.e. Central Statistical Office in Poland.

Table 5.5: Scores of the differential shifts $\left(S_{d}\right)$ per NACE employment sections grouped (1-5) as an outcome of the shift-share analysis for the Table 5.3 pairs of municipalities and poviats (I) and poviats and voivodeships (II) in 2018 compared with 2005, in number of employed, own elaboration.

\begin{tabular}{|c|c|c|c|c|c|c|c|c|c|c|c|}
\hline & I. municipality and poviat & 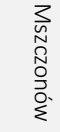 & 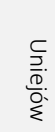 & 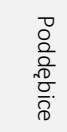 & 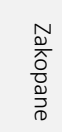 & 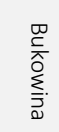 & $\begin{array}{l}\text { ㅇ. } \\
\text { O } \\
\text { 윽. }\end{array}$ & 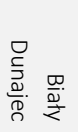 & $\begin{array}{l}\stackrel{N}{N} \\
\stackrel{N}{ \pm} \\
\stackrel{N}{2}\end{array}$ & 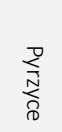 & 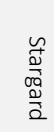 \\
\hline 1 & agriculture & -20 & -13 & -15 & -4 & -4 & -18 & -7 & 0 & 81 & -1 \\
\hline 2 & industry, construction & 295 & -46 & -215 & -84 & 4 & 32 & 8 & 74 & 85 & 752 \\
\hline 3 & trade and services & 50 & 173 & 212 & 543 & 430 & 48 & 46 & 15 & 14 & -447 \\
\hline 4 & finance and real estate & 28 & 10 & 92 & -2 & -8 & 14 & -1 & -79 & 102 & 13 \\
\hline 5 & $\begin{array}{l}\text { other (incl. other services, } \\
\text { single economic activities) }\end{array}$ & 1 & 239 & 198 & -374 & 394 & -70 & -45 & 109 & -147 & 95 \\
\hline \multicolumn{2}{|c|}{ total Sd } & 254 & 363 & 273 & 80 & 816 & 6 & 1 & 119 & 134 & 412 \\
\hline
\end{tabular}




\begin{tabular}{|c|c|c|c|c|c|c|c|c|c|c|c|}
\hline & II. poviat and voivodeship & 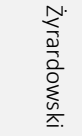 & 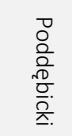 & 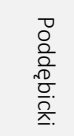 & 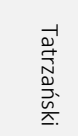 & 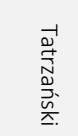 & $\begin{array}{l}\overrightarrow{1} \\
\stackrel{0}{N} \\
N \\
\stackrel{N}{N} \\
\text { N. } \\
\text { ‥ }\end{array}$ & 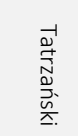 & 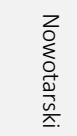 & $\begin{array}{l}\text { ָ } \\
\text { న } \\
\text { 合. }\end{array}$ & 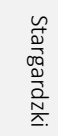 \\
\hline 1 & agriculture & 483 & -554 & -554 & 1141 & 1141 & 1141 & 1141 & -3336 & -532 & -679 \\
\hline 2 & industry, construction & -1132 & 744 & 744 & -143 & -143 & -143 & -143 & 1121 & 145 & 2656 \\
\hline 3 & trade and services & -639 & -253 & -253 & -2831 & -2831 & -2831 & -2831 & -1253 & 227 & -696 \\
\hline 4 & finance and real estate & -160 & -25 & -25 & -105 & -105 & -105 & -105 & -226 & -358 & 579 \\
\hline 5 & $\begin{array}{l}\text { other (incl. other services, } \\
\text { single economic activities) }\end{array}$ & -831 & -454 & -454 & -114 & -114 & -114 & -114 & -1006 & 241 & -386 \\
\hline \multicolumn{2}{|c|}{ total Sd } & -2279 & -542 & -542 & -2053 & -2053 & -2053 & -2053 & -4700 & -277 & 1474 \\
\hline
\end{tabular}

In order to test if either the geothermal energy network and the geothermal recreational centers and spas contribute to the employment changes illustrated by the differential shift, we check in which economic sectors they operate. The Central Registration and Information on Business (pol. CEIDG) collects the economic activities NACE classification information on all of the registered entrepreneurship forms in Poland. The institution's database identifies the NACE economic category of a registered firm of choice. The major economic activity of the geothermal heating plant is the production and supply of heat and hot water, the NACE section $D$ and $E$ (water treatment and delivery). Whereas the classification of the geothermal recreational centers is the NACE section $\mathrm{R}$ (sport, entertainment and recreation), and in case of a geothermal spa- section $\mathrm{Q}$ (medical and spa care). The geothermal plants providing water and heat encourage the activities of the NACE section C (industrial processing) and $F$ (construction). However next to it, accompanying businesses are expected to emerge. Since the geothermal recreational and health centers conduct additional commercial activities or can rent premises within the establishment, we performed a desk analysis of the dedicated geothermal water centers websites (Termalni, Infobasen). To verify the desk research the local geothermal specialists were consulted (see Acknowledgements). Using the CATI (Computer Assisted Telephone Interview) survey, the phone interviews were conducted using supporting software. The method ensures a high quality of the data collection since the interviewer is guided by the questions and interpretation errors are avoided. It is also a time optimizing method. As a complementary technique the CAWI (Computer Aided Web Interviewing) was run. The CATI and CAWI methods of data collection from a sample of individuals provide a systematic and bias reduced approach in the opinion of Lee \& Malhotra (2006) and Barbu \& Isaic-Maniu (2011). The local geothermal specialist were asked a series of questions regarding the economic activities that emerge locally related to the geothermal centers. Based in the collected information the NACE categories were matched using the CEIDG online catalogue. The experts were supplied with additional questions regarding the general economic condition of the municipalities.

The findings of the desk research and the experts interviews point out additional bundled services emerging along the geothermal spa and recreational centers. According to the NACE 
categories following employment sectors expand: hospitality and gastronomy (section I), beauty and hairdressing treatments (section S), rehabilitation treatments (section $Q$ ), retail trade (section $\mathrm{G}$ ), sports equipment rentals (section $\mathrm{N}$ ), event organization services (section $\mathrm{R}$ ) and households producing goods $(T)$. Therefore, the employment change represented by the differential shift result is associated with the group 3 (trade and services: NACE sections $G, H, I, J)$, and the group 5 (other services: NACE sections $M, N, O, P, Q, R, S, T, U$ ), in Table 5.2. No other commercial establishments in the municipalities that indicate the same NACE categories were identified throughout the CATI and CAWI research, nor the desk research. The NACE groups are already merged in the database of the Local Data Bank. We examine the differential shifts of both, the geothermal municipalities and poviats, resulting from the Table 5.3 pair comparisons. Following the differential shift results in Table 5.5, the dynamics of employment in the NACE group 3 and 5 answer our hypothesis that the local geothermal resources utilization leads to an increase of employment in the service sectors. If a growth in employment in both groups on the municipal level is observed, we associate it with the effect of the geothermal recreational and spa establishments.

Uniejów, Poddębice and Poddębicki poviat

Both municipalities observe a large growth of the employment in the two groups of NACE sectors ( 3 and 5 ) The number of trade and services employed in the poviat largely dropped there.The differential shifts for the Pyrzycki poviat yield negative for the same trade and services NACE sectors ( 3 and 5). The number of trade and services employed in the poviat largely dropped in the tested years. Hence, the factors within the Poddębice and Uniejów municipalities stimulate the growth in the services and trade employment over the 2005 and 2018 period. We associate it with the induced services employment connected to the geothermal recreational and spa centers present in both municipalities. Figure 5.1 illustrates the differential shifts values in trade and services sectors.

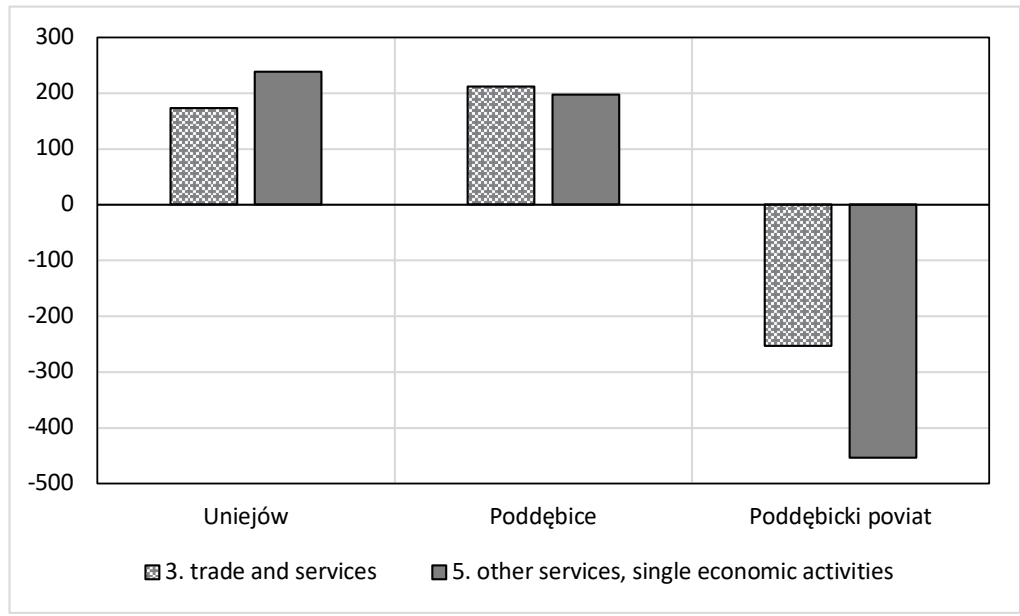


Figure 5.1: Visualization of the differential shifts $\left(S_{d}\right)$ for the Uniejów and Poddębice municipality and Poddębicki poviat in the years 2005 and 2018, per number of jobs in the two NACE categories of trade and services employment (see Table 5.5), own elaboration.

\section{Mszczonów and Żyrardowski poviat}

A moderate growth of employment in the trade and services sector of the group 3 and 5 takes place between the 2005 and 2018. The trade and services growth is related to the presence of the geothermal recreational establishment in the municipality; especially the hospitality and food establishments with other single recreational and commercial activities. Both services employment groups observe a striking decline in the poviat. Figure 5.2 presents the changes in the trade and services employment according to the obtained differential shifts.

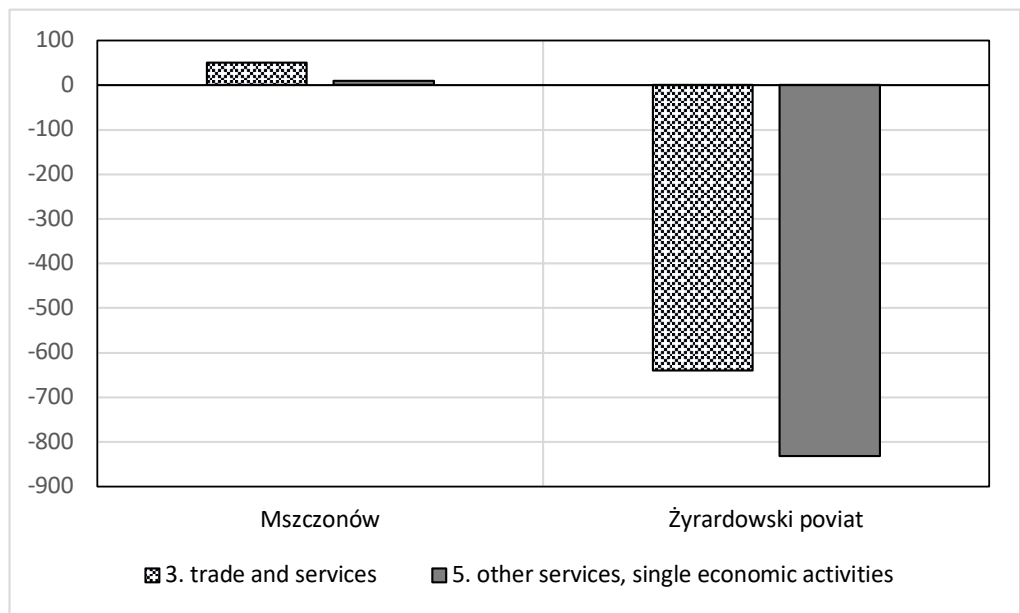

Figure 5.2: Visualization of the differential shifts $\left(S_{d}\right)$ for the Mszczonów municipality and Żyrardowski poviat in the years 2005 and 2018, per number of jobs in the two NACE categories of trade and services employment (see Table 5.5), own elaboration.

\section{Szaflary and Nowotarski poviat}

Following Table 5.5 results for Szaflary, the trade and services sectors attract the most of the employment among the other NACE categories. Group 5 shows a growth in employment, distinctly outperforming the poviat results. There are two geothermal recreational and spa centers in the municipality that cause this major employment demand in the related services sectors. The main employment trend are the services and singular economic activities that reprofile this municipality into a touristic destination. Figure 5.3 depicts the differential shifts findings. 


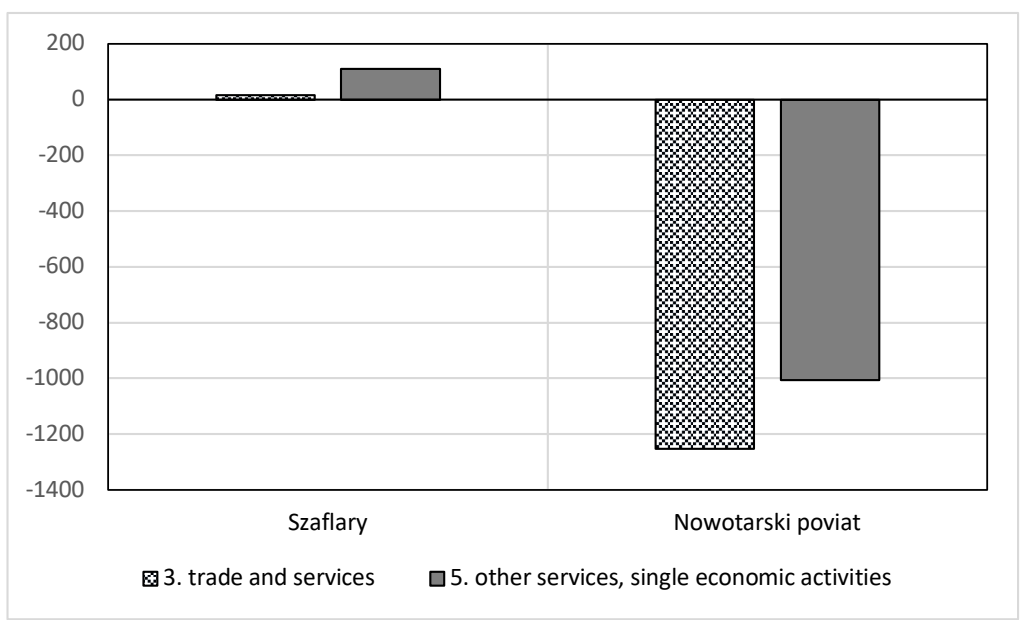

Figure 5.3: Visualization of the differential shifts $\left(S_{d}\right)$ for the Szaflary municipality and Nowotarski poviat in the years 2005 and 2018, per number of jobs in the two NACE categories of trade and services employment (see Table 5.5), own elaboration.

Zakopane, Bukowina Tatrzańska, Poronin, Biały Dunajec and Tatrzański poviat

These four municipalities are located within the same Tatrzański poviat. The strongest results of the differential shifts in the two trade and services employment categories among all of the examined locations are seen in the case of Bukowina Tatrzańska. Two big geothermal recreational centers attract new services and economic activities that distinguishes this municipality in the Tatrzański poviat. Zakopane known to be a popular tourist destination in the Polish mountains observes a large shift in the trade and services employment (group 3). However, other services and single economic activities (group 5) decline between 2005 and 2018. The geothermal recreational establishment in Zakopane is an additional tourist amenity, not a major local economic leverage. Moreover, it is a popular tourism destinations and the service sector is already vivid there. Both municipalities Poronin and Biały Dunajec observe a comparable differential shift in the trade and services employment. Between 2005 and 2018, a slight increase in the trade and services employment (group 3) is observed with a decrease in other services and activities (group 5). Both have an access to the same geothermal heating and water network, whereas no other geothermal resource utilization form is present. Therefore, it is expected that the number of trade and services jobs are generated by the tourism demand rather than the geothermal resources developments. Figure 5.4 depicts the analysis and the Tatrzański poviat losing employment in both NACE categories. 


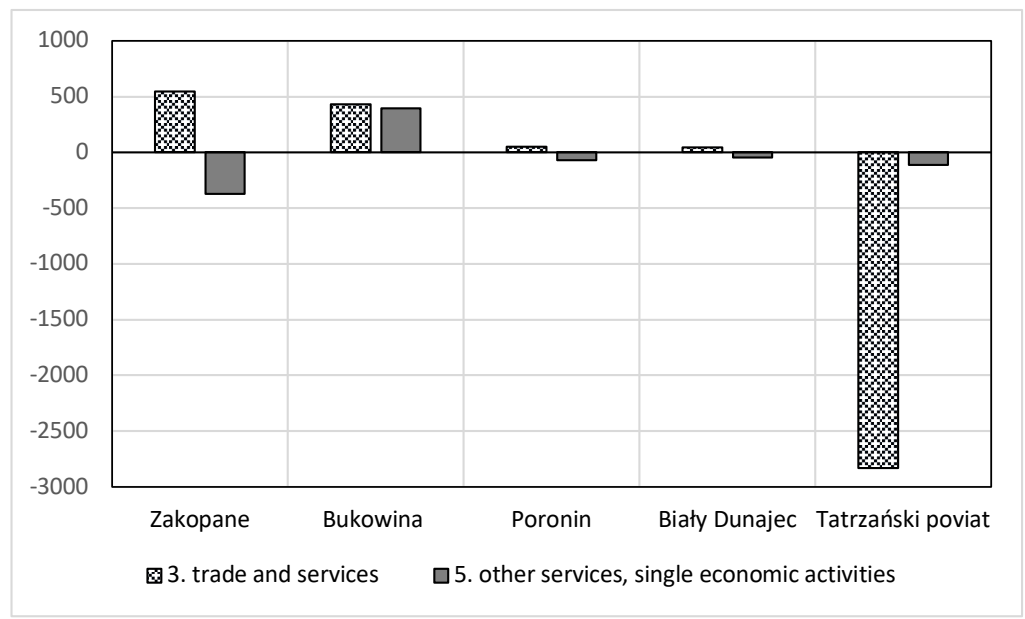

Figure 5.4: Visualization of the differential shifts $\left(S_{d}\right)$ for Zakopane, Bukowina Tatrzańska, Poronin, Biały Dunajec municipality and Tatrzański poviat in the years 2005 and 2018, per number of jobs in the two NACE categories of trade and services employment (see Table 5.5), own elaboration.

\section{Pyrzyce and Pyrzycki poviat}

The results of the differential shifts analysis point to the general growth of employment in trade and services groups in the Pyrzycki poviat, opposite to the Pyrzyce municipality where the trade and services jobs decrease (group 5) within the observed time. Figure 5.5 illustrates this finding. A geothermal heating plant is the only application of the resource in Pyrzyce.

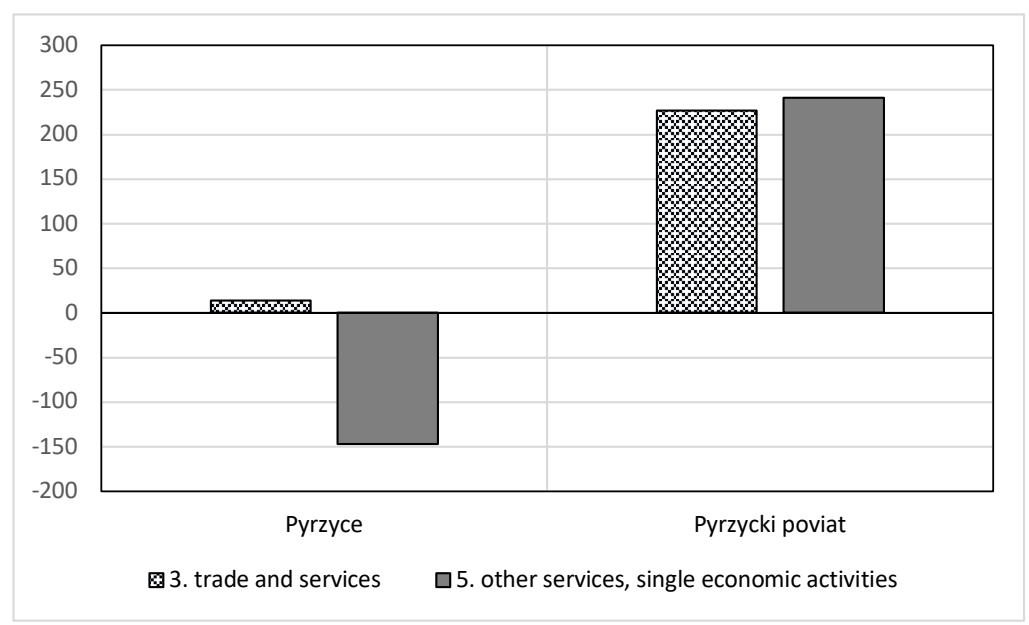

Figure 5.5: Visualization of the differential shifts $\left(S_{d}\right)$ for Pyrzyce municipality and Pyrzycki poviat in the years 2005 and 2018, per number of jobs in the two NACE categories of trade and services employment (see Table 5.5), own elaboration. 
Stargard and Stargardzki poviat

In both cases the trade and service sectors (NACE group 3) declined in employment between the years 2005 and 2018. Figure 5.6 observes the slight increase in the other services sectors and single economic activities (NACE group 5), an opposite trend to the poviat. As a municipal service Stargard offers geothermal heat and water to its inhabitants without further commercial application of this resource. Hence, the service jobs in Stargard are not directly related to the availability of geothermal utilization.

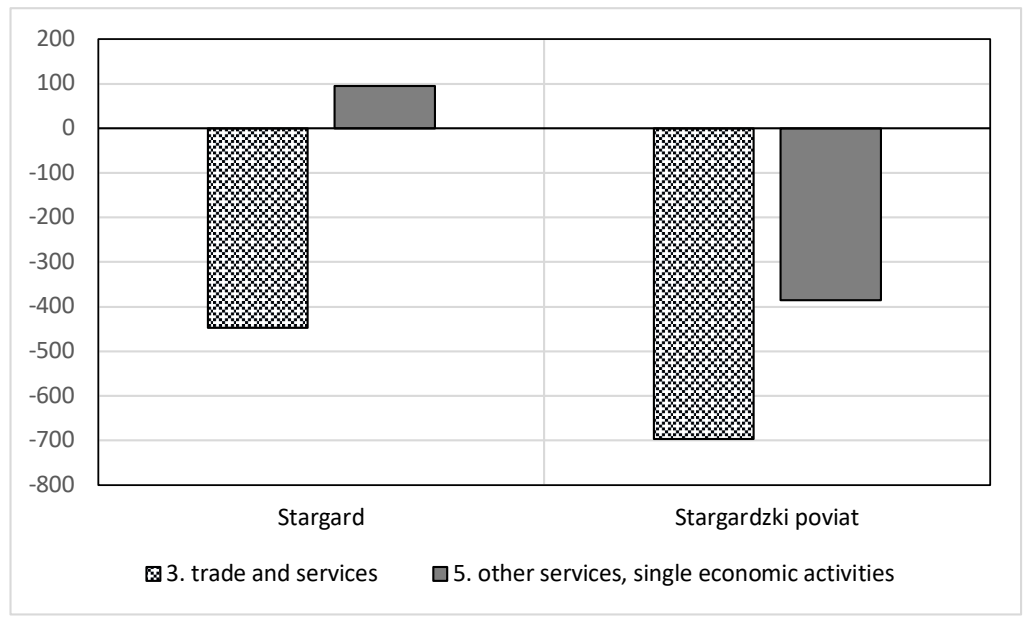

Figure 5.6: Visualization of the differential shifts $\left(S_{d}\right)$ for Stargard municipality and Stargardzki poviat in the years 2005 and 2018, per number of jobs in the two NACE categories of trade and services employment (see Table 5.5), own elaboration.

The shift- share method determines the direction of changes in the municipalities, which is then verified through the qualitative research. The analysis of the differential shifts in the NACE categories of employment in trade and services (group 3) and other services and single economic activities (group 5) shows the opposite result for the geothermal municipalities and poviats. This trend is visible especially in the municipalities with geothermal establishments. The highest number of employed persons in both services categories are found in the municipalities with at least one geothermal recreational center or spa, next to using the geothermal energy network (Uniejów, Poddębice, Mszczonów, Bukowina Tatrzańska, Szaflary). Therefore, having a geothermal establishment is considered as a local circumstance and it reveals in the positive scores of the differential shifts in the geothermal municipalities (Table 5.5). The municipalities without the geothermal recreational and spa establishments do not observe a considerable services jobs increase in our study. The control groups results confirm this observations. The shifts in the two services groups ( 3 and 5 ) are minimal regarding some unspecified factors of service employment occurring on the poviat and voivodeship level in the examined period of time. The geothermal utilization caused shifts impact stronger the employment structure in the municipalities. Therefore, we argue that employment in trade 
and services sectors has a positive contribution to the differential shift. The geothermal spas and recreational centers and the accompanying businesses contribute positively to the differential shift scores at the municipality level.

\section{5 Discussion and conclusions}

This research aims to find out if the local employment structure changes while using the geothermal resources. We zoomed into the ten cases of municipalities in Poland that utilize the resource. The employment data collection is limited to the years 2005 and 2018. We introduce the control groups of poviats. The NACE categories of employed population are used as the variables in the chosen method. The shift-share data analysis is applied, commonly used the regional sciences and here adopted to the local case study. The results show the compelling changes in the municipalities employment in the trade and services sectors linked with the presence of geothermal recreational and health establishments in Poland. These changes were not observed in the control pairs of poviats and voivodeships. The hypothesis the that the geothermal resources utilization leads to an increase of employment in the service sector at the municipality level is corroborated. The creation of the geothermal resources based tourism is expected to generate local jobs in direct and indirect forms. It is as well justified by the strong results of the differential shift in the geothermal municipalities that are associated with the local circumstances of employment dynamics.

Despite the economic growth in Poland between the 2005 and 2018 (IMF, 2018; Raszkowski \& Bartniczak, 2019), the examined geothermal municipalities observe an additional employment trigger. Our research finds out that the municipalities with a diverse utilization of the geothermal resources notice the strongest shifts in the employment towards the trade and services sectors. This trend is not found in the control group of poviats. Despite the rural typology of the municipalities, the specialization in recreation and health services emerged between 2005 and 2008. The industrial use of the geothermal resource as the heat and water provision results to be a minor factor of changes in the municipalities economic structure. The significant results of the differential shifts analysis in the trade and services sectors (group 3: NACE sections $G, H, I, J)$ and sectors representing services, sport, recreation, health care and single economic activities (group 5: NACE sections $M, N, O, P, Q, R, S, T$ ) are observed between 2005 and 2018 in each municipality that has the geothermal establishments. It indicates the increase of services jobs along the expansion of the recreational and spa geothermal centers in the municipalities. Since we obtain notable shift-share results in each municipality with at least one geothermal recreational or health establishment, we associate the change in the economic structure with this commercial utilization of the resource. The compared pairs of poviats and voivodeships do not observe this trend. Moreover, the results of the municipalities with solely a geothermal energy network do not show increased employment in the services sectors. Experts interviews confirm these findings. 
In this chapter, we consider changes the municipal level through the development of geothermal energy. The assumption of the article is to link the relationship of two phenomena: economic activity caused by geothermal energy, which began in 2005, and the impact on the employment structure in the examined municipalities. The impact is verified by analyzing quantitative data using the shift-share method. Thus, it is assumed that there is a cause and effect relationship. The shift-share results are verified through interviews with local specialists and validation of the cause-and-effect relationship between geothermal activity in areas specified by NACE categories and a determined change in the employment structure. Hence, the qualitative interview made the results credible. The dedicated reports (see: IRENA, ESMAP) show direct employment usually related to the units of produced energy. This is the commonly practiced direct jobs assessment. Our study proposes a new measuring method to evaluate the indirect employment unpaired with the energy units production. It also allows to observe if the number of new jobs are large enough to cause a structural change in the location between the examines years 2005 and 2018.

On the basis of the obtained results, their impact on the development of geothermal infrastructure is considerable. It is noticed that the sectoral structure in the municipality changes to such an extent that a specific economic sector may set the direction of the development. The structural change requires technical geothermal infrastructure. Research results show the importance of planning engineering works to utilize the resources. The development of a dedicated geothermal infrastructure is the basis for the economic use, e.g. the presented geothermal centers. Expanding the attractiveness of a municipality is driven by the targeted use of geothermal installations in the direction of e.g. health, recreation but also other direct applications indicated by the Lindal diagram.

According to the shift-share results stronger changes are seen in the municipalities economic structure than in the cases of the bigger poviats. Therefore, the geothermal resources exploitation especially in small localities can play a role of a local engine of growth or at least a new specialization opportunity. Especially Uniejów, Bukowina Tatrzańska and Szaflary with a large geothermal spas business are now considered in the public opinion as the new tourist destinations in Poland (Dej et al., 2014; Dryglas \& Hadzik, 2016; Halaj, 2015). The geothermal recreational and health establishments induce tourism, trade and accompanying economic sectors observed a growing employment demand. In the bigger local economies such as in Zakopane, Stargard, Pyrzyce the geothermal related activities are not a major economic impulse. If, it is one of the market factors among other predominant. The differential shift adopted as an indication of the geothermal effect in the municipality employment structure leads to considerably strong results in our study, opposite to the control group of poviats. This observation allows to open a further discussion about the benefits of geothermal based clusters of economic activities. The intensification of geothermal economic activities can benefit from the service sector potential. In fact, the study of Czaplicka-Kotas et al. (2020) reviews the energy cluster capacity for the Geotermia Podhalańska S.A. and the municipalities 
that use its geothermal network. The study underlines the need for the urban symbiosis based in the green geothermal energy. Nevertheless, the development of a cluster can further induce economic activities. On the other side, the geothermal cluster concept addresses the principles of the location theory. The stimulating role of geothermal centers to the local economy can attract related businesses. Therefore, considering the obtained results, our study establishes an argument for the expansion of the use of geothermal resources locally in Poland.

The geothermal energy is foreseen with future infrastructure expansion including the power production. The effectiveness of geothermal technologies enhances larger scale of the resources application argue Moya et al. (2018) and Kumari and Ranjith (2019). Advance applications of the geothermal energy production continue to develop (Ghazvini et al., 2019), also towards storage options (Wang et al., 2018). Moreover, geothermal technologies adjusted for district heating improve substantially (Weinand et al., 2019), reaching more beneficiaries of the geothermal energy. The technological advancements of the geothermal resources are expected to popularize the use geothermal resources. It helps creating further social value locally as we argue in this article. The geothermal use induces additional economic sectors, next to geothermal heat energy production. Hence, it is worth considering to invest in technologies that increase the use of geothermal energy locally.

\section{Acknowledgments}

The consultations about categorizing the NACE economic activities of the geothermal establishments were made possible by the courtesy of the following specialists, approached by personal communication (CATI and CAWI methods used): M. Balcer, B. Dajek (Geotermia Mazowiecka, April 2020); A. Biedulski (Geotermia Stargard, April 2020); W. Ignacok, M. Pelczarska (Geotermia Podhalańska, April 2020); A. Karska (Geotermia Poddębice, April 2020); B. Piątkowska (Geotermia Uniejów, April 2020); M. Szymański (Termy Mszczonów, April 2020); A. Łukaszczyk (Termy Szaflary, April 2020), B. Kępińska (Polish Geothermal Society, April 2020). 
Chapter 6

Dataset for the model of a municipality competitiveness in relation to the geothermal resources exploitation in Poland 


\section{Abstract ${ }^{18}$}

This dataset chapter corresponds with the model of local socioeconomic indicators elaborated in Chapter 2 and Chapter 3. The geothermal resources are assumed as a local competitive advantage for the municipalities that exploit them. In order to examine the relation between the exploitation of the geothermal resources and local competitiveness we determine a model of municipality competitiveness in Poland. Concept of the local competitiveness is referred to place-based measures (Kitson et al.,2004; Lovering, 1999; Mytelka \& Farinelli, 2000; Plummer \& Taylor, 2001) and it is related to the management of local resources (Malecki, 2004; Turok, 2004). Literature review suggests that the local competitiveness is best reflected in the indicators of economic welfare and sustainability (Audretsch et al., 2015; Meyer-Stamer, 2008). Therefore, we use an expert method to build the model of a municipality competitiveness indicators on the example of Poland. Throughout the Analytical Hierarchy Process (AHP) method engaged experts select the 24 indicators of local competitiveness. This method serves in situations of problem complexity (Kamenetzky, 1982; Saaty, 2008) and as a multicriteria method in the regional studies (Dinc et al.,2003). Aggregation of the AHP selected indicators yields a synthetic competitiveness index for each of the municipalities that we examine. This index constitutes the model dependent variable in the related research article. This procedure of building municipality competitiveness model sets an example of approaching a complex phenomenon such as the local competitiveness definition. The versatility of this method enables its application into related research cases.

18 Chapter published as: Kurek, K. A., Heijman, W., van Ophem, J., Gędek, S., \& Strojny, J. (2020). Dataset for the model of a municipality competitiveness in relation to the geothermal resources exploitation in Poland. Data in Brief, 31, 105687. 


\subsection{Specifications Table}

Subject

Specific subject area

Type of data

How data were acquired

Data format

Parameters for data
collection

Renewable Energy, Sustainability and the Environment

Social sciences in the context of renewable energy exploitation. Development of the local competitiveness concept determined by the endogenous indicators.

Table

Figure

The data applied in the research addresses two constrains of the research problem: the construction of a local competitiveness model and the geothermal resource parameters of the exploitation. The socioeconomic indicators data to build the local competitiveness model are collected from the Local Bank Data, the largest in Poland dataset of information on the socio-economic, demographic, social and environmental condition describing voivodships, poviats and municipalities as entities of the social and administrative organization of the state. It is developed and maintained by the Central Statistical Office in Poland. We acquire the data for the 11 geothermal municipalities and for the 55 benchmark municipalities, i.e. 63 municipalities in total. The set of raw data is collected for the years 1999-2017. This data serves to build the 24 socioeconomic indicators for each of the 63 municipalities in the given period. These indicators are further aggregated to a synthetic index using the Analytical Hierarchy Process (AHP) method by using the Super Decision software. The geothermal exploitation data in the geothermal municipalities is a primary data obtained directly from the local geothermal plants. It is represented in the GJ units and due to the restrictions of the data providers and its non-public character is kept unpublished.

Raw

Filtered

Aggregated

Analyzed

The raw data contains 3024 records that are further used to build the 24 socioeconomic indicators for the 63 municipalities for the time frame of 1999-2017. The raw data is collected from one source, 
Description of data collection

Data source location

Data accessibility the Local Data Bank. The procedure of the AHP determines the indicators model including the weight assessment for each of the model component. As a result, we obtain a synthetic index of competitiveness for each municipality. The essence of the APH method is an experts questionnaire. The biggest constrain about the AHP method is the experts selection and building a questionnaire that assures the consistency of replies. The method requires a number of experts to determine the local competitiveness data model. We reached personally to the experts' group and monitored the process of filling each AHP questionnaire. The geothermal exploitation data constitutes a primary collected data, and since it is restricted information, offered by the courtesy of the geothermal enterprises, it had to be anonymously processed in the model.

The regional economics experts and practitioners are asked to assess the indicators that represent the competitiveness of a municipality, on the example of Poland. Furthermore, using the AHP method questionnaire we approached a larger group of experts (a batch of twenty persons) to establish the hierarchy among the competitiveness indicators yielding a weights model. The AHP experts constitute a mixed group of theorists (regional economists) and practitioners (geothermal municipalities' representatives).

The geothermal data for the geothermal GJ units production variable is collected directly from the local geothermal enterprises and constitute a primary data. The data about the geothermal recreational centers is advised from the same geothermal entities and supplemented from a dedicated website (www.termalni.pl).

Country: Poland

Central Statistical Office, Local Data Bank

https://bdl.stat.gov.pl/BDL

http://termalni.pl

Geothermal enterprises:

Geotermia Mazowiecka SA, Geotermia Uniejów LLC, Geotermia Poddębice LLC, Geotermia Podhalańska SA, Bukowina Geothermal Society LLC, Geotermia Grudziądz LLC, Geotermia Pyrzyce LLC, Geotermia Stargard LLC.

Repository: Mendeley Data

Kurek, Katarzyna A., Heijman, W., van Ophem, J., Gędek, S., \&

Strojny, J. (2020c), "Dataset for the model of municipality 
competitiveness in relation to the geothermal resources exploitation in Poland.", Mendeley Data, V2.

Related research article Kurek, K. A., Heijman, W., van Ophem, J., Gędek, S., \& Strojny, J. (2020a). The impact of geothermal resources on the competitiveness of municipalities: evidence from Poland. Renewable Energy, 151, 1230-1239.

\subsection{Value of the data}

The chapter proposes a conceptualization of local competitiveness that is unobserved in existing literature. Since the local competitiveness definitions vary among scholars we provide an approach that bases in the local experts and local data assessment. Our approach presents a method to develop a single measure of the local competitiveness, i.e. the competitiveness index.

The development of the index allows for a transparent comparison and analysis of the competitiveness level for the selected municipalities. The data selected for describing the local competitiveness phenomenon represents a spectrum of municipality performance measures. The socioeconomic indicators grouped in six categories of: demographic dynamics, local economy references, state of public finances, tourism activities, infrastructure development and level of life standards illustrate a complex and practical overview of a municipality competitive condition.

The choice of the socioeconomic data is determined by the availably of the data in the Polish Central Statistical Office database. Moreover, the group of experts has indicated the data structure of the local competitiveness model. It is additionally justifying the choice of the socioeconomic indicators that refer to the local competitiveness concept. The data in such set is available for any municipality in Poland; therefore the model is replicable for other, related studies and disciplines. It allows observing the competitiveness indicators for an examined municipality as well as for comparisons of municipalities. The selection of socioeconomic indicators can be as well adjusted to examine regional or national competitiveness, not limited to Poland. Moreover, application of the proposed data and competitiveness index serves for any other research that requires local competitiveness measures.

The given dataset reveals relevant simplicity in collection procedure and broad availabilities for interpretation. It is as well a non-costs generating method because the raw data in case of the Central Statistical Office in Poland on this level of availability is free of charge and located online. This type of data composition is not found in the existing literature or in the data repositories. Yet, a new research problem is conceptualized using available and affordable sources. As a result, we deliver a comprehensive model of local competitiveness. This data can 
be used in any research projects related to the concept of competitiveness on the municipalities level.

\subsection{Data description}

The main assumption about the geothermal resources impact on local competitiveness in Poland requires appropriate data. Hence, the data selection is a decision making process. It mainly concerns the dataset that is available and comparable at the given level and in the same time reflects on the competitiveness performance. In case of this research problem, the dataset had to reflect on the local competitiveness indicators on a municipality level. We operationalize the problem of local competitiveness by the help of experts using the Analytical Hierarchy Process (AHP). Based on a hierarchical structure, this method developed by Saaty (2008) serves for managing qualitative and quantitative multi-criteria elements involving in a decision-making behavior. The decision about the structure of the data model boils down to the pairwise comparisons delivering the matrix of experts answers. The model of 24 socioeconomic indicators determining the local competitiveness is included in the example of the AHP expert questionnaire in the Appendix. The raw data extracted from the Local Data Bank online source that served to design the socioeconomic indicators model is available in the Mendeley data repository accessible by the dedicated data article (Kurek et al., 2020c). The data in the Local Data Bank allows for collection of systematized values in the selected sections. Therefore, a risk of unclassified data or sources is eliminated. Included in the Appendix, the matrix of 24 diagnostic socioeconomic indicators grouped in six categories and related four subcategories is determined by the experts. It sizes a-municipality competitiveness on the level of local demographic structure, entrepreneurship, condition of public finance, expansion of local infrastructure and level of life measures. The period of data collection regards to years 1999-2017, since the year 1999 brought the administrate reform in Poland that introduced a poviat unit. The poviat is a superior administrative area to a municipality in Poland, and two control variables of the main model in the related research article refer to the data collected on the poviats levels (Tab. 3.1 in Chapter 3). The same source of the Local Data Bank was used for these poviat variables.

Since the related research article aims to compare the local competitiveness index among the municipalities that use the geothermal resources and municipalities without the geothermal activities, the selection of Polish municipalities refers to 11 geothermal municipalities in Poland and additional 55 municipalities that were matched according to the benchmark principle (Strojny, 2015). Therefore, each of the geothermal municipality receives a group of five benchmark municipalities. The condition of the benchmarks selection required: the same administrative classification of a municipality, location within the same poviat, comparable size of inhabitants and economic profile. The data for the benchmarked municipalities is as well sourced in the same Local Data Bank database, and it is presented in the dataset article (Kurek et al., 2020c). The selection of the geothermal locations is limited to the municipalities that 
exploit the geothermal resources for a minimum of 5 years and captured in the Table 3.2 in Chapter 3. Therefore, the socioeconomic data is collected for the selection of 63 municipalities.

The Analytical Hierarchy Process experts comparisons in pairs yield weights assessment for each of the indicators (Tab. 3.4 in Chapter 3). This procedure of generating the weights is possible by using a specially designed questionnaire, which is further distributed to experts (Appendix). Each decision maker fills in questionnaire and then all the individual expert judgments are converted into the group judgments (for each one of the pair comparison) using their geometrical average. The scale ranges from 1 to 9, where 1 implies that the two elements are the same or are equally important. On the other hand, 9 implies that one element is extremely more important than the other one in a pairwise matrix. The pairwise scale and the importance value attributed to each number are explained in the Appendix of this thesis.

By the aggregation procedure (formula 2 in Chapter 3 ) the indicators weighted by the AHP method generate the synthetic local competitiveness index. This procedure repeats for each of the examined municipalities. As a result of the aggregation computations, each of the geothermal municipalities and the benchmark municipalities receive the competitiveness index $(C l)$, a singular indicator of competitiveness for each of the observed years 1999-2017. The $\mathrm{Cl}$ places in the 0-1 range, where 1 represents the highest score of the municipality competitiveness throughout the observed time period. The $\mathrm{Cl}$ determines the level of the municipality competitiveness and is used to build the dependent ( $y$ ) and the independent model variable $(x 3)$ in the description of model variables in the Table 3.1 in Chapter 3. Furthermore, the other independent model variables $x 4$ and $x 5$ are sourced in the Local Data Bank, whereas the variables $x 1$ and $x 2$ are obtained directly from the geothermal enterprises listed in the Table 3.2 in Chapter 3. These two have a non-public character. The scores of the local competitiveness indexes for the observation of selected geothermal municipalities and the assembled score for the benchmark municipalities are presented in the Table 3.5 in Chapter 3.

The selection of the local competitiveness data on the example of Polish municipalities is originally presented in our study. Nevertheless, it is not limited to the subject of the related research article. It as well reveals a potential of application into analysis that require definition of a local competitiveness in Poland. 


\subsection{Experimental design, materials and methods}

The Analytical Hierarchy Process tool i.e. the questionnaire distributed to the 20 experts is elaborated by the dedicated software Super Decisions (version 3.2). Attention is paid to the important element of the AHP analysis i.e. the Consistency Ratio (CR) coefficient that verifies the internal consistency of experts' judgements in pairs (Saaty, 1990). The acceptable CR score should be lower than 0.10 to justify the outcomes of the experts judgements. It therefore indicates the significance of the responses.

The example of the questionnaire distributed among the experts is presented in the Appendix. It starts with the introduction section that is meant to explain the tool, and purpose of acquiring an expert opinion. The experts were approached beforehand the questionnaires distribution and invited to participate in the AHP research. The local competitiveness indicators matrix that is to be assessed by the experts initiates the questionnaire. Thereafter, the questionnaire is designed in seven sections that each contains the corresponding decisive problem related to the local competitiveness model structure represented by the Table 3.3 in Chapter 3. The experts evaluate each of the section giving a judgement to each pair of given indicators. The method generates the weights model (Tab. 3.4 in Chapter 3), for each of the socioeconomic indicators that are set to describe the local competitiveness (Table 3.3 idem). This AHP questionnaire is not presented in the accompanying research article. 
Chapter 7

Synthesis 
This chapter provides a synthesis of the thesis results. It starts with a general discussion addressing the scientific problem elaboration in the study in section 1. It is followed by a discussion of the specific findings in the chapters resumed in section 2 . In section 3 , the findings of impact of geothermal resources on local development are highlighted. Section 4 deals with the considerations on and limitations of the data in each study. The last section 5 is a discussion of the function of geothermal energy in the local economy. Scenarios for the future development of the resource in general, and in Poland in particular closes this synthesis.

\subsection{General discussion}

Without natural gifts, technical rules are useless (Quintilian, 35-96 AD) ${ }^{19}$

Geothermal energy is a natural gift for locations, and tapping into it opens technical opportunities of use. This statement inspired by the Quintilian's thought, guides throughout this analysis of the role of geothermal resources in local development. The geothermal resource is argued to have a direct, indirect and derived economic effect (Hance, 2005; Jenniches, 2018; Johnson et al., 2012; Mwangi, 2010; Tourkolias \& Mirasgedis, 2011). Economic base models estimate direct, indirect, and induced impacts on basic economic activities within a defined economy as a local economy. The direct impact of the geothermal energy is associated with the demand for the energy production i.e. capacity and outputs of the geothermal plants. The indirect impact includes local financial outputs of the geothermal plants i.e. taxes fees and incomes contribution to local budgets, as well as the price of geothermal energy produced and direct employment, whereas the induced impact refers to the local consumption of the geothermal resources observed in economic activities, derived jobs, services and incomes.

This thesis is dedicated to the analysis of the geothermal resources impact on local economies. The subject of the research are the selected municipalities in Poland, that utilize the geothermal resource in available forms. Hence, the scientific problem is the change that happens in the socioeconomic structure of a municipality related to geothermal, not the performance of the geothermal plants or financial resource profitability. Whereas the direct and indirect impact have established methods of analysis in the literature, the induced impacts are yet under examined, thereby creating a research gap (see Chapter 1.4). The induced impact of the geothermal resources becomes evenly important in the development of the geothermal projects. The heavy investment costs carried upfront the geothermal installations are expected to have social and economic benefits. Since the geothermal projects require public finance support, the effect they deliver has to benefit the society. Especially in a case like Poland, where the geothermal infrastructure is financed from the state fiscal mechanisms and designated national funds (Sowiżdżał et al., 2019), therefore from the public budget. Single

19 (Quintilian, 2015) 
private initiatives are not yet observed in the geothermal infrastructure development. The main research question ( $R Q 0$ ) what is the impact of the geothermal resources utilization on the development of the municipalities in which they occur focusses on determining the type of the impact. The research problem of this thesis assumes the induced local impact. Although the induced economic impact of the renewable resources is discussed in the literature (Aniello, Többen, \& Kuckshinrichs, 2019; Hartono et al., 2020; Jenniches, 2018; Lehr, Banning, Hegazi, \& Youssef, 2012), there are no established methodologies to measure it. This study proposes various methods to analyze the research problem. The hypotheses set throughout the thesis predict what type of major changes within the geothermal location incurs with the use of the resources. The time frame in which the research problem is studied refers to the 1995-2018 period. The choice of ex-post data is argued in the nature of the research problem (see Chapter 1.7) referring to the data of 1995-2018. Table 7.1 encloses the research questions of each chapter that operationalize the research problem of this study with the accompanying hypothesis. The main research question ( $R Q 0$ ) is elaborated in the research (sub) questions RQ 1-4. In Chapter 4 and Chapter 6 the research questions are studied without a set hypothesis.

Table 7.1: The study research structure as a compilation of the research questions (RQ) and corresponding hypothesis $(\mathrm{H})$, own elaboration.

RQ 0: What is the impact of the geothermal resources utilization on the development of the municipalities in which they occur?

$\mathrm{RQ}$ 1: Whether the geothermal resources utilization impacts the performance of a municipality?

\section{Chapter 2}

$R Q$ 1.1: Whether the introduction of a geothermal spa in a municipality increases the local socioeconomic development?
$\mathrm{H}$ 1.1: Introduction of a geothermal spa accelerates the socioeconomic development of the municipality in which it is established.

\section{Chapter 3}

$R Q$ 1.2: Is there a relationship between the development of geothermal energy and the competitiveness of the municipalities?

\section{Chapter 4}

$H$ 1.2: Exploitation of the geothermal resource has a positive impact on the competitiveness of a municipality.

RQ 2: How comparable are the results yielded by the Principal Component Analysis and Analytical Hierarchy Process methods in the situation of secondary data?

\section{Chapter 5}

RQ 3: Whether the local employment

H 3: Geothermal resources utilization leads to structure changes while using the geothermal an increase of employment in the service resources? sector at the municipality level.

\section{Chapter 6}

RQ 4: Which data conceptualize local competitiveness? 
Every chapter of this thesis contributes to the elaboration of the main scientific problem of the impact of the geothermal resources utilization on the development of the municipalities in which they occur. Three chapters (Chapters: 2, 3, 5) dedicate to the methods that test the assumed impact of the geothermal resources utilization on the local economy. Research question whether the geothermal resources utilization impacts the performance of a municipality ( $R Q 1$ ) is composed out of two complementary research questions ( $R Q 1.1$ and $R Q$ 1.2), and elaborated in separate chapters (Chapter 2 and 3). Chapter 2 is focused on the relationship between the geothermal recreational and spa establishments with the developed model of local development, whereas Chapter 3 presents a method to verify the impact of the geothermal energy production on the competitiveness of municipalities.

In Chapter 2 the relationship between the emergence of the geothermal spas and recreational centers and the parameters that describe the local development are examined. The study assumes that the introduction of a geothermal spa impacts and accelerates the socioeconomic

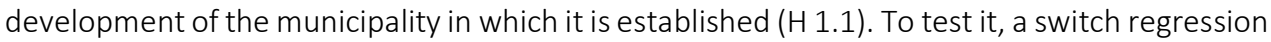
model is proposed. Using the multicriteria method Principal Component Analysis a municipality development index is generated. Statistical observation of the indexes for the six municipalities in Poland are conducted in the switch regression model. The geothermal recreational and spa centers act are found impacting the municipalities. These establishments act as a switch factor in the development trend, and in most of the cases accelerating it. In case of municipalities with lower socioeconomic indicator values before the introduction of the geothermal spa, a double of the indicator is observed. The outcomes of the model presented in Chapter 2 corroborate the hypothesis $\left(\begin{array}{ll}H & 1.1)\end{array}\right)$ that the local socioeconomic development of the municipalities where the geothermal spas and recreational centers operate grows in time. Since it is a single factor impact analysis without control variables further testing is conducted. The findings of the Chapter 2 are used tentatively and next studies continue the pre-discovered impact observations.

Chapter 3 tackles a broader research question whether there is a relationship between the development of geothermal energy and the competitiveness of the municipalities (RQ 1.2), in accordance with Porter's (2010) observations about the competitive advantage of geothermal energy. The proposed model takes into account the available forms of the geothermal resources in the selected eleven Polish municipalities. The main hypothesis that the exploitation of the geothermal resource has a positive impact on the competitiveness of a municipality ( $\left.\begin{array}{ll}H & 1.2\end{array}\right)$ is derived from the concept of endogenous resources competitiveness. The benchmark approach is used and the municipality competitiveness index to measure the assumed relationship with the geothermal resources. After conducting the sensitive analysis a significant relationship is confirmed between the competitiveness index of tested municipalities and the parameters of geothermal energy, not found for the benchmark municipalities. The hypothesis ( 1.1 and H 1.2) in both chapters are corroborated. Hence, it is argued that the utilization of the geothermal resources in municipalities impacts their 
performance. With time and the amount of geothermal energy produced they run a high chance of becoming more competitive. The establishment of the geothermal recreational and spa centers is moreover found to have a switch function to the speed of local development. The two chapters address the research question RQ 1 . The performance of a geothermal municipality (here its socioeconomic condition) improves when the geothermal resources become part of the local economy. The observations of the two chapters open a discussion if the deployment of geothermal resources in municipalities creates local endogenous innovation.

The cases of the geothermal energy impact on local employment are presented in Chapter 5. The role of the geothermal resources in the municipalities employment structure is measured. For this purpose, the research question ( $R Q$ 3) whether the local employment structure changes while using the geothermal resources is elaborated in a comparative analysis. The structure of employment of the selected geothermal municipalities is analyzed, using as well benchmark approach. In the examined cases, the employment structure notices a shift in the given time period towards services and tourism, which corroborates the hypothesis $(\mathrm{H} 3)$. The choice of the method is justified since the shift-share analysis is adopted to explain regional economic conditions that differ from national level trends. The observation of the employment data analysis point to significant growth of the employed in services in the municipalities, opposite to the employment trend in the poviats. The services activities that are related to the core profile of the geothermal recreational and spas centers are found in particular to develop in the geothermal municipalities. Moreover, the general employment numbers grew faster in the geothermal municipalities than in the reference poviats. Further observations of the shiftshare results indicate that the traditional economy sectors like agriculture and industry in the municipalities lost employees to the benefit of the service sector. The study in Chapter 5 evidences that new activities related to tourism and services emerge related to the geothermal resources application in the local economy.

Chapter 4 and 6 are dedicated to the applied methods and verification of the established models for statistical analysis. The synthetic indicators concerned the local development indicator (indicator $D$ ) for a geothermal municipality in Chapter 2 and the competitiveness index (indicator $\mathrm{Cl}$ ) that allows for comparisons between the municipalities in Chapter 3 . Although the two indicators are based in the same socioeconomic data, their values are obtained using different methods, chosen according to the assumptions of each study. Chapter 4 of this thesis is dedicated to the methodology of multicriteria analysis used in both chapters. It focuses on answering the research question (RQ 2) how comparable are the results yielded by the Principal Component Analysis and Analytical Hierarchy Process methods in the situation of secondary data. The non-parametric correlations of the indexes rankings served to tackle the research problem and a significant correlation between the indexes is confirmed. 
The interpretation allows to answer the research question (RQ 2) that both methods PCA and AHP deliver similar results using the same data. Nevertheless, to examine if both methods deliver convergent findings the integration method is introduced. It bases on the weights comparisons that both multicriteria methods generate. Moreover, the reasoning behind integrating methods of quantitative and qualitative character lies in addressing a similar research question and methods strengths according to (Hammersley \& Atkinson, 1995; Kaushik \& Walsh, 2019; Tashakkori \& Teddlie, 2010). Mixing methods should consider the epistemology principle of the paradigm of choice (Patton, 2002), that the choice of the style of mixing the methods is adopted to the research purpose. The results of mixed modelling indicated the utility of the PCA method for a multicriteria analysis of secondary data type. Chapter 4 enhanced a new methodological approach to a multicriteria analysis. The choice of the method should be done upon the research type and data specification, and following the Ockham razor principle the simplest solution is preferred.

Chapter 6 of this thesis dedicates to the development of the socioeconomic indicators model that served to determine municipalities' local development (Chapter 2) and the comparison of municipalities' competitiveness (Chapter 3 ). The chapter has a data study format led by the research question (RQ 4) which data conceptualize local competitiveness. The purpose of this analysis to develop a set of socioeconomic indicators that optimally determine the economic performance and structure of a municipality in Poland. The model that consists of the 24 indicators matrix is assessed to best represent the categories of municipalities' development. In Chapter 6 next to the socioeconomic dataset elaboration, the Analytical Hierarchy Procedure tool, i.e. the questionnaire is introduced in detail. Since it is an expert based procedure, in contrast to the self-sustained Principal Component Analysis, the questionnaire is a separate qualitative procedure. The constructed socioeconomic model for a municipality is a core element of the conducted study in this chapter.

\section{2 Discussion on chapters findings}

This thesis presents novel approaches to measure and determine the induced impact of the geothermal resources on the local economy. It focuses on a historical analysis of a phenomenon that occurred as a result of a particular investment choice in a municipality. As discussed, the induced effect derives from the geothermal activities in the Lindal diagram (Fig. 1.6 in Chapter 1; Gudmundsson et al.,1985). In the case of Poland, Kępińska (2019) lists the geothermal activities in Poland (see Fig. 1.8 in Chapter 1.3). Next to the geothermal heat energy production, the second biggest geothermal resources application in Poland is the bathing, recreational and health centers. To solve the main research question ( $R Q 0)$ what is the impact of the geothermal resources utilization on the development of the municipalities in which they occur, the geothermal activities are tested throughout models with a local data. 
In case of the selected municipalities in Poland (Tab. 1.2 in Chapter 1.7) the induced impact is found in the data examination in the Chapters 2, 3 and 5. Chapter 2 and 3 base in the operationalized concept of municipality performance, formed of the 24 socioeconomic indicators. The developed index serves as a measure of municipalities socioeconomic performance expressed as: financial condition, employment level, infrastructure investments, information about the households and environmental instruments (Chapter 6). The versality of this approach contributes to the regional sciences, where the conceptualization of local competitiveness or development is required. Importantly, this synthetic measure serves to assess the general condition of a municipality in Poland, since there are no established indicators on the municipal level corresponding with e.g. GDP (gross domestic product), GNP (gross national product) or HDI (human development index). Furthermore, the indexes are applicable in the benchmark studies and serve for derived statistical operations. Hence, the thesis contributes to the development of a generalized model that designates a municipality' development pace, or if applied as the benchmark procedure, it determines the local competitiveness. The findings of the two studies in Chapter 2 and Chapter 3 indicate a relationship between the geothermal resources and local development.

The positive role of the geothermal centers for the municipalities development is observed in the Chapter 2 and 5 results. According to the Lindal diagram the bathing and balneology use is already possible with a low temperature resource $\left(30-40 \mathrm{C}^{\circ}\right)$. This condition fosters the establishment of geothermal centers. In addition, the geothermal recreational and spa centers are found impacting the local economy, employment, tourism sector and infrastructure. It all therefore creates an argument for the development of the geothermal establishments, if the geological conditions of the resources allow for it. The geothermal resources are found to be an advantage to their local economies. They indirectly contribute to the expansion of the local service sector and to local entrepreneurship. Local economies respond to the new economic element in providing accompanying services, absent before. That is why, the geothermal resources can be portrayed as a factor endowment, a characteristics of a local development factor. The study of the World Bank (2017) considers local renewable energy resources including the geothermal as factor endowments. The expansion of the geothermal energy production contributes to reducing dependency from external development factors (i.e. energy and economic resources).

The geothermal bathing and spa centers became a tourism specialization factor in the examined municipalities in Poland. In some of them, the local economy has transferred towards tourism and related services. Since this result is not observed in the control groups, it is associated with the geothermal resources use impact. Municipalities like Szaflary, Uniejów, Poddębice and Bukowina Tatrzańska are the main examples of reprofiling their economies related to the establishment of the geothermal centers. This implies that the employment in traditional sectors declines in favor of tourism and related services. It is argued especially for the rural municipalities, where the agricultural activities decreased and tourism and single 
economic activities emerged. Chapter 5 complements these findings, including references to the location theory. A comparative analysis is carried out showing the effect of the geothermal resources commercial application on the local employment market. The data analysis points out the growth of jobs induced by the geothermal resources use. The employment in the geothermal sector is usually measured in relation to the electricity and heat production, i.e. the direct employment (Meyer \& Sommer, 2014). The employment factor helps indicating the number of jobs created per a unit of energy and it is multiplied by the resource capacity (varying per country). However, this mechanism omits the calculations of the number of employed in other than geothermal energy production activity. Therefore, the indirect and induced jobs are determined at a regional level. Lehr et al. (2012) and Llera et al. (2013) argue that in the renewable sector there is generally more indirect and induced employment than the direct one and they give indications of a socioeconomic impact. The results of this thesis show that the scale of employment caused by the geothermal resources can be measured alternatively. An indirect model of measuring a geothermal impact on employment is proposed. The shift-share method of regional studies is translated into local study cases, which is a contribution to the method popularization itself. The main finding indicate that the geothermal induced jobs in the service sector jobs add to the value chain and therefore elevate the local economy. Structural transformation from the traditional work sectors into service, tourism and entrepreneurship are the flagships of local development indicated by the World Bank (2018). The shift-share approach used in the Chapter 5 is helpful when considering future supply and demand conditions for infrastructure in a geothermal location. Hence, the proposed model is further applicable to geothermal impact studies.

Subsequent thesis findings relate to the methodology of a municipality development model. Since it is described by a matrix of indicators the multicriteria procedures were used. Chapter 4 and 6 focus on the multicriteria analysis used to build the synthetic indexes. The two chapters are complementary in the validation of the local development model. Chapter 4 elaborates a new approach to analyze two multifactor methods different in principle, the PCA and AHP. They are compared according to non-parametric testing revealing the convergence in results. This examination is used as a cross validation of the multicriteria model of socioeconomic indicators used as a core determinant of the thesis research problem. Since there is a significant correlation between the two methods, the approach is found statistically valid. Furthermore, an integration model is developed. The weights that the methods generate is what differentiate their multivariate operations. Nevertheless, the multicriteria structure that the methods propose is what determined the method choice. In the situation of a method choice the simpler solution is preferred. Ockham's razor resolves the heuristic problems that regard the choice between the simple and complex explanation, where both work equally well. In case of the study in Chapter 4, the Principle Component Analysis procedure was of a simpler structure. Therefore, it is proposed to use this factor dimension reduction method to a standardized and secondary datasets. The study in this chapter contributes to an in-depth understanding of the principles of the PCA and AHP methods. 
Chapter 6 discusses the data composition and proposes a socioeconomic model. The ex-post socioeconomic data (sourced in the Local Data Bank depository for the years 1995-2018) served to build the municipality development model. The ex-post is a forecast for a certain time period using the past data. In this case, the ex-post data are the socioeconomic indicators for the selection of 63 municipalities in Poland (see Chapter 3 and Chapter 6). According to the data structure the inductive approach is used. The posterior data serves to establish a theoretical model. Furthermore, the inductive study is followed up with deductive research to validate the model. Therefore, the conclusions are drawn from particular geothermal cases to general forecasting on the geothermal resources impact on local economies. The general statistical data model introduced in the Chapter 6 allowed inducting the impact of the geothermal resources on municipalities. The inductive reasoning concludes from particular to general interpretations. Therefore, by using the inductive reasoning it is possible to generalize the observations obtained in the thesis. Moreover, the data used in the model is openly available. That results in a versatile model, applicable to measure the local development in relation to any other phenomenon.

This thesis presents original approaches to measure and define the local induced impact of the geothermal resources. The induced impact is considered to represent an effective use of the resources in the locations. Moreover, a location gains business attractiveness for related investments. Therefore, as the relevance to the location theory, geothermal resources potential enables related businesses location. Following Porter (2010), under favorable market circumstances geothermal resources impact on local economy can lead to a cluster formation. Resulting from the thesis chapters, the key findings are summarized in Table 7.2. 
Table 7.2: Major thesis findings summarized, own elaboration.

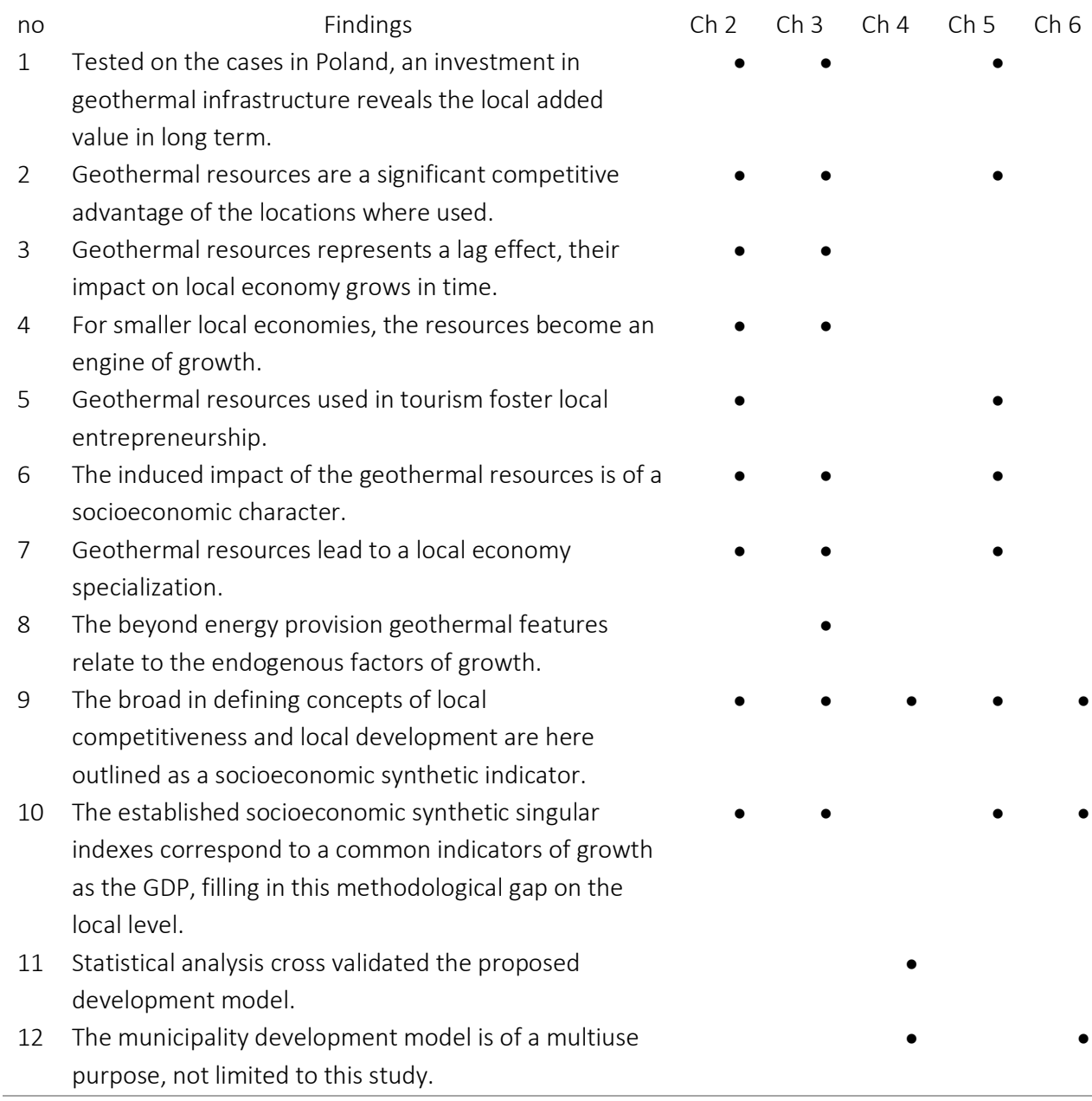

The majority of findings relate to the thesis chapters, where the statistical operations were used to determine the impact of the geothermal resources on municipalities development. The other findings point to the utility of applied methods and validate the established econometric models. The map of the chapters findings aim to illustrate the common conclusions across the chapters. It depicts as well the distribution of the research intensity among the chapters.

\section{3 Discussion on geothermal resources impact on local development}

The research problem of this thesis concerns determining the function of the geothermal resources other than the energy provision. To approach the research problem the general research question was set supported by the compilation of sub-research questions. In this 
thesis it is investigated if the geothermal resources exploitation impacts the location where exploited. The local element undergoes the analysis, since the resources are utilized in the proximity of depletion. Each of the thesis chapters is designed towards answering the main research question of the thesis. However, Chapters 2, 3, and 5 focus on the core geothermal impact analysis. Studies in the Chapter 2 and Chapter 3 answer the question whether the geothermal resources utilization impacts the performance of a municipality (RQ 1$)$. The outcomes of Chapter 2 evidence a relationship between geothermal recreational and spa centers and the local development. A certain impact on the indicator of local development is found. Different in each examined municipality case, the geothermal establishments help accelerating the development trend. It is stronger observed for a less developed municipalities, where the geothermal center has a stimulating role. It reveals as for instance attracting related business long term. These tentative observations are extended to the next study in Chapter 3.

In Chapter 3 the examined impact of the local utilization of the geothermal energy displays a lagged effect. Thus, the more geothermal energy is produced the larger the impact on the municipality's competitiveness it is in time. Porter's concept of the resources competitiveness is tested in Chapter 3. According to Porter's competitiveness theory (1999) the use of geothermal resources can endorse the endogenous development. Applying the Porter Hypothesis (see: Porter \& Van der Linde, 1995; Ambec et al., 2013), the endogenous growth is stimulated by the environmental energy policies and innovations, which improve local competitiveness. Although the Porter Hypothesis is built for the commercial sector, references to the environmental impact (Petroni et al., 2019) and to the territorial competition (Smulders, 2005) are made. Huggins \& Izushi (2011) argue that the Porter Hypothesis compliments the theory of competitive advantage. In line with the Chapter 3 results, the local competitiveness related to the specialization in geothermal utilization requires policy support and technology. Hence, the competitive effect of the geothermal energy is observed in time, as the Porter Hypothesis assumes. It can be argued about the geothermal impact on local competitiveness verified by the study in Chapter 3. Moreover, the concept of a competitiveness index (used in the study as the local competitiveness determinant) is as well exercised in Porter's works (Yglesias, 2003), where used for ranking the technological competitiveness of nations.

The results of the two studies in Chapter 2 and 3 address the research question (RQ 1 ) whether the geothermal resources utilization impacts the performance of a municipality. The forms of impact are assessed throughout the statistical methods. It is observed that the establishment of the geothermal centers positively switches the trend of local development. Moreover with time and the amount of the geothermal energy produced the municipalities become more competitive. Hence, the performance of a geothermal municipality changes when the geothermal resources become used in the local economy. Based on the definition of Drucker (1995), the performance concept refers to concentrating available resources to obtain a maximum result. At the local level, the performance of municipalities relates to actions that improve the resources allocation, measure the effectives and define the internal factors of 
development (Ghobadian \& Ashworth, 1994; Andrews, 2014). Kowalczyk (2018) points to the role of non-financial measures of municipalities performance in Poland. Thus, on the example of the two studies the performance of a municipality is as well measured in the level of using geothermal resources in the municipality

The observations about the geothermal resources impact on municipalities in Chapter 2 and 3 is further analyzed in Chapter 5 . This chapter elaborates a case study of the geothermal resources impact on a selected economic sector. The impact is measured in a comparative analysis between the geothermal municipalities and a superior administrative area, the poviat. By asking whether the local employment structure changes while using the geothermal resources (RQ 3) the induced impact on job generation is determined. The observation of the employment data analysis point to significant growth of the employed people in services in the municipalities, opposite to the employment trend in the poviats. The services activities that are related to the core profile of the geothermal recreational and spas centers are found in particular to develop in the geothermal municipalities. Hence, the use of the geothermal resources impacts the economic profile of a location. The shift-share analysis is adopted to explain regional economic conditions that differ from national level trends. This approach allowed to determine the induced impact on local employment, that is not related to the geothermal energy production or distribution. Based on the results of this study, it is argued that the geothermal spas and recreational centers induce additional employment and have an induced effect on the local employment structure. In this case, the impact on employment concerns mainly tourism and hospitality activities and related services, as well as recreational, sport services and the emerge of single economic activities i.e. entrepreneurship.

Following the concepts of local development of Coffey \& Polese (1984) and Cárdenas-García et al. (2015), the tourism sector that emerges in the geothermal municipalities in this cases, is related to the endogenous factors of development. The references to the location theory in this analysis include the specialization factor. The features of the geothermal resources enhance the local specialization. Henderson \& Thisse (2004) argue that local specialization in sectors or in production results in an array of final goods or specialized market that attracts both consumers and workers. The findings of Chapter 2 and Chapter 5 point to the new tourism specialization that arises along with the introduction of the geothermal recreational and spa centers. This impact is observed stronger in the municipalities with lower development index. Therefore, the endogenous geothermal resources provide an element of specialization and can initiate growth in small size economies. The following Table 3 recapitulates the results of research questions solving dedicated to the geothermal resources impact. Solving the main research question ( $R Q 0$ ) results from the elaboration of the sub-research questions in the thesis. 
Table 7.3: The review of the results of research on the impact of geothermal resources on the development of municipalities in Poland, own elaboration.

RQ 0: What is the impact of the geothermal resources utilization on the development of the municipalities in which they occur?

- Induced geothermal impact is argued resulting from the Chapter 2, 3 and 5 study.

- Impact interprets as a relationship between the local development indicators and geothermal parameters.

- Impact is observed in enabling new market specializations and competitive advantage.

- Geothermal resources impact stronger the smaller size economies.

- The thesis chapters deliver evidences for socioeconomic impact of the geothermal use on municipalities.

RQ 1: Whether the geothermal resources utilization impacts the performance of a municipality?

- Impact is verified in two statistical models.

- Municipality performance is stimulated with the use of the geothermal resources.

RQ 1.1: Whether the introduction of a geothermal spa in a municipality increases the local socioeconomic development?

- Impact on the growth of the local development trend.

- Greater impact on municipalities with a lower development index.
$\mathrm{RQ}$ 1.2: Is there a relationship between the development of geothermal energy and the competitiveness of the municipalities?

- Impact on the local competitiveness.

- Impact grows in time.

RQ 3: Whether the local employment structure changes while using the geothermal resources?

- Impact on change of the local employment structure.

- Impact on the increase of trade and services sectors.

This thesis focuses on a limited application of the geothermal resources in Poland. The results argue that the broader use of the resources in various sectors, the greater effect on a locality is assumed. Furthermore, extended application of the geothermal resources can add a new specialization to the local economy. Based on the chapters outcome the investment in geothermal infrastructure reveals a local added value, define here as the socioeconomic impact. The local added value of infrastructure investments concerns the local governments and the level of life for the community members according to Heinbach et al. (2014) and Hirschl et al. (2014). Therefore, the geothermal resources use in the municipalities impacts the potential of generating a local added value. 


\subsection{Some considerations on and research limitations}

One of the common thesis' consideration is an access to a validated data and reliable information sources. Not coherent variables create discrepancies in any statistical elaboration. The data used in this study are of a primary and secondary character. The socioeconomic data for the local development model is sourced in the Local Data Bank of the Central Statistical Office, and it constitutes secondary data. Regardless a homogenous resource, the data revealed challenges in the completeness and standardization throughout the time series for the period 1995-2018, and for 63 municipalities). Sometimes socioeconomic indicators required additional classification or clarification at the source. The secondary employment data on the municipality level, used in Chapter 5, was not available at the online depository and had to be generated upon order at the institution. The primary data used in Chapter 3 is collected at the source i.e. the geothermal plants in Poland. It took place due to the courtesy of the plants management and it is restricted from open publication. This geothermal data required elaboration in order to be standardized and then anonymized. Another data challenge regarded the availability of the primary geothermal data. Not all of the geothermal activities reported in Poland could be presented as a consistent dataset. Moreover, financial data about the geothermal operations faced challenged in collection. Hence, they were not considered. These circumstance imposed limitations on the analyses carried out. The more geothermal data generated, the better picture of the geothermal impact on local development is obtained. Another thesis consideration originate from the topic of the thesis that is not yet represented sufficiently in the literature. The majority of the geothermal economics findings are presented throughout the heat distribution systems or energy efficiency, as well as by the proenvironmental measures. Nevertheless, it provides an opportunity to conduct new research and develop pioneering approach.

Next to the data limitation another consideration in this study is the choice of control variables in the developed quantitative models. The control variables had to comply with the research assumptions and to help addressing the research question. Hence, the variables choice controls the relationship between the geothermal parameters and the local indicators. The local socioeconomic model has already included the data that plays the control function, i.e. state of local budgets, energy infrastructure development, employment scales. Further selection was required, constrained in the data consistency and availability on the demanded levels. The local level of the analysis is a natural limitation to the possibilities of methods and techniques. The financial angle of the geothermal activities contribution to municipality budgets is unexplored here, mostly because of the data standards at this moment. The territorial reference is as well limited to the sub-regional (counties and benchmark municipalities) because of the specifics of the geothermal resources. The local character of this renewable allows for comparative analysis on the local level. 


\subsection{Discussion on the function of the geothermal energy in local economy}

\section{5.1 Geothermal resources - local alternative for the decarbonized societies}

"Those of us who are concerned with unlocking human potentials need to recognize the importance of authorizing citizens to constitute their own local jurisdictions and associations using the knowledge and experience they have concerning the public problems they face. We have much to do to enable citizens all over the world to participate actively in local public economies"

Elinor Ostrom ${ }^{20}$

The first female Nobel winner in economics, Elinor Ostrom received this award in 2009, for her work dedicated to the economic autonomization of communities by the resources. The core of Ostrom's work is the concept of locality, a system that dictates how the resources are managed. She undermines the dominant role of national governments in imposing a central system for management of the resources. Instead, a horizontal relationship between institutions is proposed, where the local government has a leading role in policymaking. Ostrom (2002) finds three key elements that determine empowerment of communities which are: the commons (ability to manage own resources, sustainable communities competitiveness), self-governance (controlling of own resources develops local services and facilities), and poly centricity (local resilience raises from the bottom-up approach, instead of centralized solutions).

The concept of Ostrom's analysis of commons (i.e. resources) is applied to the renewable energies sustainable use (Acosta et al., 2018; Azergun, 2020; Lammers \& Hoppe, 2018; Ostrom, 2009; Wolsink, 2020). The community based resources sharing Ostrom's concept is best fitted for naturally occurring resources (Azergun, 2020). A study of Ostrom (2009) pays attention to the role of natural resources in climate change actions. The findings point to the leading function of communities in emission reducion actions at the national level. However, Ostrom underlies the need for rescaling the global environmenal policies to the capacities of local institutions. Her concept of 'energy for all' addresses the as well barriers of the geothermal energy development. The social acceptance and engagement of public institutions as significant obstacles for the geothermal energy can be solved in the principle of Ostrom's crossscale institutions linkage (Pellizzone et al., 2019). The democratization of geothermal resources exploitation according to the Ostrom's schemes is discussed in work of Dornan \& Shah (2016), Dwivedi (2018), Fiorentino et al. (2017), Klagge et al. (2020), Luketina \& Parson (2019), Rizzi \& Borzoni (2010) and Wolsink (2012). Geothermal energy development is discussed as dependent on the decentralized socio-technical networks. Covarrubias (2019) adopts the Ostrom's socio-ecological framework to analyze the sustainable geothermal resources

\footnotetext{
20 Nobel Prize winner 2009, (Ostrom, 2005)
} 
exploitation. On the example of Reykjavik, an urban nexus of water-energy-food is presented. Geothermal hot water generates energy for the city and the surplus is used for sustainable food production. Therefore, the nature of this renewable resource creates interconnections in the urban functions and operations. The fact that the geothermal infrastructure is multifunctional helps achieving synergy towards the sustainable development. The Ostrom's theory (1990) introduces a different approach to the common resources. The dichotomy between public or private governance is overcome by combinations of public and private instruments. In her view, either public or private exploitation of resources is under risk of a mismanagement or even depletion, whereas, collective actions lead to the beneficial use of a resource. It is observed on the example of the geothermal water resources. The geothermal water is considered as a common. Fiorentino et al. (2017) discuss the function of geothermal spas and bathing centers from the Ostrom's commons perspective. Next to delivering a functional value, the geothermal baths activate local identities. Within a territory new mechanisms occur based on the relation between public and private investment and ownership. It is claimed that geothermal spas address the importance of geothermal water as a resource that is not to be wasted. They as well induce new relationships between what is natural and what had to be built. The resource is managed according to the sustainable principle, especially in situations, where the geothermal bathing establishments emerge to deploy the surplus of the geothermal hot water extracted for heat purpose. The context of commons ownership (Schlager \& Ostrom, 1993, p.14) can be applied to the system of geothermal royalties. Basing on the Ostrom classification of property rights local communities can gain fairer access to the geothermal resources. Johnson (2017) and Malafeh \& Sharp (2015) argue about the system of geothermal royalties that has to be reoriented towards broader participation of stakeholders as it increases the legitimacy of a resource management regime. The concept of geothermal royalties opens a discussion about sustainable local development using common pool resources. Moreover, the system of revised geothermal royalties ignites the local energy transition. Leitch et al. (2019) and van Campen \& Archer (2016) discuss the examples of geothermal projects that replaced the fossil fuels infrastructure using the royalties.

Geothermal energy finds it role in the sustainable food production (Boedijn et al., 2020). Examples of optimization geothermal wells and heat production that can be applied in the greenhouses and fish farms as an ecological footprint in the food industry. Circular food production systems with the use geothermal energy are reported in the studies of Giordano et al. (2016), IRENA (2019a), Świątek (2020) or Thorarinsdottir \& Unnthorsson (2018). Documented cases of geothermal water aquaculture opportunities in Poland are found in Boguniewicz-Zabłocka et al. (2019) or Bujakowski et al. (2020). The Food and Agriculture Organization (FAO) dedicates a study to the role of the geothermal resources in the agroindustry (Van Nguyen et al., 2015). The FAO recognizes that the agriculture sector accounts for about $22 \%$ of greenhouse gas emissions, raising an environmental concern. The Lindal diagram presents a broad scope of the direct geothermal utilization in agriculture and food production 
(Bundschuh \& Tomaszewska, 2018). According to the temperature of the geothermal resources, they are applied in both food production and food processing. It provides sustainable opportunities for the industry and a significant carbon footprint reduction. Moreover, Van Nguyen et al. (2015) underlines the role of the geothermal energy for the developing countries in particular. Next to building energy security for the often energy challenged developing countries, the expansion of geothermal resources contributes to the food production, and therefore tackles social issues. Among the 38 countries that use geothermal resources in agriculture, 23 are developing countries. Nonetheless, according to FAO many geothermal projects could work in a start-up form. Moreover, it is underlined that governmental initiatives and sector support are necessary for the geothermal investments. Yet, the geothermal potential is untapped in the agri-food industries following the research of IRENA (2019a). The direct use of geothermal heat in soil heating, irrigation, green housing, food drying or processing reduces the food scarcity or import dependencies in the developing countries. For the developed countries, it creates new ecosystems, where energy production is paired with local food supply. Among the agriculture opportunities, geothermal green housing delivers the most of the sustainable benefits (Barbaresi et al., 2020; Kaygusuz \& Kaygusuz, 2004). Next to increasing the food security, by providing local source of fresh products, it shortens the food distribution chains and thus helps reducing polluting gases. Therefore, the geothermal greenhouses production presents with a future especially in climate challenged countries argue Shortall et al. (2015) and van Campen \& Archer (2016).

The energy transition according to an economist and social theorist Jeremy Rifkin (2019) should run under the principle of "power for everyone". For this purpose Rifkin underlines the role of developing the renewable energy infrastructure. The energy transition should be based on democratization of decarbonized energy production. The essence of this approach lies in the decentralized sources of energy. Therefore, local communities in available renewables become producers of the green energy according to their own needs. It adapts energy production according to the local demand argues Rifkin, in addition to transition from centralized fossil energy production and distribution. He points as well to the job creation and local economy benefits following the transition towards the green energies. The local production of geothermal energy fits into the concept of Rifkin's zero emission economy. He repeatedly mentions geothermal energy as one of the future sources of energy and encourages to invest in its technologies (Rifkin, 2011a, 2014). Moreover, the geothermal energy development is as well referred to in the Rifkin's pillars of the Third Industrial Revolution (Rifkin, 2011b). Among the five pillars he introduces, the geothermal resources features correspond with three. They address the demand for the non-intermittent renewable energy shift, securing energy production at the micro-level and providing the technologies for hydrogen generation and individual energy storage. Rifkin's analysis highlights the need of expansion of the geothermal power production, which is yet limited by the current technologies and geothermal exploitation costs. 
The path towards wider deployment of renewable energies is initiated by the international policies that aim to limit the global greenhouse emissions. Documents such as the Paris Agreement (COP21) or European Union energy policies like the European Green Deal (European Commision, 2020) establish environmental targets in order to shift energy systems from reliance on fossil fuels to the sustainable resources. The energy transition entails a significant structural change in the energy system and likewise economies. It has to be driven by the exploration and development of available renewables. Klenner \& Gosnold (2009) claim that the geothermal energy has the technical capacity to replace fossil fuels. Whereas Ziabakhsh-Ganji et al. (2018) study the technological possibilities utilizing the existing oil infrastructure, which significantly lowers the cost of geothermal harness. Due to the technical features of the geothermal resources and the increasing demand for heat and power it can become an enabler of the global energy transition. The enabling function comes from the geothermal capacity and price balance but as well as from the advancement of geothermal technologies that make this renewable more competitive against wind and solar. The demand from the energy consumers is as well coalesced around the most reliable, affordable, and environmentally responsible energy sources. These consumers are e.g. cities integrating renewables into their smart city plans or communities oriented at sustainable energy procurement or emerging markets that declare their development dependent on the deployment of renewables. The geothermal energy has the competitive features for supplying the demands of city networks and community energy projects (Dumas, 2016; EGEC, 2019). It fits the Renewable Energy Community concept imposed by the Clean Energy Package (EU, 2018), where local stakeholders including municipalities are the primary beneficiaries of the resources (Lowitzsch et al., 2020). Moreover, examples of the geothermal energy application showcase its significant role for the developing countries (Alemán-Nava et al., 2014; Echavarria, 2008; Kırlı \& Fahrioğlu, 2019; Singh et al., 2016; Zhu et al., 2015). In case of islands, the geothermal resources are discussed as ensuring energy independence, especially from the imports of electricity (Andritsos et al., 2003; Calise et al., 2018; Harrison \& Popke, 2018; Karytsas et al., 2019; Lucas et al., 2017; Manologlou et al., 2004; Østergaard \& Lund, 2011; Rangel et al., 2015). Therefore, the deployment of new geothermal technologies is likely to facilitate further decrease of its costs and accelerate national energy transitions across the world.

Geothermal energy because of its features and scope of use has a chance to become a flagship renewable for the ongoing world's decarbonization (Connolly et al., 2014; Paulillo et al., 2019; Weinand et al., 2019). IRENA (2019b) predicts the global geothermal energy production to raise to the $1.76 \mathrm{EJ}$ level in 2050. This amount of energy is compiled with the expansion of the geothermal power production and of geothermal heat pumps for individual buildings The forecasts of International Energy Agency (IEA, 2020) point to the function of the geothermal energy in sustainable development scenario that assumes a significant decarbonization of power production worldwide. The IEA estimates that by the 2030 circa 280 TWh of electricity will be geothermally produced. However, this amount of power growth is conditioned, 
according to IEA, to the development of dedicated geothermal risk policies. The World Bank (Fridriksson et al., 2016) widely engages in the financing of geothermal projects recognizing its low emissions technology. The literature presents examples of global energy transition scenarios enabled by the deployment of the geothermal resources (Bartels et al., 2018; Franco \& Ponte, 2019; Menéndez et al., 2019; Smith, 2019). Global geothermal investment value reached 320 billion \$ in 2018 (FS-UNEP, 2020) with predictions to unlock additional 25 \$ billion in the next five years. Contrary to wind and solar, this optimistic forecasts are based on the fact that the surface footprint of a geothermal plant has the advantage of being much lower in terms of km2 per MW of produced electricity (Rystad Energy, 2020). To meet the growing demand for urban heat consumption faced with the European Green Deal, and considering its enabling function (Deloitte, 2018; Moriarty \& Honnery, 2016) more attention should be paid to geothermal energy policies suggest Dalla Longa et al. (2020), EGEC (2020) or Simionescu et al. (2020).

In the light of the future of the geothermal energy, the resources displays a competitive advantage over other renewables. Figure 7.1 illustrates the geothermal capacity for the three pillars of energy demand i.e.: heating, cooling and electricity production. Among the popularly used renewables, only the geothermal energy has the technical capacity to supply these demands. Moreover, the geothermal resources comply well in cogeneration processes, where electricity and heat are generated within the same power plant. The future of the geothermal energy relates to its technology for storage (Sarbu \& Sebarchievici, 2017) and hydrogen or lithium production (Elders et al., 2019). It adds to another advantage over other renewables, that focus on improvements of the existing technologies.

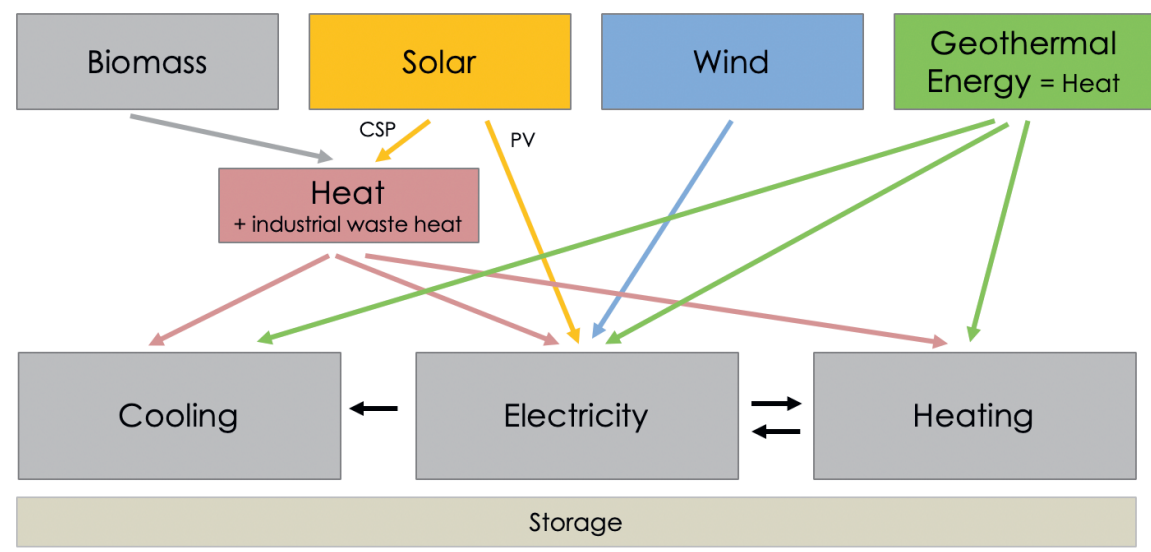

Figure 7.1 : Spectrum of geothermal energy application vs. other renewable energies, Richter (2020). 


\subsubsection{Geothermal development scenario for Poland}

In case of Poland, the best feasible scenario for the future of geothermal resources is the district heating expansion (Hast et al., 2018). It feeds the dense district heating network (see Chapter 1, Figure 1.9), which is at present coal supplied in the majority of district heating in Poland (Pająk et al., 2020). In addition, the price of geothermal heat is found to be competitive with conventional resources (Huculak, Jarczewski, \& Dej, 2015). The future of the geothermal in Poland fits to the energy cluster concept. Wiktor-Sułkowska (2018) discusses the potential of the energy clusters at the local level. The clean energy clusters based on mixes of geothermal, photovoltaic or wind installations create an energy independence for communities. That is why, the cluster initiatives in Poland should be launched by local authorities since the benefits including environmental reveal locally. The clean energy clusters are affordable since the operating costs between the cluster stakeholders are shared (Underwood et al., 2007; Hentschel et al., 2018). Moreover, the geothermal energy clusters have the additional advantage of the non-intermittent base and undisturbed energy production, which is not the case of wind or solar installations requiring conventional energy backups. Sowiżdżał et al. (2019) deliver environmental arguments for the further development of geothermal energy in Poland. The use of the resource in the heating district significantly contributes to the reduction of emissions in the examined locations and to local air quality improvement. Increasing the use of the geothermal recreation and health centers is as well discussed, as they deliver social benefits. The prospects of the geothermal lie as well in developments based in the geothermal water for agricultural and industrial purposes (Tyszer et al., 2020).

The energy transition limiting coal is expected for Poland to happen in the coming decades, triggered by both energy policies and the demand for greener resources (Poland's Energy Policy until 2040). Especially the district heating is challenged with the decarbonization process (Hasterok et al., 2021). The percentage of coal in the country energy mix is still about four times above EU average (IEA 2021). The World Bank (2018) recommends for Poland to decarbonize the district heating networks in a sustainable way, that next to a reducing air pollution is delivering a local social impact. Implications for the transition from coal in the Polish coal regions are to incorporate the socioeconomic benefits for local communities. The compensation for coal regions transition is expected to pay attention to e.g. jobs generation and economic growth opportunities (Alves Dias et al., 2018). Geothermal development because of its local character, in opposite the other carbon neutral infrastructure, can address to certain degree the needs of local communities in the coal regions in Poland. The coal related employment loss in the decarbonization process is one of the major policy concerns (World Bank, 2018). Fostering the creation of clean energy sector employment is on the climate policies agenda including Poland (Marks-Bielska et al., 2020). It can be addressed by the broader application of geothermal resources and intensification of utilization. Expansion of geothermal potential into industry and food production can potentially accommodate part the 
labor force reduced because of the coal transition. The role of geothermal energy in the decarbonization process in Poland is underlined in work of e.g. Qvist et al. (2021), Kudełko (2021) and Sowizdżał et al. (2021). Next to the climate change, the regional economies change can be affected. The function of geothermal resources for clean heating including district one and agriculture sector development is crucial in Poland (McKinsey, 2020). The national largescale investment in decarbonization is expecting returns, which also refers to a positive socioeconomic impact. This angle of decarbonization policies creates a room for the geothermal energy. A societal impact and induced economic benefits (i.e. job market stimulation) is an advantage of this renewable. A limited shot of the impact analysis is presented in this thesis using examples of partial geothermal application. Nevertheless, geothermal should be wider included in the Polish decarbonization plans also because of its local development factor function.

The findings of the thesis find the expansion of the geothermal infrastructure in Poland worth considering. The discovered positive impact on the local economy other than the provision of clean energy source adds an argument for more of the dedicated national level policies. The broad and direct application of the geothermal accompanied with the socioeconomic impact they deliver is a strategic element for modelling the local economies development based on the resources. The geothermal energy is recognized as a strategic element of local energy strategy, also as a prevention from the energy poverty (Świerszcz \& Ćwik, 2017). The municipalities that use the geothermal resources include them in their development strategy documents (e.g.: UG Szaflary, 2012; UM Pyrzyce, 2015; UM Uniejów, 2012; UM Zakopane, 2016). The Municipality Development Strategy ${ }^{21}$ is formed by a municipality to plan long-term activities and at the same time to hierarchize its needs. This document defines the priorities, goals and directions of the social and economic development of a given commune. Kępińska (2018) lists the key national regulations that aim to enhance the geothermal development in Poland. Nevertheless, the legal obstacles in the national mining regulations that concerns the geothermal heat production are present. Kępińska argues as well about the lack of a geological risk insurance fund risk. This financial mechanism organized by the state is already functioning in the EU supporting the geothermal infrastructure investments. Hence, the supportive regulatory frame dedicated to the geothermal resources is far need for a large scale local geothermal energy use in Poland.

\footnotetext{
${ }^{21}$ The Municipality Development Strategy (pol. Strategia Rozwoju Gminy) is the basic document thanks to which the commune is able to plan long-term activities and at the same time to hierarchize the needs. This document defines the priorities, goals and directions of the social and economic development of the commune.
} 


\subsection{Final word}

This study approaches the research problem about the impact of the geothermal resources utilization on the development of the municipalities. Selected statistical solutions attempted to measure this local impact. The growth of the municipalities development indicators and the opportunities of the local entrepreneurship and investment related to the use of the geothermal resources are justified in the examined local cases in Poland. Moreover, with time the impact of the geothermal water and spa centers on local economies is observed. Barbier (1999) argues that endogenous growth can overcome resources scarcity if the long term resources availability is concerned. The endogenous growth regards as well the innovations connected to the use of energy resources. Geothermal energy assures its permanence as long as there are physical processes in the interior of the planet. In Poland, the role of renewable energies for the endogenous growth is already acknowledged (Igliński et al., 2015; Szymańska \& Chodkowska-Miszczuk, 2011). Since the perception of endogenous refers to being a part of the system, the utilization of the geothermal resources can be a local system factor endowment. It is discussed in this thesis that the geothermal recreational and spa centers already contribute to the municipality's economy. The recommendation resulting from this research is to maximize the local potential of geothermal use. That includes expanding the direct energy utilization forms but as well the investment in clean electricity production where feasible. Another applications of the geothermal resources are potentially additional development factors, especially geothermal use in food production, agriculture and expanded tourism amenities. Poland's favorable condition of geothermal resources allocation is advised to be used and the socioeconomic potential to be considered by social planners. Further deployment of geothermal installations in municipalities is found positive for the development of local economies (as it is corroborated in this thesis) but as well for the environmental energy concerns. The findings of this study point to the socioeconomic advantage of the geothermal resources. The local induced effect on local employment and competitiveness is addressed. Further local studies including financial impact aspects and a geothermal plant perspective are recommended. The geothermal resource accompanies mankind in its search for improving living conditions. The impact of the geothermal resources on quality of human life will continue in the coming decades. 


\section{References}

Abdi, H., \& Williams, L. J. (2010). Principal Component Analysis. Wiley Interdisciplinary Reviews: Computational Statistics, 2(4), 433-459. doi:10.1002/wics.101

Abdi, H., Williams, L. J., \& Valentin, D. (2013). Multiple Factor Analysis: Principal Component Analysis for multitable and multiblock data sets. Wiley Interdisciplinary Reviews: Computational Statistics, 5(2), 149-179. doi:10.1002/wics.1246

Acosta, C., Ortega, M., Bunsen, T., Koirala, B. P., \& Ghorbani, A. (2018). Facilitating energy transition through energy commons: An application of socio-ecological systems framework for integrated community energy systems. Sustainability, 10(2), 366. doi:10.3390/su10020366

Acs, Z. J., \& Armington, C. (2003). Endogenous growth and entrepreneurial activity in cities. Citeseer. Washington DC, USA.

Acs, Z., \& Armington, C. (2004). Employment growth and entrepreneurial activity in cities. Regional Studies, 38(8), 911-927. doi:10.1080/0034340042000280938

Act of 8 March 1990 on local government. Journal of Laws 1990, No. 16, item 95.

Act of 9 June 2011, Geological and Mining Law. Journal of Laws 2011, No 163, item 981.

Act on Energy of 8 January 2010 amending the Act on Energy of 10 April 1997. Journal of Laws 2010, No 21, item 104.

Adao, R., Kolesár, M., Morales, E., 2019. Shift-Share Designs: Theory and Inference. Quarterly Journal of Economics. 134 (4), 1949-2010. doi: 10.1093/qje/qjz025.

Adaro, J. A., Galimberti, P. D., Lema, A. I., Fasulo, A. I., \& Barral, J. R. (1999). Geothermal contribution to greenhouse heating. Applied Energy, 64(1-4), 241-249. doi:10.1016/S0306-2619(99)00049-5

Aghion P. \& Howitt P. (1998). Endogenous Growth Theory. Cambridge, MIT Press. MA, USA.

Aghion, P., Ljungqvist, L., Howitt, P., Howitt, P. W., Brant-Collett, M., \& GarcíaPeñalosa, C. (1998). Endogenous growth theory. MIT Press. MA, USA.

Aguilar, F. X., Goerndt, M. E., Song, N., \& Shifley, S. (2012). Internal, external and location factors influencing cofiring of biomass with coal in the US northern region. Energy Economics, 34(6), 1790-1798. doi:10.1016/j.eneco.2012.07.005

Akella, A., Saini, R., \& Sharma, M. P. (2009). Social, economical and environmental impacts of renewable energy systems. Renewable Energy, 34(2), 390-396. doi:10.1016/j.renene.2008.05.002

Akorede, M. F., Hizam, H., \& Pouresmaeil, E. (2010). Distributed energy resources and benefits to the environment. Renewable and Sustainable Energy Reviews, 14(2), 724734. doi:10.1016/j.rser.2009.10.025

Al-Harbi, K. M. A. S. (2001). Application of the AHP in project management. International Journal of Project Management, 19(1), 19-27. doi:10.1016/S0263-7863(99)00038-1

Alacevich, M. (2020). Paul Rosenstein-Rodan and the Birth of Development Economics. CHOPE Working Paper. Center for the History of Political Economy at Duke University Working Paper Series. doi:10.2139/ssrn.3552940

Alemán-Nava, G. S., Casiano-Flores, V. H., Cárdenas-Chávez, D. L., Díaz-Chavez, R., Scarlat, N., Mahlknecht, J., . . Parra, R. (2014). Renewable energy research progress in 
Mexico: A review. Renewable and Sustainable Energy Reviews, 32, 140-153.

doi:10.1016/j.rser.2014.01.004

Allan, G., McGregor, P., \& Swales, K. (2017). Greening regional development: employment in low-carbon and renewable energy activities. Regional studies, 51(8), 12701280. doi:10.1080/00343404.2016.1205184

Almeida, R. (2007). Local economic structure and growth. Spatial Economic Analysis, 2(1), 65-90. doi:10.1080/17421770701232442

Alphonce, C. B. (1997). Application of the analytic hierarchy process in agriculture in developing countries. Agricultural systems, 53(1), 97-112. doi:10.1016/S0308-521X(96)00035-2

Altman, M. (1986). Resource endowments and location theory in economic history: a case study of Quebec and Ontario at the turn of the twentieth century. Journal of Economic History, 999-1009.

Alves Dias, P. et al., EU coal regions: opportunities and challenges ahead. Publications Office of the European Union. JRC112593. Luxembourg. doi:10.2760/064809

Ambec, S., Cohen, M. A., Elgie, S., \& Lanoie, P. (2013). The Porter hypothesis at 20: can environmental regulation enhance innovation and competitiveness? Review of environmental economics and policy, 7(1), 2-22. doi:10.1093/reep/res016

Amin, A. (1999). An institutionalist perspective on regional economic development. International Journal of Urban and Regional Research, 23(2), 365-378.

Amorim, M., \& da Mata, D. (2009). The Cariri Region of Ceara and the Footwear Cluster. In M. Zhang (Ed.), Competitiveness and growth in Brazilian cities: local policies and actions for innovation. The World Bank. doi:10.1596/978-0-8213-8157-1

Anderson, N. H. (1961). Scales and statistics: parametric and nonparametric. Psychological bulletin, 58(4), 305. doi:10.1037/h0042576

André, F. J., \& Smulders, S. (2004). Energy use, endogenous technical change and economic growth. Conference Paper. EEARE 13th Annual Conference. Budapest, Hungary.

Andrews, R. (2014). Performance management and public service improvement. Evidence review prepared for the Commission on Public Service, Governance and Delivery. Report No.3. The Public Policy Institute for Wales. Cardiff, UK.

Andritsos, N., Dalampakis, P., \& Kolios, N. (2003). Use of geothermal energy for tomato drying. GHC bulletin, 24(1).

Aniello, G., Többen, J., \& Kuckshinrichs, W. (2019). The Transition to Renewable Energy Technologies - Impact on Economic Performance of North Rhine-Westphalia. Applied Sciences, 9(18), 3783. doi:10.3390/app9183783

Arcelus, F. J. (1984). An extension of shift-share analysis. Growth and change, 15(1), 3-8.

Arent, D. J., Wise, A., \& Gelman, R. (2011). The status and prospects of renewable energy for combating global warming. Energy Economics, 33(4), 584-593. doi:10.1016/j.eneco.2010.11.003

Aretz, A., Böther, T., Hirschl, B., Prahl, A., \& Heinbach, K. (2010). Local value added by renewable energy technologies. IÖW Text Series 196(10). Institute for Ecological Economy Research (IÖW). Berlin. Germany.

Armstead, H. (1978). Geothermal energy: Its past, present, and future contributions to the energy needs of man. E. \& FN Spon. London, UK. 
Arrow, K. (1962). J., 1962, Economic Welfare and The Allocation of Resources for Invention. In The Rate and Direction of Inventive Activity: Economic and Social Factors. 609626. Princeton University Press and NBER.

Artige, L., \& Van Neuss, L. (2014). A new shift-share method. Growth and change, 45(4), 667-683. doi:10.1111/grow.12065

Asafu-Adjaye, J. (2000). The relationship between energy consumption, energy prices and economic growth: time series evidence from Asian developing countries. Energy economics, 22(6), 615-625. doi:10.1016/S0140-9883(00)00050-5

Atkinson, R., \& Willis, P. (2006). Community capacity building-A practical guide. Paper No. 6. Housing and Community Research Unit (1-15). University of Tasmania. Hobart. Australia.

Audretsch, D. B., Link, A. N., \& Walshok, M. L. (2015). (Eds). The Oxford handbook of local competitiveness. Oxford University Press. doi:10.1093/oxfordhb/9780199993307.001.0001

Avtar, R., \& Kumar, P. (2016). Geothermal Energy as a Major Source of Renewable Energy-Learning from Asian Neighbours. Advances in Geothermal Energy, 37. doi:10.5772/62084

Axelsson, G., Gudmundsson, A., Steingrimsson, B., Palmason, G., Armannsson, H., Tulinius, H., ... Stefansson, V. (2001). Sustainable production of geothermal energy: suggested definition. IGA-News, 43, 1-2.

Aydin, B., 2014, March. SWOT analysis of renewable energy. In Green Energy for Sustainable Development (ICUE), 1-7. International Conference and Utility Exhibition on Green Energy for Sustainable Development (ICUE). Pattaya, Thailand.

Ayres, R. U. (2001). The minimum complexity of endogenous growth models:: the role of physical resource flows. Energy, 26(9), 817-838. doi:10.1016/S03605442(01)00031-7

Azergun, N. (2020). Resource allocation at an income-sharing community: An application of Elinor Ostrom's commons framework. Economic Affairs, 40(3), 367-384.

Babi, Y., Dobbi, A., Saighi, M., \& Bouchekima, B. (2007). Heating an agricultural greenhouse by using geothermal energy. Revue des Energies Renouvelables CER, 7, 265268.

Bagdonavicius, V., Kruopis, J., \& Nikulin, M. S. (2013). Nonparametric tests for complete data. John Wiley \& Sons. UK.

Baguley, T. (2009). Standardized or simple effect size: What should be reported?. British Journal of Psychology, 100(3), 603-617. doi:10.1348/000712608X377117

Balat, M., Balat, H., \& Faiz, U. (2009). Utilization of geothermal energy for sustainable global development. Energy Sources, Part B, 4(3), 295-309. doi:10.1080/15567240701621158

Baltagi, B. (2008). Econometric analysis of panel data. John Wiley \& Sons.

Barbacki, A. (2012). Classification of geothermal resources in Poland by exergy analysis-Comparative study. Renewable and Sustainable Energy Reviews, 16(1), 123-128. doi:10.1016/j.rser.2011.07.141

Barbaresi, A., Maioli, V., Bovo, M., Tinti, F., Torreggiani, D., \& Tassinari, P. (2020). Application of basket geothermal heat exchangers for sustainable greenhouse cultivation. Renewable and Sustainable Energy Reviews, 129, 109928. doi:10.1016/j.rser.2020.109928 
Barbier, E. (1997). Nature and technology of geothermal energy: a review. Renewable and Sustainable Energy Reviews, 1(1-2), 1-69. doi:10.1016/S13640321(97)00001-4

Barbier, E. (2002). Geothermal energy technology and current status: an overview. Renewable and Sustainable Energy Reviews, 6(1-2), 3-65. doi:10.1016/S13640321(02)00002-3

Barbier, E. B. (1999). Endogenous growth and natural resource scarcity. Environmental and Resource Economics, 14(1), 51-74. doi:10.1023/A:1008389422019

Barbier, E., \& Homer-Dixon, T. (1996). Resource scarcity, institutional adaptation, and technical innovation: can poor countries attain endogenous growth? Occasional Paper. American Association for the Advancement of Science and the University of Toronto.

Barbu, A., \& Isaic-Maniu, A. (2011). Data collection in Romanian market research: a comparison between prices of PAPI, CATI and CAWI. Management \& Marketing, 6(3), 349-364.

Bartels, N., Bussmann, G., \& Ignacy, R. (2018). Geothermal Energy in the Context of the Energy Transition Process. Conference Paper. International IEEE Conference and Workshop in Óbuda on Electrical and Power Engineering (CANDO-EPE). Hungary.

Bartholomew, W., \& Peck, J. E. (1989). Shift-share analysis of structural change in the local economy: a case study. American Journal of Business, 4(1), 45-52. doi:10.1108/19355181198900008

Barton, H., Grant, M., \& Guise, R. (2020). Shaping neighbourhoods: for local health and global sustainability: Routledge.

Beckers, K. F., Lukawski, M. Z., Reber, T. J., Anderson, B. J., Moore, M. C., \& Tester, J. W. (2013). Introducing GEOPHIRES v1. 0: Software package for estimating levelized cost of electricity and/or heat from enhanced geothermal systems. Conference Paper. Thirty-Eighth Workshop on Geothermal Reservoir Engineering, Stanford University, Stanford, CA, USA.

Beer, M., Rybár, R., \& Kal'avský, M. (2018). Renewable energy sources as an attractive element of industrial tourism. Current Issues in Tourism, 21(18), 2139-2151. doi:10.1080/13683500.2017.1316971

Berg, B. L., Lune, H., \& Lune, H. (2004). Qualitative research methods for the social sciences (Vol. 5). Teaching Sociology 18(4), 195-208. doi:10.2307/1317652

Bertani, R. (2009). Geothermal energy: an overview on resources and potential. International Geothermal Days Slovakia 2009 Conference and Summer School, Session (Vol. 1).

Bertani, R. (2017). Perspectives for geothermal energy in Europe. WSPC Europe.

Beugelsdijk, S., De Groot, H. L., \& Van Schaik, A. B. (2004). Trust and economic growth: a robustness analysis. Oxford Economic Papers, 56(1), 118-134.

doi:10.1093/oep/56.1.118

Björnsson, O. (2009). Geothermal energy as replacement for oil and gas-a proven option among the renewables. Electric power, 12000(14000), 16000.

Blakely, E. J. (1989). Planning Local Economic Development: Theory and Practice. Sage. Newbury Park, CA, USA. doi:10.1080/03768359008439548

Blodgett, L., \& Slack, K. (2009). Geothermal 101: basics of geothermal energy production and use. Geothermal Energy Association. Washington, DC, USA. 
Bloomquist, R., Culver, G., Ellis, P., Higbee, C., Kindle, C., Lienau, P., . . Wright, P. (1989). Geothermal direct use engineering and design guidebook. Geo-Heat Center. Oregon Inst. of Tech. Klamath Falls, USA. doi:10.2172/6345835

Blyth, W., Gross, R., Speirs, J., Sorrell, S., Nicholls, J., Dorgan, A., \& Hughes, N. (2014). Low carbon jobs: The evidence for net job creation from policy support for energy efficiency and renewable energy. UK Energy Research Centre. London, UK.

Boedijn, A., Tsafaras, I., van den Ven, R., Espinal, C. A., Thorarinsdottir, R., Turnsek, M. a., \& Baeza, E. (2020). Modelling and dimensioning of circular food production systems fed by geothermal energy: aquaponics. Acta Hortic, 1268, 59-64. doi:10.17660/ActaHortic.2020.1268.8

Boguniewicz-Zabłocka, J., Łukasiewicz, E., \& Guida, D. (2019). Analysis of the sustainable use of geothermal waters and future development possibilities- A case study from the Opole Region, Poland. Sustainability, 11(23), 6730. doi:10.3390/su11236730

Bohdanowicz, P., Churie-Kallhauge, A., Martinac, I., \& Rezachek, D. (2001). Renewable energy for sustainable tourism. Conference Paper. Proceedings International conference for renewable energy and energy education, Vol. 2, No. 12, 2019. Cuba.

Boltho, A., \& Holtham, G. (1992). The assessment: new approaches to economic growth. Oxford Review of Economic Policy, 8(4), 1-14.

Boulanger, P.-M., \& Bréchet, T. (2005). Models for policy-making in sustainable development: The state of the art and perspectives for research. Ecological economics, 55(3), 337-350. doi:10.1016/j.ecolecon.2005.07.033

Boyce, D. (2003). A short history of the field of regional science. Papers in Regional Science, 83(1), 31-57. doi:10.1007/s10110-003-0176-9

Boyle, G. (1996). Renewable energy: power for a sustainable future: Oxford University Press. UK.

Brander, J. A., \& Taylor, M. S. (1998). The simple economics of Easter Island: A Ricardo-Malthus model of renewable resource use. American Economic Review, 119-138.

Braunerhjelm, P., Acs, Z. J., Audretsch, D. B., \& Carlsson, B. (2010). The missing link: knowledge diffusion and entrepreneurship in endogenous growth. Small Business Economics, 34(2), 105-125. doi:10.1007/s11187-009-9235-1

Brdulak, J. (2013). Cechy rozwoju lokalnego. . In K. Hełpa-Liszkowska (Ed.), Dziedzictwo kulturowe jako czynnik rozwoju lokalnego. Studia Oeconomica Posnaniensia. Vol. 1(6), pp. 5-18.

Bristow, G. (2005). Everyone's a 'winner': problematising the discourse of regional competitiveness. Journal of Economic Geography, 5(3), 285-304. doi:10.1093/jeg/lbh063

Bronisz, U., Heijman, W., \& Miszczuk, A. (2008). Regional competitiveness in Poland: Creating an index. Jahrbuch für Regionalwissenschaft, 28(2), 133-143. doi:10.1007/s10037-008-0026-y

Brown, G. M. (2000). Renewable natural resource management and use without markets. Journal of Economic Literature, 38(4), 875-914. doi:10.1257/jel.38.4.875

Bujakowski, W., \& Barbacki, A. (2004). Potential for geothermal development in Southern Poland. Geothermics, 33(3), 383-395.

Bujakowski, W., Bielec, B., Miecznik, M. et al. (2020). Reconstruction of geothermal boreholes in Poland. Geothermal Energy 8, 10. doi:10.1186/s40517-02000164-x 
Bulu, M. (2011). Measuring competitiveness of cities: Turkish experience. International Journal of Knowledge-Based Development, 2(3), 267-281. doi:10.1504/IJKBD.2011.042522 Press. UK.

Bundschuh, J., \& Tomaszewska, B. (2018). Geothermal water management. CRC

Bundschuh, J., Chen, G., Chandrasekharam, D., \& Piechocki, J. (2017). Geothermal, wind and solar energy applications in agriculture and aquaculture: CRC Press. UK.

Bunge, M. (2001). Epistemology of sociology. In N. J. Smelser \& P. B. Baltes (Eds.), International Encyclopedia of the Social \& Behavioral Sciences, Vol. 19, 14569-14574. Elsevier. New York, USA.

Button, K. (1998). Infrastructure investment, endogenous growth and economic convergence. The annals of regional science, 32(1), 145-162.

Button, K. (2011). The economist's perspective on regional endogenous development. In R. Stimson et al.(Eds.), Endogenous Regional Development: Perspectives, Measurement and Empirical Investigation, 20-39. Edward Elgar Publishing. Cheltenham, UK. doi:10.4337/9781849804783.00006

Calise, F., Di Fraia, S., Macaluso, A., Massarotti, N., \& Vanoli, L. (2018). A geothermal energy system for wastewater sludge drying and electricity production in a small island. Energy, 163, 130-143. doi:10.1016/j.energy.2018.08.062

Camagni, R. (1991). Local Milieu, Uncertainty and Innovation Networks: Towards a New Dynamic Theory of Economic Space Innovation networks: spatial perspectives. Belhaven-Pinter. London, UK.

Camagni, R. (2002). On the concept of territorial competitiveness: sound or misleading?. Urban studies, 39(13), 2395-2411. doi:10.1080/0042098022000027022

Canan, P. (1986). Rethinking geothermal energy's contribution to community development. Geothermics, 15(4), 431-434. doi:10.1016/0375-6505(86)90013-1

Canjels, E., \& Watson, M. W. (1997). Estimating deterministic trends in the presence of serially correlated errors. The Review of Economics and Statistics, 79(2), $184-$ 200. doi:10.1162/003465397556773

Capello, R. (2011). Location, regional growth and local development theories. Aestimum 58, 1-25.

Caramizaru, A., \& Uihlein, A. (2020). Energy communities: an overview of energy and social innovations. JRS Publications. Luxembourg. doi:10.2760/180576

Cárdenas-García, P. J., Sánchez-Rivero, M., \& Pulido-Fernández, J. I. (2015). Does tourism growth influence economic development? Journal of Travel Research, 54(2), 206221. doi:10.1177/0047287513514297

Carley, S., Lawrence, S., Brown, A., Nourafshan, A., \& Benami, E. (2011). Energybased economic development. Renewable and Sustainable Energy Reviews, 15(1), 282-295. doi:10.1016/j.rser.2010.08.006

Cataldi, R. (1993). Review of historiographic aspects of geothermal energy in the Mediterranean and Mesoamerican areas prior to the Modern Age. Geo-Heat Center Quarterly Bulletin;(United States), 15(1).

Cataldi, R. (2001, November). Sustainability and renewability of geothermal energy. In Proceedings of the International Scientific Conference on Geothermal Energy in Underground Mines, 4. 
Cataldi, R., \& Chiellini, P. (1995). Geothermal energy in the Mediterranean area before the Middle Ages. Stories from a Heated Earth, 373-380. GRC Geothermal Library.

Central Statistical Office. (2018). Population. Size and structure and vital statistics in Poland by territorial division in 2018. As of December, 31. Statistics Poland. Warsaw.

Chakravorty, U., Roumasset, J., \& Tse, K. (1997). Endogenous substitution among energy resources and global warming. Journal of Political Economy, 105(6), 1201-1234. doi:10.1086/516390

Chandrasekharam, D. (1995). A prehistoric view of the hot springs of India. Stories from a Heated Earth, 356-365. GRC Geothermal Library.

Chandrasekharam, D., \& Bundschuh, J. (2002). Geothermal energy resources for developing countries: CRC Press.

Chatterjee, S., \& Hadi, A. S. (2009). Sensitivity analysis in linear regression (Vol. 327). John Wiley \& Sons.

Cheshire, P., \& Magrini, S. (2000). Endogenous processes in European regional growth: convergence and policy. Growth and Change, 31(4), 455-479. doi:10.1111/00174815.00140

Chiasson, A. (2015). Direct Use of Geothermal Energy. Handbook of Clean Energy Systems, 1-13. doi:10.1002/9781118991978.hces071

Chou, T.-Y., Hsu, C.-L., \& Chen, M.-C. (2008). A fuzzy multi-criteria decision model for international tourist hotels location selection. International journal of hospitality management, 27(2), 293-301. doi:10.1016/j.ijhm.2007.07.029

Chowaniec, J., Poprawa, D., \& Witek, K. (2001). Occurrence of thermal waters in the Polish Carpathians (southern Poland). Przeglad Geologiczny, 49(8), 734-742.

Cingano, F., \& Schivardi, F. (2004). Identifying the sources of local productivity growth. Journal of the European Economic association, 2(4), 720-742. doi:10.1162/1542476041423322

Clarke, T. (2019). Creative Destruction, Technology Disruption, and Growth Oxford Research Encyclopedia of Economics and Finance: Oxford University Press.

Cleveland, C. J., \& Morris, C. G. (2005). Dictionary of energy: Elsevier.

Coffey, W. J., \& Polese, M. (1984). The concept of local development: a stages model of endogenous regional growth. Papers in Regional Science, 55(1), 1-12. doi:10.1111/j.1435-5597.1984.tb00823.x

Coffey, W. J., \& Polese, M. (1985). Local development: Conceptual bases and policy implications. Regional studies, 19(2), 85-93. doi:10.1080/09595238500185101

European Commision. (2020). The European Green Deal. Communication from the Commission to the European Parliament, the European Council, the Council, the European Economic and Social Committee and the Committee of the Regions COM(2019) 640.

Compernolle, T., Welkenhuysen, K., Petitclerc, E., Maes, D., \& Piessens, K. (2019). The impact of policy measures on profitability and risk in geothermal energy investments. Energy Economics, 84, 104524.

Connolly, D., Lund, H., Mathiesen, B. V., Werner, S., Möller, B., Persson, U., . . . Nielsen, S. (2014). Heat Roadmap Europe: Combining district heating with heat savings to decarbonise the EU energy system. Energy Policy, 65, 475-489.

doi:10.1016/j.enpol.2013.10.035

Conti, S., \& Giaccaria, P. (2013). Local development and competitiveness (Vol. 59). Springer Science \& Business Media. 
Cooke, P. (1997). Regions in a global market: the experiences of Wales and Baden-Wurttemberg. Review of International Political Economy, 4(2), 349-381. doi:10.1080/096922997347814

Covarrubias, M. (2019). The nexus between water, energy and food in cities: towards conceptualizing socio-material interconnections. Sustainability Science, 14(2), 277287. doi:10.1007/s11625-018-0591-0

Cox, A. M., Alwang, J., \& Johnson, T. G. (2000). Local preferences for economic development outcomes: analytical hierarchy procedure. Growth and change, 31(3), 341366. doi:10.1111/0017-4815.00132

Csirmaz, É., \& Pető, K. (2015). International Trends in Recreational and Wellness Tourism. Procedia Economics and Finance, 32, 755-762. doi:10.1016/S22125671(15)01458-6

Cuka, P., \& Rachwal, T. (2013). Economic, touristic and therapeutic potential of natural water springs in Slovakia. SGEM: Surveying Geology \& Mining Ecology Management, Vol. 2, 89-96.

Czaplicka-Kotas, A., Kulczycka, J., \& Iwaszczuk, N. (2020). Energy Clusters as a New Urban Symbiosis Concept for Increasing Renewable Energy Production-A Case Study of Zakopane City. Sustainability, 12(14), 5634. doi:10.3390/su12145634

Da Silva, P. P., Oliveira, C., \& Coelho, D. (2013). Employment effects and renewable energy policies: applying input-output methodology to Portugal. International Journal of Public Policy 14, 9(3), 147-166. doi:10.1504/IJPP.2013.055702

Dalla Longa, F., Nogueira, L. P., Limberger, J., van Wees, J.-D., \& van der Zwaan, B. (2020). Scenarios for geothermal energy deployment in Europe. Energy, 118060. doi:10.1016/j.energy.2020.118060

Dalton, T. R., Coats, R. M., \& Asrabadi, B. R. (2005). Renewable resources, property-rights regimes and endogenous growth. Ecological economics, 52(1), 31-41. doi:10.1016/j.ecolecon.2004.03.033

Daniilidis, A., Alpsoy, B., \& Herber, R. (2017). Impact of technical and economic uncertainties on the economic performance of a deep geothermal heat system. Renewable Energy, 114, 805-816. doi:10.1016/j.renene.2017.07.090

Davidson-Hunt, I. J., \& Turner, K. L. (2012). Indigenous communities, the bioeconomy and natural resource development. Journal of Enterprising Communities: People and Places in the Global Economy, 6(3). doi:10.1108/jec.2012.32906caa.001

Davis, R. A., Lee, T. C. M., \& Rodriguez-Yam, G. A. (2006). Structural break estimation for nonstationary time series models. Journal of the American Statistical Association, 101(473), 223-239. doi:10.1198/016214505000000745

Davis, R. J., \& Davis, R. A. (1994). Framework for Managing Process Improvement: Benchmark Tutorial. Systems Research and Applications. Arlington VA, USA.

De Jesus, A. (2016). Environmental benefits and challenges associated with geothermal power generation Geothermal Power Generation (pp. 477-498): Elsevier.

Dej, M., Huculak, M., \& Jarczewski, W. (2013). Recreational use of geothermal water in Visegrad Group countries: Kraków: Institute of Urban Development.

Dej, M., Huculak, M., \& Jarczewski, W. (2014). Recreational use of geothermal water in Poland and Slovakia. Current Issues of Tourism Research, 3(1), 12-21.

Del Río, P., \& Burguillo, M. (2008). Assessing the impact of renewable energy deployment on local sustainability: Towards a theoretical framework. Renewable and Sustainable Energy Reviews, 12(5), 1325-1344. doi:10.1016/j.rser.2007.03.004 
Del Rio, P., \& Burguillo, M. (2009). An empirical analysis of the impact of renewable energy deployment on local sustainability. Renewable and Sustainable Energy Reviews, 13(6-7), 1314-1325. doi:10.1016/j.rser.2008.08.001

Deloitte. (2018). Global renewable energy trends. Deloitte Insights.

Demirbas, A. H. (2008). Global geothermal energy scenario by 2040. Energy Sources, Part A, 30(20), 1890-1895. doi:10.1080/15567030701468027

Dickson, M. H., \& Fanelli, M. (2013). Geothermal energy: utilization and technology. Routledge.

Dijkstra, L., Annoni, P., \& Kozovska, K. (2011). A new regional competitiveness index: Theory, methods and findings: European Commission. Directorate-General for Regional Policy.

Dinc, M., Haynes, K. E., \& Tarimcilar, M. (2003). Integrating models for regional development decisions: A policy perspective. The Annals of Regional Science, 37(1), 31-53. doi:10.1007/s001680200093

Dincer, I. (2018). Comprehensive energy systems. Elsevier.

Dincer, I. (2000). Renewable energy and sustainable development: a crucial review. Renewable and Sustainable Energy Reviews, 4(2), 157-175. doi:10.1016/S13640321(99)00011-8

Dincer, I., \& Acar, C. (2015). A review on clean energy solutions for better sustainability. International Journal of Energy Research, 39(5), 585-606. doi:10.1002/er.3329

Directive (EU) 2018/2001 of the European Parliament and of the Council of 11 December 2018 on the promotion of the use of energy from renewable sources, L 328/82 C.F.R. (2018).

Directive (EU) 2019/944 on Common Rules for the Internal Market for Electricity and Ammending Directive 2012/27/EU, No. July 2019 C.F.R. (2019).

Directive 2009/28/EC of the European Parliament and of the Council of 23 April 2009 on the promotion of the use of energy from renewable sources and amending and subsequently repealing Directives 2001/77/EC and 2003/30/EC, 5 C.F.R. (2009).

Dopfer, K. (2006). The origins of meso economics: Schumpeter's legacy. Papers on Economics and Evolution. No 0610. Max Planck Institute of Economics. Jena. Germany.

Dopfer, K., Foster, J., \& Potts, J. (2004). Micro-meso-macro. Journal of Evolutionary Economics, 14, 263-279. doi:10.1007/s00191-004-0193-0

Dornan, M., \& Shah, K. U. (2016). Energy policy, aid, and the development of renewable energy resources in Small Island Developing States. Energy Policy, 98, 759-767. doi:10.1016/j.enpol.2016.05.035

Dorożyński, T. (2009). Przyczyny regionalnych nierówności gospodarczych w świetle wybranych teorii. Studia Prawno-Ekonomiczne(80), 179-199.

Draper, N. R., \& Smith, H. (2014). Applied regression analysis. John Wiley \& Sons.

Drucker, P. F. (1995). Managing the non-profit organization: Practices and principles: Taylor \& Francis.

Dryglas, D. (2013). Spa and wellness tourism as a spatially determined product of health resorts in Poland. Current Issues of Tourism Research, 2(2), 30-38.

Dryglas, D., \& Hadzik, A. (2016). The development of the thermal tourism market in Poland//Rozwój rynku turystyki termalnej w Polsce. Geotourism/Geoturystyka(46-47), 27. 
Duffield, W. A., \& Sass, J. H. (2003). Geothermal energy: Clean power from the earth's heat (Vol. 1249). US Geological Survey.

Dumas, P. (2016). A European perspective of the development of deep geothermal in urban areas: Smart thermal grids, geothermal integration into smart cities. Geomechanics and Tunnelling, 9(5), 447-450. doi:10.1002/geot.201600030

Dumas, P., \& Angelino, L. (2015). Financing geothermal energy. In Proceedings of the World Geothermal Congress, Melbourne, Australia.

Dunn, E. S. (1960). A statistical and analytical technique for regional analysis. Papers in Regional Science, 6(1), 97-112. doi:10.1111/j.1435-5597.1960.tb01705.x

Dunning, J. H. (1993). Multinational Enterprises and the Global Economy: Reading, Mass.: Addison-Wesley.

Dursun, B., \& Gokcol, C. (2012). The role of geothermal energy in sustainable development of Turkey. Energy exploration \& exploitation, 30(2), 207-222. doi:10.1260/0144-5987.30.2.207

Dvořák, P., Martinát, S., Van der Horst, D., Frantál, B., \& Turečková, K. (2017). Renewable energy investment and job creation; a cross-sectoral assessment for the Czech Republic with reference to EU benchmarks. Renewable and Sustainable Energy Reviews, 69, 360-368. doi:10.1016/j.rser.2016.11.158

Dwivedi, K. (2018). Dissection on the Current Sustainability Concepts. European Journal of Sustainable Development, 7(1), 342-342.doi:10.14207/ejsd.2018.v7n1p342

Echavarria, F. R. (2008). Geothermal Energy Development in Africa-A Status Report. Distributed Generation and Alternative Energy Journal, 1(1), 5-7.

EEA. (2020). Air quality in Europe-2020 report. EEA Report. European Environment Agency. Luxembourg.

EGEC. (2019). Report on Competitiveness of the Geothermal Industry. European Geothermal Energy Council. Brussels, Belgium.

EGEC. (2020a). European Geothermal Market Report 2019. European Geothermal Energy Council. Brussels, Belgium.

EGEC. (2020b). Smart Sectoral Integration. The Multiple Benefits of Geothermal Energy. European Geothermal Energy Council. Brussels, Belgium.

Elbasha, E. H., \& Roe, T. L. (1996). On endogenous growth: the implications of environmental externalities. Journal of Environmental Economics and Management, 31(2), 240-268.

Elders, W. A., Osborn, W. L., Raju, A. S., \& Martinez-Morales, A. (2019). The Future Role of Geothermal Resources in Reducing Greenhouse Gas Emissions inCalifornia and Beyond. Conference Paper. Proceedings 44th Workshop on Geothermal Reservoir Engineering. Stanford, CA, USA.

England, R. W. (2000). Natural capital and the theory of economic growth. Ecological Economics, 34(3), 425-431. doi:10.1016/S0921-8009(00)00187-7

Erfurt-Cooper, P., \& Cooper, M. (2009). Health and wellness tourism: Spas and hot springs. Channel View Publications. Salisbury, UK.

Eskelinen, H., Hannibalsson, I., Malmberg, A., Maskell, P., \& Vatne, E. (2002). Competitiveness, localised learning and regional development: specialization and prosperity in small open economies. Routledge. London, UK. doi:10.4324/9780203030165

ESMAP. (2019). Gender Equality in the Geothermal Energy Sector: Road to Sustainability. Knowledge Series 028/19. World Bank. Washington, DC. 
Esteban, J. (2000). Regional convergence in Europe and the industry mix: a shiftshare analysis. Regional science and urban economics, 30(3), 353-364. doi:10.1016/S01660462(00)00035-1

Euroheat. (2019). District Energy in Poland. Country Profile. Euroheat and Power.

European Commision. (2010). Cohesion Policy Support for Local Development:

Best Practice and Future Policy Options. Final Report no. CCI n.2009.CE.16.0.AT.081.

Brussels, Belgium.

European Commission. (2001). Community Value Added: Definition and Evaluation Criteria. Brussels, Belgium.

European Commission.(2011). Energy Road Map 2050. Communication from the Commission to the European Parliament, the Council, The European Economic and Social Committee and the Committee of the Regions Energy Roadmap 2050 /* COM/2011/0885 final */

Eurostat. (2016). Glossary: Statistical classification of economic activities in the European Community (NACE). Eurostat Statistics Explained.

Eurostat. (2019). Renewable Energy Statistics. Eurostat Statistics Explained.

Fabbri, P., Pola, M., Piccinini, L., Zampieri, D., Roghel, A., \& Dalla Libera, N. (2017). Monitoring, utilization and sustainable development of a low-temperature geothermal resource: A case study of the Euganean Geothermal Field (NE, Italy). Geothermics, 70, 281-294. doi:10.1016/j.geothermics.2017.07.002

Fabrigar, L. R., \& Wegener, D. T. (2011). Exploratory factor analysis. Oxford University Press. UK.

Felter, A., Skrzypczyk, L., Socha, M., Sokołowski, J., Stożek, J., \& GryczkoGostyńska, A. (2015). Map of the management of groundwater classified as minerals in Poland. Polish Geological Institute. Warsaw, Poland.

Feng, X., \& Wen, Q. Q. (2011). The research of evaluation for growth suitability of carya cathayensis sarg. Based on PCA and AHP. Procedia Engineering, 15, 1879-1883. doi:10.1016/j.proeng.2011.08.350

Fiorentino, E., Curioni, S., \& Pisano, C. (2017). The common ground of thermal baths. WIT Transactions on Ecology and the Environment, 216, 287-297. doi:10.2495/WS170281

Foster, J. (2014). Energy, knowledge and economic growth. Journal of Evolutionary Economics, 24(2), 209-238. doi:10.1007/s00191-014-0348-6

Franco, A., \& Ponte, C. (2019). The role of geothermal in the energy transition in the Azores, Portugal. European Geologist. Geology and Energy Transition, 47, 21-27.

Fridleifsson, I. B. (1998). Direct use of geothermal energy around the world. National Energy Authority. Reykjavik, Iceland.

Fridleifsson, I. B. (2001). Geothermal energy for the benefit of the people. Renewable and Sustainable Energy Reviews, 5(3), 299-312. doi:10.1016/S13640321(01)00002-8

Fridleifsson, I. B. (2003). Status of geothermal energy amongst the world's energy sources. Geothermics, 32(4-6), 379-388. doi:10.1016/j.geothermics.2003.07.004

Fridleifsson, I. B. (2007). Geothermal energy and the millennium development goals of the United Nations. Conference Paper. Proceedings of the European Geothermal Congress. Unterhaching, Germany.

Fridleifsson, I. B., \& Ómarsdóttir, M. (2013). Geothermal Energy in Developing Countries and the MDGs. United Nations University. [online at 04.10.2013]. 
Fridleifsson, I. B., Bertani, R., Huenges, E., Lund, J. W., Ragnarsson, A., \& Rybach, L. (2008). The possible role and contribution of geothermal energy to the mitigation of climate change. In O. Hohmeyer and T. Trittin (Eds.) Proceedings IPCC Scoping Meeting on Renewable Energy Sources, 59-80. Luebeck, Germany.

Fridriksson, T., Mateos, A., Audinet, P., \& Orucu, Y. (2016). Greenhouse Gases from Geothermal Power Production. World Bank. Washington DC, USA.

Fried, R., \& U. Gather. (2005). Robust Trend Estimation for AR(1) Disturbances. Austrian Journal of Statistics, Vol. 34. 139 - 151. doi:10.17713/ajs.v34i2.407

FS-UNEP. (2020). Global Trends in Renewable Energy Investment 2020. In T. Ajadi, V. Cuming, R. Boyle, D. Strahan, M. Kimmel, M. Logan, \& A. McCrone (Eds.). Frankfurt: Frankfurt School-UNEP Centre/BNEF.

Fytikas, M., Leonidopoulou, G., \& Cataldi, R. (1999). Geothermal energy in ancient Greece: From mythology to late antiquity (3rd century AD). In Stories from a heated Earth. Our geothermal heritage, 69-102. Geothermal Resources Council \& International Geothermal Association. Sacramento, California, USA.

Gandolfo, G. (1997). Economic dynamics: study edition. Springer Science \& Business Media.

Gardiner, B., Martin, R., \& Tyler, P. (2012). Competitiveness, productivity and economic growth across the European regions. In Regional competitiveness, 61-84. Routledge. Cambrigde, UK.

Gareev, T. R. (2012). Clusters in the institutional perspective: on the theory and methodology of local socioeconomic development. Baltic Region, 4(3), 4-24. doi:10.5922/2079-8555-2012-3-1

Garrett-Peltier, H., 2017. Green versus brown: Comparing the employment impacts of energy efficiency, renewable energy, and fossil fuels using an input-output model. Econ. Model. 61, 439-447. doi:10.1016/j.econmod.2016.11.012.

Gazel, R. C., \& Schwer, R. K. (1998). Growth of international exports among the states: can a modified shift-share analysis explain it? International Regional Science Review, 21(2), 185-204.doi:10.1177/016001769802100205

Gędek, S., Strojny, J. and Kościółek, M., 2013. Wykorzystanie benchmarkingu w zarządzaniu strategicznym administracją publiczną. Przedsiębiorczość i Zarzq̨dzanie, 14(12, cz. 2 Zarządzanie w XXI wieku. Menedżer innowacyjnej organizacji. Część II), 127-142.

GeoVision. (2019). Harnessing the Heat Beneath Our Feet. U.S. Department of Energy. Oak Ridge, TN.

Ghazvini, M., Sadeghzadeh, M., Ahmadi, M. H., Moosavi, S., \& Pourfayaz, F. (2019). Geothermal energy use in hydrogen production: A review. International Journal of Energy Research, 43(14), 7823-7851. doi:10.1002/er.4778

Ghobadian, A., \& Ashworth, J. (1994). Performance measurement in local government-concept and practice. International Journal of Operations \& Production Management, Vol. 14(5), 35-51. doi:10.1108/01443579410056786

Giordano, N., Canalis, L., Ceppa, L., Comina, C., Degiorgis, L., Giuliani, A., . . . Marcon, G. (2016). How open-loop heat pumps on lakes can help environmental control: an example of geothermal circular economy. Conference Paper. Proceedings European Geothermal Congress. Strasbourg, France.

Gladysz, M., Sokolowska, J., \& Sokolowski, J. (1994). Geothermal projects in Poland. GRC Bulletin, 23(6), 201-207. 
Glaeser, E. L., Kallal, H. D., Scheinkman, J. A., \& Shleifer, A. (1992). Growth in cities. Journal of Political Economy, 100(6), 1126-1152. doi:10.1086/261856

Glassley, W. E. (2014). Geothermal energy: renewable energy and the environment. CRC press. $2^{\text {nd }}$ ed.

Glauben, T., Petrick, M., Tietje, H.r., \& Weiss, C. (2009). Probability and Timing of Succession or Closure in Family Firms: A Switching Regression Analysis of Farm Households in Germany. Applied Economics, 41(1), 45-54. doi:10.1080/00036840601131722

Glomm, G., \& Ravikumar, B. (1992). Public versus private investment in human capital: endogenous growth and income inequality. Journal of Political Economy, 100(4), 818-834. doi:10.1086/261841

Goldfeld, S., \& Quandt, R. (1973). The estimation of structural shifts by switching regressions. In Annals of Economic and Social Measurement, Vol. 2(4), 475-485. NBER.

Goldstein, B. A., Hiriart, G., Tester, J., Bertani, B., Bromley, R., Gutierrez-Negrin, L., ... \& Zui, V. I. (2011). Great expectations for geothermal energy to 2100. In Proceedings Thirty-Sixth Workshop on Geothermal Reservoir Engineering. Stanford University, Stanford, CA, USA.

Góra, J. (2013). Miejska turystyka uzdrowiskowa i kierunki jej ewolucji w Polsce. Studia Ekonomiczne, 147, 53-67.

Górecki, W., Sowiżdżał, A., Hajto, M., \& Wachowicz-Pyzik, A. (2015). Atlases of geothermal waters and energy resources in Poland. Environmental Earth Sciences, 74(12), 7487-7495. doi:10.1007/s12665-014-3832-2

Górecki, W., Szczepański, A., Sadurski, A., Hajto, M., Papiernik, B., Kużniak, T., ... \& Strzetelski, W. (2006). Atlas of geothermal resources of mesozoic formations in the Polish Lowlands. AGH KSE, Kraków.

Górecki, W., Sowiżdżał, A., Jasnos, J., Papiernik, B., Hajto, M., Machowski, G., . . . Kotyza, J. (2012). Geothermal atlas of the Carpathian Foredeep. AGH KSE, Kraków.

Govaert, G. (2013). Data analysis. John Wiley \& Sons.

Green, B.D. and Nix, R.G., 2006. Geothermal--the energy under our feet: Geothermal resource estimates for the United States (No. NREL/TP-840-40665). National Renewable Energy Laboratory (NREL), Golden, CO.

Greene, W. H. (2000). Econometric analysis. Prentice- Hall Inc., NJ, USA.

Greenpeace. (2015). Energy [R]evolution - A sustainable world energy outlook 2015. 100\% Energy for all. Report World Energy Scenario $5^{\text {th }}$ Edition.

Gross, S., \& Ringbeck, J. (2008). Environmental Sustainability as a Driver for Competitiveness. The Travel \& Tourism Competitiveness Report 2008, 27-40. Booz Allen Hamilton.

Grossman, G. M., \& Helpman, E. (1991). Innovation and Growth in the Global Economy. MIT press.

Grossman, G. M., \& Helpman, E. (1994). Endogenous innovation in the theory of growth. Journal of Economic Perspectives, 8(1), 23-44. doi:10.1257/jep.8.1.23

Grzebyk, M., \& Stec, M. (2015). Sustainable development in EU countries: concept and rating of levels of development. Sustainable Development, 23(2), 110-123. doi:10.1002/sd.1577

Gudmundsson, J. S., Freeston, D. H., \& Lienau, P. J. (1985). The Lindal Diagram. GRC Transactions, 9(1), 15-19.

Gudmundsson, J.-S. (1988). The elements of direct uses. Geothermics, 17(1), 119136.doi:10.1016/0375-6505(88)90009-0 
Gul, S., \& Aslanoglu, V. (2018). Drilling and well completion cost analysis of geothermal wells in Turkey. Conference Paper. SGP-TR-213. Proceedings 43rd Workshop on Geothermal Reservoir Engineering Stanford University, Stanford, CA, USA.

Hähnlein, S., Bayer, P., Ferguson, G., \& Blum, P. (2013). Sustainability and policy for the thermal use of shallow geothermal energy. Energy Policy, 59, 914-925. doi:10.1016/j.enpol.2013.04.040

Hałaj, E. (2012). Kąpieliska i ośrodki wypoczynkowe na Podhalu i Niżu Polskim jako przykłady bezpośredniego wykorzystania wód geotermalnych w Polsce. Technika Poszukiwań Geologicznych, 51(2), 3--15.

Hałaj, E. (2012). Kąpieliska i ośrodki wypoczynkowe na Podhalu i Niżu Polskim jako przykłady bezpośredniego wykorzystania wód geotermalnych w Polsce. Technika Poszukiwań Geologicznych. Geotermia, Zrównoważony Rozwój, 51(2), 3-15.

Halaj, E. (2015). Geothermal bathing and recreation centres in Poland. Environmental Earth Sciences, 74(12), 7497-7509. doi:10.1007/s12665-014-3740-5

Hamilton, J. D. (1989). A new approach to the economic analysis of nonstationary time series and the business cycle. Econometrica: Journal of the Econometric Society, 57, 357-384. doi:10.2307/1912559

Hammersley, M., \& Atkinson, P. (1995). Ethnography: Practices and principles. Routledge. New York, USA.

Hammons, T. (2007). Geothermal power generation: global perspectives; USA and Iceland; technology, direct uses, plants, and drilling. International Journal of Power \& Energy Systems, 27(2), 157.

Hance, C. N. (2005). Geothermal industry employment: Survey results \& analysis. Geothermal Program Research document. Geothermal Energy Association. USA. doi:10.2172/897431

Harrison, C., \& Popke, J. (2018). Geographies of renewable energy transition in the Caribbean: Reshaping the island energy metabolism. Energy research \& social science, 36, 165-174. doi:10.1016/j.erss.2017.11.008

Harrison, J. (2007). From competitive regions to competitive city-regions: a new orthodoxy, but some old mistakes. Journal of Economic Geography, 7(3), 311-332. doi:10.1093/jeg/lbm005

Hartono, D., Hastuti, S. H., Halimatussadiah, A., Saraswati, A., Mita, A. F., \& Indriani, V. (2020). Comparing the impacts of fossil and renewable energy investments in Indonesia: A simple general equilibrium analysis. Heliyon, 6(6), e04120.

doi:10.1016/j.heliyon.2020.e04120

Hast, A., Syri, S., Lekavičius, V., \& Galinis, A. (2018). District heating in cities as a part of low-carbon energy system. Energy, 152, 627-639.doi:10.1016/j.energy.2018.03.156 Hasterok, D., Castro, R., Landrat, M., Pikoń, K., Doepfert, M., \& Morais, H. (2021). Polish Energy Transition 2040: Energy Mix Optimization Using Grey Wolf Optimizer. Energies, 14(2), 501. doi:10.3390/en14020501

Heijman, W. J. M., \& Schipper, R. A. (2010). Space and Economics: An introduction to regional economics (Vol. 7). Wageningen Academic. The Netherlands.

Heijman, W., van Ophem, J., Bronisz, U., \& Varivoda, V. (2010). Regional Competitiveness: A European approach. In Bielik, P.(ed.) Economics, Social Policies and Citizenship in the Europe of Regions. Slovak University of Agriculture in Nitra. Slovakia. 
Heinbach, K., Aretz, A., Hirschl, B., Prahl, A., \& Salecki, S. (2014). Renewable energies and their impact on local value added and employment. Energy, Sustainability and Society, 4(1), 1. doi:10.1186/2192-0567-4-1

Hełdak, D. (2017). Rozwój usług turystycznych na Podhalu na przykładzie miejscowości Białka Tatrzańska. Annales Universitatis Mariae Curie-Sklodowska, sectio BGeographia, Geologia, Mineralogia et Petrographia, 71(2), 129.

doi:10.17951/b.2016.71.2.129

Helpman, E. (1992). Endogenous macroeconomic growth theory. European Economic Review, 36(2-3), 237-267. doi:10.1016/0014-2921(92)90083-9

Henderson, V., \& Thisse, J.-F. (2004). Handbook of regional and urban economics: cities and geography (Vol. 4). Elsevier. Amsterdam, The Netherlands.

Henriques, C. O., Coelho, D. H., \& Cassidy, N. L. (2016). Employment impact assessment of renewable energy targets for electricity generation by 2020-An IO LCA approach. Sustainable Cities and Society, 26, 519-530. doi:10.1016/j.scs.2016.05.013 Herath, G., \& Prato, T. (2006). Role of multi-criteria decision making in natural resource management. In (Eds. Herath \& Prato). Using multi-criteria decision analysis in natural resource management. Ashgate, Burlington, Vermont, USA, 1-10.

Hernández-Galán, J. L., Lámbarri, J., \& Suarez Arriaga, M. C. (1999). An overview of the historical aspects of geothermal influences in Mesoamerica. Stories from a Heated Earth, 518-532.

Herzog Jr, H. W., \& Olsen, R. J. (1977). Shift-share analysis revisited: The allocation effect and the stability of regional structure. Journal of Regional Science, 17(3), 441-454. doi:10.1111/j.1467-9787.1977.tb00514.x

Hirschl, B., Aretz, A., Heinbach, K., Prahl, A., \& Salecki, S. (2014). Renewable Energies and their Impact on Local Value Added and Employment. Energy, Sustainability and Society, 4(1), 1-10. doi:10.1186/2192-0567-4-1

Hjartarson, H., Maack, R., \& Johannesson, S. (2005). Húsavik energy multiple use of geothermal energy. GHC Bull, 26(2), 7-13.

Ho, W. (2008). Integrated analytic hierarchy process and its applications-A literature review. European Journal of Operational Research, 186(1), 211-228. doi:10.1016/j.ejor.2007.01.004

Hoang, H. T., Truong, Q. H., Nguyen, A. T., \& Hens, L. (2018). Multicriteria Evaluation of Tourism Potential in the Central Highlands of Vietnam: Combining Geographic Information System (GIS), Analytic Hierarchy Process (AHP) and Principal Component Analysis (PCA). Sustainability, 10(9), 3097. doi:10.3390/su10093097

Hoenig, H. (2005). Geothermal Resources as a Promoter of Regional Development, The Success Story of the Styrian Volcanic Region. In Proceedings World Geothermal Congress 2005 (pp. 24-29). Antalya, Turkey.

Hoffmann, D. (2009). Creation of regional added value by regional bioenergy resources. Renewable and Sustainable Energy Reviews, 13(9), 2419-2429. doi:10.1016/j.rser.2009.04.001

Hoppes, R. B. (1997). Shift-share analysis for regional health care policy. Journal of Regional Analysis and Policy, 27, 35-46.

Horton, D., Ballantyne, P., Peterson, W., Uribe, B., Gapasin, D., \& Sheridan, K. (1993). Monitoring and evaluating agricultural research: a sourcebook. Cab International. 
How, B. S., \& Lam, H. L. (2017). Novel evaluation approach for biomass supply chain: an extended application of PCA. Chemical Engineering Transactions, 61, 1591-1596. doi:10.3303/CET1761263

Hsiao, C., (2003). Analysis of Panel Data. Cambridge University Press. $2^{\text {nd }}$ ed.

Hübler, M., Baumstark, L., Leimbach, M., Edenhofer, O., \& Bauer, N. (2012). An integrated assessment model with endogenous growth. Ecological economics, 83, 118-131. doi:10.1016/j.ecolecon.2012.07.014

Huculak, M., Jarczewski, W., \& Dej, M. (2015). Economic aspects of the use of deep geothermal heat in district heating in Poland. Renewable and Sustainable Energy Reviews, 49, 29-40. doi:10.1016/j.rser.2015.04.057

Huggins, R. (2003). Creating a UK competitiveness index: regional and local benchmarking. Regional studies, 37(1), 89-96. doi:10.1080/0034340022000033420 Huggins, R., \& Izushi, H. (2011). Competition, competitive advantage, and clusters: the ideas of Michael Porter. Oxford University Press.

Hunt, S. D. (1999). A general theory of competition: Resources, competences, productivity, economic growth. Sage Publications.

Huovari, J., Kangasharju, A., \& Alanen, A. (2002). Constructing an Index for Regional Competitiveness. In: Acs Z.J., de Groot H.L.F., Nijkamp P. (eds) The Emergence of the Knowledge Economy. Advances in Spatial Science. Springer, Berlin, Heidelberg. doi:10.1007/978-3-540-24823-1_7

IEA (2011). Technology Roadmap. Geothermal Heat and Power. Paris: International Energy Agency.

IEA. (2019). World Energy Outlook 2019. International Energy Agency. Paris

IEA. (2020a). Geothermal Renewables. International Energy Agency. Paris

IEA. (2020b). Tracking Power 2020. International Energy Agency. Paris

IEA (2021). Data and Statistics. Country: Poland. International Energy Agency.

Paris.

Igliński, B., Piechota, G., \& Buczkowski, R. (2015). Development of biomass in polish energy sector: an overview. Clean Technologies and Environmental Policy, 17(2), 317-329. doi:10.1007/s10098-014-0820-x

IMF. (2018). Country Data: Republic of Poland. International Monetary Fund.

Ioppolo, G., Cucurachi, S., Salomone, R., Saija, G., \& Shi, L. (2016). Sustainable local development and environmental governance: A strategic planning experience. Sustainability, 8(2), 180. doi:10.3390/su8020180

IRENA. (2011). Renewable Energy Jobs: Status, Prospects \& Policies. IRENA Working Paper. Abu Dhabi: International Renewable Energy Agency.

IRENA. (2013). Renewable Energy and Jobs. Abu Dhabi: International Renewable Energy Agency.

IRENA. (2018). Renewable Energy and Jobs - Annual Review 2018. Abu Dhabi: International Renewable Energy Agency.

IRENA. (2019a). Accelerating geothermal heat adoption in the agri-food sector: Key lessons and recommendations. Abu Dhabi: International Renewable Energy Agency.

IRENA. (2019b). Global energy transformation: A roadmap to 2050 (2019 edition). Abu Dhabi: International Renewable Energy Agency.

IRMA. (2012). Regional Development: Concepts, Methodologies, Tools and Applications. Hershey, USA: IGI Gobal. 
Isard, W. (1965). Location and space-economy: A general theory relating to industrial location, market areas, land use, trade, and urban structure. The MIT Press, USA. Ishizaka, A., \& Labib, A. (2009). Analytic hierarchy process and expert choice: Benefits and limitations. Or Insight, 22(4), 201-220. doi:10.1057/ori.2009.10 Jakovlev, Z., Koteski, C., Dimitrov, N., Josheski, D., Serafimova, M., \& Zezova, A. (2016). Basic socioeconomic parameters for promoting tourism in the municipality of Dojran in the Republic of Macedonia. Wulfenia Journal, 23(2), 523-535.

Jänicke, M. (2012). "Green growth": from a growing eco-industry to economic sustainability. Energy Policy, 48, 13-21. doi:10.1016/j.enpol.2012.04.045 Jarczewski, W., Huculak, M., \& Dej, M. (2015). Wykorzystanie energii geotermalnej w Polsce. Prace geograficzne(141). doi:10.1016/j.rser.2015.04.057 Jenei, T. (2012). SWOT analyses of geothermal investment projects-case studies. International Review of Applied Sciences and Engineering, 3(2), 97-103. doi:10.1556/irase.3.2012.2.2

Jenniches, S. (2018). Assessing the regional economic impacts of renewable energy sources-A literature review. Renewable and Sustainable Energy Reviews, 93, 35-51. doi:10.1016/j.rser.2018.05.008

Jesus, A. C. d. (1997). Environmental sustainability of geothermal development. Energy sources, 19(1), 35-47. doi:10.1080/00908319708908830 Ji-Yang, W. (1995). 23. Historical Aspects of Geothermal Waters in China. Conference Paper. Proceedings of the World Geothermal Congress 1995, 389-394. Florence, Italy,

Jiricka, A., Salak, B., Eder, R., Arnberger, A., \& Pröbstl, U. (2010). Energetic tourism: exploring the experience quality of renewable energies as a new sustainable tourism market. WIT Transactions on Ecology and the Environment, 139(4), 55-68.

Jóhannesson, G. P., Skaptadóttir, U. D., \& Benediktsson, K. (2003). Coping with social capital? The cultural economy of tourism in the North. Sociologia Ruralis, 43(1), 3-16. doi:10.1111/1467-9523.00226

Johansson, B., Karlsson, C., \& Stough, R. (2011). Theories of endogenous regional growth-lessons for regional policies. In (Eds. Johansson et al.) Theories of endogenous regional growth (pp. 406-414). Springer.

Johnson, C., Augustine, C., \& Goldberg, M. (2012). Jobs and Economic Development Impact (JEDI) Model Geothermal User Reference Guide. Retrieved fromJobs and Economic Development Impact (JEDI) Model Geothermal User Reference Guide (No. NREL/TP-6A20-55781). National Renewable Energy Lab.(NREL). CO, USA.

Johnson, J. (2017). Creating Accidental Environmentalists in America: Reconsidering Why Green Initiatives Have Fallen Flat. Geo. Wash. J. Energy \& Envtl. L., 8, 175.

Johnson, R. B., \& Onwuegbuzie, A. J. (2004). Mixed methods research: A research paradigm whose time has come. Educational researcher, 33(7), 14-26. doi:10.3102/0013189X033007014

Jolliffe, I. T. (1986). Principal component analysis. Springer.

Jonas, A. E., While, A., \& Gibbs, D. (2010). Carbon control regimes, eco-state restructuring and the politics of local and regional development. Handbook of local and regional development, 283. doi:10.4324/9780203842393.ch24 
Jones, T., Shone, M. C., \& Memon, P. A. (2003). Emerging Tourism Planning Processes and Practices in New Zealand: a local and regional perspective. Tourism Recreation Research and Education Centre (TRREC) Report No. 56. Lincoln University.

Juma, C., Fang, K., Honca, D., Huete-Perez, J., Konde, V., Lee, S. H., ... \& Singh, S. (2001). Global governance of technology: meeting the needs of developing countries. International Journal of Technology Management, 22(7-8), 629-655. doi:10.1504/IJTM.2001.002982

Kaczmarczyk, M. (2018). Potential of existing and newly designed geothermal heating plants in limiting of low emissions in Poland. E3S Web of Conferences 44, 00062. doi:10.1051/e3sconf/20184400062

Kagel, A. (2006a). A handbook on the externalities, employment, and economics of geothermal energy. Geothermal Energy Association. Washington DC, USA.

Kagel, A. (2006b). Socioeconomics and geothermal energy. Geothermal Resources Council Trans, 30, 1045-1051.

Kalbacher, J. Z. (1979). Shift-share analysis: A modified approach. Agricultural Economics Research, 31(1), 12-25.

Kamenetzky, R. D. (1982). The relationship between the analytic hierarchy process and the additive value function. Decision Sciences, 13(4), 702-713. doi:10.1111/j.1540-5915.1982.tb01900.x

Karytsas, S., Polyzou, O., \& Karytsas, C. (2019). Social aspects of geothermal energy in Greece Geothermal Energy and Society (pp. 123-144). Springer.

Kaushik, V., \& Walsh, C. A. (2019). Pragmatism as a research paradigm and its implications for social work research. Social Sciences, 8(9), 255. doi:10.3390/socsci8090255

Kaygusuz, K., \& Kaygusuz, A. (2004). Geothermal energy in Turkey: the sustainable future. Renewable and Sustainable Energy Reviews, 8(6), 545-563. doi:10.1016/j.rser.2004.01.001

Keil, S. R. (1992). On the value of homotheticity in the shift-share framework. Growth and change, 23(4), 469-493. doi:10.1111/j.1468-2257.1992.tb00945.x

Kępińska, B. (2002). Thermal springs and spas in Poland. GHC Bulletin, 23(1), 1017.

Kepińska, B. (2003). Current geothermal activities and prospects in Poland-an overview. Geothermics, 32(4-6), 397-407. doi:10.1016/j.geothermics.2003.07.006

Kępińska, B. (2016). Przegląd Stanu Wykorzystania Energii Geotermalnej na Świecie i w Europie w Latach 2013-2015. Technika Poszukiwań Geologicznych. Geotermia, Zrównoważony Rozwój, 1, 5-17.

Kępińska, B., Kiełczawa, B., Liber-Makowska, E., \& Blachowski, J. (2017). Geothermal energy-a basis for low-emission space heating, improving living conditions and sustainable development-preliminary studies for selected areas in Poland Study Visits' Report.

Kępińska, B. (2018). A review of geothermal energy uses in Poland in 2016-2018. Technika Poszukiwań Geologicznych, 57, 11-27.

Kępińska, B. (2019). Geothermal energy use-Country update for Poland, 20162018. Proceedings of the European Geothermal Congress 2019, The Hague, The Netherlands.

Kil, S.-H., Lee, D. K., Kim, J.-H., Li, M.-H., \& Newman, G. (2016). Utilizing the analytic hierarchy process to establish weighted values for evaluating the stability of slope 
revegetation based on hydroseeding applications in South Korea. Sustainability, 8(1), 58. doi:10.3390/su8010058

Kim, H. J., \& Chen, M. H. (2006). Tourism expansion and economic development: The case of Taiwan. Tourism Management, 27(5), 925-933.

doi:10.1016/j.tourman.2005.05.011

Kim, J. O., \& Ferree Jr, G. D. (1981). Standardization in causal

analysis. Sociological Methods \& Research, 10(2), 187-210.

doi:10.1177/004912418101000203

Kim, J.-O., Ahtola, O., Spector, P. E., \& Mueller, C. W. (1978). Introduction to factor analysis: What it is and how to do it. Sage.

Kitson, M., Martin, R., \& Tyler, P. (2004). Regional competitiveness: an elusive yet key concept? Regional studies, 38(9), 991-999. doi:10.1080/0034340042000320816

Kitson, M., Martin, R., \& Tyler, P. (2005). The regional competitiveness debate. University of Cambridge.

Kırlı, M. S., \& Fahrioğlu, M. (2019). Sustainable development of Turkey: Deployment of geothermal resources for carbon capture, utilization, and storage. Energy Sources, Part A: Recovery, Utilization, and Environmental Effects, 41(14), 1739-1751. doi:10.1080/15567036.2018.1549149

Klagge, B., Greiner, C., Greven, D., \& Nweke-Eze, C. (2020). Cross-scale linkages of centralized electricity generation: Geothermal development and investor-community relations in Kenya. Politics and Governance, 8(3), 211-222. doi:10.17645/pag.v8i3.2981

Klenner, R., \& Gosnold, W. (2009). Can Geothermal Power Replace Fossil Fuels? AGUFM, 2009, H53F-1004.

Klijs, J., Heijman, W., Maris, D. K., \& Bryon, J. (2012). Criteria for comparing economic impact models of tourism. Tourism Economics, 18(6), 1175-1202. doi:10.5367/te.2012.0172

Knudsen, D. C. (2000). Shift-share analysis: further examination of models for the description of economic change. Socio-Economic Planning Sciences, 34(3), 177-198. doi:10.1016/S0038-0121(99)00016-6

Kobylińska, U. \& Glińska, E., (2008). Wykorzystanie benchmarkingu w doskonaleniu systemów zarządzania placówkach samorządu terytorialnego. In B. Plawo (ed.) Polska Wschodnia-zarzqdzanie rozwojem, WSAP. Białystok, Poland.

Kolenikov, S., \& Angeles, G. (2005). The use of discrete data in principal component analysis for socio-economic status evaluation. University of North Carolina at Chapel Hill, Carolina, NC.

Komac, M. (2006). A landslide susceptibility model using the analytical hierarchy process method and multivariate statistics in perialpine Slovenia. Geomorphology, 74(1-4), 17-28.doi:10.1016/j.geomorph.2005.07.005

Konak, G., \& Pamukcu, C. (2006). Geothermal energy-economy, potential and utilization possibilities in Turkey. Energy exploration \& exploitation, 24(4), 271-283.

Korff, R. (2003). Local enclosures of globalization. The power of locality. Dialectical Anthropology, 27(1), 1-18. doi:10.1023/A:1025466127833

Kościelecki, P., Bloch, E., Śpiewak, R., \& Zalewska, K. (2010). Handbook on creating systems and evaluating indicators in local development strategies. ECO s.c. Poland. Kowalczyk, M. (2018). Key Performance Indicators in local government in Poland. Prace Naukowe Uniwersytetu Ekonomicznego we Wrocławiu (503), 236-245. doi:10.15611/pn.2018.503.21 
Kowalski, M. (2015). Pozarolnicza działalność gospodarcza w gminie Uniejów. Biuletyn Uniejowski(4), 143-156.

Kristjánsdóttir, H., \& Margeirsson, Á. (2012). Geothermal Cost and Investment Factors. In A. Sayigh (Ed.), Comprehensive Renewable Energy (Vol. 7, pp. 259-270). Elsevier. Oxford, UK.

Kristmannsdóttir, H., \& Ármannsson, H. (2003). Environmental aspects of geothermal energy utilization. Geothermics, 32(4-6), 451-461. doi:10.1016/S03756505(03)00052-X

Kruczek, Z. (2016). Frekwencja w atrakcjach turystycznych. EPT. 3 (35), 25-35. doi:10.18276/ept.2016.3.35-02

Krueger, R., \& Gibbs, D. (2008). 'Third wave'sustainability? Smart growth and regional development in the USA. Regional Studies, 42(9), 1263-1274. doi:10.1080/00343400801968403

Krugman, P. (1995). Development, economic geography and economic theory. Cambridge, MA: MIT Press.

Krutilla, K., \& Reuveny, R. (2006). The systems dynamics of endogenous population growth in a renewable resource-based growth model. Ecological economics, 56(2), 256-267. doi:10.1016/j.ecolecon.2005.02.002

Kudełko, M. Modeling of Polish energy sector-tool specification and results. Energy, 215, 119149. doi:10.1016/j.energy.2020.119149

Kukula, K. (2014). Zero Unitarization Method as a tool in ranking research. Economic Sciences for Rural Development, No. 36, p. 95-100. doi:10.22630/ASPE.2017.16.4.48

Kukula, K., \& Bogocz, D. (2014). Zero unitarization method and its application in ranking research in agriculture. Economic and Regional Studies (Studia Ekonomiczne i Regionalne), 7(673-2017-2604), 5-13. doi:10.22004/ag.econ.265035

Kulesza, M., \& Sześciło, D. (2012). Chapter 20: Local Government in Poland. In A. M. Moreno (Ed.), Local government in the Member States of the European Union: a comparative legal perspective, 485. INEP.

Kunkel, T., Ghomshei, M., \& Ellis, R. (2012). Geothermal Energy as an Indigenous Alternative Energy Source in BC. Journal of Ecosystems and Management, 13(2). 1-16.

Kumari, W. G. P., \& Ranjith, P. G. (2019). Sustainable development of enhanced geothermal systems based on geotechnical research-A review. Earth-Science Reviews, 199, 102955. doi:10.1016/j.earscirev.2019.102955.

Kurek, K. A. (2016). An Approach to Geothermal Resources as a Regional Development Driver in Poland. Humanities and Social Sciences, XXI(4), 173-188. doi:10.7862/rz.2016.hss.68

Kurek, K. A. (2019). Dataset for The impact of geothermal resources on the competitiveness of municipalities: evidence from Poland. Mendeley Data, V1. doi:10.17632/htrmm4r6dv.1

Kurek, K. A. (2020). Dataset for Measuring local competitiveness: comparing and integrating two methods PCA and AHP. Mendeley Data, V2. doi:10.17632/z72tgw2phx.2

Kurek, K. A., Heijman, W., van Ophem, J., Gędek, S., \& Strojny, J. (2020a). The impact of geothermal resources on the competitiveness of municipalities: evidence from Poland. Renewable Energy, 151, 1230-1239. doi:10.1016/j.renene.2019.11.126 
Kurek, K. A., Heijman, W., van Ophem, J., Gędek, S., \& Strojny, J. (2020b). Geothermal spas as a local development factor, the case of Poland. Geothermics, 85, 101777. doi:10.1016/j.geothermics.2019.101777

Kurek, K. A., Heijman, W., van Ophem, J., Gędek, S., \& Strojny, J. (2020c). Dataset for the model of municipality competitiveness in relation to the geothermal resources exploitation in Poland. Mendeley Data, V2. doi:10.17632/zfndmn3f55.2

Kurek, K. A., Heijman, W., van Ophem, J., Gędek, S., \& Strojny, J. (2020d). Dataset for the model of a municipality competitiveness in relation to the geothermal resources exploitation in Poland. Data in Brief, 31, 105687. doi:10.1016/j.dib.2020.105687

Kurek, K. A., Heijman, W., van Ophem, J., Gędek, S., \& Strojny, J. (2020e). Dataset for: The Contribution of the Geothermal Resources to Local Employment: Case study from Poland. Mendeley Data, V4. doi:10.17632/cs9hw7dp2z.4

Kurek, K. A., Heijman, W., van Ophem, J., Gędek, S., \& Strojny, J. (2021). The contribution of the geothermal resources to local employment: Case study from Poland. Energy Reports, 7, 1190-1202. doi:10.1016/j.egyr.2021.01.092

Kurlansky, M. (2011). Salt: Random House.

Kurre, J. A., \& Weller, B. (1989). Forecasting the local economy, using time-series and shift-share techniques. Environment and Planning A, 21(6), 753-770.

Kusz, D., Gędek, S. \& Kata, R. (2015). Macroeconomic Determinants of the Dynamics of Investment in Agriculture (Case of Poland). Scientific Papers Series Management, Economic Engineering in Agriculture and Rural Development. Vol. 15, Issue 2, 171-178.

Lammers, I., \& Hoppe, T. (2018). Analysing the institutional setting of local renewable energy planning and implementation in the eu: A systematic literature review. Sustainability, 10(9), 3212. doi:10.3390/su10093212

Leardini, T., \& Falcon, N. L. (1974). Geothermal power [and Discussion]. Philosophical Transactions of the Royal Society of London. Series A, Mathematical and Physical Sciences, 276(1261), 507-526. doi:10.1098/rsta.1974.0035

Lee, C.I., \& Solon, G. (2009). Trends in intergenerational income mobility. The Review of Economics and Statistics, 91(4), 766-772. doi:10.1162/rest.91.4.766

Lee, G. K., \& Chan, E. H. (2008). The analytic hierarchy process (AHP) approach for assessment of urban renewal proposals. Social Indicators Research, 89(1), 155-168. doi:10.1007/s11205-007-9228-x Polytechnic

Lee, J., \& Malhotra, N. K. (2006). Marketing Research. Singapore Ngee Ann

Lee, J., Kang, S.-H., Rosenberger, J., \& Kim, S. B. (2010). A hybrid approach of goal programming for weapon systems selection. Computers \& Industrial Engineering, 58(3), 521-527. doi:10.1016/j.cie.2009.11.013

Lee, K. C. (2001). Classification of geothermal resources by exergy. Geothermics, 30(4), 431-442. doi:10.1016/S0375-6505(00)00056-0

Lehr, U., Banning, M., Hegazi, A., \& Youssef, E. A. (2012). The Socio-Economic impacts of Renewable Energy and Energy Efficiency in Egypt-Local Value and. World Economy, 46(15), 8374-8381.

Lehr, U., Lutz, C., \& Edler, D. (2012). Green jobs? Economic impacts of renewable energy in Germany. Energy Policy, 47, 358-364. doi:doi.org/10.1016/j.enpol.2012.04.076 
Leitch, A., Haley, B., \& Hastings-Simon, S. (2019). Can the oil and gas sector enable geothermal technologies? Socio-technical opportunities and complementarity failures in Alberta, Canada. Energy Policy, 125, 384-395. doi:10.1016/j.enpol.2018.10.046

Lengyel, I., \& Rechnitzer, J. (2013). The competitiveness of regions in the Central European transition countries. The Macrotheme Review, 2(4), 106-121.

Lesser, J. A. (1994). Estimating the economic impacts of geothermal resource development. Geothermics, 23(1), 43-59. doi:10.1016/0375-6505(94)90045-0

Lew, A. (2005). Remarks on the Polish Translation of the Handbook of Literary Rhetoric. Meander, 60(1), 122-126.

Li, K., Bian, H., Liu, C., Zhang, D., \& Yang, Y. (2015). Comparison of geothermal with solar and wind power generation systems. Renewable and Sustainable Energy Reviews, 42, 1464-1474. doi:10.1016/j.rser.2014.10.049

Li, X., Lu, J., Gao, Z., \& Yang, Y. (2018). Effectiveness Evaluation of Kill Chain Based on PCA, AHP and Entropy Weight Method. Conference Paper. Proceedings of 2018 3rd International Conference on Modelling, Simulation and Applied Mathematics (MSAM 2018).

Limberger, J., Boxem, T., Pluymaekers, M., Bruhn, D., Manzella, A., Calcagno, P., . . . van Wees, J.-D. (2018). Geothermal energy in deep aquifers: A global assessment of the resource base for direct heat utilization. Renewable and Sustainable Energy Reviews, 82, 961-975. doi:10.1016/j.rser.2017.09.084

Linkov, I., \& Moberg, E. (2011). Multi-criteria decision analysis: environmental applications and case studies. CRC Press. doi:10.1201/b11471

Llera, E., Scarpellini, S., Aranda, A., \& Zabalza, I. (2013). Forecasting job creation from renewable energy deployment through a value-chain approach. Renewable and Sustainable Energy Reviews, 21, 262-271. doi:10.1016/j.rser.2012.12.053

Local Data Bank. www.bdl.stat.gov.pl/BDL/start [accessed 30.09.2016].

López, A. J., \& Moreno, B. (2010). Renewable Energy in the European Union: An Econometric approach to trends and effects. Conference Paper. International Conference on Biosciences. Cancun, Mexico, 2010, pp. 95-98. doi:10.1109/BioSciencesWorld.2010.20 Lösch, A. (1954). Economics of location. New Heaven: Yale University Press.

Lovekin, J. (2000). The Economics of Sustainable Geothermal Development. Transactions- Geothermal Resources Council No.24, 113-118.

Lovering, J. (1999). Theory led by policy: the inadequacies of the 'New Regionalism' (illustrated from the case of Wales). International Journal of Urban and Regional Research, Vol. 23, 379-395.

Lowitzsch, J., Hoicka, C., \& Van Tulder, F. (2020). Renewable energy communities under the 2019 European Clean Energy Package-Governance model for the energy clusters of the future? Renewable and Sustainable Energy Reviews, 122, 109489. doi:10.1016/j.rser.2019.109489

Lucas Jr, R. E. (1988). On the mechanics of economic development. Journal of Monetary Economics, 22(1), 3-42. doi:10.1016/0304-3932(88)90168-7

Lucas, H., Fifita, S., Talab, I., Marschel, C., \& Cabeza, L. F. (2017). Critical challenges and capacity building needs for renewable energy deployment in Pacific Small Island Developing States (Pacific SIDS). Renewable energy, 107, 42-52. doi:doi.org/10.1016/j.renene.2017.01.029 
Luke, J. S., Ventriss, C., Reed, B., \& Reed, C. M. (1988). Managing economic development: A guide to state and local leadership strategies. Jossey-Bass Publishers. Los Angeles, CA, USA.

Luketina, K., \& Parson, P. (2019). New Zealand's Public Participation in Geothermal Resource Development. In Geothermal Energy and Society, 193-216. Springer. Lund, J. W. (1996). Lectures on direct utilization of geothermal energy: United Nations University Geothermal Training Programme Reykjavik, Iceland.

Lund, J. W. (2006). Geothermal energy focus: Tapping the earth's natural heat. Refocus, 7(6), 48-51. doi:10.1016/S1471-0846(06)70660-6

Lund, J. W., \& Boyd, T. L. (2016). Direct utilization of geothermal energy 2015 worldwide review. Geothermics, 60, 66-93. doi:10.1016/j.geothermics.2015.11.004

Lund, J. W., Freeston, D. H., \& Boyd, T. L. (2011). Direct utilization of geothermal energy 2010 worldwide review. Geothermics, 40(3), 159-180.

doi:10.1016/j.geothermics.2011.07.004

Lund, J., \& Boyd, T. (1999). Small geothermal power project examples. Geo-Heat Centre Quarterly Bulletin, 20(2), 9-26.

Lund, P. D. (2009). Effects of energy policies on industry expansion in renewable energy. Renewable energy, 34(1), 53-64. doi:10.1016/j.renene.2008.03.018

Macharis, C., Springael, J., De Brucker, K., \& Verbeke, A. (2004). PROMETHEE and AHP: The design of operational synergies in multicriteria analysis.: Strengthening PROMETHEE with ideas of AHP. European Journal of operational research, 153(2), 307-317. doi:10.1016/S0377-2217(03)00153-X

Maddala, G. S., \& Lahiri, K. (1992). Introduction to econometrics (Vol. 2). Macmillan. New York, USA.

Madlener, R., \& Alcott, B. (2009). Energy rebound and economic growth: A review of the main issues and research needs. Energy, 34(3), 370-376. doi:10.1016/j.energy.2008.10.011

Makštutis, A., Balkytè, A., \& Tumalavičius, V. (2012). Security, Sustainability and Competitiveness: Benchmarking Attempts. Journal of Security \& Sustainability Issues, 2(1), 5-12. doi:10.9770/jssi/2012.2.1(1)

Malafeh, S., \& Sharp, B. (2015). Role of royalties in sustainable geothermal energy development. Energy Policy, 85, 235-242. doi:10.1016/j.enpol.2015.06.023

Malecki. E.J. (2001). Economic Geography. In P. B. B. Neil J. Smelser (Ed.), International Encyclopedia of the Social \& Behavioral Sciences (pp. 4084-4089): Pergamon.

Malecki, E. (2004). Jockeying for position: what it means and why it matters to regional development policy when places compete. Regional studies, 38(9), 1101-1120. doi:10.1080/0034340042000292665

Malecki, E. J. (1993). Entrepreneurship in regional and local development. International Regional Science Review, 16(1-2), 119-153. doi:10.1177/016001769401600107

Maletič, D., Lasrado, F., Maletič, M., \& Gomišček, B. (2016). Analytic hierarchy process application in different organisational settings. Applications and Theory of Analytic Hierarchy Process: Decision Making for Strategic Decisions, 89. doi:10.5772/64511

Mamalakis, M. J. (1996). Introduction: poverty and inequality in Latin America. Journal of Inter-American Studies and World Affairs, 1-13. doi:10.1017/S0022193700014590 
Mann, S. (2011). Sectors matter!: Exploring mesoeconomics: Springer Science \& Business Media.

Manologlou, E., Tsartas, P., \& Markou, A. (2004). Geothermal energy sources for water production-socio-economic effects and people's wishes on Milos island: a case study. Energy Policy, 32(5), 623-633. doi:10.1016/S0301-4215(02)00315-4

Manzella, A., Bonciani, R., Allansdottir, A., Botteghi, S., Donato, A., Giamberini, S., ... Scrocca, D. (2018). Environmental and social aspects of geothermal energy in Italy. Geothermics, 72, 232-248. doi:10.1016/j.geothermics.2017.11.015

Mariita, N. O. (2002). The impact of large-scale renewable energy development on the poor: environmental and socio-economic impact of a geothermal power plant on a poor rural community in Kenya. Energy Policy, 30(11-12), 1119-1128. doi:10.1016/S03014215(02)00063-0

Márquez, M. A., Ramajo, J., \& Hewings, G. J. (2009). Incorporating sectoral structure into shift-share analysis. Growth and change, 40(4), 594-618.

doi:10.1111/j.1468-2257.2009.00502.x

Markandya, A., González-Eguino, M., Román, M.V., 2016. Towards a green energy economy? Tracking the employment effects of low-carbon technologies in the European Union. Applied Energy, 179, 1342-1350. doi:10.1016/j.apenergy.2016.02.122.

Marks-Bielska, R., Bielski, S., Pik, K., \& Kurowska, K. (2020). The importance of renewable energy sources in Poland's energy mix. Energies, 13(18), 4624.

doi:10.3390/en13184624

Martín, M. B. G. (2005). Weather, climate and tourism a geographical perspective. Annals of tourism research, 32(3), 571-591. doi:10.1016/j.annals.2004.08.004

Martin, R. (2005). Thinking About Regional Competitiveness-Critical Issues. Policy paper. Nottingham: East Midlands Development Agency, UK.

Martinot, E. (2005). Global revolution: a status report on renewable energy worldwide. Renewable Energy World, 28-30.

Martinussen, J. (2004). Society, state and market: A guide to competing theories of development. 4th Edition. HSRC Publishers. Pretoria, SA.

Mason, J. (2006). Mixing methods in a qualitatively driven way. Qualitative Research, 6(1), 9-25. doi:10.1177/1468794106058866

Matei, A., \& Dorobantu, A. D. (2015). Social economy-added value for local development and social cohesion. Procedia Economics and Finance, 26, 490-494. doi:10.1016/S2212-5671(15)00878-3

Matek, B. and Gawell, K., 2015. The benefits of baseload renewables: a misunderstood energy technology. The Electricity Journal, 28(2), 101-112. doi:10.1016/j.tej.2015.02.001

McAdam, D., McCarthy, J. D., \& Zald, M. N. (1996). Comparative perspectives on social movements: Political opportunities, mobilizing structures, and cultural framings: Cambridge University Press Cambridge. doi:10.1017/CBO9780511803987

McKinsey. (2020). Carbon-neutral Poland 2050. Turning a challenge into an opportunity. McKinsey and Company. Poland.

Mehmet, O., \& Yorucu, V. (2020). Location Theory and the Modern Geopolitics of Hydrocarbons in The Eastern Mediterranean. In Modern Geopolitics of Eastern Mediterranean Hydrocarbons in an Age of Energy Transformation. Lecture Notes in Energy, vol 78. Springer, Cham. doi:10.1007/978-3-030-43585-1_3 
Menard, S. (2004). Six approaches to calculating standardized logistic regression coefficients. The American Statistician, 58(3), 218-223. doi:10.1198/000313004X946

Menéndez, J., Ordóñez, A., Álvarez, R., \& Loredo, J. (2019). Energy from closed mines: Underground energy storage and geothermal applications. Renewable and Sustainable Energy Reviews, 108, 498-512. doi:10.1016/j.rser.2019.04.007

Meyer-Stamer, J. (2008). Systemic competitiveness and local economic development. In S. Bodhanya (Ed.), Large Scale Systemic Change: Theories, Modelling and Practices. Duisburg, Germany.

Meyer, I., \& Sommer, M. W. (2014). Employment Effects of Renewable Energy Supply-A Meta Analysis. WWWforEurope Policy Paper, No. 12, WWWforEurope, Vienna.

Meyers, R. A. (2012). Encyclopedia of sustainability science and technology. Springer. New York, USA.

Michaelides, E. E. S. (2016). Future directions and cycles for electricity production from geothermal resources. Energy Conversion and Management, 107, 3-9. doi:10.1016/j.enconman.2015.07.057

Michalek, J., \& Zarnekow, N. (2012). Application of the rural development index to analysis of rural regions in Poland and Slovakia. Social indicators research, 105(1), 1-37. doi:10.1007/s11205-010-9765-6

Milićević, S., \& Petrović, J. (2016). Entrepreneurship as basis of Serbian Spa tourism competitiveness in international tourism market. In Tourism in Function of Development of The Republic of Serbia. Tourism International Scientific Conference Vrnjačka Banja, 1(1), 52-69.

Ministry of Economy. (2009). Poland's Energy Policy till 2030. Appendix to Resolution no. 202/ 2009 of the Council of Ministers of 10 November 2009. Warsaw.

Ministry of Energy (2019). Poland's energy policy until 2040. Warsaw, Poland.

Ministry of Environment. (2019). National Energy and Climate Plan for the years 2021- 2030. Objectives, targets, policies and measures. Warsaw. Poland.

Mishra, R., \& Mishra, O. N. (2018). A hybrid PCA-AHP-Multi-grade Fuzzy approach to assess marketing-based flexibility. Marketing Intelligence \& Planning, 36(11). doi:10.1108/MIP-07-2017-0144

Mitchell, G., May, A., \& McDonald, A. (1995). Picabue: a methodological framework for the development of indicators of sustainable development. The International Journal of Sustainable Development \& World Ecology, 2(2), 104-123.

doi:10.1080/13504509509469893

Mock, J. E., Tester, J. W., \& Wright, P. M., 1997. Geothermal energy from the earth: its potential impact as an environmentally sustainable resource. Annual review of Energy and the Environment, 22(1), pp. 305-356. doi:10.1146/annurev.energy.22.1.305

Moreno, B., \& Lopez, A. J. (2008). The effect of renewable energy on employment. The case of Asturias (Spain). Renewable and Sustainable Energy Reviews, 12(3), 732-751. doi:10.1016/j.rser.2006.10.011

Moschos, D. (1989). Export expansion, growth and the level of economic development: an empirical analysis. Journal of Development Economics, 30(1), 93-102. doi:10.1016/0304-3878(89)90052-7

Mouton, J., \& Marais, H. (1996). Basic concepts in the methodology of the social sciences, $5^{\text {th }}$ Edition.HSRC publishers, Pretoria, SA. 
Moya, D., Aldás, C., Kaparaju, P., 2018. Geothermal energy: Power plant technology and direct heat applications. Renew. Sustain. Energy Rev. 94, 889-901. doi:10.1016/j.rser.2018.06.047.

Muniyoor, K. (2020). Is there a trade-off between energy consumption and employment: Evidence from India. Journal of Cleaner Production, 255, 120262.

doi:10.1016/j.jclepro.2020.120262

Murai, T. (2002). Development strategy of geothermal energy in conformity with the earth environment. IGA News, 49(10).

Murphy, H. and Niitsuma, H., 1999. Strategies for compensating for higher costs of geothermal electricity with environmental benefits. Geothermics, 28(6), 693-711. doi:10.1016/S0375-6505(99)00018-8

Murphy, K. M., Shleifer, A., \& Vishny, R. W. (1989). Industrialization and the big push. Journal of Political Economy, 97(5), 1003-1026.

Murray, A. (2017). Location Theory: Oxford University Press.

Mwangi, M. N. (2010). Environmental and socio-economic issues of geothermal development in Kenya. GRC Bulletin, 4, 24-35.

Myna, A. (1998). Rozwój loklny, regionalne strategie rozwoju, regionalizacja. Samorzqd Terytorialny(11), 30-48.

Myna, A. (2007). Local Goverment Investments and Financial Liabilities- the Example of Mid-Eastern Poland. Economic \& Business Review, 9(2).

Mytelka, L., \& Farinelli, F. (2000). Local clusters, innovation systems and sustained competitiveness. UNU/INTECH Discussion Paper(2005).

Nagy, A. (2011). Health tourism in Hungary. In Agricultural Bulletin of Stavropol Region. Quarterly Research and Practice Journal, 48-51.

Nanda, R., Younge, K., \& Fleming, L. (2014). Innovation and entrepreneurship in renewable energy . In A. Jaffe \& $\mathrm{B}$. Jones (Eds.) The changing frontier: Rethinking science and innovation policy, 199-232. University of Chicago Press.

Naudé, W. A., \& Saayman, A. (2005). Determinants of tourist arrivals in Africa: a panel data regression analysis. Tourism Economics, 11(3), 365-391.

doi:10.5367/000000005774352962

Nevima, J., \& Melecký, L. (2011). Regional competitiveness evaluation of Visegrad Four countries through econometric panel data model. In Liberec Economic Forum, Vol. 10(1), 348-361.

Ney, R. (1997). Zasoby energii geotermalnej w Polsce i możliwe kierunki jej wykorzystania. W: Materiały z seminarium naukowego pn. Problemy wykorzystania energii geotermalnej i wiatrowej w Polsce. Wyd. IGSMiE PAN. Kraków-Zakopane.

Ney, R. (1999). The role of geothermal energy in development of space heating sector in Poland. Technika Poszukiwań Geologicznych, 38(4-5), 14-20. Brighton, UK.

Ng, Y.-K. (1986). Mesoeconomics: a micro-macro analysis. Wheatsheaf Books

Ngugi, P. K. (2014). Risk and risk mitigation in geothermal development. Short Course VI on Utilization of Low- and Medium-Enthalpy Geothermal Resources and Financial Aspects of Utilization, UNU-GTP, El Salvador, March 23-29, 2014.

Niitsuma, H., \& Nakata, T. (2003). EIMY (Energy In My Yard)-a concept for practical usage of renewable energy from local sources. Geothermics, 32(4-6), 767-777. doi:10.1016/S0375-6505(03)00056-7 
Nijkamp, P., Van den Bergh, C., \& Soeteman, F. J. (1990). Regional sustainable development and natural resource use. The World Bank Economic Review, 4(suppl_1), 153188.

Nogueira, C. A. G., \& Lopes, D. A. F. (2008). Employment growth in Ceará: A shiftshare analysis (2000-2005). Instituto de Pesquisa e Estratégia Econômica do Ceará, 3-33. Fortaleza-CE. Brasil.

Nowobilska, E. (2011). Możliwości wykorzystania zasobów wód termalnych w rejonie Podhala. Inżynieria Ekologiczna, 136-143.

NREL. (2004). Buried Treasure. The Environmental, Economic, and Employment Benefits of Geothermal Energy. US Department of Energy. Washington DC. USA.

Nuclear Energy Regulatory Commission. (2017). Glossary: Capacity factor (net). NCR Library.

O'Riordan, T., \& Voisey, H. (1997). The political economy of sustainable development. Environmental Politics, 6(1), 1-23. doi:10.1080/09644019708414309

Oddershede, A., Arias, A., \& Cancino, H. (2007). Rural development decision support using the Analytic Hierarchy Process. Mathematical and Computer Modelling, 46(7-8), 1107-1114. doi:10.1016/j.mcm.2007.03.006

OECD. (2001). Best Practices in Local Development. Paris, France: OECD Publications.

OECD. (2003). Entrepreneurship and Local Economic Development: Programme and Policy Recommendations. Paris: OECD Publishing.

OECD. (2017). Employment Implications of Green Growth: Linking jobs, growth and green policies. OECD Report for the G7 Environment Ministers.

Olewiler, N. (2006). Environmental sustainability for urban areas: The role of natural capital indicators. Cities, 23(3), 184-195. doi:10.1016/j.cities.2006.03.006

Operacz, A., \& Chowaniec, J. (2018). Perspectives of geothermal water use in the Podhale Basin according to geothermal step distribution. Geology, Geophysics and Environment, 44. doi:10.7494/geol.2018.44.4.379

$\varnothing$ stergaard, P. A., \& Lund, H. (2011). A renewable energy system in Frederikshavn using low-temperature geothermal energy for district heating. Applied Energy, 88(2), 479487. doi:10.1016/j.apenergy.2010.03.018

Ostrom, E. (1990). Governing the commons: The evolution of institutions for collective action: Cambridge University Press. UK.

Ostrom, E. (2002). Common-pool resources and institutions: Toward a revised theory. Handbook of Agricultural Economics, 2, 1315-1339. doi:10.1016/S15740072(02)10006-5

Ostrom, E. (2005). Unlocking public entrepreneurship and public economies. WIDER Discussion Paper, No. 2005/01, ISBN 9291906700, The United Nations University World Institute for Development Economics Research (UNU-WIDER). Helsinki, Finland.

Otsuka, A. (2016). Regional energy demand in Japan: dynamic shift-share analysis. Energy, Sustainability and Society, 6(1), 10. doi:10.1186/s13705-016-0076-x

Özaslan, M., Dincer, B., \& Ozgur, H. (2006). Regional disparities and territorial indicators in Turkey: Socio-economic development index (SEDI). In: Proceedings of the 46th Congress of the European Regional Science Association: "Enlargement, Southern Europe and the Mediterranean". Volos, Greece. 
Özgüler, M. E., \& Kasap, A. (1999). The geothermal history of Anatolia, Turkey. Stories from a Heated Earth. Special Report No 19. Sacramento: Geothermal Resources Council, International Geothermal Association.

Pack, H. (1994). Endogenous growth theory: intellectual appeal and empirical shortcomings. Journal of Economic perspectives, 8(1), 55-72. doi:10.1257/jep.8.1.55

Pająk, L., Tomaszewska, B., Bujakowski, W., Bielec, B., \& Dendys, M. (2020). Review of the low-enthalpy lower cretaceous geothermal energy resources in Poland as an environmentally friendly source of heat for urban district heating systems. Energies, 13(6), 1302. doi:10.3390/en13061302

Palei, T. (2015). Assessing the impact of infrastructure on economic growth and global competitiveness. Procedia Economics and Finance, 23(2015), 168-175. doi:10.1016/S2212-5671(15)00322-6

Palese, L. L. (2018). A random version of principal component analysis in data clustering. Computational biology and chemistry, 73, 57-64. doi:10.1016/j.compbiolchem.2018.01.009

Pandey, S., Vishal, V., \& Chaudhuri, A. (2018). Geothermal reservoir modeling in a coupled thermo-hydro-mechanical-chemical approach: A review. Earth-Science Reviews, 185, 1157-1169. doi:10.1016/j.earscirev.2018.09.004

Parker, J. (2012). Learning Time-Series Econometrics. Reed College Press. OR, USA.

Parpairis, D. A., \& Lagos, D. (2013). Endogenous Tourism Development Through Renewable Energy Governance: A Questionable Challenge. In Renewable Energy Governance (81-100). Springer. doi:10.1007/978-1-4471-5595-9_5

Parysek, J. (2001). Podstawy gospodarki lokalnej. [Rudiments of local economy]. Wydawnictwo UAM. Poznań, Poland.

Patsa, E., Zarrouk, S., \& Zyl, D. (2015). The lindal diagram for mining engineering. GRC Transactions, 39, 151-156.

Patton, M. Q. (1990). Qualitative evaluation and research methods. SAGE Publications, inc. doi:10.1002/nur.4770140111

Patton, M. Q. (2002). Two decades of developments in qualitative inquiry: A personal, experiential perspective. Qualitative social work, 1(3), 261-283. doi:10.1177/1473325002001003636

Paulillo, A., Striolo, A., \& Lettieri, P. (2019). The environmental impacts and the carbon intensity of geothermal energy: A case study on the Hellisheiđi plant. Environment International, 133, 105226. doi:10.1016/j.envint.2019.105226

Pawluszek, K., \& Borkowski, A. (2017). Impact of DEM-derived factors and analytical hierarchy process on landslide susceptibility mapping in the region of Rożnów Lake, Poland. Natural Hazards, 86(2), 919-952. doi:10.1007/s11069-016-2725-y

Peake, S. (2018). Renewable energy-power for a sustainable future. No.Ed.4. Oxford University Press. Oxford, UK.

Pedamallu, L. R., Nelson, E., \& Ramiro, J. (2017). Onshore and Offshore Geothermal Energy Resource Potential of Portugal-A Case Study. GRC Transactions, 41.

Pejanović, R., Glavaš-Trbić, D., \& Tomaš, M. (2011). Public-Private Partnerships as a solution for solving economic and energetic problems in a community. Agroekonomika/Agrieconomica, 49-50, 5-16. 
Pellizzone, A., Allansdottir, A., De Franco, R., Muttoni, G., \& Manzella, A. (2017). Geothermal energy and the public: A case study on deliberative citizens' engagement in central Italy. Energy Policy, 101, 561-570. doi:10.1016/j.enpol.2016.11.013

Pellizzone, A., Allansdottir, A., \& Manzella, A. (2019). Geothermal Resources in Italy: Tracing a Path Towards Public Engagement. In Geothermal Energy and Society (159178). Springer.

Persson, U. (2013). Heat Roadmap Europe 2050. Conference Paper. CEM\&IEA CHP/DHC Joint Workshop, Helsinki. www.4dh.eu.

Peters, H. R. (1981). Mesoeconomic Theory of Structural Policy in the New Political Economy. Wirtschaftsdienst.

Peterson, S., Widner, L., \& Nelson, J. (2005). Economic Impacts of a potential geothermal electricity generation facility at Willow Springs, Idaho. Extension Series 304837, University of Idaho, Department of Agricultural Economics and Rural Sociology. Idaho, USA.

Petroni, G., Bigliardi, B., \& Galati, F. (2019). Rethinking the Porter hypothesis: The underappreciated importance of value appropriation and pollution intensity. Review of Policy Research, 36(1), 121-140. doi:10.1111/ropr.12317

Phillips, P. C. (1986). Understanding spurious regressions in econometrics. Journal of econometrics, 33(3), 311-340. doi:10.1016/0304-4076(86)90001-1

Picchi, A. (1994). The Relation Between Central and Loca Powers as Context for Endogenous Development. In J.D. Van der Ploeg et al. (Eds.), Born from within: Practice and perspectives of endogenous rural development, 195. Van Gorcum and Comp BV.

Pieterse Nederveen, J. (2010). Development Theory, 2nd edition. London: Sage.

Pieterse, J. N. (2001). Development theory: deconstructions/reconstructions. Sage. London, UK.

Pike, A., Rodríguez-Pose, A., \& Tomaney, J. (2016). Local and Regional Development. Routledge.

Pike, A., Tomaney, J., \& Rodriguez-Pose, A. (2006). Local and regional development. Routledge. doi:10.4324/9781315767673

Pires, S. M., Fidélis, T., \& Ramos, T. B. (2014). Measuring and comparing local sustainable development through common indicators: Constraints and achievements in practice. Cities, 39, 1-9. doi:10.1016/j.cities.2014.02.003

Pittel, K., \& Rübbelke, D. (2011). Energy supply and the sustainability of endogenous growth. Handbook of Sustainable Use of Energy, 161-180.

Pletsch, C. E. (1981). The Three Worlds, or the division of social scientific labor, circa 1950-1975. Comparative Studies in Society and History, 23(4), 565-590.

Plummer, P., \& Taylor, M. (2001). Theories of local economic growth (part 1): concepts, models, and measurement. Environment and Planning A, 33(2), 219-236. doi:10.1068/a339a

Plummer, P., Tonts, M., \& Martinus, K. (2014). Endogenous growth, local competitiveness and regional development: Western Australia's Regional Cities, 20012011. Journal of Economic \& Social Policy, 16(1), 146.

Polish Geological Institute. www.pgi.gov.pl [accessed: 12.03.2016].

Popov, E. V. (2005). Minieconomics as a separate part of microeconomics. Atlantic Economic Journal, 33(1), 133.

Popovski, K., \& Vasilevska, S. P. (2003). Prospects and problems for geothermal use in agriculture in Europe. Geothermics, 32(4-6), 545-555.

doi:10.1016/j.geothermics.2003.07.009 
Popp, D., Newell, R. G., \& Jaffe, A. B. (2010). Energy, the environment, and technological change Handbook of the Economics of Innovation Vol. 2, 873-937). Elsevier. doi:10.1016/S0169-7218(10)02005-8

Porter, M. E. (1990). The competitive advantage of nations. Harvard Business Review, 68(2), 73-93.

Porter, M. E. (1994). The role of location in competition. Journal of the Economics of Business, 1(1), 35-40. doi:10.1080/758540496

Porter, M. E. (1998). Clusters and the new economics of competition. Harvard Business Review. Vol. 76, No. 6, pp. 77-90.

Porter, M. E. (1999). Michael Porter on competition. Antitrust Bull., 44, 841.

Porter, M. E. (2000a). Attitudes, values, beliefs, and the microeconomics of prosperity. In L. Harrison \& S. Huntington (Eds.) Culture Matters. Basic Books, 14-28. New York, USA.

Porter, M. E. (2000b). Location, competition, and economic development: Local clusters in a global economy. Economic Development Quarterly, 14(1), 15-34. doi:10.1177/089124240001400105

Porter, M. E. (2001). Strategy and the Internet. Harvard Business Review, 72(2), 63-78.

Porter, M. E. (2004). Building the microeconomic foundations of prosperity: Findings from the business competitiveness index. In M. Porter et al. (Eds. ), The Global Competitiveness Report 2003- 2004, 29-56. Oxford University Press.

Porter, M. E. (2008). Regional competitiveness in a global economy. Summit for American Prosperity. Conference Paper. The Brookings Institution. Washington D.C, USA.

Porter, M. E. (2010). The Icelandic geothermal cluster: Enhancing competitiveness and creating a new engine of Icelandic growth. In Proceedings of Icelandic Geothermal Conference, Reykjavik, Iceland (Vol. 1).

Prais, S. J., \& Winsten, C. B. (1954). Trend Estimators and Serial Correlation. Discussion Paper No. 383. Yale University, New Haven, CT, USA.

Prinsloo, F. C. (2013). Impact of renewable energy structures on tourism. Research Report. University of Stellenbosch. SA.

Pulido Fernández, J.I., Sánchez Rivero, M., (2010). Clustering tourism destinations by means of composite indices of sustainability. In F Cerina et al. (Eds.), Economics of sustainable tourism. Routledge.

Puu, T. (2003). Location Theory. In Mathematical Location and Land Use Theory. Advances in Spatial Science. Springer. Berlin, Heidelberg. doi:10.1007/978-3-540-247852_2

Quandt, R. E. (1972). A new approach to estimating switching regressions. Journal of the American Statistical Association, 67(338), 306-310.

doi:10.1080/01621459.1972.10482378

Quintilian. (2015). Complete Works (Illustrated): Delphi Classics.

Qvist, S., Gładysz, P., Bartela, Ł. \& Sowizdżał, A. (2021). Retrofit Decarbonization of Coal Power Plants- A Case Study for Poland. Energies Vol. 14, Issue 120. doi:10.3390/en14010120

Rafferty, K. (1992). A century of service: the Boise Warm Springs water district system. Geo-Heat Center Quarterly Bulletin, 14(2), 1-5.

Randolph, J. B., \& Saar, M. O. (2011). Coupling carbon dioxide sequestration with geothermal energy capture in naturally permeable, porous geologic formations: 
Implications for CO2 sequestration. Energy Procedia, 4, 2206-2213.

doi:10.1016/j.egypro.2011.02.108

Raszkowski, A., \& Bartniczak, B. (2019). On the road to sustainability:

Implementation of the 2030 agenda sustainable development goals (SDG) in Poland.

Sustainability, 11(2), 366. doi:10.3390/su11020366

Rebelo, S. (1991). Long-run policy analysis and long-run growth. Journal of Political Economy, 99(3), 500-521. doi:10.1086/261764

Register, D. L., Lambert, D. M., English, B. C., Jensen, K. L., Menard, R. J., \& Wilcox, M. D. (2012). Geographic distribution of renewable energy sector industries: an analysis using recent developments in industry concentration measurement. Conference Paper. Agricultural and Applied Economics Association (AAEA), Annual Meeting, Seattle, Washington. doi:10.22004/ag.econ.124038

Regulation of the Council of Ministers of 24 December 2007 on the Polish Classification of Activities (PKD), Dz.U.2007.251.1885 appendix C.F.R. (2007).

Reinert, H., \& Reinert, E. S. (2006). Creative destruction in economics: Nietzsche, Sombart, Schumpeter In Friedrich Nietzsche (1844-1900), (55-85). Springer, Boston, MA.

Rezaei-Moghaddam, K., \& Karami, E. (2008). A multiple criteria evaluation of sustainable agricultural development models using AHP. Environment, Development and Sustainability, 10(4), 407-426. doi:10.1007/s10668-006-9072-1

Richter, A. (2020a). A market and good resources do not seem enough to kick off geothermal development in Poland. Press Release. Thinkgeoenergy.

Richter, A. (2020b). Power, energy, electricity, heat and geothermal - the importance of the right terminology. Press Release. Thinkgeoenergy.

Rifkin, J. (2011). The third industrial revolution: how lateral power is transforming energy, the economy, and the world. Macmillan.

Rifkin, J. (2014) An interview with Jeremy Rifkin/Interviewer: R. Janssen. Energy in Demand. July 26, 2014.

Rifkin, J. (2019). The Green New Deal: Why the Fossil Fuel Civilization Will Collapse by 2028, and the Bold Economic Plan to Save Life on Earth. St. Martin's Press.

Rizzi, F., \& Borzoni, M. (2010). An evolutionary Triple Helix to strengthen energy regulation: implications for management. Conference Paper. 21st World Energy Congress (WEC), Quebec Canada

Romer, P. M. (1986). Increasing returns and long-run growth. Journal of Political Economy, 94(5), 1002-1037.

Romer, P. M. (1990). Endogenous technological change. Journal of Political Economy, 98(5, Part 2), S71-S102. doi:10.1086/261725

Romer, P. M. (1994). The origins of endogenous growth. Journal of Economic perspectives, 8(1), 3-22. doi:10.1257/jep.8.1.3

Rondo-Brovetto, P., \& Saliterer, I. (2007). Comparing regions, cities, and communities: local government benchmarking as an instrument for improving performance and competitiveness. The Public Sector Innovation Journal, 12(3), 1-18.

Rose, A. (1977). Economic impact of geothermal energy development. US Department of Energy. USA.

Rutkauskas, A. V. (2008). On the sustainability of regional competitiveness development considering risk. Technological and Economic development of Economy, 14(1), 89-99. doi:10.3846/2029-0187.2008.14.89-99 
Rybach, L. (2003). Geothermal energy: sustainability and the environment. Geothermics, 32(4-6), 463-470. doi:10.1016/S0375-6505(03)00057-9

Rybach, L. (2010). The future of geothermal energy and its challenges.

Conference Paper. Proceedings World Geothermal Congress, Bali, Indonesia.

Rybach, L. (2014). Geothermal power growth 1995-2013-A comparison with other renewables. Energies, 7(8), 4802-4812. doi:10.3390/en7084802

Rystad Energy. (2020). Geothermal power set to climb to 24 GW by 2025, upcoming projects to attract \$25 billion. Press Release. Rystad Energy.

Saaty, T. L. (1988). What is the analytic hierarchy process? Mathematical models for decision support (109-121): Springer.

Saaty, T. L. (1990). How to make a decision: the analytic hierarchy process. European Journal of operational research, 48(1), 9-26. doi:10.1016/0377-2217(90)90057-I

Saaty, T. L. (1994). How to make a decision: the analytic hierarchy process. Interfaces, 24(6), 19-43. doi:10.1287/inte.24.6.19

Saaty, T. L. (2000). Fundamentals of decision making and priority theory with the analytic hierarchy process (Vol. 6). RWS publications. Pittsburgh, USA.

Saaty, T. L. (2008). Decision making with the analytic hierarchy process. International Journal of Services Sciences, 1(1), 83-98.

Saaty, T. L., \& Kearns, K. P. (1985). Analytical Planning: The Organization of Systems. International Series in Modern Applied Mathematics and Computer Science, Vol. 7. doi:10.1016/0377-2217(90)90057-I

Saaty, T. L., \& Vargas, L. G. (2007). Dispersion of group judgments. Mathematical and Computer Modelling, 46(7-8), 918-925. doi:10.1016/j.mcm.2007.03.004

Sacarto D. M. (1976). State policies for geothermal development. Technical Report. National Conference of State Legislatures, Denver, CO USA. doi:10.2172/7231413

Sacco, P. L., \& Segre, G. (2009). Creativity, cultural investment and local development: a new theoretical framework for endogenous growth. Growth and Innovation of Competitive Regions (281-294). Springer.

Sáez, L., \& Periáñez, I. (2015). Benchmarking urban competitiveness in Europe to attract investment. Cities, 48, 76-85. doi:10.1016/j.cities.2015.06.002

Sæpórsdóttir, A. D., \& Ólafsson, R. (2010). Nature tourism assessment in the Icelandic Master Plan for geothermal and hydropower development. Part I: rapid evaluation of nature tourism resources. Journal of Heritage Tourism, 5(4), 311-331. doi:10.1080/1743873X.2010.517839

Sala, J. (2017). Geothermal waters as a factor fostering the development of tourism in the Podhale area. Praca i Studia Geograficzne, T.62, Z.2, 87-103

Sala, K. (2018). Przemysłowe wykorzystanie energii geotermalnej w Polsce na przykładzie geotermalnego zakładu ciepłowniczego w Bańskiej Niżnej. Prace Komisji Geografii Przemysłu Polskiego Towarzystwa Geograficznego, 32(2), 73-82.

San Cristóbal, J. R. (2012). Multi criteria analysis in the renewable energy industry. Springer Science \& Business Media.

Sánchez-Velasco, R., López-Díaz, M., Mendoza, H., \& Tello, R. (2003). New CFE geothermal village power plant in Mexico bestows local residents with prosperity - and children with ice cream. Comisión Federal de Electricidad, Mexico, 4.

Sarbu, I., \& Sebarchievici, C. (2017). Thermal Energy Storage. Solar Heating and Cooling Systems, 99-138. 
Schlager, E., \& Ostrom, E. (1993). Property-rights regimes and coastal fisheriesAn empirical analysis. In T. Anderson \& R. Simmons (Eds.), The Political Economy of Customs and Culture-Informal Solutions to the Commons Problem (pp. 13-42). Rowman \& Littlefield. Lanham, MD, USA.

Schumpeter, J. (1934). The Theory of Economic Development. Oxford Univeristy Press. New York, USA.

Schumpeter, J. (1942). Capitalism, Socialism and Democracy. Harper 1975. New York, USA.

Schütz, F., Huenges, E., Spalek, A., Bruhn, D., Pérez, P., \& Gregorio, M. (2013). Employment study: solutions on lack of skilled workers in the geothermal sector and results of the questionnaires. GEOELEC, Deliverable no. 5.1.

Scipioni, A., Mazzi, A., Mason, M., \& Manzardo, A. (2009). The Dashboard of Sustainability to measure the local urban sustainable development: The case study of Padua Municipality. Ecological indicators, 9(2), 364-380. doi:10.1016/j.ecolind.2008.05.002

Scott, A. J. (1995). The geographic foundations of industrial performance. Competition \& Change, 1(1), 51-66. doi:10.1177/102452949500100104

Scott, D., de Freitas, C., \& Matzarakis, A. (2009). Adaptation in the tourism and recreation sector. In Biometeorology for adaptation to climate variability and change (171194). Springer. Dordrecht, The Netherlands.

Sekioka, M. (1995). Geothermal energy in history. The case of Japan: Our common heritage. Conference Paper. Proceedings of the World Geothermal Congress 1995, Florence, Italy.

Sestini, G. (1970). Superheating of geothermal steam. Geothermics, 2, 622-648. doi:10.1016/0375-6505(70)90064-7

Seyboth, K., Beurskens, L., Langniss, O. and Sims, R.E., 2008. Recognising the potential for renewable energy heating and cooling. Energy Policy, 36(7), pp.2460-2463. doi:10.1016/j.enpol.2008.02.046

Sharp, J. L., Mobley, C., Hammond, C., Withington, C., Drew, S., Stringfield, S., \& Stipanovic, N. (2012). A mixed methods sampling methodology for a multisite case study. Journal of mixed methods research, 6(1), 34-54. doi:10.1177/1558689811417133

Shaw, G. K. (1992). Policy implications of endogenous growth theory. The Economic Journal, 102(412), 611-621. doi:10.2307/2234298

Shi, C.-Y., \& Yang, Y. (2008). A review of shift-share analysis and its application in tourism. International Journal of Management Perspectives, 1(1), 21-30.

Shi, H. (2012). Applying Principal Component Analysis and Group-Decision Analytical Hierarchy Process for the Fuzzy Risk Assessment of Construction Project. Advanced Science Letters, 6(1), 779-782. doi:10.1166/asl.2012.2264

Shortall, R., \& Kharrazi, A. (2017). Cultural factors of sustainable energy development: A case study of geothermal energy in Iceland and Japan. Renewable and Sustainable Energy Reviews, 79, 101-109. doi:10.1016/j.rser.2017.05.029

Shortall, R., Davidsdottir, B., \& Axelsson, G. (2015a). Development of a sustainability assessment framework for geothermal energy projects. Energy for Sustainable Development, 27, 28-45. doi:10.1016/j.esd.2015.02.004

Shortall, R., Davidsdottir, B., \& Axelsson, G. (2015b). Geothermal energy for sustainable development: A review of sustainability impacts and assessment frameworks. Renewable and Sustainable Energy Reviews, 44, 391-406. doi:10.1016/j.rser.2014.12.020 
Shortall, R., Davidsdottir, B., \& Axelsson, G. (2015c). A sustainability assessment framework for geothermal energy projects: Development in Iceland, New Zealand and Kenya. Renewable and Sustainable Energy Reviews, 50, 372-407. doi:10.1016/j.rser.2015.04.175

Siegel, S. (1957). Nonparametric statistics. The American Statistician, 11(3), 1319. doi:10.1080/00031305.1957.10501091

Siegel, S., \& Castellan, N. (1988). The case of k related samples. In Nonparametric statistics for behavioral sciences, 170-174. McGraw-Hill. New York, USA.

Simionescu, M., Păuna, C. B., \& Diaconescu, T. (2020). Renewable Energy and Economic Performance in the Context of the European Green Deal. Energies, 13(23), 6440. doi:10.3390/en13236440

Singh, H. K., Chandrasekharam, D., Trupti, G., Mohite, P., Singh, B., Varun, C., \& Sinha, S. K. (2016). Potential geothermal energy resources of India: a review. Current Sustainable/Renewable Energy Reports, 3(3-4), 80-91. doi:doi.org/10.1007/s40518-0160054-0

Singh, R. P., \& Nachtnebel, H. P. (2016). Analytical hierarchy process (AHP) application for reinforcement of hydropower strategy in Nepal. Renewable and Sustainable Energy Reviews, 55, 43-58. doi:10.1016/j.rser.2015.10.138

Sipahi, S., \& Timor, M. (2010). The analytic hierarchy process and analytic network process: an overview of applications. Management Decision, 48(5), 775-808. doi:10.1108/00251741011043920

Skjærseth, J. B. (2014). Implementing EU climate and energy policies in Poland. FNI Report 8/2014. Fridtjof Nansen Institute. Norway.

Slesser, M. (1988). Dictionary of Energy. Palgrave Macmillan. $2^{\text {nd }}$ Edition.

Small, H. (1974). Dow Chemical in Geothermal.In Geothermal Energy: Volume 2. Dept. of Energy. Division of Geothermal Energy. USA.

Smith, D. P. (2019). Fitting geothermal energy into the energy transition. Netherlands Journal of Geosciences, 98. E6. doi:10.1017/njg.2019.5

Smith, S., \& Albaum, G. (2004). Measurement and scaling in marketing research. Fundamentals of marketing research, 371-410. SAGE Publications, Inc; 1st edition.

Smulders, S. (2005). Endogenous technological change, natural resources and growth. In R. D. Simpson, M. A. Toman, \& R. U. Ayres (Eds.), Scarcity and growth revisited: Natural resources and the environment in the new millennium RFF Press.

Solow, R. M. (1956). A contribution to the theory of economic growth. Quarterly Journal of Ecoomics, 70, 65-94. doi:10.2307/1884513

Sowiżdżał, A., Tomaszewska, B., \& Drabik, A. (2017). Environmental aspects of the geothermal Energy utilisation in Poland. E3S Web of Conferences. Vol. 22. No 00164. doi:10.1051/e3sconf/20172200164

Sowizdzal, A. (2018). Geothermal energy resources in Poland-overview of the current state of knowledge. Renewable and Sustainable Energy Reviews, 82, 4020-4027. doi:10.1016/j.rser.2017.10.070

Sowiżdżał, A., Chmielowska, A., Tomaszewska, B., Operacz, A., \& Chowaniec, J. (2019). Could geothermal water and energy use improve living conditions? Environmental effects from Poland. Archives of Environmental Protection, 45.

doi:10.24425/aep.2019.127985 
Sowiżdżał, A., Gładysz, P., \& Pająk, L. (2021). Sustainable Use of Petrothermal Resources-A Review of the Geological Conditions in Poland. Resources, 10(1), 8. doi:10.3390/resources10010008

Stanik, A., Podlasek, B., \& Raś, A. (2011). Przegląd nowych ośrodków rekreacyjnych w Polsce stosujących wody geotermalne Technika Poszukiwań Geologicznych. Geotermia, Zrównoważony Rozwój, 1-2, 245-256.

Statistics Poland. (2019). Energy from renewable sources in 2018. Statistical Analysis. Warsaw, Poland.

Stevens, B. H., \& Moore, C. L. (1980). A critical review of the literature on shiftshare as a forecasting technique. Journal of Regional Science, 20(4), 419-437. doi:10.1111/j.1467-9787.1980.tb00660.x

Stigka, E. K., Paravantis, J. A., \& Mihalakakou, G. K. (2014). Social acceptance of renewable energy sources: A review of contingent valuation applications. Renewable and Sustainable Energy Reviews, 32, 100-106. doi:10.1016/j.rser.2013.12.026

Stimson, R. J., Stough, R., \& Nijkamp, P. (Eds.). (2011). Endogenous regional development: perspectives, measurement and empirical investigation. Edward Elgar Publishing.

Stöhr, W., \& Taylor, D. R. F. (1981). Development from above or below? The dialectics of regional planning in developing countries. Wiley Publishers. New York, USA.

Storper, M. (1997). The regional world: territorial development in a global economy. Guilford press.

Strojny, J. (2015). Implementation of the AHP and benchmarking in Strategic Analysis of Polish Regions. Procedia-Social and Behavioral Sciences, 213, 229-235. doi:10.1016/j.sbspro.2015.11.530

Strojny, J., \& Hejman, W. (2016). AHP based multicriteria comparative analysis of regions of eastern Poland. International Journal of the Analytic Hierarchy Process, 8(1). doi:10.13033/ijahp.v8i1.373

Strojny, J., Heijman, W., \& Stefanów, P. (2015). The Competitiveness of Podkarpackie Region in Poland: a Comparative Analysis with Respect to Chosen Benchmarks. Modern Management Review, $20(22$ (1)), 173-184.

Stupnicka, E., \& Stempień-Sałek, M. (1997). Geologia regionalna Polski: Wydawn. Uniw. Warszawskiego. Warszawa, Poland.

Subbaiah, K. V., Prasad, K., Bharathi, M. U., Rao, K., \& Sekhara, S. (2011). Integrating factor analysis and analytic hierarchy process for library service quality. International Journal for Quality Research, 5(3), 205-212.

Subramanian, N., \& Ramanathan, R. (2012). A review of applications of Analytic Hierarchy Process in operations management. International Journal of Production Economics, 138(2), 215-241. doi:10.1016/j.ijpe.2012.03.036

Sutter, J., \& Githui, D. (2013). Reasons for and impact of having majorly powered geothermal economy: a critique of Kenyan power system. Conference Paper. Thirty-Eighth Workshop on Geothermal Reservoir Engineering, Stanford, California.

Swan, T. W. (1956). Economic growth and capital accumulation. Economic Record, 32, 334-361. doi:10.1111/j.1475-4932.1956.tb00434.x

Świątek, L. (2020). A case study of geothermal resources use for the innovative aquaculture from perspective of syntropic development concept. International Journal of Energy Production and Management, 5(1), 60-69.doi:10.2495/EQ-V5-N1-60-69 
Świerszcz, K., \& Ćwik, B. (2017). Geothermal energy as a Part of Non-military Defence Strategy in the Context of the Prevention of Energy Poverty of Local Communities. Przedsiębiorczość i Zarzqdzanie, 18(5), 135-150.

Sykora, L. (2002). Global competition, sustainable development and civil society: three major challenges for contemporary urban governance and their reflection in local development practices in Prague. Acta Universitatis Carolinae: Geographica, 37(2), 65-83.

Szewczuk, A., Kogut-Jaworska, M., \& Zioło, M. (2011). Rozwój lokalny i regionalny. Teoria i praktyka, Wydawnictwo CH Beck, Warszawa, Poland.

Sztando, A. (1998). Oddziaływanie samorządu lokalnego na rozwój lokalny w świetle ewolucji modeli ustrojowych gmin. Samorzqd Terytorialny, 11(1998), 11.

Szulc-Wrońska, A., \& Tomaszewska, B. (2020). Low Enthalpy Geothermal Resources for Local Sustainable Development: A Case Study in Poland. Energies, 13(19), 5010. doi:10.3390/en13195010

Szulecki, K., Fischer, S., Gullberg, A. T., \& Sartor, O. (2016). Shaping the 'Energy Union': between national positions and governance innovation in EU energy and climate policy. Climate Policy, 16(5), 548-567. doi:10.1080/14693062.2015.1135100

Szymańska, D., \& Chodkowska-Miszczuk, J. (2011). Endogenous resources utilization of rural areas in shaping sustainable development in Poland. Renewable and Sustainable Energy Reviews, 15(3), 1497-1501. doi:10.1016/j.rser.2010.11.019

Tabbachi, M. (2008). American and European spa. In G. Bodeker \& M. Cohen (Eds.), Understanding the global spa industry: Spa management. Routledge. $1^{\text {st }}$ edition.

Taherdoost, H., Sahibuddin, S., \& Jalaliyoon, N. (2014). Exploratory factor analysis; concepts and theory. Advances in Applied and Pure Mathematics, 375382.

Tahvonen, O., \& Salo, S. (2001). Economic growth and transitions between renewable and nonrenewable energy resources. European Economic Review, 45(8), 13791398. doi:10.1016/S0014-2921(00)00062-3

Tashakkori, A., \& Teddlie, C. (2010). Handbook of mixed methods in social \& behavioral research. Sage. CA, USA.

Taylor, M., \& Plummer, P. (2011). Endogenous regional theory: A geographer's perspective and interpretation. Endogenous Regional Development: Perspectives, Measurement and Empirical Investigation, 39-59.

Tee, S., Liu, Q., \& Wang, Z. (2017). Insulation condition ranking of transformers through principal component analysis and analytic hierarchy process. IET Generation, Transmission \& Distribution, 11(1), 110-117.

Termalni.www.termalni.pl [accessed 15.01.2017].

Thompson, M. A., \& Rushing, F. W. (1996). An empirical analysis of the impact of patent protection on economic growth. Journal of Economic Development, 21(2), 61-79.

Thorarinsdottir, R., \& Unnthorsson, R. (2018). Direct Use of Geothermal Resources for Circular Food Production. Conference Paper. Proceedings 18th International Conference on Experimental Mechanics (ICEM18). doi:10.3390/ICEM18-05405

Tomaszewska, B., and Szczepański, A. (2014). Possibilities for the efficient utilisation of spent geothermal waters. Environmental Science and Pollution Research, 21(19), pp.11409-11417. doi:10.1007/s11356-014-3076-4

Tomić, N., Stojsavljević, R., Stamenković, I., \& Berić, D. (2013). The use of Geothermal Energy Resources in the Tourism Industry of Vojvodina (Northern Serbia). European researcher. Series A, (2-3), 443-454. 
Toth, A. N., Sztermen, A., \& Fenerty, D. K. (2015). Social Acceptance of Geothermal Energy Through Tourism and Balneology. Conference Paper. Proceedings World Geothermal Congress. Melbourne, Australia.

Tourkolias, C., \& Mirasgedis, S. (2011). Quantification and monetization of employment benefits associated with renewable energy technologies in Greece. Renewable and Sustainable Energy Reviews, 15(6), 2876-2886. doi:10.1016/j.rser.2011.02.027

Traistaru, I., \& Wolff, G. B. (2002). Regional Specialization and Employment Dynamics in Transition Countries. ZEI Working Paper, No. B 18-2002, Rheinische FriedrichWilhelms-Universität Bonn. Zentrum für Europäische Integrationsforschung (ZEI). Bonn, Germany.

Trisnawati, R., Wiyadi, W., \& Priyono, E. (2008). Analysis of the Competitiveness Tourism Industries Increasing the Local Economy (The Comparative Study Analysis of the Competitiveness Tourism between Surakarta and Yogyakarta). Economic Journal of Emerging Markets, 13(2).

Turok, I. (2004). Cities, regions and competitiveness. Regional studies, 38(9), 1069-1083. doi:10.1080/0034340042000292647

Tyszer, M., Bujakowski, W., Tomaszewska, B., \& Bielec, B. (2020). Geothermal Water Management Using the Example of the Polish Lowland (Poland)-Key Aspects Related to Co-Management of Drinking and Geothermal Water. Energies, 13(10), 2412. doi:10.3390/en13102412

UG Szaflary. (2012). Założenia do planu zaopatrzenia w ciepło, energię elektrycznq i paliwa gazowe gminy Szaflary na lata 2012-2030. Kraków: Centrum-Krak.

Ulrich, P., Distelkamp, M., \& Lehr, U. (2012). Employment effects of renewable energy expansion on a regional level-first results of a model-based approach for Germany. Sustainability, 4(2), 227-243. doi:10.3390/su4020227

UM Pyrzyce. (2015). Strategia Rozwoju Gminy Pyrzyce na lata 2015-2025. Szczecin: Instytut Rozwoju Regionalnego.

UM Uniejów. (2012). Strategia rozwoju Gminy Uniejów na lata 2013 - 2020. Urząd Miasta Uniejów.

UM Zakopane. (2016). Strategia Rozwoju Miasta Zakopane na lata 2017-2026. Urząd Miasta Zakopane.

UN. (2019). The Sustainable Development Goals Report 2019. United Nations. New York, USA.

UNESCO. (2009). On Target: A Guide for Monitoring and Evaluating CommunityBased Projects. United Nations Educational, Scientific and Cultural Organisation. Paris, France.

Underwood, C. P., Ramachandran, J., Giddings, R. D., \& Alwan, Z. (2007). Renewable-energy clusters for remote communities. Applied Energy, 84(6), 579-598. doi:10.1016/j.apenergy.2007.01.017

Van Campen, B., \& Archer, R. (2016). Geothermal Resource Management and Reporting: learning from (NZ) petroleum regulator experience. Conference Paper. Proceeding European Geothermal Congress. Strasbourg, France.

Van der Zwaan, B. C., Gerlagh, R., \& Schrattenholzer, L. (2002). Endogenous technological change in climate change modelling. Energy Economics, 24(1), 1-19. doi:10.1016/S0140-9883(01)00073-1 
Van Nguyen, M., Arason, S., Gissurarson, M., \& Pálsson, P. G. (2015). Uses of geothermal energy in food and agriculture. Opportunities for developing countries. Food and Agriculture Organization of the United Nations (FAO). Rome, Italy.

Van Zon, A., \& Yetkiner, I. H. (2003). An endogenous growth model with embodied energy-saving technical change. Resource and Energy Economics, 25(1), 81-103.

Vittinghoff, E., Glidden, D. V., Shiboski, S. C., \& McCulloch, C. E. (2011). Regression methods in biostatistics: linear, logistic, survival, and repeated measures models. Springer Science \& Business Media. doi:10.1007/978-1-4614-1353-0

Vyas, S., \& Kumaranayake, L. (2006). Constructing socio-economic status indices: how to use principal components analysis. Health policy and planning, 21(6), 459-468. doi:10.1093/heapol/czl029

Walker, G., Hunter, S., Devine-Wright, P., Evans, B., \& Fay, H. (2007). Harnessing community energies: explaining and evaluating community-based localism in renewable energy policy in the UK. Global Environmental Politics, 7(2), 64-82.

Wang, X., Fragano, F., Gehringer, M., Johnson, T. M., Lecaros, F., Lima, E., \& Lin, J. (2012). Drilling down on geothermal potential: an assessment for Central America. World Bank Group. Washington DC, USA.

Wang, H., Jasim, A., \& Chen, X. (2018). Energy harvesting technologies in roadway and bridge for different applications-A comprehensive review. Applied Energy, 212, 1083-1094. doi:10.1016/j.apenergy.2017.12.125

Weber, A. (1929). Theory of the Location of Industries: University of Chicago Press.

Wei, M., Patadia, S., \& Kammen, D. M. (2010). Putting renewables and energy efficiency to work: How many jobs can the clean energy industry generate in the US? Energy Policy, 38(2), 919-931. doi:10.1016/j.enpol.2009.10.044

Weinand, J. M., Kleinebrahm, M., McKenna, R., Mainzer, K., \& Fichtner, W. (2019). Developing a combinatorial optimisation approach to design district heating networks based on deep geothermal energy. Applied Energy, 251, 113367.

doi:10.1016/j.apenergy.2019.113367

Weisbrod, G., \& Weisbrod, B. (1997). Measuring economic impacts of projects and programs. Economic Development Research Group, 10, 1-11. Boston MA. USA

Wilson, R. (1977). The Factor Endowment Trade and Investment in the Middle East. Palgrave Macmillan. London, UK.

Wolfson, R. (2012). Energy and Heat Energy, Environment and Climate. Norton. New York, USA. $2^{\text {nd }}$ ed.

Wolsink, M. (2020). Distributed energy systems as common goods: Socio-political acceptance of renewables in intelligent microgrids. Renewable and Sustainable Energy Reviews, 127, 109841. doi:10.1016/j.rser.2020.109841

Woolcock, M., \& Narayan, D. (2000). Social capital: Implications for development theory, research, and policy. The World Bank Research Observer, 15(2), 225-249. doi:10.1093/wbro/15.2.225

Word Bank. (2018). Jobs in value chains survey toolkit. The World Bank Group. Washington DC, USA.

World Energy Council. (2013). Geothermal. World Energy Resources 2013. World Energy Council, UK.

World Energy Council. (2016). World Energy Resources 2016. World Energy Council, UK. 
World Bank. (2018). Poland Energy Transition. The Path to Sustainability in the Electricity and Heating Sector. The World Bank Group. Washington DC, USA.

$\mathrm{Wu}, \mathrm{N}$. (2008). Renewable energy, and economic development: examining three provinces in China. USAEE Working Paper No. WP, 08-011. doi:10.2139/ssrn.1289827

Xia, L., \& Zhang, Y. (2019). An overview of world geothermal power generation and a case study on China-The resource and market perspective. Renewable and Sustainable Energy Reviews, 112, 411-423. doi:10.1016/j.rser.2019.05.058

Yasukawa, K., \& Anbumozhi, V. (2018). Assesment of Necessary Innovations for Sustainable Use of Conventional and New-Type Geothermal Resources and their Benefits in East Asia. ERIA Research Project Report 2017 No.07. Economic Research Institute for ASEAN and East Asia.

Yasukawa, K., Kubota, H., Soma, N., \& Noda, T. (2018). Integration of natural and social environment in the implementation of geothermal projects. Geothermics, 73, 111123. doi:10.1016/j.geothermics.2017.09.011

Yasukawa, K. (2019). Issues Around Geothermal Energy and Society in Japan. In Geothermal Energy and Society (179-191): Springer. doi:10.1007/978-3-319-78286-7_12

Yeung, O., \& Johnson, K. (2014). Global Spa \& Wellness Economy Monitor. SRI International and the Global Wellness Institute. USA.

Yglesias, E. (2003). Porter vs. Porter: Modeling the technological competitiveness of nations. Scientometrics, 57(2), 281-293. doi:10.1023/a:1024193803372

Young, K. R., Levine, A., Cook, J., Ho, J. L., Heimiller, D. M., \& Hernandez, K. (2017). Crossing the Barriers: An Analysis of Market Barriers to Geothermal Development and Potential Improvement Scenarios (No. NREL/CP-6A20-68996). National Renewable Energy Lab.(NREL), Golden, CO USA.

Zall Kusek, J., \& Rist, R. (2004). Ten steps to a results-based monitoring and evaluation system: a handbook for development practitioners. The World Bank. Washington DC, USA.

Zavadskas, E. K., Kaklauskas, A., Vainiūnas, P., \& Šaparauskas, J. (2004). A model of sustainable urban development formation. International Journal of Strategic Property Management, 8, 219-229. doi:10.3846/1648715X.2004.9637519

Zhang, J., \& Jensen, C. (2007). Comparative advantage: explaining tourism flows. Annals of Tourism Research, 34(1), 223-243. doi:10.1016/j.annals.2006.08.004

Zhao, J. X., Li, L., Gou, M., \& Xia, Y. B. (2013). The Research of Safety Management Model of Shield Metro Construction Based on PCA-AHP-FUZZY. Applied Mechanics and Materials, Vol. 438-439, 1032-1037. doi:10.4028/www.scientific.net/AMM.438-439.1032

Zhou, J.-L., Xu, Q.-Q., \& Zhang, X.-Y. (2018). Water resources and sustainability assessment based on group AHP-PCA method: a case study in the Jinsha River Basin. Water, 10(12), 1880. doi:10.3390/w10121880

Zhu, J., Hu, K., Lu, X., Huang, X., Liu, K., \& Wu, X. (2015). A review of geothermal energy resources, development, and applications in China: Current status and prospects. Energy, 93, 466-483. doi:10.1016/j.energy.2015.08.098

Ziabakhsh-Ganji, Z., Nick, H. M., Donselaar, M. E., \& Bruhn, D. F. (2018). Synergy potential for oil and geothermal energy exploitation. Applied Energy, 212, 1433-1447. doi:10.1016/j.apenergy.2017.12.113

Zulkarnain, I., Furqan, T., Yuafrinaldi, \& Kartadjoemena, J. (2016). Geothermal Multiplier Benefits for Triggering Local Economic Growth. Working Paper Series no 101-2016. Ametis Institute. 


\section{Appendix}

Expert Questionnaire: Model of municipality competitiveness.

\begin{tabular}{|c|c|c|c|c|c|}
\hline \multicolumn{6}{|c|}{ INDICATORS OF MUNICIPALITY COMPETITIVENESS } \\
\hline \multicolumn{6}{|c|}{ Model of the synthetic competitiveness indicator $(\mathrm{Cl})$} \\
\hline \multicolumn{6}{|c|}{ categories } \\
\hline $\begin{array}{l}\text { Population } \\
\qquad\left(C_{p}\right)\end{array}$ & $\begin{array}{l}\text { Economy } \\
\qquad\left(C_{e}\right)\end{array}$ & $\begin{array}{l}\text { Local } \\
\text { government } \\
\left(C_{g}\right)\end{array}$ & Tourism $\left(C_{t}\right)$ & Infrastructure $\left(C_{i}\right)$ & Level of life $\left(C_{1}\right)$ \\
\hline \multicolumn{6}{|c|}{ subcategories } \\
\hline $\begin{array}{c}\text { Internal } \\
\text { migration/ } \\
10.000 \\
\text { inhabitants } \\
\left(C_{p} 1\right)\end{array}$ & $\begin{array}{c}\% \text { of } \\
\text { employed } \\
\text { inhabitants } \\
\left(C_{e} 1\right)\end{array}$ & $\begin{array}{l}\text { Own } \\
\text { municipality } \\
\text { income/inha } \\
\text { bitant }\left(C_{g} 1\right)\end{array}$ & $\begin{array}{c}\text { Polish tourists } \\
\text { accommodated } / 1 \\
000 \text { inhabitants } \\
\left(\mathrm{C}_{\mathrm{t}} 1\right)\end{array}$ & $\begin{array}{l}\text { Industrial and } \\
\text { domestic water } \\
\text { consumption } \\
\text { /inhabitant } \\
\left(C_{i} 1\right)\end{array}$ & $\begin{array}{c}\text { Out-Patient } \\
\text { health care } \\
\text { facilities } / 10.000 \\
\text { inhabitants }\left(C_{1} 1\right)\end{array}$ \\
\hline $\begin{array}{c}\text { Natural } \\
\text { increase/ } \\
10.000 \\
\text { inhabitants } \\
\left(C_{p} 2\right)\end{array}$ & $\begin{array}{l}\text { No of private } \\
\text { economic } \\
\text { activities } \\
\left(C_{e} 2\right)\end{array}$ & $\begin{array}{c}\text { Municipality } \\
\text { investment } \\
\text { expenses/ } \\
\text { inhabitant } \\
\left(C_{g} 2\right)\end{array}$ & $\begin{array}{c}\text { Foreign tourists } \\
\text { accommodated } / 1 \\
000 \text { inhabitants } \\
\left(C_{t} 2\right)\end{array}$ & $\begin{array}{l}\text { Cubic volume of } \\
\text { delivered buildings } \\
\text { / inhabitant }\left(C_{i} 2\right)\end{array}$ & $\begin{array}{c}\text { Environmental } \\
\text { protection } \\
\text { investment/inhabi } \\
\text { tant }\left(\mathrm{C}_{1} 2\right)\end{array}$ \\
\hline $\begin{array}{c}\% \text { of } \\
\text { population } \\
\text { in productive } \\
\text { age }\left(C_{p} 3\right)\end{array}$ & $\begin{array}{c}\text { No of } \\
\text { national } \\
\text { commercial } \\
\text { companies } \\
\left(\mathrm{C}_{\mathrm{e}} 3\right)\end{array}$ & $\begin{array}{l}\text { PIT income/ } \\
\text { employed } \\
\text { inhabitant } \\
\left(C_{g} 3\right)\end{array}$ & $\begin{array}{c}\text { Tourism } \\
\text { accommodation } \\
\text { establishments/10 } \\
00 \text { inhabitants } \\
\left(\mathrm{C}_{\mathrm{t}} 3\right)\end{array}$ & $\begin{array}{l}\text { Km of water-supply } \\
\text { and sanitation } \\
\text { network/inhabitant } \\
\qquad\left(\mathrm{C}_{\mathrm{i}} 3\right)\end{array}$ & $\begin{array}{l}\text { Primary and lower } \\
\text { secondary } \\
\text { education } \\
\text { expenses/pupil } \\
\text { (C,3) }\end{array}$ \\
\hline $\begin{array}{l}\text { Birth rate } \\
\qquad\left(C_{p} 4\right)\end{array}$ & $\begin{array}{c}\text { No of } \\
\text { commercial } \\
\text { companies } \\
\text { with foreign } \\
\text { capital }\left(C_{e} 4\right)\end{array}$ & $\begin{array}{c}\text { Budget } \\
\text { deficit/ } \\
\text { inhabitant } \\
\left(C_{g} 4\right)\end{array}$ & $\begin{array}{l}\text { Overnights spent } \\
\qquad\left(C_{t} 4\right)\end{array}$ & $\begin{array}{c}\text { Residential water } \\
\text { system connections } \\
\text { /inhabitant } \\
\left(C_{i} 4\right)\end{array}$ & $\begin{array}{l}\text { \% of population } \\
\text { connected to } \\
\text { wastewater } \\
\text { treatment plants } \\
\qquad\left(\mathrm{C}_{1} 4\right)\end{array}$ \\
\hline \multicolumn{6}{|l|}{ LEGEND } \\
\hline $\begin{array}{l}\text { 1-Both criter } \\
\text { 3-One criter } \\
5 \text {-One criter } \\
\text { 7-One criter } \\
\text { 9-One criter }\end{array}$ & $\begin{array}{l}n \text { have the sam } \\
n \text { is slightly mo } \\
n \text { is more impo } \\
n \text { is clearly mo } \\
n \text { is much mor }\end{array}$ & $\begin{array}{l}\text { impact on the } \\
\text { e important th } \\
\text { tant than the } \\
\text { important th } \\
\text { important tha }\end{array}$ & $\begin{array}{l}\text { hoice } \\
\text { the other } \\
\text { her, but the advanta } \\
\text { the other } \\
\text { the other }\end{array}$ & is at an average lev & \\
\hline
\end{tabular}




\begin{tabular}{|c|c|c|c|c|c|c|c|c|c|c|}
\hline \multicolumn{11}{|c|}{$\begin{array}{l}\text { 1. Which dimensions of the endogenous potential of a municipality is th } \\
\qquad \text { view of its competitiveness? } \\
\text { (mark the value of your choice) }\end{array}$} \\
\hline Factor & 9 & 7 & 5 & 3 & 1 & 3 & 5 & 7 & 9 & Factor \\
\hline Population $\left(C_{p}\right)$ & 9 & 7 & 5 & 3 & 1 & 3 & 5 & 7 & 9 & Economy $\left(C_{e}\right)$ \\
\hline Population $\left(C_{p}\right)$ & 9 & 7 & 5 & 3 & 1 & 3 & 5 & 7 & 9 & Local government $\left(C_{B}\right)$ \\
\hline Population $\left(C_{p}\right)$ & 9 & 7 & 5 & 3 & 1 & 3 & 5 & 7 & 9 & Tourism $\left(C_{t}\right)$ \\
\hline Population $\left(C_{p}\right)$ & 9 & 7 & 5 & 3 & 1 & 3 & 5 & 7 & 9 & Infrastructure $\left(C_{1}\right)$ \\
\hline Population $\left(C_{p}\right)$ & 9 & 7 & 5 & 3 & 1 & 3 & 5 & 7 & 9 & Level of life $\left(C_{1}\right)$ \\
\hline Economy $\left(C_{e}\right)$ & 9 & 7 & 5 & 3 & 1 & 3 & 5 & 7 & 9 & Local government $\left(C_{B}\right)$ \\
\hline Economy $\left(C_{e}\right)$ & 9 & 7 & 5 & 3 & 1 & 3 & 5 & 7 & 9 & Tourism $\left(C_{t}\right)$ \\
\hline Economy $\left(C_{e}\right)$ & 9 & 7 & 5 & 3 & 1 & 3 & 5 & 7 & 9 & Infrastructure $\left(C_{1}\right)$ \\
\hline Economy $\left(C_{e}\right)$ & 9 & 7 & 5 & 3 & 1 & 3 & 5 & 7 & 9 & Level of life $\left(C_{1}\right)$ \\
\hline Local government $\left(C_{B}\right)$ & 9 & 7 & 5 & 3 & 1 & 3 & 5 & 7 & 9 & Tourism $\left(C_{t}\right)$ \\
\hline Local government $\left(C_{B}\right)$ & 9 & 7 & 5 & 3 & 1 & 3 & 5 & 7 & 9 & Infrastructure $\left(C_{1}\right)$ \\
\hline Local government $\left(C_{g}\right)$ & 9 & 7 & 5 & 3 & 1 & 3 & 5 & 7 & 9 & Level of life $\left(C_{1}\right)$ \\
\hline Tourism $\left(C_{t}\right)$ & 9 & 7 & 5 & 3 & 1 & 3 & 5 & 7 & 9 & Infrastructure $\left(C_{1}\right)$ \\
\hline Tourism $\left(C_{t}\right)$ & 9 & 7 & 5 & 3 & 1 & 3 & 5 & 7 & 9 & Level of life $\left(C_{1}\right)$ \\
\hline Infrastructure $\left(C_{1}\right)$ & 9 & 7 & 5 & 3 & 1 & 3 & 5 & 7 & 9 & Level of life $\left(C_{1}\right)$ \\
\hline
\end{tabular}

2. Which social potential parameters (dimension: Population) are the most important from the point of the municipalities' competitiveness?

(mark the value of your choice)

\begin{tabular}{|c|c|c|c|c|c|c|c|c|c|c|}
\hline Factor & 9 & 7 & 5 & 3 & 1 & 3 & 5 & 7 & 9 & Factor \\
\hline $\begin{array}{l}\text { Internal migration/ } 10.000 \\
\text { inhabitants }\left(C_{p} 1\right)\end{array}$ & 9 & 7 & 5 & 3 & 1 & 3 & 5 & 7 & 9 & $\begin{array}{c}\text { Natural increase/ } \\
10.000 \text { inhabitants } \\
\left(C_{p} 2\right)\end{array}$ \\
\hline $\begin{array}{l}\text { Internal migration/ } 10.000 \\
\text { inhabitants }\left(C_{p} 1\right)\end{array}$ & 9 & 7 & 5 & 3 & 1 & 3 & 5 & 7 & 9 & $\begin{array}{c}\text { The percentage of } \\
\text { population in } \\
\text { productive age }\left(C_{p} 3\right)\end{array}$ \\
\hline $\begin{array}{c}\text { Internal migration/ } 10.000 \\
\text { inhabitants }\left(C_{p} 1\right)\end{array}$ & 9 & 7 & 5 & 3 & 1 & 3 & 5 & 7 & 9 & Birth rate $\left(C_{p} 4\right)$ \\
\hline
\end{tabular}




\begin{tabular}{|c|l|l|l|l|l|l|l|l|l|l|l|l|l|l|l|l|l|l|}
\hline $\begin{array}{c}\text { Natural increase/ 10.000 } \\
\left.\text { inhabitants ( } \mathrm{C}_{\mathrm{p}} 2\right)\end{array}$ & 9 & 7 & 5 & 3 & 1 & 3 & 5 & 7 & 9 & $\begin{array}{c}\text { The percentage of } \\
\text { population in } \\
\text { productive age }\left(\mathrm{C}_{p} 3\right)\end{array}$ \\
\hline $\begin{array}{c}\text { Natural increase/ 10.000 } \\
\text { inhabitants }\left(\mathrm{C}_{\mathrm{p}} 2\right)\end{array}$ & 9 & 7 & 5 & 3 & 1 & 3 & 5 & 7 & 9 & Birth rate $\left(\mathrm{C}_{\mathrm{p}} 4\right)$ \\
\hline $\begin{array}{c}\text { The percentage of population } \\
\text { in productive age }\left(\mathrm{C}_{\mathrm{p}} 3\right)\end{array}$ & 9 & 7 & 5 & 3 & 1 & 3 & 5 & 7 & 9 & Birth rate $\left(\mathrm{C}_{\mathrm{p}} 4\right)$ \\
\hline
\end{tabular}

\begin{tabular}{|c|c|c|c|c|c|c|c|c|c|c|}
\hline \multicolumn{11}{|c|}{$\begin{array}{l}\text { 3. Which parameters of the economic potential (dimension: Economy) are t } \\
\text { of the municipalities' competitiveness? } \\
\text { (mark the value of your choice) }\end{array}$} \\
\hline Factor & 9 & 7 & 5 & 3 & 1 & 3 & 5 & 7 & 9 & Factor \\
\hline $\begin{array}{l}\text { The percentage of employed } \\
\text { inhabitants }\left(C_{e} 1\right)\end{array}$ & 9 & 7 & 5 & 3 & 1 & 3 & 5 & 7 & 9 & $\begin{array}{l}\text { No of private } \\
\text { economic activities } \\
\left(\mathrm{C}_{\mathrm{e}} 2\right)\end{array}$ \\
\hline $\begin{array}{l}\text { The percentage of employed } \\
\text { inhabitants }\left(C_{e} 1\right)\end{array}$ & 9 & 7 & 5 & 3 & 1 & 3 & 5 & 7 & 9 & $\begin{array}{l}\text { No of national } \\
\text { commercial } \\
\text { companies }\left(\mathrm{C}_{\mathrm{e}} 3\right)\end{array}$ \\
\hline $\begin{array}{l}\text { The percentage of employed } \\
\text { inhabitants }\left(\mathrm{C}_{\mathrm{e}} 1\right)\end{array}$ & 9 & 7 & 5 & 3 & 1 & 3 & 5 & 7 & 9 & $\begin{array}{l}\text { No of commercial } \\
\text { companies with } \\
\text { foreign capital }\left(\mathrm{C}_{\mathrm{e}} 4\right)\end{array}$ \\
\hline $\begin{array}{c}\text { No of private economic } \\
\text { activities }\left(\mathrm{C}_{\mathrm{e}} 2\right)\end{array}$ & 9 & 7 & 5 & 3 & 1 & 3 & 5 & 7 & 9 & $\begin{array}{l}\text { No of national } \\
\text { commercial } \\
\text { companies }\left(\mathrm{C}_{e} 3\right)\end{array}$ \\
\hline $\begin{array}{c}\text { No of private economic } \\
\text { activities }\left(\mathrm{C}_{\mathrm{e}} 2\right)\end{array}$ & 9 & 7 & 5 & 3 & 1 & 3 & 5 & 7 & 9 & $\begin{array}{l}\text { No of commercial } \\
\text { companies with } \\
\text { foreign capital }\left(\mathrm{C}_{\mathrm{e}} 4\right)\end{array}$ \\
\hline $\begin{array}{c}\text { No of national commercial } \\
\text { companies }\left(\mathrm{C}_{\mathrm{e}} 3\right)\end{array}$ & 9 & 7 & 5 & 3 & 1 & 3 & 5 & 7 & 9 & $\begin{array}{l}\text { No of commercial } \\
\text { companies with } \\
\text { foreign capital }\left(\mathrm{C}_{\mathrm{e}} 4\right)\end{array}$ \\
\hline
\end{tabular}

\begin{tabular}{|c|c|c|c|c|c|c|c|c|c|c|}
\hline \multicolumn{11}{|c|}{$\begin{array}{l}\text { 4. Which parameters of the institutional capacity of local government (dimension: Local government) are the } \\
\text { most important from the point of the municipalities' competitiveness? } \\
\text { (mark the value of your choice) }\end{array}$} \\
\hline Factor & 9 & 7 & 5 & 3 & 1 & 3 & 5 & 7 & 9 & Factor \\
\hline $\begin{array}{c}\text { Own municipality } \\
\text { income/inhabitant }\left(C_{g} 1\right)\end{array}$ & 9 & 7 & 5 & 3 & 1 & 3 & 5 & 7 & 9 & $\begin{array}{l}\text { Municipality investment } \\
\text { expenses/ inhabitant } \\
\qquad\left(C_{g} 2\right)\end{array}$ \\
\hline $\begin{array}{c}\text { Own municipality } \\
\text { income/inhabitant }\left(C_{g} 1\right)\end{array}$ & 9 & 7 & 5 & 3 & 1 & 3 & 5 & 7 & 9 & $\begin{array}{c}\text { PIT income/ employed } \\
\text { inhabitant }\left(C_{g} 3\right)\end{array}$ \\
\hline $\begin{array}{c}\text { Own municipality } \\
\text { income/inhabitant }\left(C_{g} 1\right)\end{array}$ & 9 & 7 & 5 & 3 & 1 & 3 & 5 & 7 & 9 & Budget deficit $\left(C_{g} 4\right)$ \\
\hline $\begin{array}{c}\text { Municipality investment } \\
\text { expenses/ inhabitant }\left(C_{g} 2\right)\end{array}$ & 9 & 7 & 5 & 3 & 1 & 3 & 5 & 7 & 9 & $\begin{array}{c}\text { PIT income/ employed } \\
\text { inhabitant }\left(C_{g} 3\right)\end{array}$ \\
\hline
\end{tabular}




\begin{tabular}{|c|c|c|c|c|c|c|c|c|c|c|c|c|c|c|c|c|c|c|}
\hline $\begin{array}{c}\text { Municipality investment } \\
\text { expenses/ inhabitant }\left(\mathrm{C}_{\mathrm{g}} 2\right)\end{array}$ & 9 & 7 & 5 & & 3 & & 1 & & 3 & & 5 & & 7 & 9 & Budget deficit $\left(\mathrm{C}_{\mathrm{g}} 4\right)$ \\
\hline $\begin{array}{c}\text { PIT income/ employed } \\
\text { inhabitant }\left(\mathrm{C}_{\mathrm{g}} 3\right)\end{array}$ & 9 & 7 & 5 & 3 & 1 & 3 & 5 & 7 & 9 & Budget deficit $\left(\mathrm{C}_{\mathrm{g}} 4\right)$ \\
\hline
\end{tabular}

\begin{tabular}{|c|c|c|c|c|c|c|c|c|c|c|}
\hline \multicolumn{11}{|c|}{$\begin{array}{l}\text { 5. Which tourism potential parameters (dimensions: Tourism) are the } \mathrm{m} \\
\text { municipalities' competitiveness? } \\
\text { (mark the value of your choice) }\end{array}$} \\
\hline Factor & 9 & 7 & 5 & 3 & 1 & 3 & 5 & 7 & 9 & Factor \\
\hline $\begin{array}{l}\text { Polish tourists } \\
\text { accommodated } / 1000 \\
\text { inhabitants }\left(\mathrm{C}_{\mathrm{t}} 1\right)\end{array}$ & 9 & 7 & 5 & 3 & 1 & 3 & 5 & 7 & 9 & $\begin{array}{l}\text { Foreign tourists } \\
\text { accommodated } / 1000 \\
\text { inhabitants }\left(C_{t} 2\right)\end{array}$ \\
\hline $\begin{array}{l}\text { Polish tourists } \\
\text { accommodated } / 1000 \\
\text { inhabitants }\left(C_{t} 1\right)\end{array}$ & 9 & 7 & 5 & 3 & 1 & 3 & 5 & 7 & 9 & $\begin{array}{c}\text { Tourism } \\
\text { accommodation } \\
\text { establishments } / 1000 \\
\text { inhabitants }\left(C_{t} 3\right)\end{array}$ \\
\hline $\begin{array}{l}\text { Polish tourists } \\
\text { accommodated } / 1000 \\
\text { inhabitants }\left(C_{t} 1\right)\end{array}$ & 9 & 7 & 5 & 3 & 1 & 3 & 5 & 7 & 9 & Overnights spent $\left(C_{t} 4\right)$ \\
\hline $\begin{array}{l}\text { Foreign tourists } \\
\text { accommodated } / 1000 \\
\text { inhabitants }\left(C_{t} 2\right)\end{array}$ & 9 & 7 & 5 & 3 & 1 & 3 & 5 & 7 & 9 & $\begin{array}{c}\text { Tourism } \\
\text { accommodation } \\
\text { establishments } / 1000 \\
\text { inhabitants }\left(C_{t} 3\right)\end{array}$ \\
\hline $\begin{array}{l}\text { Foreign tourists } \\
\text { accommodated } / 1000 \\
\text { inhabitants }\left(C_{t} 2\right)\end{array}$ & 9 & 7 & 5 & 3 & 1 & 3 & 5 & 7 & 9 & Overnights spent $\left(C_{t} 4\right)$ \\
\hline $\begin{array}{l}\text { Tourism accommodation } \\
\text { establishments/1000 } \\
\text { inhabitants }\left(C_{t} 3\right)\end{array}$ & 9 & 7 & 5 & 3 & 1 & 3 & 5 & 7 & 9 & Overnights spent $\left(C_{t} 4\right)$ \\
\hline
\end{tabular}

\begin{tabular}{|c|c|c|c|c|c|c|c|c|c|c|}
\hline \multicolumn{11}{|c|}{$\begin{array}{l}\text { 6. Which infrastructure potential parameters (dimensions: Infrastructure) are the most important from the } \\
\text { point of municipalities' competitiveness? } \\
\text { (mark the value of your choice) }\end{array}$} \\
\hline Factor & 9 & 7 & 5 & 3 & 1 & 3 & 5 & 7 & 9 & Factor \\
\hline $\begin{array}{l}\text { Industrial and domestic } \\
\text { water consumption } \\
\text { /inhabitant } \\
\left(C_{i} 1\right)\end{array}$ & 9 & 7 & 5 & 3 & 1 & 3 & 5 & 7 & 9 & $\begin{array}{l}\text { Cubic volume of } \\
\text { delivered buildings / } \\
\text { inhabitant }\left(\mathrm{C}_{\mathrm{i}} 2\right)\end{array}$ \\
\hline $\begin{array}{c}\text { Industrial and domestic } \\
\text { water consumption } \\
\text { /inhabitant } \\
\left(\mathrm{C}_{\mathrm{i}} 1\right)\end{array}$ & 9 & 7 & 5 & 3 & 1 & 3 & 5 & 7 & 9 & $\begin{array}{l}\text { Km of water-supply and } \\
\text { sanitation } \\
\text { network/inhabitant }\left(\mathrm{C}_{\mathrm{i}} 3\right)\end{array}$ \\
\hline $\begin{array}{l}\text { Industrial and domestic } \\
\text { water consumption } \\
\text { /inhabitant }\left(C_{i} 1\right)\end{array}$ & 9 & 7 & 5 & 3 & 1 & 3 & 5 & 7 & 9 & $\begin{array}{l}\text { Residential water system } \\
\text { connections /inhabitant } \\
\qquad\left(C_{i} 4\right)\end{array}$ \\
\hline
\end{tabular}




\begin{tabular}{|c|c|c|c|c|c|c|c|c|c|c|}
\hline $\begin{array}{l}\text { Cubic volume of delivered } \\
\text { buildings / inhabitant }\left(\mathrm{C}_{\mathrm{i}} 2\right)\end{array}$ & 9 & 7 & 5 & 3 & 1 & 3 & 5 & 7 & 9 & $\begin{array}{l}\text { Km of water-supply and } \\
\text { sanitation } \\
\text { network/inhabitant }\left(\mathrm{C}_{\mathrm{i}} 3\right)\end{array}$ \\
\hline $\begin{array}{l}\text { Cubic volume of delivered } \\
\text { buildings / inhabitant }\left(\mathrm{C}_{\mathrm{i}} 2\right)\end{array}$ & 9 & 7 & 5 & 3 & 1 & 3 & 5 & 7 & 9 & $\begin{array}{l}\text { Residential water system } \\
\text { connections /inhabitant } \\
\left(\mathrm{C}_{\mathrm{i}} 4\right)\end{array}$ \\
\hline $\begin{array}{l}\text { Km of water-supply and } \\
\text { sanitation } \\
\text { network/inhabitant }\left(C_{i} 3\right)\end{array}$ & 9 & 7 & 5 & 3 & 1 & 3 & 5 & 7 & 9 & $\begin{array}{c}\text { Residential water system } \\
\text { connections /inhabitant } \\
\left(\mathrm{C}_{\mathrm{i}} 4\right)\end{array}$ \\
\hline
\end{tabular}

\begin{tabular}{|c|c|c|c|c|c|c|c|c|c|c|}
\hline \multicolumn{11}{|c|}{$\begin{array}{l}\text { 7. Which level of life increase potential parameters (dimensions: Level of Life) a } \\
\text { the point of the municipalities' competitiveness? } \\
\text { (mark the value of your choice) }\end{array}$} \\
\hline Factor & 9 & 7 & 5 & 3 & 1 & 3 & 5 & 7 & 9 & Factor \\
\hline $\begin{array}{l}\text { Out-Patient health care } \\
\text { facilities } / 10.000 \\
\text { inhabitants }\left(C_{1} 1\right)\end{array}$ & 9 & 7 & 5 & 3 & 1 & 3 & 5 & 7 & 9 & $\begin{array}{c}\text { Environmental } \\
\text { protection } \\
\text { investment/inhabitant } \\
\left(\mathrm{C}_{1} 2\right)\end{array}$ \\
\hline $\begin{array}{l}\text { Out-Patient health care } \\
\text { facilities } / 10.000 \\
\text { inhabitants }\left(C_{1} 1\right)\end{array}$ & 9 & 7 & 5 & 3 & 1 & 3 & 5 & 7 & 9 & $\begin{array}{l}\text { Primary and lower } \\
\text { secondary education } \\
\text { expenses/pupil }\left(\mathrm{C}_{1} 3\right)\end{array}$ \\
\hline $\begin{array}{l}\text { Out-Patient health care } \\
\text { facilities } / 10.000 \\
\text { inhabitants }\left(C_{1} 1\right)\end{array}$ & 9 & 7 & 5 & 3 & 1 & 3 & 5 & 7 & 9 & $\begin{array}{l}\text { Population connected to } \\
\text { wastewater treatment } \\
\text { plants }\left(\mathrm{C}_{1} 4\right)\end{array}$ \\
\hline $\begin{array}{l}\text { Environmental protection } \\
\text { investment/inhabitant } \\
\qquad\left(\mathrm{C}_{1} 2\right)\end{array}$ & 9 & 7 & 5 & 3 & 1 & 3 & 5 & 7 & 9 & $\begin{array}{l}\text { Primary and lower } \\
\text { secondary education } \\
\text { expenses/pupil }\left(C_{\mid} 3\right)\end{array}$ \\
\hline $\begin{array}{l}\text { Environmental protection } \\
\text { investment/inhabitant } \\
\left(\mathrm{C}_{1} 2\right)\end{array}$ & 9 & 7 & 5 & 3 & 1 & 3 & 5 & 7 & 9 & $\begin{array}{c}\text { Population connected to } \\
\text { wastewater treatment } \\
\text { plants }\left(C_{1} 4\right)\end{array}$ \\
\hline $\begin{array}{l}\text { Primary and lower } \\
\text { secondary education } \\
\text { expenses/pupil }\left(\mathrm{C}_{\mid} 3\right)\end{array}$ & 9 & 7 & 5 & 3 & 1 & 3 & 5 & 7 & 9 & $\begin{array}{c}\text { Population connected to } \\
\text { wastewater treatment } \\
\text { plants }\left(\mathrm{C}_{1} 4\right)\end{array}$ \\
\hline
\end{tabular}




\section{Sum mary}

This thesis presents approaches to measure and determine the induced impact of the geothermal resources on local economy. The variety of the direct geothermal utilization as presented by the Lindal diagram activates the induced geothermal effect locally. Hence the analysis has to start from the identification of the direct geothermal application in a municipality. The thesis focuses on the examples of Polish municipalities using geothermal resources. To answer the main research question of the thesis what is the impact of the geothermal resources utilization on the development of the municipalities in which they occur, the geothermal activities are tested on the developed models with the local data. The research is conducted in seven chapters. Chapter 1 introduces the scientific problem of this work. The description of the study object is given together with defining the research problem. Moreover, the presented theoretical background that substantiates the theoretical arguments of the thesis. Proposed framework of research questions and methods to solve them closes this section.

Chapter 2 dedicates to testing the relationship between the emergence of the geothermal spas and recreational centers and the parameters that describe the local development. The study assumes that the introduction of a geothermal spa accelerates the socioeconomic development of the municipality, in which it is established. To test it, a switch regression model is proposed. A relationship between the geothermal recreational and spa establishments and the indicator of local development is examined. A multicriteria method is used to establish the local development indicator. The geothermal centers result as a switch factor in the municipalities development trend, accelerating it. In case of the municipalities with the lower socioeconomic indicator values before the introduction of the geothermal spas, a double indicator growth is observed. The outcomes of the model positively verifies the hypothesis, the local socioeconomic development of the municipalities where the geothermal spas and recreational centers operate grows in time. Chapter 2 findings point to the new tourism specialization, that arises with the introduction of the geothermal establishments. Therefore, the endogenous geothermal resources are an element of specialization and they initiate growth in small size economies.

Chapter 3 tackles a broader research question if there is a relationship between the development of geothermal energy and the competitiveness of the municipalities. It continues on the endogeneity of the geothermal resources as they are factors of growth. The proposed model takes into account the available forms of the geothermal resources in the selected eleven Polish municipalities. Nevertheless, the concept of the municipality competitiveness is referred to the competitive advantage that the geothermal resources use entails. To measure the competitiveness of the municipalities the socioeconomic indicators are compared according to the benchmark principle. The benchmark municipalities do not exploit the 
geothermal resources. To measure the competitiveness of municipalities and their benchmarks, the competitiveness index is developed by the multicriteria expert method. The panel data model used the index as the model key determinant. The sensitive analysis conducted reveals a significant relationship between the competitiveness indicator and the geothermal activities coded into model variables. This relationship does not appear for the benchmark municipalities. Moreover, the local utilization of the geothermal energy displays a lag effect. Hence, the more geothermal energy is produced and applied, the larger impact on the municipality competitiveness reveals.

Analysis of the two established indicators of local development and local competitiveness in the light of the methodology of multicriteria analysis constitute the core of Chapter 4 . The socioeconomic data used to construct the two indicators is processed by two different in nature methods the Principle Component Analysis (PCA) and the Analytical Hierarchy Process (AHP). Chapter 4 focuses on answering the research question how comparable are the results yielded by the PCA and AHP methods in the situation of secondary data. The data used is considered as a secondary type since sourced in the in the same depository of the Central Statistical Office, i.e. the Local Data Bank. The non-parametric correlations of the both indexes rankings served to tackle the research problem. The correlations are used as a statistical approach to assess the comparability of the Chapter 2 and Chapter 3 results. The study framework corresponds with the nature of epistemological context. Throughout the analysis the justification of the multicriteria method choice for a set of socioeconomic variables takes place. The model testing pointed to the significant correlations between the indexes. The interpretation allows to answer the research question that the both PCA and AHP delivered similar results. Nevertheless, a further integration experiment is carried out. It serves to identify the strength of the two methods by mixing the weights generation processes and the models structure predetermined by each method. The most significant correlation results for the data model structure proposed by the PCA. This method is therefore better advised for a secondary data to use for a multicriteria phenomenon analysis.

The new approach to the shift-share analysis is used in the Chapter 5. This method commonly applied in the regional studies, is yet used in this thesis to the local employment data for the geothermal municipalities in Poland. Since the chapters 2 and 3 study the relationship between the geothermal exploitation parameters and performance of a municipality expressed in the socioeconomic indicators, the Chapter 5 presents a case study of the selected economic sectors. In this chapter, the role of the geothermal resources for the municipalities where exploited, is measured by the employment in the related sectors. For this purpose, the research question whether the local employment structure changes while using the geothermal resources is elaborated in the comparative analysis. The structure of employment of the selected geothermal municipalities and referred areas is observed, if a structural change in the employment sectors took place in time. The results of the shift-share analysis shows noticeable shifts of employed into the service sectors from the traditional sectors throughout 
the tested time frame. Moreover, the general employment grew more in the geothermal municipalities than in the referred poviat areas. Based on the results of this study it is argued that the geothermal spas and recreational centers induce additional employment and they have an induce effect on the local employment structure. In case of the presented study the impact on employment concerns mainly tourism and hospitality activates and related services, as well as recreational, sport services and the emerge of single economic activities. The shiftshare approach used in the Chapter 5 is helpful when considering future supply and demand conditions for infrastructure in a geothermal location, based upon discovered economic growth prospects. Hence, the proposed model is further applicable into the geothermal impact studies.

Chapter 6 is dedicated to the development of the socioeconomic indicators model that served to determine municipalities' local development (Chapter 2) and the comparison of municipalities' competitiveness (Chapter 3). The chapter has a data study format led by the research question which data conceptualize the local competitiveness. The purpose of this analysis to develop a set of socioeconomic indicators that optimally determine the economic performance and socioeconomic structure of a municipality in Poland. The presented data model that consists of the 24 indicators matrix is assessed to best represent the categories of municipalities' development. Chapter 6 analysis next to motivating the socioeconomic dataset, introduces in detail the Analytical Hierarchy Procedure tool, i.e. the questionnaire. Since it is an expert base procedure, in contrary to the self-sustained and automatized Principal Component Analysis, the questionnaire is a separate and additional qualitative procedure to be justified when applied. The constructed socioeconomic model for a municipality in this section is then the core element of the analysis conducted throughout the thesis.

Synthesis of the chapters' analysis is enclosed in Chapter 7. Mapping of the major findings supports the discourse over the main research question in this thesis. Based on the research results the impact of the geothermal energy on local development is determined. Discussion about the role of the geothermal resources for local economy and energy transition is further presented. Some considerations to the data collection are listed. Thesis concludes with predictions of the geothermal development directions in Poland and worldwide. 


\section{Streszczenie polskie}

W niniejszej pracy przedstawiono metody pomiaru i określania wywołanego typu wpływu zasobów geotermalnych na lokalną gospodarkę. Różnorodność bezpośredniego wykorzystania energii geotermalnej określona modelem Lindala (ang. Lindal diagram) wskazuje na lokalne użytkowanie zasobów geotermalnych. Stąd też analiza tematu rozpoczyna się od określenia bezpośredniego zastosowania geotermii lokalnie tj. w gminie. Rozprawa obejmuje przykłady polskich gmin, które wykorzystują zasoby geotermalne. Aby odpowiedzieć na główne pytanie badawcze tezy tzn. jaki jest wpływ wykorzystania zasobów geotermalnych na rozwój gmin, w których występują zasoby, opracowane zostały modele zawierające dane lokalne i aktywności geotermalne w gminach. Rozprawę stanowi siedem rozdziałów. Rozdział 1 przedstawia problem naukowy tej pracy. Podano opis przedmiotu badań wraz z określeniem problemu badawczego. Ponadto przedstawiono tło teoretyczne, które uzasadnia argumenty badawcze tezy i użyte teorie naukowe. Ramy pytań badawczych i metody ich rozwiązywania zaproponowane w pracy zamykają ten rozdział.

Rozdział 2 poświęcony jest zbadaniu zależności między pojawieniem się uzdrowisk geotermalnych i ośrodków rekreacyjnych w gminach, a parametrami opisującymi rozwój lokalny. W opracowaniu przyjęto, że wprowadzenie uzdrowiska geotermalnego w lokalną gospodarkę przyspiesza rozwój społeczno-gospodarczy gminy. W badaniu zaproponowano model regresji przełącznika (ang. switch regression model). Przetestowano zależność między geotermalnymi obiektami rekreacyjnymi i uzdrowiskowymi, a wskaźnikiem rozwoju lokalnego. Do ustalenia wskaźnika rozwoju lokalnego zastosowano metodę wielokryterialną. Ośrodki geotermalne są czynnikiem przełączającym trend rozwoju gmin i przyspieszającym go. W przypadku gmin o niskiej wartości wskaźnika rozwojowego razem z wprowadzeniem uzdrowisk geotermalnych obserwuje się jego dwukrotny wzrost. Wyniki modelu pozytywnie weryfikują hipotezę, iż lokalny rozwój społeczno-gospodarczy gmin, w których działają uzdrowiska geotermalne i ośrodki rekreacyjne rośnie w czasie. Wyniki rozdziału 2 wskazują na nową, lokalną specjalizację turystyczną, która pojawia się wraz z wprowadzeniem obiektów geotermalnych. Można stwierdzić, iż endogeniczne zasoby geotermalne są elementem specjalizacji i inicjują wzrost małych gospodarek lokalnych.

Rozdział 3 dotyczy szerszej kwestii badawczej, to znaczy czy istnieje związek między rozwojem energii geotermalnej, a konkurencyjnością gmin. To badanie kontynuuje rozważania nad endogenicznością zasobów geotermalnych, uznanych jako czynniki wzrostu lokalnego. Zaproponowany model uwzględnia dostępne formy zasobów geotermalnych w wybranych jedenastu polskich gminach. Pojęcie konkurencyjności gminy odnosi się do przewagi konkurencyjnej, jaką niesie ze sobą wykorzystanie zasobów geotermalnych. Aby zmierzyć konkurencyjność gmin, porównano wskaźniki społeczno-ekonomiczne zgodnie z metodologią benchmark. Gminy stanowiące grupę odniesienia tj. benchmarki nie wykorzystują zasobów 
geotermalnych. Dla porównania konkurencyjności gmin i ich benchmarków, opracowano wskaźnik konkurencyjności używając eksperckiej metody wielokryterialnej. Model oparty o analizę panelową wykorzystał stworzony indeks jako zmienną zależną w modelu. Przeprowadzona statystyczna analiza wrażliwości ujawniła istotny związek między wskaźnikiem konkurencyjności, a zmiennymi określającymi produkcję i wykorzystanie zasobów geotermalnych w gminach. Zależność ta nie występuje w przypadku gmin dobranych jako benchmarki. Ponadto, badanie ujawniło, że efekty wykorzystania lokalnego energii geotermalnej potęgują się w czasie. W związku z tym im więcej energii geotermalnej jest wytwarzane i wykorzystywane lokalnie, tym większy jest jej wpływ na konkurencyjność gminy.

Analiza dwóch ustalonych wskaźników rozwoju lokalnego i lokalnej konkurencyjności w świetle metodologii analizy wielokryterialnej stanowi podstawę badań w rozdziale 4. Dane społecznoekonomiczne użyte do skonstruowania dwóch wskaźników są przetwarzane za pomocą dwóch różnych w podstawie metod tj. Analizy Głównych Składowych (PCA) i Analitycznego Procesu Hierarchicznego (AHP). Rozdział 4 skupia się na odpowiedzi na pytanie badawcze jak porównywalne są wyniki metod PCA i AHP w sytuacji wielokryterialnego zestawu danych wtórnych. Wykorzystywane dane do konstrukcji obu wskaźników są traktowane jako wtórne, ponieważ pochodzą z tego źródła tj. Banku Danych Lokalnych GUS. Do rozwiązania problemu badawczego posłużyły nieparametryczne korelacje rankingów obu wskaźników z rozdziału 2 i rozdziału 3. Ramy badania zawierają się w naturze kontekstu epistemologicznego. Dzięki analizie korelacji wyników obu metod można uzasadnić wybór metody wielokryterialnej do ujęcia problemu badawczego opisanego zbiorem zmiennych socjoekonomicznych. Testowanie modelu wskazało na istotne korelacje między indeksami PCA i AHP. Interpretacja wyników wysokiej korelacji między wskaźnikami pozwala odpowiedzieć na pytanie badawcze, w przypadku tego zestawu danych zarówno PCA, jak i AHP pozwala uzyskać podobne wyniki. Następnie przeprowadzono kolejny eksperyment polegający na integracji metod. Posłużył on do określenia przewagi metodologicznej obu metod poprzez zmieszanie procesów generowania wag i struktury modelu wyznaczanych przez każdą metodę. Najbardziej znaczące wyniki korelacji dla struktury zmiksowanego modelu danych uzyskano dla struktury modelu zaproponowanego przez PCA. Na tej podstawie można wnioskować, że ta metoda jest lepsza do użycia w przypadku danych wtórnych w analizie zjawiska wielokryterialnego.

Nowe podejście do analizy potencjałów regionalnych (analiza shift-share) zastosowano w rozdziale 5. Ta metoda powszechnie stosowana $w$ badaniach regionalnych, została zastosowana w niniejszej pracy do zbadania lokalnych danych zatrudnienia w wyznaczonych gminach geotermalnych w Polsce. Ponieważ w rozdziałach 2 i 3 badane są zależności pomiędzy parametrami eksploatacji geotermii, a wynikami gminy wyrażonymi wskaźnikami rozwoju społeczno-ekonomicznego, w rozdziale 5 przedstawiono studium przypadku wybranych sektorów gospodarki w związku z wykorzystaniem lokalnym zasobu. W tym rozdziale rolę zasobów geotermalnych w gminach mierzy się jako zatrudnienie w powiązanych sektorach gospodarki. $W$ tym celu $w$ analizie porównawczej postawiono pytanie badawcze, czy lokalna 
struktura zatrudnienia zmienia się w trakcie korzystania z zasobów geotermalnych. Struktura zatrudnienia w wybranych gminach geotermalnych i powiatach (przyjętych jako obszar porównawczy) jest obserwowana pod kątem nastąpienia zmiany strukturalnej w sektorach zatrudnienia w czasie. Wyniki analizy shift-share wskazują na zauważalne przesunięcia pracujących do sektorów usługowych z tradycyjnych sektorów w badanym okresie. Ponadto zatrudnienie wzrastało szybciej w gminach geotermalnych, niż w powiatach. Na podstawie wyników tego badania stwierdza się, że uzdrowiska geotermalne i ośrodki rekreacyjne generują dodatkowe zatrudnienie i wpływają na zmianę na lokalną strukturę zatrudnienia wywołując dodatkowe zapotrzebowanie na usługi. W przypadku prezentowanych badań wpływ na zatrudnienie dotyczy głównie działalności turystycznej i hotelarskiej oraz usług z nią związanych, a także usług rekreacyjno-sportowych oraz jednoosobowych działalności gospodarczych. Podejście shift-share zastosowane w rozdziale 5 jest pomocne przy rozważaniu warunków podaży i popytu na infrastrukturę w lokalizacji geotermalnej, w oparciu o zaprezentowane perspektywy wzrostu gospodarczego. W związku z tym zaproponowany model ma dalsze zastosowanie $w$ badaniach oddziaływania geotermalnego na rozwój lokalny.

Rozdział 6 poświęcony jest opracowaniu modelu wskaźników społeczno-ekonomicznych, który posłużył do określenia rozwoju lokalnego gmin (rozdział 2) oraz porównania konkurencyjności gmin (rozdział 3). Rozdział ten ma format ustalonego badania danych, opartemu o pytanie badawcze jakie dane pozwalają określić lokalną konkurencyjność. Celem tego rozdziału jest opracowanie zestawu wskaźników społeczno-ekonomicznych wyrażonych modelem, który określa wyniki gospodarcze i strukturę społeczno-ekonomiczną gminy w Polsce. Ocenia się, że zaprezentowany model danych, który składa się z macierzy 24 wskaźników, odzwierciedla kategorie rozwoju gmin. Rozdział 6, obok przedstawienia genezy konstrukcji zbioru danych społeczno-ekonomicznych, szczegółowo przedstawia narzędzie Analitycznego Procesu Hierarchicznego (AHP), czyli kwestionariusz ekspercki. Ponieważ jest to procedura oparta na ekspertyzie, w przeciwieństwie do niezależnej i zautomatyzowanej Analizy Głównych Składowych (PCA), kwestionariusz ekspercki jest odrębną i dodatkową procedurą jakościową, którą należy uzasadnić w przypadku jej zastosowania. Skonstruowany model społecznoekonomiczny dla gminy $w$ tym rozdziale jest zatem podstawowym elementem analizy prowadzonej w całej rozprawie.

Syntezę rozdziałów pracy zawarto w rozdziale 7. Przedstawiona mapa głównych ustaleń z kolejnych badań wspiera dyskusję nad głównym pytaniem badawczym w tej pracy. $\mathrm{Na}$ podstawie wyników badań określono wpływ energii geotermalnej na rozwój lokalny. W dalszej części omówiono rolę zasobów geotermalnych dla lokalnej gospodarki i transformacji energetycznej. Wymienione zostały niektóre kwestie związane z ograniczeniami w gromadzeniu danych badawczych. Rozprawę kończy prognoza kierunków lokalnego rozwoju geotermii w Polsce i na świecie. 


\section{Acknowledgments}

This dissertation would not have come about without the significant contribution of many people who believed in me or in the geothermal energy.

Firstly, I would like to express my sincere gratitude to my supervisor prof. Wim Heijman for the chance of working together and inviting to this cooperation dr Johan van Ophem as the cosupervisor. I am very grateful to prof. Heijman for valuable guidance throughout the whole cycle of this thesis, for his merit and efficient mentorship, that next to improving the research quality, has remarkably expanded my personal researcher horizon. His professionalism and academic spirit are truly inspirational. Dr van Ophem has continuously and patiently supported this research sharing his great knowledge in social theories, supervising the analytical parts of the thesis with inexhaustible encouragement and setting this work on a right path. I have received a desirable supervision.

Words of appreciation are dedicated to my second co-supervisor dr Jacek Strojny, who has introduced me to the world of research conceptualization, always sharing his enthusiasms and experience. I am thankful for his availability to discuss my concerns during the studying and writing.

My sincere thanks extend to the co-author of our scientific papers prof. Stanisław Gędek, who has offered his immense knowledge and academic experience, believing in this thesis project and in our cooperation.

I appreciate that our collaboration has resulted in discovering new methods and describing new economic phenomenon, next to establishing an efficient research team.

Besides my promotors, I would like to thank the rest of my thesis committee: dr Beata Kępińska, prof. Nico Heerink, dr Hans-Peter Weikard and prof. David Bruhn, for their insightful comments and encouragement, but also for the hard questions which incented me to widen my research from another perspective.

I am thankful to the chairs of the groups Agriculture Economics and Rural Policy: prof. Justus Wessler and Urban Economics: prof. Eveline van Leeuwen for hosting and supporting this research during my in-house time at the university. Thank you to the AEP and UEC colleagues, tones of laughs, meaningful exchange, and lasting friendships. I am grateful as well to the groups' secretariat staff: Karen, Betty, Dineke and Frank for their never-ending professionalism and kindness. 
I would like to sincerely thank all the geothermal professionals and local government authorities in Poland for their participation in the surveys and interviews that supported my work and helped me obtained better quality results. Moreover, I express gratitude to the regional economics scholars approached to participate in the expert group and to the interviewed specialists from the geothermal centers.

The thesis research would not be possible to conduct without a specific data. That is why I direct my words of thanks to the management of the geothermal plants in Poland, that have accredited this work and granted me access to the geothermal data production. I am thankful to the managers and delegated staff of Geotermia Mazowiecka, Geotermia Uniejów, Geotermia Podhalańska, Geotermia Poddębice, Geotermia Stargard | G-Term Energy, and Geotermia Pyrzyce among others. I could always count on their expertise and willingness to collaborate in the geothermal studies.

The topic of the thesis allowed me to get involved in the Polish Geothermal Society and International Geothermal Association. It is an honor to meet the real geothermal enthusiasts who dedicate their professional lives to the wonders of the geothermal resources.

Lastly, I would like to thank my family and friends for supporting and motivating me throughout writing this thesis, and outside of the thesis world. 


\section{Thesis Curriculum}

Scientific articles published in reference to the thesis research problem:

1. Kurek, K. A., Heijman, W., van Ophem, J., Gędek, S., \& Strojny, J. (2021). The contribution of the geothermal resources to local employment: Case study from Poland. Energy Reports, 7, 1190-1202. doi:10.1016/j.egyr.2021.01.092

2. Kurek, K. A., Heijman, W., van Ophem, J., Gędek, S., \& Strojny, J. (2020). Dataset for the model of a municipality competitiveness in relation to the geothermal resources exploitation in Poland. Data in Brief, 105687. doi:10.1016/j.dib.2020.105687

3. Kurek, K. A., Heijman, W., van Ophem, J., Gędek, S., \& Strojny, J. (2020). Geothermal spas as a local development factor, the case of Poland. Geothermics, 85, 101777. doi:10.1016/j.geothermics.2019.101777

4. Kurek, K. A., Heijman, W., van Ophem, J., Gędek, S., \& Strojny, J. (2020). The impact of geothermal resources on the competitiveness of municipalities: evidence from Poland. Renewable Energy, 151, 1230-1239. doi:10.1016/j.renene.2019.11.126

5. Kurek, K. A. (2016). An Approach to Geothermal Resources as a Regional Development Driver in Poland. Humanities and Social Sciences, vol. 23 (4/2016), 175191. doi:10.7862/rz.2016.hss.68

Thesis assumptions and findings discussed during conferences:

1. $12^{\text {th }}$ European Geothermal PhD Day, 15-16 February 2021, CY Cergy Paris University (CYU, France) and University of Neuchâtel (UniNE, Switzerland). Online. "Geothermal resources and local development in Poland". Oral and poster presentation.

2. $8^{\text {th }}$ European Geothermal Workshop 2020, 7-8 October 2020, LabEx G-eau-thermie profonde in partnership with Karlsruhe Institute of Technology (KIT) and EERA, Online. "Added value of local geothermal energy utilization". Oral presentation.

3. $7^{\text {th }}$ Polish National Geothermal Congress, 22 September 2020, Polish Geothermal Society, Online, "Geothermal spas as a local development factor, the case of Poland". Abstract presentation.

4. $6^{\text {th }}$ AGRIMBA- AVA Congress, 17-19 June 2019, Mongolian University of Life Sciences, Ulaanbaatar, Mongolia. "The competitiveness of geothermal energy in Polish municipalities". Oral presentation.

5. $7^{\text {th }}$ Multinational Energy and Value Conference, 23-25 May 2019 , OSTIM Technical University, Ankara, Turkey, "The competitiveness of geothermal energy producing Polish municipalities". Oral presentation.

6. 10 ${ }^{\text {th }}$ European Geothermal PhD Day, 25-27 February 2019, GFZ Helmholz German Research Centre for Geoscience, Potsdam, Germany, "Added value of local geothermal energy development". Poster presentation.

7. $2^{\text {nd }}$ GEORG Geothermal Workshop 2018, 14-15 November 2018, Reykjavik, Iceland, "Geothermal source of local development". Oral presentation. 
8. $9^{\text {th }}$ European Geothermal PhD Day, 14-16 March 2018, Swiss Federal Institute of Technology (ETH), Zurich, Switzerland, "Geothermal source of local development". Oral presentation.

9. $5^{\text {th }}$ AGRIMBA- AVA Congress, 19-24 June 2017, University of Debrecen, Debrecen, Hungary, "Geothermal source of local competitiveness". Abstract presentation.

10. $2^{\text {nd }}$ National Scientific Conference of Energy Security: pillars and development perspective, 24-25 April 2017, Rzeszów University of Technology, Rzeszów, Poland "Geothermal source of local development - insights into the local economy based on geothermal resources". Poster presentation.

11. $5^{\text {th }}$ National Geothermal Congress, 11-13 October 2016, Polish Geothermal Society, Mszczonów, Poland, "Geothermal resource of local development - insights into the local economy based on geothermal resources". Oral presentation.

12. National Scientific Conference on European Union Energy Policy - pillars and development perspective, 25-26 April 2016, Rzeszów University of Technology, Rzeszów, Poland, "Renewable energy resources as an activator of local economy, the case of geothermal resources". Oral presentation.

13. $7^{\text {th }}$ European Geothermal PhD Day, 24-26 February 2016, University of Bari, Bari, Italy, "Geothermal resources in local community and regional economy". Oral presentation.

14. $6^{\text {th }}$ European Geothermal PhD Day, 25-27 February 2015, TU Delft, Delft, The Netherlands, "Towards a geothermal municipality- Polish examples versus European experience". Oral presentation.

Workshops and seminars participation related to the thesis research problem

1. Seminar and workshop: "Educational Project - Laboratory of sustainable energy and water consumption", 21-22 November 2016, Warsaw University of Technology, Warsaw, Poland.

2. Danubionet Innovation Project workshop: "How the biogas technology can help the development of new solutions within the circular bioeconomy concept and create new supply chains using new feedstock or new approaches to deliver not only energy but variety of bio-based materials", 25 October 2016, Timisoara, Romania.

3. Academic seminar: "Multicriteria analysis in regional development", 24 March 2016, Rzeszów University of Technology, Rzeszów, Poland.

Awards

1. Polish Geothermal Society Scientific Award laurate for the best geothermal publication in 2018-2020 (recognition for: Kurek, K. A., Heijman, W., van Ophem, J., Gędek, S., \& Strojny, J. (2020). Geothermal spas as a local development factor, the case of Poland. Geothermics, 85, 101777).

2. Winner of the International Geothermal Association 2019 Geothermal Photo and Video Contest. Competing work: Geothermal unknown magic. Tsenkher, Mongolia. https://www.geothermal-energy.org/iga-photo-contest-winner-announced/ 


\section{About author}

Katarzyna A. Kurek has completed her MSc in social sciences from the Warsaw University and then moved to the Netherlands to pursue another MSc study in urban and transport economics at the Erasmus University. She has remained at the university and continued to work as a researcher and lecturer. Afterwards, she has collected professional experience in public organizations (e.g. Port of Rotterdam, European Parliament) and in private companies, specializing in infrastructure development and regional economics. She has been a guest lecturer and speaker at many international conferences. Her latest appointment in the EU policymaking sector in Brussels ran parallel to conducting her PhD research at the Wageningen University. Katarzyna is an active member of the Polish Geothermal Society and International Geothermal Association, where she interacts with the international geothermal specialists. Lastly, Katarzyna was raised in a geothermal resources powered town in Poland. 


\section{Colophon}

Financial support from the Agricultural Economics and Rural Policy and Urban Economics groups of the WASS/WUR for printing this thesis is gratefully acknowledged.

Printed by Proefschriftmaken.nl || www.proefschriftmaken.nl 


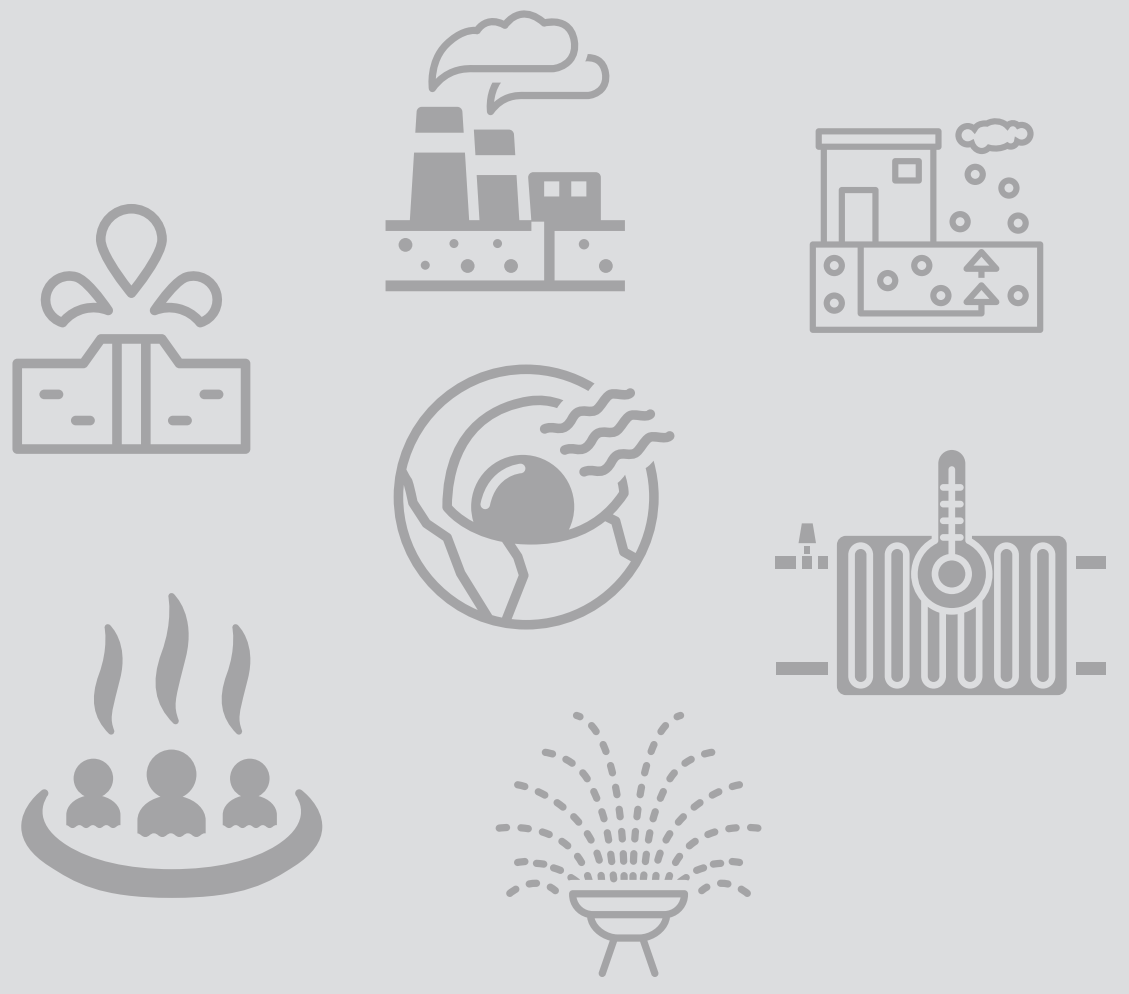

